\title{
Preventive Conservation for Paper-based Collections within Historic Buildings
}

\author{
ANNA ElisABETH BÜLOW \\ A thesis submitted to the School of Molecular Sciences \\ In partial fulfilment of the requirements for the degree of \\ Doctor of Philosophy
}

De Montfort University

Leicester

November 2002 
How glad I shall be when I can say, like that good old Quarter Master who, entering the Channel on a gloomy November morning, exclaimed: 'Ah, here there are none of those $\mathrm{d} \_\mathrm{d}$ blue skies'

Charles Danwin and the Voyage of the "Beagle", 1836 


\section{ABSTRACT}

Previous research has been carried out concerning the conservation of both historic buildings and library and archive collections. Little work has, however, been undertaken to look at the interface between the two. The following research has been carried out in the context of an interdisciplinary project linking key disciplines in an examination of the issues relating to conservation problems in historic buildings used for library and archive purposes.

This thesis presents a comprehensive literature review, evaluating published data on both the preservation of paper-based collections in libraries and archives, and preventive conservation of historic buildings and monuments. Emphasis is given to the interface between the two. Furthermore, a survey of British archives and libraries has been carried out, including the evaluation of questionnaire and site data. The survey focuses on preventive conservation measures as well as past and present problems of dampness. This survey proved problems with dampness to be often misdiagnosed and the consequences of damage underestimated. From the surveyed collections, two case studies have been selected for environmental monitoring in order to investigate macro- and micro-climates under different environmental conditions. Resulting data suggest that the micro-environment of a confined space is influenced by the amount of paper housed within it. This has assisted in explaining the interaction between paper and the immediate environment. At the same time, data has confirmed that the overall surface area of paper available for environmental interaction is more important than paper type or book size, with respect to the overall conditions within the storage space. Although degradation mechanisms of paper with respect to cycling conditions are not entirely clear, results of this study emphasise the importance of ventilation and dehumidification in order to avoid mould germination and/or growth.

The data have been used to determine whether the internal environment of enclosed bookcases, and hence the immediate environment of the collection, can be adequately predicted from ambient data taken within the room. Mathematical 
models have been developed for both metal and wooden bookcases, and have shown that even when the ambient conditions are unstable, the relationship between ambient $\mathrm{RH}$ and the $\mathrm{RH}$ inside a book in an enclosed bookcase can be predicted within a $5 \%$ margin ( $1 \%$ for a stable environment). 


\section{LIST OF CONTENTS}

Abstract iii

List of Contents v v

List of Figures viii

List of Appendices $\quad x$

Abbreviations $\quad$ xi

Declaration xii

Acknowledgements xiii

1 Introduction 1

2 Aims and Objectives 3

3 Literature Review and Background Information 4

3.1 Paper and Paper-based Collections 4

3.1.1 The Manufacture and Use of Paper 4

3.1.2 Paper-based Collections 8

3.1.3 National and International Guidance 13

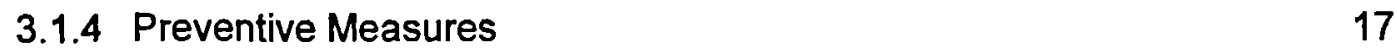

3.2 Historic Buildings and Monuments 21

$\begin{array}{ll}3.2 .1 & \text { Buildings and Building Performance }\end{array}$

3.2.2 Historic Buildings and Monuments 22

3.2.3 Traditional Materials and Forms of Construction 24

3.2.4 National and International Guidance 25

$\begin{array}{ll}3.2 .5 \text { Preventive Conservation } & 27\end{array}$

4 Interface between Collections and Historic Buildings 33

4.1 The Interface between Paper-based Collections and Historic Buildings 33

4.1.1 The Nature of Libraries and Archives 33

4.1.2 Collections within Historic Buildings and Monuments 35

4.2 Specific Damp-related Problems 41

4.2.1 Paper-based Collections 41

4.2.2 Historic Buildings 46

4.2.3 Mould 52

$\begin{array}{lll}\text { 4.2.4 Pests } & 67\end{array}$ 
4.3 Relationship between Humidity and Paper $\quad 72$

$\begin{array}{ll}\text { 4.3.1 Degradation } & 72\end{array}$

4.3.2 Influence of Moisture Content on Paper Properties 73

$\begin{array}{ll}\text { 4.3.3 Sorption Mechanisms } & 74\end{array}$

4.3.4 Cycling Conditions / Air Circulation $\quad 75$

$\begin{array}{ll}\text { 4.3.5 Buffer Capacity of Paper } & 78\end{array}$

4.4 Predictive Tools for Environmental Analysis 80

5 Survey of Record Repositories in the United Kingdom 84

5.1 Methodology 84

5.2 Results and Discussion $\quad 85$

5.2.1 Building 85

5.2.2 Extemal / Internal Environment 88

5.2.3 Library / Archive Collection 90

5.3 Existing Surveys within the United Kingdom 92

5.3.1 English Archives $\quad \cdot \quad 93$

5.3.2 Scottish Archives $\quad 94$

$\begin{array}{ll}\text { 5.3.3 Welsh Archives } & 96\end{array}$

6 Experimental 103

6.1 Case Studies 103

$\begin{array}{ll}\text { 6.1.1 Guildhall Museum Leicester } & 103\end{array}$

6.1.2 Brontë Parsonage Museum, Haworth 105

$\begin{array}{ll}6.2 \text { Methodology } & 106\end{array}$

$\begin{array}{ll}\text { 6.2.1 Datalogger Locations } & 107\end{array}$

6.2.2 Positioning the Dataloggers within the Dummy Books 108

6.2.3 Placing the Dataloggers within the Bookcase 109

$\begin{array}{ll}\text { 6.2.4 Data Collection } & 109\end{array}$

$7 \quad$ Results and Discussion $\quad 110$

$\begin{array}{ll}7.1 \text { Environmental Monitoring } & 110\end{array}$

$\begin{array}{ll}7.1 .1 \text { Guildhall Museum Library } & 110\end{array}$

$\begin{array}{ll}7.1 .2 \text { Brontë Parsonage Museum } & 118\end{array}$

$\begin{array}{lr}7.2 \text { Modelling } & 142\end{array}$

7.2.1 Climate Notebook 142

$\begin{array}{ll}\text { 7.2.2 Developing a Mathematical Model } & 150\end{array}$ 
8 Conclusions and Further Work 163

9 References 167

9.1 Guidelines and Reports 167

9.2 References 168

9.3 Key Texts 179

Appendices $\quad 182$

Publications 236

Attended Conferences 236

Additional Training 236

$\begin{array}{ll}\text { Field Trips } & 237\end{array}$ 


\section{LIST OF FIGURES}

Figure 1: Good practice: emergency kit and instructions easily accessible

(Credit: D.S. Watt)

Figure 2: Lack of regular maintenance may lead to problems elsewhere

(Credit: D.S. Watt)

Figure 3: Typical example: converted rectory (Flintshire Record Office)

(Credit: D.S.Watt)

Figure 4: Cellars and attics in use for storage $\quad 87$

Figure 5: Cause of dampness $\quad 88$

Figure 6: Environmental monitoring 89

Figure 7: Environmental control 90

Figure 8: Nature of collections $\quad 91$

Figure 9: Age of collections 91

Figure 10: Bath and North East Somerset Record Office at Bath Guildhall 98

Figure 11: Leicestershire Record Office: modern storage facility built behind historic school (Credit: D.S. Watt)

Figure 12: Canterbury Cathedral Library and Archives: extension integrated with cloister (first floor)

Figure 13: West Yorkshire Archive Service, Bradford: raised floor levels (Credit: D.S. Watt)

Figure 14: West Yorkshire Archive Service, Bradford: industrial machinery within strongroom (Credit: D.S. Watt)

Figure 15b: Position of datalogger within dummy book (Credit: D.S. Watt) 121

Figure 16a: Minimum Relative Humidity (July) (@ Met Office UK) 122

Figure 16b: Minimum Relative Humidity (January) (c Met Office UK) 122

Figure 17: RH conditions: external, ambient, full \& empty shelf 123

Figure 18: External vs ambient RH (August/September 2001) 124

Figure 19: Ambient RH: 30 day continuous average vs 7 day average $\quad 125$

Figure 20: External vs ambient temperature (August/September 2001) 126

$\begin{array}{ll}\text { Figure 21: RH full shelf vs RH empty shelf } & 127\end{array}$

Figure 22: RH full and empty shelf vs ambient RH 128

Figure 23: $\mathrm{RH}$ lignin-containing vs $\mathrm{RH}$ rag paper dummy $\quad 129$

Figure 24: RH fluctuation within shelf and rag paper dummy (August/September 2001)

Figure 25a: Determining the half-time for $\mathrm{RH}$ equilibrium in the small and big book

Figure 25b: Comparison between the RH equilibration of the small and big books within the bookcase at the Guildhall Library 131

Figure 26: RH rag paper dummy vs shelf RH 132

Figure 27: RH vs AH of lignin-containing and rag paper dummy 133

Figure 28: Lignin-containing dummy and full shelf: $\mathrm{RH}$ vs $\mathrm{AH} \quad 134$

Figure 29: Small dummy vs upper shelf \& ambient RH 135

Figure 30: RH lignin-containing dummy vs full shelf (August/September 2001) 136

Figure 31: full shelf and lignin-containing dummy $\mathrm{RH}$ vs ambient $t$ (August/ September 2001)

Figure 32a: Time lag in temperature (December) 138 
Figure 32b: Time lag in temperature (March)

Figure 32c: Time lag in temperature (July)

Figure 33: Brontë vs Guildhall: ambient and shelf conditions (RH)

Figure 34: RH conditions: bookshelves at Brontë vs Guildhall (August) September 2001)

Figure 35: $\mathrm{RH}$ and temperature conditions: room vs bookshelf (August/ September 2001)

Figure 36: Variation in ambient RH (monthly average values)

Figure 37: Comparison of the variation in $\mathrm{RH}$ between the lignin-containing book and ambient conditions

Figure 38: Deriving the mathematical model for the Guildhall Museum library $\quad 155$

Figure 39: Modelling the changes in $\mathrm{RH}$ inside a bookcase from ambient $\mathrm{RH}$ measurements

Figure 40: Correlation between measured and predicted $\mathrm{RH}$ values in the bookcases

Figure 41: Using hourly monitoring to predict RH inside the lignin-containing book157

Figure 42: Modelling the $\mathrm{RH}$ inside the lignin-containing book using ambient $\mathrm{RH}$ values (30-day rolling average)

Figure 43: Comparing the ambient conditions within Brontë Parsonage Museum and Guildhall

Figure 44: Comparing the ambient $\mathrm{RH}$ and the $\mathrm{RH}$ within the Bookcase at Bronte Parsonage Museum

Figure 45: Ambient and bookcase variation in $\mathrm{RH}$ (monthly average)

Figure 46: Deriving the mathematical model for the Brontë Parsonage Museum 161

Figure 47: Comparing predicted and measured $\mathrm{RH}$ values in the bookcases of both Brontë Parsonage Museum and Guildhall Library 


\section{LIST OF APPENDICES}

Appendix A: Mechanisms of Deterioration and Decay (Buildings) 183 Appendix B: Outline Questionnaire

Appendix C: Libraries and Archives Contacted during the Survey

188

Appendix D: Case Studies

196

Appendix E: Notes for Meetings

218

Appendix F: Details of Dummy Books

219

Appendix G: Preventive Conservation of Collections

Publications

Attended Conferences

236

Additional Training

236

Field Trips

237 


\section{ABBREVIATIONS}

\begin{tabular}{|c|c|}
\hline $\begin{array}{l}\text { AH } \\
\text { AIC } \\
\text { AICCM } \\
\text { ANSI } \\
\text { APPA } \\
\text { APT } \\
\text { ARSAG } \\
\text { ASHRAE }\end{array}$ & $\begin{array}{l}\text { Absolute humidity } \\
\text { American Institute for Conservation of Historic and Artistic Works } \\
\text { Australian Institute for Conservation of Cultural Materials } \\
\text { American National Standards Institute } \\
\text { Association of Physical Plant Administrators } \\
\text { Association for Preservation Technology } \\
\text { Association pour la Recherche Scientifique sur les Arts Graphiques } \\
\text { American Society of Heating, Refrigerating and Air-Conditioning } \\
\text { Engineers }\end{array}$ \\
\hline BMS & Building Management System \\
\hline BSI & British Standards Institution \\
\hline $\mathrm{CCl}$ & Canadian Conservation Institute \\
\hline DNH & Department of National Heritage \\
\hline DoE & Department of the Environment \\
\hline DPC & Damp proof course \\
\hline ECPA & European Commission on Preservation and Access \\
\hline ECCO & European Confederation of Conservator-Restorers' Organizations \\
\hline EMC & Equilibrium moisture content \\
\hline EMMS & East Midlands Museums Service \\
\hline HLF & Heritage Lottery Fund \\
\hline HMC & Historical Manuscripts Commission \\
\hline ICA & International Council on Archives \\
\hline ICCROM & $\begin{array}{l}\text { International Centre for the Conservation and Restoration of Cultural } \\
\text { Property }\end{array}$ \\
\hline ICOM & International Council of Museums \\
\hline ICOM-CC & International Council of Museums, Committee for Conservation \\
\hline ICOMOS & Council on Monuments and Sites \\
\hline IFLA & International Federation of Library Associations and Institutions \\
\hline IIC & International Institute for Conservation \\
\hline IPC & Institute of Paper Conservation \\
\hline ISO & International Standards Organization \\
\hline JAIC & Journal of the American Institute for Conservation \\
\hline MC & Moisture content \\
\hline MGC & Museums \& Galleries Commission \\
\hline NCCR & National Council for Conservation-Restoration \\
\hline NEDCC & Northeast Document Conservation Center \\
\hline NISO & National Information Standards Organization \\
\hline NPO & National Preservation Office \\
\hline NSCC & Northem States Conservation Center \\
\hline RH & Relative humidity \\
\hline SPAB & Society for the Protection of Ancient Buildings \\
\hline Sof & Society of Archivists \\
\hline & Scottish Society for Conservation and Rest \\
\hline & or Conse \\
\hline & 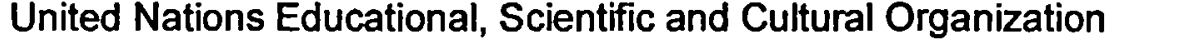 \\
\hline
\end{tabular}




\section{DECLARATION}

The work discussed in this thesis was carried out while the author was registered with the Department of Chemistry, latterly the School of Molecular Science, De Montfort University, Leicester, between November 1999 and November 2002. It is the original work of the author unless otherwise stated.

This thesis has not been submitted for any other degree at this or any other university.

Alim buth

Anna Bülow

November 2002 


\section{ACKNOWLEDGEMENTS}

I would like to thank:

- Dr Belinda Colston and Dr David Watt for their supervision and advice throughout this research project. They have visited two of the case studies and accompanied me on many others.

- De Montfort University for their financial support of this work. Thanks to Resource: The Council for Museums, Archives and Libraries for funding the initial project which underpinned the development of this research. I am also grateful to Hanwell Ltd. for subsidising the experimental equipment.

- Nick Ladlow, Curator Manager - Old Town, Leicester and Rachel Terry, Curator at the Brontë Parsonage Museum for their support with the two case studies.

- Dr Colin James from the Faculty of Computing Sciences and Engineering at De Montfort University for his help with the statistical analysis of the survey results.

- All individuals who have contributed to the survey by completing the questionnaires or answering questions during the site visits.

In addition, I am indebted to all those who have provided me with literature over the past years: Nancy Bell, then acting Librarian for the Institute of Paper Conservation (IPC, Oxford), Jean Tétreault and Carole Dignard from the Canadian Conservation Institute ( $\mathrm{CCl}$, Ottawa), and Anne-Laurence Dupont from Centre de Recherches sur la Conservation des Documentes Graphiques (CRCDG, Paris).

I am grateful to James Reilly, Douglas Nishimura and the staff at Image Permanence Institute (IPI, Rochester) for introducing me to 'Climate Notebook', and for their great openness and interest during my visit.

Very special thanks go to Julien Barthez and Anne-Laurence Dupont at CRCDG for carrying out the fibre analysis of the two dummy books.

Finally, thanks are due to all those who have furthered my work through their advice and interest or helpful discussions, and to my family and friends, who have supported me over the past three years. 


\section{INTRODUCTION}

Previous research has been carried out on the conservation of both historic buildings and library and archive collections. Little work has, however, been undertaken to look at the interface between the two. As a result, what might be considered good conservation practice for one may be detrimental to the other.

This research addresses issues of preventive conservation in historic buildings that house library or archive collections. Since modern media (e.g. photographic material, magnetic tapes, digital media) generally require different storage conditions to paperbased collections, they have been specifically excluded from this program.

The study is presented in five sections. The first is based on an extensive literature review, in which published information on issues of paper preservation as well as the conservation and maintenance of historic buildings is collated and analysed. This task has particular importance as published data so far rarely focus on both collection and building issues. The resulting literature review is divided into topics relating to paper-based collections, and those relating to historic buildings and monuments. In these, the specific materials, ways of production and other specific issues are summarised. In addition, national and international guidance on preservation and preventive measures is given.

The following section looks in detail at the interface between paper-based collections and buildings, drawing particular attention to damp-related problems (e.g. mould and pest outbreaks). The relationship between humidity and paper, and its implication on degradation mechanisms of paper, are discussed and, following this, past and present predictive tools for environmental analysis are reviewed.

Subsequent sections present the novel contributions made by this research programme. Firstly, a survey has been carried out by questionnaire, designed to gain information on buildings, environment and collection. The results of the survey are 
outlined and discussed, as well as comparisons made with existing surveys in the United Kingdom.

Two case studies were selected for detailed environmental monitoring. The experimental section gives background information and details of the chosen methodology. The results of this study give a new insight into the microenvironmental conditions within books and their immediate surrounding, and other conclusions for improved means of preservation.

The experimental section includes a discussion of recently-developed computeraided models for environmental analysis. Particular attention has been given to a computer model currently under field trial within the United States (Climate Notebook).

The final section presents a mathematical model developed from data obtained during the experimental phase at the two case-study locations.

Conclusions and recommendations for further research form the last section of this thesis. 


\section{AIMS AND OBJECTIVES}

Study of micro-climatic conditions within confined spaces has attracted increasing attention over the last few years (Kamba 1994; Reilly et al. 1995; Bigourdan and Reilly 1997; Di Pietro and Ligterink 1999). However, very few studies deal with environmental changes within small spaces near books or paper-based material (Christoffersen 1995; Daniel and Maekawa 1993). The ultimate aim of this project is to develop a mathematical model for predicting conditions within various enclosed spaces from measured ambient conditions. It is anticipated that the model will aid in determining conditions within various micro-environments, which otherwise could not easily be measured. By utilising only measured ambient conditions, current preventive conservation practices (i.e. monitoring ambient temperature and relative humidity) would be sufficient to allow the model to be used. The following objectives have been set for this research programme in order to address the overall aim of the work:

- To study the mechanisms and conditions that affect the interface between historic buildings and their contents, with a view to understanding the nature and extent of causal factors and associated effects;

- To compile a database of cause and effect with respect to preventive conservation. Environmental as well as anthropogenic factors influencing the mechanisms of deterioration in buildings and collections will be assessed. This database will eventually be incorporated into a computer-based predictive model;

- To choose two case-study sites and set up a 12-month environmental monitoring programme at each;

- To investigate the effects of a fluctuating environment on paper-based collections. The research seeks to improve the understanding of micro- and macro-environments by monitoring key environmental conditions inside bookcases as well as within books made of different paper types;

- To determine the relationship between ambient $\mathrm{RH}$ and the $\mathrm{RH}$ inside bookcases and within books, under various conditions, and define the relationships mathematically. 


\section{LITERATURE REVIEW AND BACKGROUND INFORMATION}

\subsection{Paper and Paper-based Collections}

The history of paper has been documented many times before. Nevertheless, it is appropriate to recall the most important changes in papermaking, in order to understand the development of different types of paper that are currently found in libraries and archives.

\subsubsection{The Manufacture and Use of Paper}

The principle of papermaking, invented in China about two thousand years ago, has undergone little change. As its history has been thoroughly described (e.g. Hunter 1978), this overview focuses only on issues relating to different paper types and their stability. The following section outlines briefly the historical developments in papermaking since the beginning of paper manufacture in Europe in the Middle Ages and is based on previous research by Bülow (1999).

\section{Rag Paper}

Paper is defined as a web consisting mainly of vegetable fibres, traditionally produced by dipping a mould into a fibre suspension. In addition, paper may contain fillers and colouring matters, and may be sized to make it impervious to ink and to enhance its strength.

Paper manufactured in Europe, since the middle of the twelfth century, consisted of fibres derived from rags, whose principal constituent is cellulose. Whilst pure cellulose is known to be very stable, it seldom occurs in the pure state in nature. The undesirable impurities are, however, usually removed during the papermaking process. 
The use of rags as the main source of fibres, a common practice until the middle of the nineteenth century, enabled the papermaker to produce paper of great stability. Rags consisted mainly of linen (flax) as well as hemp and, later, cotton. These fibres have a small amount of impurities with respect to pure cellulose, which is one of the main reasons for the stability of rag papers. In addition, the quality of water at the time, as well as the use of lime as an aid in the fermentation of rags, contributed to paper stability.

Also of great importance is the type of sizing used before the nineteenth century. After the paper was dry, it was dipped into a size, which the papermaker usually made from the parings of hides. ${ }^{1}$ Rag papers sized with this animal glue were found to be very stable. There is, however, evidence that, in the late seventeenth century, alum was added in order to harden the size. This is one of the primary causes of deterioration of paper made after the mid-seventeenth century (Barrow 1967: 16).

The invention of movable types during the fifteenth century and the rapid increase in literacy during the eighteenth century caused a greater demand for paper than ever before. This resulted in a scarcity of rags, the main source of fibres, and a drive towards more economical papermaking.

As a result of the rapidly-increasing need for paper in the eighteenth century, new fibre sources ${ }^{2}$ and pulping processes were sought.

1 The refuse of tanning works and scraps of parchment were most valued for this purpose, since they could be used without further preparation. Tanned leather could be used by employing a special process to remove tannic acids, thus allowing the hide to dissolve in water (Dawidowski 1884).

2 In 1719 René Antoine Ferchault de Réaumur suggested the use of wood as a papermaking material and Jean Étienne Guettard advocated several forms of vegetation in his publication of 1768 (Recherches sur les matières qui peuvent servir à faire du papier in: Mémoires sur différentes parties des Sciences et Arts, Paris, 1768 (Hunter 1978: 316). Extensive work on this subject was also done by Jacob Christian Schäffer. He published six volumes between 1765 and 1771 , in which he used different samples of paper in order to demonstrate the use of different fibre sources (Versuche und Muster ohne alle Lumpen oder doch mit einem geningen Zusatze derselben Papier zu machen. Regensburg 1765-1771 [Hunter 1978: 317]). 


\section{Groundwood Process}

Matthias Koops was the first person to make paper from vegetable sources on a commercial scale. He used straw as the sole fibre source for his book published in $1800 .^{3}$

The discovery of chlorine, however, in 1774 by Karl Wilhelm Scheele, and the subsequent discovery that chlorine was capable of bleaching dyed and discoloured rags, meant the immediate need for alternative fibre sources was deferred. Coloured rags, previously discarded, were now usable. Furthermore, the invention of the cotton gin in 1793, a machine that was able to separate cotton seeds from their seed hairs, doubled cotton production and was increasingly used in the manufacture of fabrics. This resulted in a higher cotton content of the rags used for papermaking (Barrow 1967: 14-15).

The increasing need for paper also led to the development of a papermaking machine. In France, in 1798, Louis Nicolas Robert invented a paper machine that was able to produce long sheets of paper, which could be used for wallpaper. Shortly after that, in 1804, Bryan Donkin, then working in England for Henry and Sealy Fourdrinier, invented the first continuous paper machine (André 1996: 84-85). The patent for this machine was given to Henry Fourdrinier in 1806. The principle of this 'Fourdrinier machine' has undergone comparatively little change and is still in use in the paper industry of today.

One of the most important changes in papermaking was the invention of alum-rosin size in 1807 by Moritz Friedrich Illig. ${ }^{4}$ Alum-rosin sizing had the principal advantage that it could be added directly to the beater, thus eliminating a separate sizing step and hence reducing manufacturing costs. Consequently, alum-rosin gradually

3 Historical Account of the Substances Which have been Used to Describe Events and to Convey Ideas, from the Earliest Date to the Imvention of Paper. Printed by T. Burton, London (Hunter 1978: 332).

4 The commonly-used resin is colophony, which is insoluble in water. It is therefore boiled together with sodium carbonate to form a resinate. The solution is filtered and added to the beater. The addition of alum (aluminium sulphate) causes a precipitation of the dissolved rosin on to the fibres (Witham 1920). 
displaced animal glue as a sizing. It is known to have been introduced to the United States in about 1830, but it seems to have been used infrequently until about 1870 when it became the universal sizing agent (Barrow 1967: 17).

The use of fillers as a loading material for paper was adopted in 1733 by William Cookworthy in England, but did not become general practice until the nineteenth century (Barrow 1967: 18). Before the invention of effective bleaching processes, fillers were used to improve the colour of the rags. With the introduction of the Fourdrinier machine, paper was sold by weight instead of by sheet or ream. This led the papermaker to make extensive use of loading material, since fillers were both heavier and cheaper than fibres. Early fillers were barium sulphate and calcium sulphate (gypsum). Later, more expensive fillers, such as zinc oxide, zinc sulphide and titanium dioxide, were used in accordance with the purpose of the paper (Grant 1937: 20-21). Calcium carbonate fillers could not be introduced into papermaking before the 1950s, since their use requires an alkaline environment that could not be accomplished in combination with alum-rosin as the common sizing (Espy 1990: 2829).

The increasing demand for paper in the nineteenth century led, in 1840 , to the invention of the groundwood process by Friedrich Gottlob Keller. It allowed for the economic use of wood as a principal fibre source. Voelter and Voith further developed the process in 1846, which started the mechanical wood-pulping industry. Since paper containing mechanical wood pulp was found to exhibit low strength properties and tended to turn yellow in sunlight and in storage, chemical woodpulping processes were developed.

\section{Modern Paper Types}

The process of pulping wood under pressure in sodium hydroxide was patented in 1853. The first commercial mill for alkaline- or soda-pulping was erected in the United States in 1854. Carl Dahl further modified this process for economical reasons in 1879 by using sodium sulphate, which could be recovered from the system and reused. This process produced a very strong paper and is therefore 
called kraft pulping ('Kraft' is the German word for 'strength') (Rydholm 1985: 17879).

As a result of experiments in an American soda mill, the sulphite process was invented in 1866. This process treated wood under pressure with solutions of bisulphites and sulphurous acid. It was first used commercially when, in 1874, it was found that the addition of magnesium bisulphite with excess sulphurous acid considerably improved the pulp (Rydholm 1985: 179).

The paper industry did not undergo any major changes until 1955 when Aquapel, an alkaline sizing agent, was introduced (Espy 1990: 28). This enabled the papermaker to produce alkaline paper, which in tum made the use of calcium carbonate as a filler possible. It was not before the 1980 s, however, that the majority of paper mills switched their papermaking processes over to alkaline pulping.

\subsubsection{Paper-based Collections}

\section{Paper Types}

Today, libraries and archives are faced with a very large variety of paper types. As described in the previous section, this is mainly due to the development and improvement of papermaking processes throughout the centuries.

The earliest European papers, made from rags, are found widely in all early forms of bindings, books, letters, deeds, and documents. ${ }^{5}$ Rag paper is fairly consistent in its composition and is usually of low concern in terms of preservation and conservation issues.

5 Important documents were usually written on parchment due to its superior quality. 
After the middle of the nineteenth century, when the groundwood process and alumrosin sizing had been introduced to the papermaking industry, most books were printed on this type of paper. Due to its low strength properties and its tendency to turn yellow under the influence of light, it was soon recognised to be of inferior quality to rag paper. These highly lignin-containing papers are therefore only found in the period from $c .1850$ until the 1980s. Today, they are almost exclusively used for newspapers, since their production is cheap. It must, however, be kept in mind that the bulk of material in most archives and libraries is from the aforementioned period and so of great concern with respect to its preservation.

\section{Binding Techniques}

Libraries and, in particular, archives generally consist of a wide range of different forms of books and materials. The following section summarises the most important changes in bookbinding techniques and is based on publications by various authors (e.g. Davenport 1908; Diehl 1980; Needham 1979). The different binding techniques used throughout history and in different parts of the world are, however, too numerous to be covered in this summary. The focus will therefore lie on basic binding types that can still be found in most archives, typically material from the early Middle Ages until the present. These demonstrate the complexity of binding structures and the variety of materials used.

In the history of bookbinding, two inventions were of utmost importance for the further development of books. First, the invention of the codex form instead of the common scroll during the first centuries $A D$ and, second, Gutenberg's invention of printing with movable type during the fifteenth century.

As stated previously, the art of papermaking did not reach Europe before the twelfth century. The previously-prevalent papyrus had been superseded by parchment, not only because of its superior qualities to write on, but also its durability (e.g. permanence, stitching). Groups of leaves were joined together and sewn through the fold. Most early codices are such single quire constructions. Their structural drawback lies in the fact that no more than about 50 sheets (giving 100 leaves and 
200 pages) could conveniently be used. The more sheets were used, the greater the stress at the stitching. In addition, the closed codex tended to spring open and the central leaves protruded at the fore edge when the codex was closed. Cutting back those protruding edges resulted in a decreased amount of space to write on towards the centre of the book.

In order to overcome the problem of protruding edges, books were made of several sections. This was accomplished by an unsupported link stitch, which linked the sections with the sewing thread alone. The endbands were an integral part of the sewing. This technique was further developed by attaching wooden or pasted boards on top and bottom of the book block as covers.

The use of parchment as a common writing material, as well as the type of storage, had influence on the design of the cover. Parchment is an extremely hygroscopic material and tends to buckle in changing storage conditions. It was therefore necessary to develop a system for keeping parchment manuscripts closed. This would, at the same time, protect the illuminations against dust and light. The solution to this problem was the use of different types of clasp.

Western manuscripts tended to be large and heavy. Since the sewing thread was not strong enough to hold the sections as well as the boards together, sewing cords came into use. ${ }^{6}$ Depending on the size of the book, several cords ran across the spine, in addition to the thread that runs along the sections. The cords not only supported the book block as a whole, but were also strong enough to connect the book block with the cover.

The books were kept flat on their sides. The boards were of the same size as the book block and were protected from mechanical damage (e.g. friction) with metal bosses and comers. They were often shelved with their fore edge towards the outside, which is the reason for titles of medieval books often being found written on the fore edge.

6 Cords were typically made of flax or twisted leather; they developed later into woven bands made from cotton and/or linen. 
With the foundation of the first universities in Europe in the thirteenth and fourteenth centuries, books became more widely available. Storing books flat on their sides took up too much space; they were now shelved vertically. The change from horizontal to vertical shelving had consequences on the binding structure, since different forces now affected the spine. Flushed boards were abandoned. In order to protect the book block from the shelves, the edges now protruded beyond the book block. The upright position of the book resulted, however, in damage to the binding, because the full weight of the text block pulls the back inwards until the lower end of the front rests upon the shelf.

The introduction of paper into Europe and its increasing acceptance during the fourteenth and fifteenth centuries lay the ground for one of the most important inventions in Western civilisation. During the middle of the fifteenth century, Gutenberg invented printing with movable type, which in turn led to increasing literacy and the exchange of knowledge. With the possibility of printing, rather than hand-writing, book production increased vastly, which at the same time diminished their value. The increased number of books resulted in space problems within libraries and consequently in the exclusive vertical storage of books. This led to the abandance of bosses and, depending on the design, the clasps as well. Vertical storage also marked the beginning of writing titles on the spine.

The increase in book production also led to a simplification in binding techniques. The various forms of endband, that were once an integral part of the sewing, were stitched separately on the head and tail of the book. At the same time, a more economic way of attaching the boards was necessary, and hence cords were no longer laced through the whole board. The methods of attaching the boards to the book block underwent many modifications throughout history, signifying an ongoing concern for the intrinsic weakness of the joint region that has attracted attention up to the present day.

The deformation of the book block through vertical storage, in addition to the natural tendency of the spine to take on a concave shape upon usage, led to the idea of 
shaping spines in a convex manner. This had the effect of increasing stability and counteracting the sagging of the fore edge. The rounded spine became a general feature in the fifteenth century and marked an important milestone in book-binding techniques, since it had important implications for the longevity of the book. Unfortunately, the advantages of the rounded spine do not manifest themselves when the book is read, but only when it is closed. Even though the rounded spine did not, in extreme cases, allow proper reading of the book, it eventually superseded the more flexible flat spine, for aesthetic reasons, in the sixteenth century.

During this time, books became lighter and, on the whole, smaller. Pasteboards made from several layers of paper came into use, instead of the heavy wooden boards. One of the main characteristics of the modern book, compared to its antecedents, is the hollow back. By using a hollow back, where the spine surface and the cover, usually made from leather due to its flexibility, are separated, titles and ornaments could be applied. Unfortunately, the hollow back results in considerable strain on the hinges, the most vulnerable part of the binding, when the book is opened. In addition, books with hollow backs have the tendency to pull up the first few pages adjacent to the boards. Numerous constructions of different endleaf techniques were therefore invented. These are either designed to provide greater tolerance or to better resist the stress through the application of stronger materials.

Contemporary books are usually made by machine for economical reasons. Their book block is either machine sewn or glued together and their covers are made separately. Cover and book block are only adhered to one another by means of the pastedown and the headbands are machine made and glued on. Although this technique does not contribute to the strength of the binding, it conforms with modern needs and usage of the books. 


\subsubsection{National and International Guidance}

Guidance on the preservation of library and archive material exists in many different formats. Various bodies have published standards, guidelines, code of ethics, and other forms of recommendation, all of which contain information on the preservation of movable and immovable collections. It is important to note that national preservation policies, where they exist, are dictated by government and therefore may not necessarily reflect the implications of the guidelines or standards published by conservation associations.

Standards are published by national or international standardising bodies, whereas guidelines and codes of ethics are usually formulated by conservation associations. In principle, a code of ethics states and explains a certain goal in a very broad sense. Guidelines and recommendations, on the other hand, may give specific advice on a particular issue. The following section gives a brief overview of guidance within the United Kingdom, compared with international guidance on preventive conservation issues.

In this, it must be kept in mind that the present thesis focuses on preventive conservation relating to problems of dampness - only temperature and relative humidity $(\mathrm{RH})$ are therefore considered. Other agents of deterioration will be reviewed briefly in sections 4.2 .3 and 4.2 .4 of this thesis.

\section{Guidance in the United Kingdom}

The British Standards Institution has recently revised its standard on the storage and exhibition of archival materials, BS 5454 (BSI 2000). This standard is the most recent of its kind and gives guidance concerning the siting of buildings, construction and protection, fire precautions, storage environment, lighting, equipment for storage and production, packaging for storage, storage of modern media and other materials, and exhibitions. The Standard also provides exact temperature and RH specifications for various types of materials. 
Similar, but much less complex, is the guidance for record repositories published by the Historical Manuscripts Commission (HMC 1997). This is based on BS 5454, but is less specific. There is, for example, no distinction between frequently and less frequently handled material, and no recommendations are made in relation to exhibiting material or light protection.

The guidelines given by the National Preservation Office (NPO) are very broad and refer to the recommendations stated above. In addition, the former Museums \& Galleries Commission published leaflets, which were mainly targeted at nonprofessionals (e.g. Cox 1999; Winsor 1999), and a Code of Practice on Archives for Museums (MGC 1996). The Society of Archivists has a Code of Practice for Archivists and Records Managers (SoA 2001), but this only refers to 'accepted external standards'. The Society of Archivists also has a Best Practice Guideline relating to preservation and conservation, which again only refers to existing standards (e.g. BS 5454 and BS 4971), and does not give specific values (Pickford et al. 1997).

General guidance published by the NPO in its 'Preservation Management Series' includes The Application and Use of Standards in the Care and Management of Libraries and Archives (Cox 1999), Good Handling Principles and Practice for Library and Archive Materials (NPO 2000), Guidance for Exhibiting Archive and Library Materials (Mclntyre et al. 2000), and Building Blocks for a Preservation Policy (Foot 2001).

Other NPO publications of relevance to this thesis include those in the 'Security Matters' series - Carrying out a Library Security Survey and Drafting a Security Policy (NPO 1992), How to Deal with Criminal and Anti-Social Behaviour (NPO 1994) and Designing Out Crime (NPO 1996). 
Further guidance has been provided by the Department of National Heritage (DNH 1995), the Welsh Office (Welsh Office 1995), and the Scottish Record Office (now National Archives of Scotland). ${ }^{7}$

In summary, the most widely used parameters for the storage of library and archive material (i.e. paper and parchment) are those given in BS 5454 and by the Historical Manuscripts Commission. These recommend the following conditions within British repositories:

- temperature between 16 and $19^{\circ} \mathrm{C}$ (with a tolerance of $1^{\circ} \mathrm{C}$ on either side) and a relative humidity between 45 and $60 \%$ (with a tolerance of $5 \%$ on either side) for frequently-handled material (BSI, 2000)

- temperature between 13 and $16^{\circ} \mathrm{C}$ (with a tolerance of $1^{\circ} \mathrm{C}$ on either side) and a relative humidity between 45 and $60 \%$ (with a tolerance of $5 \%$ on either side) for infrequently-handled material ${ }^{8}$ (BSI, 2000)

- temperature between 13 and $18^{\circ} \mathrm{C}$ and a relative humidity between 55 and $65 \%$ (HMC 1997)

\section{International Guidance}

Considering the large variation in climatic conditions around the world, it is clear that international organisations cannot advise on specific storage conditions for every country. There has been a shift in recent years from tight environmental guidelines towards parameters taking account of both local climate and economical factors.

The European Confederation of Conservator-Restorers' Organizations and the International Council of Museums, Committee for Conservation have both published professional guidelines. As explained above, however, these give broad advice on the preservation of heritage material (E.C.C.O. 1993; ICOM-CC 1986).

\footnotetext{
For further information, see HMC 1999.

8 The material should be allowed to acclimatise before use.
} 
Publications by the International Council on Archives, such as the General Intermational Standard Archival Description (ICA 2000), are mainly targeted at management issues faced by archives.

In terms of international standards, the International Standards Organization intended to publish a standard concerning storage requirements (ISO 11799: Document Storage Requirements for Archive and Library Materials). This has never been published for various reasons (Bansa 2001). ${ }^{9}$

The United Nations Educational, Scientific and Cultural Organization (UNESCO) has also published two documents on the preservation of library material. The first, published in 1984, concerns only photographic material and gives specific parameters for the storage of this material (Hendriks 1984). More important, however, are the General Guidelines to Safeguard Documentary Heritage (Foster et al. 1995), which provide information on management, selection of registered libraries, preservation, access and distribution, and awareness raising. This document, like the other internationally-developed recommendations, only gives general guidance for the storage of library material.

The most relevant international guidelines, with respect to the preservation of library and archive material, are published by the International Federation of Library Associations and Institutions (IFLA) (Adcock 1998). The IFLA has responsibility for encouraging the acceptance and diffusion of professional principles of preservation

9 The same happened to an attempt of the American NISO (National Information Standards Organization) to publish a standard on storage requirements. Since NISO, a committee of the American National Standards Institute (ANSI), was unable to reach consensus on environmental standards for long-term storage of paper, it published a technical report under the title Environmental Guidelines for the Storage of Paper Records (Wilson 1995). NISO, however, put forward a draft version of recommendations on conditions for exhibiting paper objects in 1995. In this, environmental conditions of $30-55 \% \mathrm{RH}$ and a temperature below $21^{\circ} \mathrm{C}$ were suggested (Henderson 1996). These conditions are recommended by most North American institutions, including the American Society of Heating, Refrigerating and Air-Conditioning Engineers (ASHRAE), Canadian Conservation Institute $(\mathrm{CCl})$, Northern States Conservation Center (NSCC), and Northeast Document Conservation Center (NEDCC). It seems, however, that BS 5454: 2000 used a draft form of the ISO standard 11799 as a reference. 
and conservation. ${ }^{10}$ The IFLA publication Principles for the Care and Handling of Library Material concentrates on certain key elements of preservation and gives information on issues such as security and disaster planning, environment, different materials, and reformatting. It also explains concepts of humidity and general aspects of environment. On these matters it is argued that there is no single set of ideal environmental conditions and, consequently, parameters concerning the storage of collections should be considered with a view of particular circumstances.

\subsubsection{Preventive Conservation}

Taking preventive measures rather than the traditional conservation approach has become necessary due to the fast and ever increasing growth of collections, while financial resources in these institutions are usually shrinking. Preventive conservation in libraries and archives has therefore attracted more and.more attention over the past decade. With respect to collections, it is usually distinguished from conservation as those activities that are not interventive or include any form of treatment. Preventive conservation of buildings is addressed in section 3.2.5.

The following outline of preventive measures is largely based on the excellent compilation of guidelines and recommendations by the International Federation of Library Associations and Institutions (IFLA) (Adcock 1998). Preventive conservation within paper-based collections includes (de Torres 1995: 185):

- Assessment of conservation status and needs of a collection

- Environmental monitoring and control of storage and exhibition areas

- Design and implementation of a disaster plan

- Good housekeeping

- Integrated pest management

- Proper housing and mounting of objects

- Appropriate storage facilities

10 The above-mentioned UNESCO document of 1995 was prepared on behalf of the IFLA. 
- Education and training of staff

In order to implement sensible preservation strategies, it is advisable to first assess the current situation of a certain collection. In this, particular problems and needs, as well as general aims need to be defined. Usually, libraries and archives have certain policies with respect to acquisition and preservation of their material already in place. Assessing and implementing preservation needs should always be a joint effort between all levels of staff involved. A survey will try to identify potential risks to the collection, including current disaster preparedness and response plans. Furthermore, the condition of the collection and its specific problems should be assessed. This will, at the same time, help to identify size of the collection and the kind of material present. In addition, a survey affords the opportunity to pinpoint advantages and disadvantages of currently used environmental control systems.

Environmental monitoring and control is vital for the preservation of any collection. It is, however, of particular concern in library and archive collections, as they typically hold many different materials. While there is no single set of conditions suitable for all materials, collections are known to benefit from stable conditions rather than fluctuating $\mathrm{RH}$ and temperature. One of the most important preventive measures therefore is adequate monitoring and recording of conditions, not only within storage areas, but also in exhibition and reading rooms. Having evidence of past and present conditions will not only confirm the equipment to work properly, but also support requests for upgrading where necessary.

Environmental control also includes the control of light levels within the various areas of a building and the control of gaseous and particulate pollutants entering and circulating around the building.

Designing and implementing a disaster plan should incorporate staff at all levels. It typically includes measures to prevent criminal and anti-social behaviour as well as prepare for any natural or man-made disasters. If no disaster plan is in place, it is sensible to approach disaster preparedness in phases, first assessing the dangers to a particular building and collection, then removing or reducing the danger, and 
developing a plan of response and recovery. The disaster plan and other information (e.g. contact details of key personnel and local police) should be easily accessible to all staff.

Good housekeeping is one of the key issues in the preservation of collections. While being a relatively cheap measure, it protects the material from pests and fungi by depriving them of optimum living conditions. Cleaning should be carried out with care and only using agents that are non-toxic and of no threat to the collection from solvent fumes or abrasives. It is important that cleaning personnel are instructed to avoid potential damage to the collection. Materials and equipment used should remove rather than redistribute dirt. The shelves and the collection material itself is best cleaned by trained staff.

Integrating pest management into collection care is essential for the long-term preservation of library and archive material. Pest management should be an ongoing routine rather than a crisis-driven activity. Typically, it will try to eliminate insect attractors around the building, such as defective drainage, plantings, and waste. Physical exclusion of pests from the building by appropriate sealings and doors is one of the key elements. Constant monitoring of all areas, including loading bays, and the quarantine of newly arriving material, will help to detect the presence of pests early. In addition, plans of action in case of infestation should be in place, so that an immediate and appropriate response is possible (Strang 1996).

Beneficial to the collection, with respect to preventive conservation, are the proper housing and mounting of objects. Appropriate wrapping material for different objects may seem costly, however, will pay off in the long run. This also includes storage boxes made from acid-free material and considerate packing for objects going on loan in a different location. As a measure of preventive conservation, some collections have developed a method of mounting that will be fit for both storage and exhibition, which in turn decreases the amount of handling necessary. Books, in particular, require attention for storage and exhibition, as their binding structure often inhibits proper opening or is too weak to support the book block within the shelf. 
Book rests and properly fitting book shoes are therefore an important measure of preservation.

Preventive conservation strategies within storage facilities include a stable environment, as well as the exclusion of natural light sources and pollutants. In addition, the type of shelving itself is important, as wooden shelves as well as paint and vamishing material may off-gas volatile compounds that adversely affect the material (Tétreault 1999). Metal shelving is preferred and recommended (BS 5454). No objects should be allowed to be stored directly on the floor. Generally, adequate air movement throughout the entire storage area will prevent localised damp spots with their increased danger of developing mould growth or pest damage.

For preventive conservation to be effective, it is paramount that staff at all levels be trained in all issues relating to the preservation of the collection. In particular, staff from different departments should understand the differing issues involved. This is especially important where there is fragmentation of responsibilities and where responsibility for maintenance and repair of the building is separated from those involved with the preservation of the collection.

Many measures that can be taken in order to preserve the collection are relatively cheap to achieve (e.g. appropriate cleaning utensils, training of staff to an understanding level), yet make a significant difference to the overall condition of building and collection. Published sources can offer useful guidance on implementing a preservation plan for library and archive collections, e.g. (Adcock 1998). 


\subsection{Historic Buildings and Monuments}

\subsubsection{Buildings and Building Performance}

A building may be considered as a container or envelope that buffers or filters external conditions for internal needs. In order to be successful, the design and construction of a building must meet certain criteria. These may be considered under the headings of functional, performance, statutory and user requirements.

Every building, regardless of its original, intermediate or ultimate use, must fulfil certain basic functional requirements. These are primarily concerned with protection from the external environment, human comfort, and organisation of activity and space. Other functional needs might include the creation of a particular sense of identity or place, or the control of competing or conflicting internal uses.

The manner in which a building meets its functional requirements may be determined by how it performs in relation to a number of defined performance criteria. These may include access and egress, appearance, durability, dimensional stability, strength and stability, weather exclusion, sound control, thermal comfort, fire protection, lighting and ventilation, sanitation, security, and cost. Many of these performance requirements form the basis for statutory and non-statutory control in relation to the design, construction and use of buildings.

Other requirements relate to the health, safety and well-being of persons who design, build, manage, repair, maintain, occupy, and demolish buildings.

The user of a building can expect to live or work in a space that satisfies basic human requirements and, in addition, certain needs that are specific to the activities being performed. The ways in which these are met, and whether one is in conflict with the other, is a measure of how appropriate the building is for the activity or activities in question. Fitness for purpose is an important measure of how a building matches the requirements of its user. 
Where buildings are designed or adapted for specific needs, these basic requirements may be replaced or supplemented by further considerations. These may be prescriptive in nature and, as such, might include requirements under specific headings (e.g. floor loadings, lighting levels). In such a situation, study of the particular needs of the user will assist in identifying what the building has to provide in order to satisfy user activities.

The user requirements within a particular building may, at times, conflict with the structural, material and/or environmental needs of the building or its contents. This may be of particular concern when dealing with historic buildings, where careless alterations or adaptations can cause irreparable damage both to the structure and fabric of the building, and the aesthetic qualities of its spaces. Where such conflict exists, it is important that the needs of both the building and its user(s) are clearly recognised, and the implications of bias or compromise fully understood.

\subsubsection{Historic Buildings and Monuments}

Historic buildings and monuments play an important part in the character and setting of urban and rural communities, and provide a tangible continuity between each successive generation or phase of human development. There is thus an intimate relationship between such reminders of the past and the needs and aspirations of today that has implications for education, employment, tourism, training, leisure, and recreation.

Public attitudes towards historic buildings, and the current acceptance of conservation ideologies and constraints imposed on individuals and property owners, demonstrate recognition (albeit often challenged) of this powerful stimulus. 


\section{Buildings of Special Architectural or Historic Interest}

At a general level, buildings may be seen in terms of their history and can be categorised according to their age, stylistic influences, and manner of construction. This categorisation forms the basis for the system of grading buildings of special architectural or historic interest in England and Wales (DoE/DNH 1994: section 6.11). The grading system for buildings on statutory lists takes account of the following criteria:

- age and rarity, particularly where buildings are proposed for listing on the strength of their historic interest; the older a building is, and the fewer the surviving examples of its kind, the more likely it is to have historic importance

- all buildings built before 1700 that survive in anything like their original condition are listed

- most buildings of about 1700 to 1840 are listed, though some selection is necessary

- after about 1840 , because of the greatly increased number of buildings erected and the much larger numbers that have survived, greater selection is necessary to identify the best examples of particular building types, and only buildings of definite quality and character are listed

- for the same reasons, only selected buildings from the period after 1914 are normally listed

- buildings that are less than 30 years old are normally listed only if they are of outstanding quality and under threat

- buildings that are less than 10 years old are not listed

Grade I and $\|^{*}$ buildings are of outstanding architectural or historic interest, and represent about $6 \%$ of all listed buildings. Grade II buildings form a major element in the historic quality of towns, villages and the countryside, and represent about $94 \%$ of all listed buildings.

In Scotland, Category A buildings represent $7.5 \%$ of all listed buildings, Category $B$ represent $60 \%$, and Category $C(S)$ represent $32.5 \%$ (Mays 2001). 


\section{Ancient Monuments}

A 'monument' is defined in the Ancient Monuments and Archaeological Areas Act (1979) as 'any building, structure or work, whether above or below the surface of the land; any cave or excavation; any site comprising the remains of any such building, structure of work or of any cave or excavation; and any site comprising, or comprising the remains of, any vehicle, vessel, aircraft or other movable structure or part thereof'.

An 'ancient monument' is defined as 'a monument, which in the opinion of the Secretary of State, is of public interest by reason of any historic, architectural, traditional, artistic or archaeological qualities attaching to it'.

The criteria used for scheduling ancient monuments include period, rarity, documentation, group value, survival/condition, fragility/vulnerability, diversity, and potential (DoE 1990: Annex 4).

In this work, the term 'historic monument' is taken to mean a 'structural' monument (i.e. a building scheduled as an ancient monument that is capable of beneficial use).

\subsubsection{Traditional Materials and Forms of Construction}

Buildings are, by their very nature, composites of differing materials and forms of construction. Each has its own characteristics that, together, influence the durability and performance of the building.

In the case of a historic building or monument, the demands placed upon it by its occupants and users relate to various factors:

- location and siting

- climatic and environmental conditions

- the manner in which it is used 
- changes to user activities and demands placed on structure, fabric and services

- patterns of repair and maintenance

- current (and past) levels of damage, deterioration and decay

Buildings constructed before the Second World War typically include traditional materials and forms of construction that were understood by both designer and constructor. The performance and durability of such buildings remain a testament both to their fitness for purpose and inherent flexibility to be put to new uses when their original application ceases or is no longer viable (i.e. uneconomic, unfashionable). The intensity of change to have affected many important historic buildings and monuments is evidence of this lasting value over time.

Despite these lasting qualities, all buildings, of whatever age and arrangement, are subject to natural and man-made mechanisms of deterioration and decay. Without basic levels of repair and maintenance, these buildings would probably not survive in an acceptable state beyond the generation that built them. Of the various defects and mechanisms of deterioration and decay acting on the exterior and interior of a building (Appendix A), it is moisture that has the potential to cause the most harm.

\subsubsection{National and International Guidance}

The ways in which historic buildings and monuments are conserved and managed have developed within a specific framework that encompasses various separate and related issues (e.g. philosophical, legal, technical, financial, managerial, curatorial).

These issues, and others, are enshrined in international charters, resolutions and recommendations drawn up by the United Nations Educational, Scientific and Cultural Organization (UNESCO), the Council of Europe, and the International Council on Monuments and Sites (ICOMOS), and in guidance documents and legal enactments produced by the individual countries. 
Some of the more influential and widely known within the United Kingdom include the Manifesto of the Society for the Protection of Ancient Buildings (SPAB 1877), the Venice Charter (ICOMOS 1964), and the Burra Charter (ICOMOS 1999). Other useful documents include the New Orleans Charter for Joint Preservation of Historic Structures and Artifacts (APT/AIC 1992).

The primary legislative enactment relating to the historic environment (i.e. historic buildings and areas) in England and Wales is the Planning (Listed Buildings and Conservation Areas) Act 1990, and in Scotland the Planning (Listed Buildings and Conservation Areas) (Scotland) Act 1997. Additional guidance is provided within key documents - Planning Policy Guidance 15: Planning and the Historic Environment (DoE/DNH 1994) for England, the Memorandum of Guidance on Listed Buildings and Conservation Areas (1998b) and National Planning Policy Guidelines 18: Planning and the Historic Environment (1999) for Scotland, and Circular 61/96: Planning and the Historic Environment: Historic Buildings and Conservation Areas (1996a) and Circular 1/98: Planning and the Historic Environment: Directions by the Secretary of State for Wales (1998a) for Wales.

General guidance is also provided in British Standard 7913: Guide to the Principles of the Conservation of Historic Buildings (BSI 1998).

A recent review of policies relating to the historic environment of England, undertaken by English Heritage on behalf of the Government, also provides a useful summary of policy and practice. The report - Power of Place - stresses the need to understand and make better use of the nation's historic buildings and acknowledges that 'Museums, libraries and archives are central to any initiative to introduce people to the historic environment' (2000d: para. 70). Recommendation 9 is for the heritage sector to 'Work with museums, libraries and archives to widen access', for local authorities and regional bodies to '...identify opportunities to improve access to information', and for owners of heritage attractions to 'draw up access programmes to attract new audiences'. 
Recent guidelines published by the Council of Europe (2000b; 2000c) address issues relating to the protection of the 'movable heritage' (as well as the archaeological and architectural heritage), yet exclude 'specific measures concerning archives and libraries':

No doubt documentary records such as books can be made subject to the general rules on public collections or protected objects in private ownership, but special rules relating to their collection, classification and communication to the public already exist and have been covered by various guidelines from the International Council on Archives and the International Federation of Library Associations.

In terms of putting policy into practice, the National Trust owns some 400,000 volumes that form 'a unique source for the history of the English country house library, the intellectual pursuits of their owners, and the history of the English book trade'. Few of these books are of outstanding rarity and their main value lies in their significance as artefacts (1996b: 36-37). The conservation of these books, and other works of art on paper (e.g. architectural drawings, globes, unbound prints and archival documents of artistic importance), is carried out in 'an extremely conservative manner'. Most of the archives of the houses have been deposited in local record offices.

\subsubsection{Preventive Conservation}

Although the principles of preventive conservation have typically been developed by those dealing with museums and galleries, they can equally well be applied to historic buildings and monuments, together with their fixtures and fittings. This is particularly so for those buildings and monuments that are empty or intermittently used (e.g. churches, chapels).

In assessing a historic building or monument with a view to developing and implementing a programme of preventive conservation, it is necessary to consider some or all of the following: 
- location and situation (e.g. prevailing wind, sources of atmospheric pollution)

- building construction (e.g. levels of insulation, air infiltration, weathertightness)

- building morphology (e.g. volume, area, floor-to-ceiling heights)

- occupancy (e.g. constant, intermittent, empty)

- user activities (e.g. public access, floor loading)

- support activities (e.g. security, cleaning staff)

- environmental conditions (e.g. temperature, humidity, light, ventilation, fluctuations in conditions)

- risk assessments (e.g. theft of valuable objects)

- presence of contaminants and pollutants (e.g. chemical interaction and offgassing from exhibits)

- documentation (e.g. inventories for fixtures, fittings and chattels)

Once background information has been collected and collated, it is necessary to consider ways in which the building and its contents might be protected from unnecessary risk or damage. In this, consideration should ideally be given to ways in which existing facilities and services may be modified to improve conditions, before deciding on the addition or insertion of new installations.

Preventive conservation measures for buildings may include the modification of building fabric (e.g. draught sealing, additional thermal insulation), the provision of physical buffers and/or barriers (e.g. storm porches, re-ordering use of rooms, changing routes around building), modification or revision of existing building services (e.g. provision of constant background heat, use of humidistats instead of thermostats), or the installation of new building services (e.g. air conditioning, humidification, de-humidification).

\section{Monitoring and Control}

In understanding how a building performs, it should be remembered that less than $10 \%$ of the fabric of the building is usually available for direct observation and assessment during a survey, whilst the structure and other parts of the fabric remain 
hidden below ground, within the construction, or covered by finishes and decorations.

In order to understand the construction of the building and identify actual or potential defects, investigation and survey may require a range of non-destructive survey techniques. Such techniques include the use of radiography, surface penetrating or impulse radar, microwave analysis, thermography, infrared photography, acoustic testing, magnetometry, micro-drilling, fibre optics, and various geotechnical and geophysical survey methodologies (Watt 1999: 165-72).

Most defects are, however, progressive in nature and can be monitored over a period of time. In order to provide evidence as to the nature and timing of the defect, monitoring usually includes a level of absolute or relative measurement.

How monitoring is performed depends on difficulties of access, the overall condition of the building, the need to obtain a standard and continual sequence of information, and available finance. Accuracy will typically increase with complexity and cost. The reasons for monitoring must also be considered, whether it be to record progressive conditions, or detect certain changes or conditions before damage is sustained.

Monitoring is commonly undertaken in relation to environmental conditions, structural distortion and movement, and material deterioration and decay.

The three environmental conditions that have the greatest effect on buildings and their contents are temperature (ambient and surface), humidity (absolute and relative) and sunlight (visible and ultraviolet). Each can be measured and monitored to provide necessary information for corrective measures or suitable protection. Consideration may, in addition, have to be given to air movement and atmospheric pollution.

As with all monitoring, it is important to establish a pattern of readings over a period of time to take account of such variables as seasonal, diumal and nocturnal 
differences; times and levels of occupancy; movement of caretaking, security and cleaning staff; and use of service installations.

On-site measurement may be undertaken using simple diagnostic instruments (e.g. thermometer, whirling hygrometer, thermohygrograph, electronic meters), but for more accurate measurement and monitoring the investigator will require specific instrumentation. This typically takes the form of sensors, data loggers and radio telemetry systems (e.g. Grant Instruments' SquirreßB, Hanwell Instruments' Humbug®, Hutton + Rostron's Curator $\circledast$, Preservation Equipment's Tinytag/ Tinytalk®). Such systems, together with computerised building management systems (BMS), may also be used to control specific environmental functions (e.g. lighting, hearing, ventilation, air conditioning).

Systems may also be designed and installed to monitor and detect specific parameters (e.g. moisture content, pipe leakage, gutter overflow), as well as respond to pre-determined trigger events (e.g. trace heating tapes in valley gutters).

\section{Planning for Accidents and Emergencies}

The preparation of an accident and emergency plan is based on a thorough inspection of the building and an assessment of the hazards and risks associated with its usage, together with a programme of training and familiarisation.

Planning for an accident or emergency, and establishing a mechanism that will ensure swift and effective action, is a specialised skill that requires detailed knowledge of the building and its various occupants and users. It is also reliant on the co-operation and support of owners, users and staff (Figure 1). 


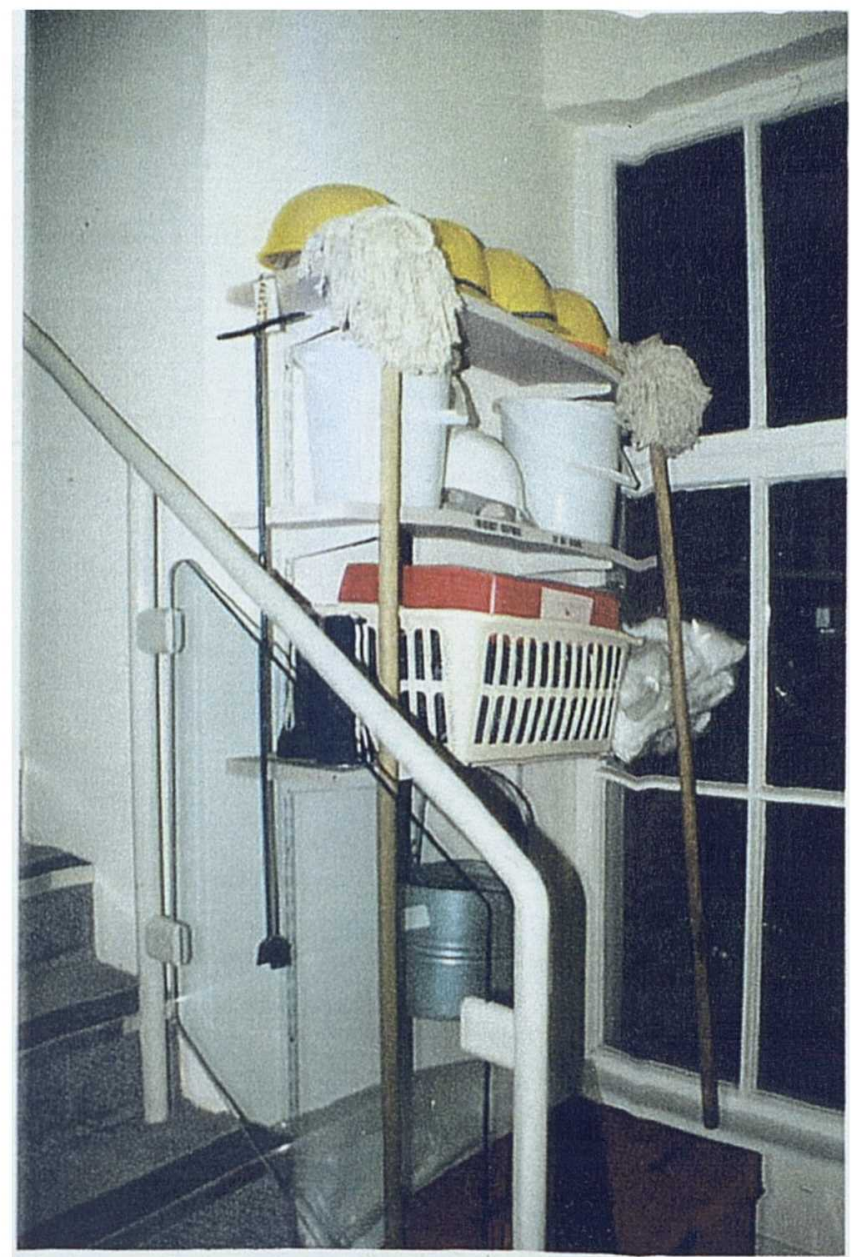

Figure 1: Good practice: emergency kit and instructions easily accessible

Whilst there are various publications that cover accident and emergency planning, such as the recently-published interactive CD-ROM Emergency Manual for Historic Buildings and Collections (EMMS 2001), the following list includes those tasks that relate particularly to the building (rather than the collection):

- regular inspection and survey of building (e.g. quinquennial system)

- regular inspection and testing of building services

- preparation and maintenance of records (e.g. floor plans showing fire extinguishers)

- preparation of risk assessments (e.g. identify ways to remove hazard or prevent/minimise risk) 
- assessment of housekeeping (e.g. regular cleaning regime, appropriate methods and products)

- assessment of support staff and services (e.g. security, caretakers, ground staff)

- monitoring of work conditions (e.g. staff facilities, meetings)

- management of building works (e.g. induction for new staff and contractors, hotwork permits)

- preparation of inventories (e.g. written and photographic records, security coding)

- sourcing of information (e.g. emergency contact numbers, access keys/codes, insurance documents, maintenance and operating manuals, local authority disaster plans)

- sourcing of help and assistance (e.g. fire service, police, local contacts, response staff)

- assessing availability of duplicate information and/or equipment (e.g. copies of important information, such as inventories, maintained off site)

- assessing specific protection for valuable objects or sensitive information

- developing logistics of disaster plan (e.g. communication network, training and familiarisation for staff, assignment of key responsibilities, fire practices, evacuation procedures)

- preparation of instructions for seldom-performed tasks (e.g. means of escape from upper storeys)

- providing practical instruction (e.g. use of fire extinguishers, facilities for disabled persons)

- reviewing and monitoring procedures (e.g. learn from experience, up-date procedures, publish and disseminate relevant information) 


\section{INTERFACE BETWEEN COLLECTIONS AND HISTORIC BUILDINGS}

\subsection{The Interface between Paper-based Collections and Historic Buildings}

The following section seeks to improve the understanding and current knowledge about the interface between paper-based collections and historic buildings.

\subsubsection{The Nature of Libraries and Archives}

The nature of libraries and archives differs in various ways from the nature of museums and other collections. Libraries and archives themselves also have different purposes - these will be outlined in the following section based largely on the 28th report of the Historical Manuscripts Commission (HMC 1999).

The main difference between an archive and a library is seen in the former being a primary source of information, whereas the latter is mostly a secondary source. At the same time, archives have no tumover of stock like a lending library, but only the continual addition of new items or whole new collections. Consequently, every item in an archive is intended for permanent preservation (Kitching 1993: 5). This very essential difference implies different approaches, not only towards the preservation of archival material, but also towards public access.

Compared with libraries, the tension between 'access' and 'preservation' is much greater for archives. Archive material is unique and irreplaceable. Objects can therefore not be borrowed or moved from one room to another, unless under supervision. In addition, readers require more attention, either in terms of observation and instruction in handling archival material or with guidance on how to find relevant material for their particular field of interest. 
It follows from the uniqueness of the material that the main emphasis in archives must lie with the long-term preservation of its material rather than the provision of user-friendly facilities. Buildings that house archives therefore have to conform more strictly to common standards for the preservation of paper-based collections. In cases where local libraries share space with archives, buildings are not usually designed to cope with the specific requirements of the archive. It is, for example, common practice in libraries to allow users to browse through open shelves in order to find the literature of interest. This is not possible in archives since the public must be excluded from storage areas in order to protect stored material.

Particularly in cases where less frequently used archival material or modem media is housed in cool storage, it is necessary to allow the material some time to adapt to the warmer environment of the reading room upon request to avoid condensation or distortion of composite objects. This will impose special requirements on the building.

Archive repositories also suffer from a widespread lack of awareness for their activities and specific requirements. This is especially common in relation to funding for building maintenance and improvements. Unlike library or museum visitors, who may use existing facilities simply because they wish to be entertained, archive users come for very specific reasons and are a small minority of the total population of the United Kingdom.

Compared with archives and libraries, museums are often in a better financial situation. This is not only due to their ability to charge the visitor a certain entrance fee, but also because they usually receive governmental support, as their value as a tourist attraction for a particular region is well recognised.

In addition, objects in museums and other collections are in a very different situation from library and archive material. Their main purpose is to be viewed, which means they can fulfil the visitor needs by simply being exhibited. Books and archival materials, on the other hand, have to be capable of being handled in order to satisfy the needs of the user. Although new technologies over the past decade have made it possible to look at certain items using other media (e.g. microfiche), it seems that the 
demand for looking at original material has not decreased. This distinguishes preservation and conservation of books and other archival material from preservation measures for museum objects.

Storage, in particular, requires a very different approach, since museum material is not constantly being transferred between storage and users. In museums, an item is on exhibition for a certain period of time, after which it will be returned to storage. Adaptation to a different environment has therefore only rarely to be accomplished.

This fact also places additional responsibilities on the management and staff of archives and libraries.

\subsubsection{Collections within Historic Buildings and Monuments}

\section{Early Libraries}

The development of libraries can be linked with the break-up of the Roman Empire in the fifth century $A D$ and the spread of Christianity. The church provided a focus for culture and learning, and book production was practised exclusively in the monasteries of the early Middle Ages. Such books were both rare and costly, and their value in monastic life was high.

The earliest monasteries had very few books and these were stored simply within heavy wooden chests inside various rooms. Some libraries, such as that at Westminster Abbey, still house their muniments within wooden chests. In many cases, these documents later formed the core of public archives. As the number of books increased with time, however, lack of space became an increasing problem. Eventually, storage closets were constructed inside the monastic cloisters (i.e. forming the later scriptorium), but as the collections grew, further space for storage and study was created. The books were kept in special cupboards within the library, resembling the Roman 'armarium' (Lat. 'cupboard, chest') (Douglas 1990). 
Since books were of such high value, chaining them was a common practice even until the seventeenth century. Chained books could not be taken away to be read at a convenient light source, which is why this arrangement also had an influence on the design of early libraries. Libraries were furnished with lecterns, set at right angles between windows, and it was only with the decreasing value of books in later centuries that this design was abandoned (Douglas 1990).

\section{Country House Libraries}

The changing role and importance of private books and libraries in country houses have been admirably covered by Mark Girouard in Life in the English Country House (Girouard 1980) and the late Gervase Jackson-Stops in The English Country House: A Grand Tour (Jackson-Stops and Pipkin 1993: 198-211). Drawing from these sources, and others, it is clear that books have been of great importance and value to house owners since the Middle Ages. By the eighteenth century, a classical education, combined with the opportunity to travel, gave an impetus for books to be collected and gathered into the libraries.

Aside from a small number of special collections formed during the Middle Ages such as that of Duke Humphrey of Gloucester that forms the nucleus of the Bodleian Library at Oxford - learning was the preserve of the Church. Whilst an inventory of 1423 records the presence of a liberaria in the house of Henry Bowet, Archbishop of York, private collections were, by comparison, small, as with that at Hardwick Hall (Derbyshire), where an inventory of 1601 lists only six books.

With the Reformation and the resulting spread of education among the upper classes, Tudor gentry sought to pursue Renaissance ideas through education and learning. In spite of the corresponding increase in literacy, the number of books in country houses remained small and many houses had no books at all. Only a dozen or so members of the upper classes, excluding clerics, are known to have owned more than a hundred books in the sixteenth century, with only two men - Lord Lumley and Lord Burghley - owning more than a thousand books. 
Books and personal items were typically housed in the gentleman's closet and the earliest libraries - such as that at Ham House (Surrey) - were developed as extensions to these rooms; theological books were sometimes kept in or next to the chapel. Such rooms were strictly utilitarian, as seen in the designs for a 'book closet' by Robert Smythson of c.1600. In this, there are open compartments from floor to ceiling with spaces for a mix of manuscripts, papers and books; the proportions suggest that the books were laid on their sides on top of one another. Whilst small collections of books were usually kept in chests, compact book storage came in with the organised institutional libraries of the seventeenth century - such as the Bodleian in Oxford - where tiers of shelves with ladders and galleries were introduced in 1601-12. This arrangement was copied and provided the basis for many countryhouse libraries in the seventeenth century.

Surviving 'book closets' from the early seventeenth century are rare or non-existent, with the best example being, not in a country house, but a church. Sir John Kederminster, a learned landowner, built a small library attached to the church at Langley Marish (Buckinghamshire) in c.1620 and left his collection of books upon his death. The books are kept behind doors in shelved cupboards or presses.

With the increase in learning among the gentry of the later seventeenth century, ${ }^{11}$ books and libraries became more numerous in country houses. The private library in the London house of Samuel Pepys is shown in an engraving of c.1690, complete with a series of glazed oak bookcases or presses rather than fitted shelves (freestanding bookcases were not widely seen in country houses until the mid-eighteenth century). These books and their presses were moved to Magdalene College, Cambridge, during Pepys's lifetime. The oldest surviving country-house library (i.e. room rather than collection) is that at Ham House (Surrey), which was installed by the Duke of Lauderdale in the 1670s. This is housed in two small rooms - referred to as the library and library closet in contemporary inventories - positioned between the private rooms and those accessible to others.

11 This is, in part, associated with the founding of the Royal Society in 1660. 
Where books were to be found on display, they were rarely kept on shelves in one place and were typically displayed with their spines facing inwards (the titles being written on the fore-edge). The quality of bindings is often extremely high, often using vellum or calf leather with embossed gilt emblems or 'livery bindings' of later countryhouse libraries. The significance and value of books is often emphasised in their inclusion within portraits of the country-house owners.

The architectural development and presentation of country-house libraries began in earnest in the eighteenth century, with that designed by William Kent for Houghton Hall (Norfolk) being one of the earliest. Dating from the late 1720 s, the library adjoins the dressing room and bedroom of Sir Robert Walpole and confirmed architectural pretensions - the architecture comes first and the books are ingeniously fitted into the scheme. In the 'secret library' on the top floor of Sir Thomas Chester's house at Chicheley (Buckinghamshire), all the bolection panels (including those in the dado, fluted pilasters and their bases) open to reveal bookshelves behind.

The library at Holkham Hall (Norfolk), again by William Kent, remains part of Lord Leicester's private apartments, rather than the state rooms, and was effectively a communal family or 'living room' rather than a study. In his design, Kent used the pedimented bookcases of the library to dictate the architectural scheme. The design and use of such a library are in sharp contrast to the place of study of $\mathbf{5 0}$ years earlier. This informality is captured by William Hogarth in a conversation piece of 1738 , showing Lord and Lady Cholmondeley with their children at ease in the library.

Throughout the eighteenth century, gentlemen amassed large collections of books, art-objects and curiosities with shelves and presses taking up entire walls of rooms. Libraries were enlarged and enriched by new books and portfolios. Presses were often arranged by the subjects of interest and fashion - architecture, topography, botany, genealogy, philosophy, theology, and science appear in the 1730s' library of Lord Warrington at Dunham Massey (Cheshire). The library at Blickling Hall (Norfolk) similarly contains a fine and wide-ranging collection in mid-eighteenth-century presses that were re-styled and carved with naturalistic foliage in the late 1850s, whilst that at Belton House (Lincolnshire), created for Viscount Tyrconnel in 1737, 
epitomises the character of the male library/study (complete with wooden 'books' having titles invented by the owner at the end of the shelves). Growing interests in British literary heritage and a revival in antiquarianism also resulted in a fashion for Gothic libraries, such as that at Strawberry Hill (London) and Felbrigg Hall (Norfolk).

Many such libraries were often no longer the private sanctums of the owners, but instead available to family and guests; that at Wrest (Bedfordshire) was being used in 1745 as an evening sitting room by the family. Large houses retained both booklined studies for the owner and libraries of common resort for his family and friends. Their use as communal living rooms, together with the need for additional accommodation of pictures and sculptures, helped to destroy the balance of the formal house and bring about a revised form of house planning.

Furniture was designed with the library in mind - 'library tables' were common in houses by Adam (such as at Nostell Priory and Harewood House in West Yorkshire), whilst chairs were upholstered in leather to reflect the colour and texture of the book bindings. The library itself, like the dining room, was still considered essentially masculine in character and not subject to the changing fashions that dictated the appearance of other rooms (such as the drawing room). At Kedleston Hall (Derbyshire), Robert Adam used the bolder Doric order for the library, as opposed to the Corinthian of the drawing room, with the glazing bars of the bookcases echoing the octagonal compartments of the ceiling. Gothic-inspired libraries - such as that at Arundel Castle (West Sussex) of c.1800 - offered scope for creating rich ecclesiastical interiors, complete with clustered columns supporting a sexpartite vault. Jib-doors, often with false book-spines, helped preserve the symmetry of a room whilst allowing private circulation.

The late eighteenth and early nineteenth centuries saw the demise of the library typically the main informal room in a large house - with many combined with communal living rooms to become 'sitting libraries', as at Kenwood (London) and Petworth House (West Sussex). Such a library at Woburn Abbey, created by Henry Holland in the 1790s, was praised by Humphry Repton as allowing groups of family and guests to enjoy different pursuits in an atmosphere that was cultivated but at the 
same time informal. At Chatsworth (Derbyshire), the library was remodelled in 181530 to provide a room of warmth and comfort similar to that of a luxuriously-appointed London club, whilst the Gothic library of 1819 at Althorp (Northamptonshire) was the last and most lived-in of a series that filled most of the ground floor of the house.

The libraries of later nineteenth-century houses remained in much the same relationship with dining and drawing rooms as in earlier houses. They were pleasant living rooms with less of a significant role in the planning and use of the house.

\section{Public Libraries and Archives}

Away from the country house, 'rational recreation' was seen by Octavia Hill (one of the founders of The National Trust in 1895) and other nineteenth-century reformers as the way to improve the mind of the working man. Public art galleries and museums, together with cheap or circulating libraries, were provided for the good of the nation.

In contrast, public archives and record offices grew out of the personal records of the monarch in the Middle Ages, and were created in the course of governing the kingdom. As the monarch travelled from one estate to another, the documents were carried with him. Royal administration developed and gained in complexity from the early twelfth century and this, in turn, resulted in difficulties housing the records. Many royal palaces and public buildings were used for storage, including the Tower of London and Westminster Abbey. In later centuries, over 200 sites came to be used to hold the nation's records, scattered all over London and elsewhere.

It was only in the nineteenth century that recommendation was made to establish an official public record office, leading to the Public Record Office Act of 1838. This enactment provided the all-important legislation to protect public records by creating an official archive, with the first purpose-built record repository and reading room being built in Chancery Lane, London, in 1858 (PRO 2002). 


\subsection{Specific Damp-related Problems}

The impact of different environmental and biological factors on buildings as well as library and archive collections has been described many times before (e.g. Banks 1988; Erhardt and Mecklenburg 1994; Massari and Massari 1993). Comparatively little work has, however, been undertaken in looking at the interface between the two. The following section is intended to summarise previously-published work, identifying possible hazards to library and archive collections as well as to historic buildings.

\subsubsection{Paper-based Collections}

The major factors to affect the longevity of materials are temperature, relative humidity (RH), airborne pollutants, and electromagnetic radiation. Biological factors, such as mould and pest infestations, can also have a significant impact, as can human interactions (e.g. use, handling, storage, loan, transportation of objects). Other factors, such as natural disasters (e.g. earthquakes, floods, storms, avalanches), pose an additional risk to a collection. These natural phenomena cannot readily be prevented, but measures can be taken to minimise their impact on buildings and collections.

Library and archive collections contain a wide range of different organic and inorganic materials, such as paper, parchment and vellum, leather, photographic materials, sound recordings, magnetic and digital media, easel paintings, and various artefacts. ${ }^{12}$ The essential difference between libraries and archives is seen in archival material being a primary source of information, whereas library material is regarded as a secondary source. This fact demands different preventive measures.

All these materials undergo a natural ageing process as their complex molecular structure depolymerizes. Natural ageing is a slow, but inevitable process. The rate of 
decay is dependent on the composition and therefore the chemical stability of the different materials. The deterioration of most materials is greatly affected by temperature and $\mathrm{RH}$ and, moreover, by the rate and magnitude of changes in both parameters.

\section{Relative Humidity and Temperature}

Relative humidity $(\mathrm{RH})$ and temperature differ from other environmental factors, such as light and pollution, in being interdependent ${ }^{13}$. They are closely linked, since the capacity of air to hold water depends on its temperature. Both factors are known to have significant impact on the rate of deterioration, as the rate of most chemical reactions increases when temperature is increased, whereas water is an important reactant in decay mechanisms of organic material. At the same time, their effects on objects are more varied and complex, since objects are also affected by the rate and magnitude of changes in temperature and relative humidity (Erhardt and Mecklenburg 1994: 32). At ambient temperatures, RH must be considered as the most critical factor with respect to the degradation of organic material.

\section{Background to RH control}

The important role that $\mathrm{RH}$ plays in the well-being of objects was first recognised at the turn of the twentieth century. Only a few decades later, $\mathrm{RH}$ fluctuations were proven to cause damage to objects like panel paintings. Over time, $\mathrm{RH}$ specifications were proposed according to local climate and feasibility, which led to tight recommendations during the 1980 s as techniques of environmental control became more sophisticated (including the increased use of air-conditioning systems). The cost of maintaining these specific conditions was tremendous and only rarely were recommendations based on actual scientific knowledge (Michalski 1993: 624).

\footnotetext{
12 As mentioned before, modern media (e.g. photographic material, magnetic tapes, digital media) were excluded from this report.

13 Relative humidity is also associated with absolute humidity (AH). AH describes the amount of water vapour in the air, but, unlike $\mathrm{RH}$, does not vary with changes in temperature.
} 


\section{Direct and Indirect Effects of RH on Collections}

High RH levels can have direct or indirect effects on the material in an archive collection. Paper, as the most prevalent material, is known to be significantly affected over time by the amount of moisture present (Zou et al. 1996: 252-53). Moisture content will affect all chemical and physical properties, such as strength and dimensional stability, whilst the presence of excess moisture will accelerate the ageing of organic material. In addition, the different organic materials in library and archive collections are all, to a different extent, hygroscopic (i.e. they can absorb moisture from the air as well as lose moisture to the air until they reach their specific equilibrium moisture content). Dimensional changes caused by the absorption of moisture may therefore cause damage to objects made from different materials (e.g. book covers will warp). This is also of particular concem in the case of maps since the accuracy of scale is jeopardised.

Among the indirect effects of high $\mathrm{RH}$ levels are the increasing risks of bacterial and mould growth and insect pest infestations (see section 4.2.3 and 4.2.4). These organisms favour high $\mathrm{RH}$ conditions. Additional problems arise with the movement of collection items between less-than-ideal storage conditions and reading rooms usually the material is not given sufficient time to adapt to the differing conditions.

\section{Storage Conditions - Reasons for Compromise}

It has often been recommended that archive collections, with their typically wide range of materials, should be stored at temperatures between 19 and $21^{\circ} \mathrm{C}$ and with a relative humidity of about $50 \%$ (see Appendix G). In addition, conditions are required to be stable throughout the year. These generally-accepted conditions are based on a compromise between human comfort and the requirements for archive collections.

These values are also mid-way between 65 and $70 \% \mathrm{RH}$ to prevent mould growth and 40 to $45 \% \mathrm{RH}$ to prevent mechanical failure of materials such as wood and ivory (Erhardt and Mecklenburg 1994:32). The most common RH and temperature settings in collections (e.g. 55-65\% RH / 13-18 $\mathrm{C}$ [BSI 2000]; 40-50\% RH / $21^{\circ} \mathrm{C}$ 
[Briggs 1987]) therefore minimise biological attack, mechanical damage, and the efflorescence of salts. These are, however, simply the most visible and often fastest forms of damage to be seen (Erhardt and Mecklenburg 1994: 37).

Other compromises are indicated according to local climate and are usually reflected in the relevant standards or recommendations of a particular country. Storage recommendations in North America, for example, require less humid conditions than in England. This accounts for the fact that North American winters are very dry and it is therefore easier to maintain stable conditions at an RH between 40 and $50 \%$. In the United Kingdom, on the other hand, it is easier to keep conditions constant between 50 and $60 \%$ RH (Banks 1988: 84 ).

It must also be kept in mind that archive collections comprise a very wide range of material, even if only organic materials are being considered. As yet, there seem to be discordant opinions as to the ideal storage conditions for parchment. While Banks (1988: 78) suggests significantly higher $\mathrm{RH}$ values for parchment than for paper, others class it as similar to paper (Erhardt and Mecklenburg 1994: 36) or even call for lower RH (Hansen et al. 1992: 340).

\section{Stable Conditions}

Strictly speaking, since both humidity and temperature contribute to the deterioration of materials, any degree of humidity accelerates decay. One can therefore only minimise, but not eliminate, the effects of $\mathrm{RH}$. Although low temperature has a greater effect on the life expectancy of an object, low RH levels have proved to be more practical for collections in day-to-day use and can be achieved more easily. In the range of $75-90 \% \mathrm{RH}$, a reduction of $10 \% \mathrm{RH}$, for example, will control mould growth as much as dropping the temperature from 30 to $10^{\circ} \mathrm{C}$. The trend over the past decade has therefore been towards correct and incorrect values, rather than a single set-point of conditions (Erhardt and Mecklenburg 1994; Michalski 1993). Ideal conditions for one group of objects may be detrimental to another. 
The possible reduction of damage at a certain $\mathrm{RH}$ level is partially due to the stabilisation of conditions and avoidance of damaging extremes rather than specific values (Erhardt and Mecklenburg 1994: 32). Fluctuations of less than one hour do not affect most museum objects (Michalski 1993: 626). The effects of transient variations in moisture content caused by cyclic humidity changes in $\mathrm{RH}$ are, however, known to be detrimental to the durability of paper ${ }^{14}$ (Ramarao 1999: 532). This is partly due to the sorption hysteresis of paper (i.e. the sorption isoterms are different for adsorption and desorption of moisture). Paper generally absorbs moisture faster than it desorbs it (Brandon 1981). The most stressful fluctuations for paper objects are therefore those that are longer than the response time, but shorter than the stress relaxation time. Even stresses below the critical value can cause damage, since the extent of damage depends greatly on the geometry of the assembly (Michalski 1993: 626). Objects that contain restrained materials (e.g. books) are more vulnerable than objects composed of a single material. It is also suspected that cycling humidity may induce the migration of water-soluble degradation products inward from and outwards towards the surface area of books that is exposed to the environment (Banks 1988: 81).

Michalski (1993) has, however, shown that pure paper objects can be stored successfully at considerably dryer conditions and even leather bindings on nonacidic paper must be considered as only moderately vulnerable to $\mathrm{RH}$ changes. Most paper objects could survive a drop of $25 \% \mathrm{RH}$ per day. There is, on the other hand, concern about the storage of collagen-based objects such as manuscripts on parchment or vellum at low RH levels. Highly-desiccated collagen (stored below $25 \%$ $\mathrm{RH}$ for a considerable amount of time) does not completely rehydrate afterwards. It will therefore lose ductility and is less able to withstand deformation (Erhardt and Mecklenburg 1994: 36) In addition, at low humidity, ink on parchment may become brittle and therefore highly vulnerable (Michalski 1993: 628).

14 Usually, durability of paper is distinguished from permanence as a resistance to mechanical violence, whereas permanence is the capacity to preserve original properties. 


\section{Summary}

Extreme environmental conditions in library or archive collections over a long period of time must be avoided for two reasons. Although low temperatures and humidities over extended periods might slow the ageing processes, they cause embrittlement of paper, leather, parchment, glues, and inks, making them extremely vulnerable to handling. Inaccessible material, in turn, defeats the very purpose of an archive. Extremely high humidity and temperature levels, on the other hand, can cause watersoluble inks to offset (i.e. they leave a mirror image on adjacent pages) and coated papers to block (i.e. pages of a book adhere together and can only be separated with great loss of material and information) (Ritzenthaler 1993: 46). Animal glues tend to soften and lose adhesive strength at humidities above $80 \% \mathrm{RH}$ (Erhardt and Mecklenburg 1994: 33). In addition, as mentioned before, high $\mathrm{RH}$ levels over a long period of time favours mould growth, especially on leather and other nutrient-rich substances (Michalski 1993: 625).

Generally, short periods of very high $\mathrm{RH}$ are less harmful than longer periods of humidity just above the recommended level (i.e. 60\% RH) (Michalski 1993: 625). At the same time, the most basic principle of upgrading the quality of the storage environment is to make the worst time of the year better, rather than make the good times better still (Reilly 1997: 75).

\subsubsection{Historic Buildings}

The moist temperate climate within the United Kingdom and much of continental Europe is variable and subject to extremes. These variations have an important influence on both the design of buildings and on the performance and longevity of building materials.

Local weather conditions are influenced by aspects of the natural and built environments, with factors such as topography (e.g. hills, valleys), vegetation (e.g. trees), buildings (e.g. situation, orientation) and human activity (e.g. pollution) 
creating and affecting individual micro-climates. Each of these factors may be used to modify or control the effects of the weather on individual buildings and on conditions within.

Excess moisture has long been the scourge of old buildings and those who live in them. From concerns over nocturnal dampness expressed in the epitaph 'All who come my grave to see; avoid damp beds and think of me' to the 'constant refrain from foreign visitors about how the wet climate has given English women a stunningly rich complexion' but also 'the constant defect...so many of them seem to have such big feet' or that '...a combination of too much meat and a wet and gloomy climate had made the English peculiarly vulnerable to melancholy' (Paxman 1999: 126), the problems of dampness have had to be contended with by generations.

There have been many and various methods of alleviating the effects, if not the causes, of dampness over the centuries. Some have passed into the history of construction technology as nothing more than eccentric invention, whilst a few have remained (albeit in a revised form) where the underlying theory has achieved practical success. Commentary on Rent Day by Pieter Breughel the Younger (15641638), for instance, suggests the use of hemp rope for absorbing moisture from the atmosphere (Culverhouse 2001). This evidently relates to the buffering capacity of that material with practical application in historic buildings today.

The later adoption, in the early twentieth century, of damp-proof courses (DPCs) at the base of walls to prevent rising damp, and cavity construction to improve weatherresistance and thermal properties has been retained, in principle, in modern construction practice.

In spite of the adoption of such construction practices (or in certain cases because of them), dampness or unwanted moisture - caused by rising and penetrating damp, condensation, leakage, spillage and construction processes - has remained the most widespread and damaging cause of deterioration and decay affecting buildings. 
Unacceptable levels of dampness may be defined as moisture within or on the surface of materials that detrimentally affects the building or its occupants (Figure 2). The effects on the materials from which buildings are constructed can be devastating, as the susceptibility of timber to fungal attack is increased, conditions for chemical and biological degradation are set up, and surface finishes are destroyed. There are also potential health problems for occupants due to the development of moulds, spores and associated mites.

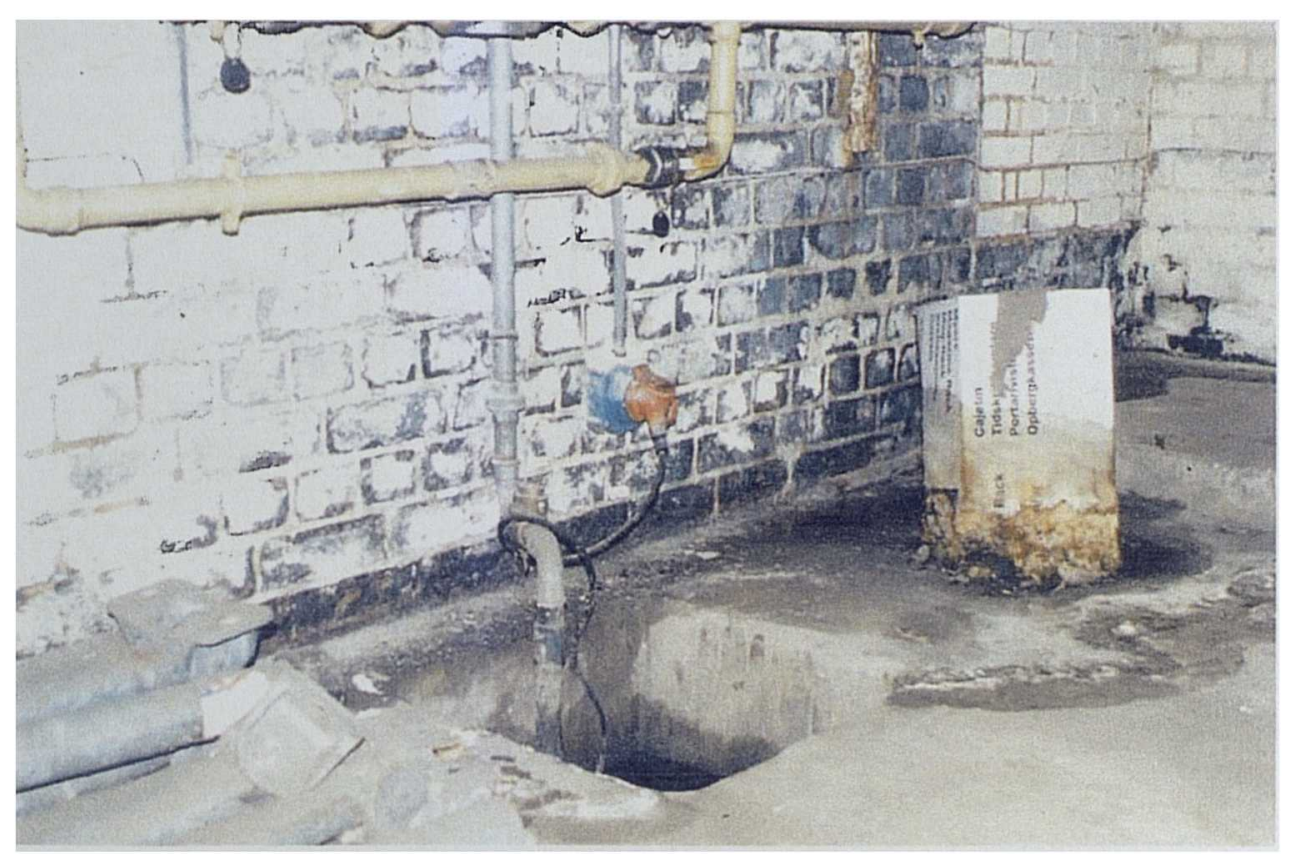

Figure 2: Lack of regular maintenance may lead to problems elsewhere

Changes in lifestyle have also created higher levels of moisture. The drive for energy efficiency and personal comfort, with the increased use of insulation products, double glazing and draught-proofing, the move away from open fires, and the desire for higher levels of space heating, have all had an effect on the internal climate of homes and places of work.

The principal sources of moisture that cause dampness in buildings are:

- moisture rising from the ground

- moisture penetrating through the external envelope 
- moisture forming as condensation

- leaking services and spillage

- moisture from the construction process in new or renovated properties

Moisture that accumulates within porous materials inside and outside a building is termed a 'moisture reservoir' (e.g. masonry, timber, insulation products, accumulated debris, unventilated voids, raised ground levels) (Singh 1994: 5-13). This moisture is balanced by 'moisture sinks' (e.g. evaporation, ventilation, heating, extraction). Any action or omission that adversely affects the equilibrium between moisture reservoirs and sinks can lead to dampness, with corresponding levels of damage, deterioration and decay.

\section{Rising Damp}

Water will rise within a wall due to the surface tension (i.e. capillary action) between it and the capillaries or pores of porous building materials, and natural osmosis causing water to move from solutions of lower to higher salt concentration.

The presence of excess dampness will increase the risk of fungal attack to skirting boards, floorboards and embedded timbers; cause disruption to internal wall surfaces with staining and damage to finishes; and promote the risk of damage to external walling through salt crystallisation and frost action (i.e. freeze-thaw cycling). Increased levels of associated moisture vapour within a building may also lead to surface or interstitial condensation.

Remedial action in response to rising damp must be based on both removing the cause of the dampness (e.g. installation of a DPC) and removing its effects (e.g. removing salt contaminated plaster, decayed timber, masonry repairs).

Dampness in basements and cellars, caused by the vertical and/or lateral penetration of moisture into an area wholly or partially below ground level, may be rectified by lowering existing ground levels, the use of external or internal tanking systems, lining and drainage systems, or vented lining systems. 


\section{Penetrating Damp}

The risk of penetrating dampness will depend on the condition of the external building envelope, the degree of exposure (e.g. wind, rain, topography), the length of time the envelope is exposed to specific conditions, and the internal pore structure of the material.

Whether moisture penetrates the thickness of a wall and manifests itself on the internal surfaces will depend on the rate at which it is lost through evaporation to the outside air. Remedial action relates to general maintenance and repair of the building (e.g. re-pointing, replacing damaged bricks).

\section{Surface and Interstitial Condensation}

Relative humidity $(\mathrm{RH})$ is inversely proportional to the temperature of the air, so that a drop in temperature will increase the relative level of humidity to a point where vapour will condense (i.e. dew point). When air becomes saturated (100\% RH), water droplets will condense on the surface of a material (e.g. glass, tiles, impermeable gloss paint, vinyl wallpaper). This is 'surface condensation' and may lead to mould growth in poorly-ventilated areas. Where the dew point temperature is reached within the thickness of the construction, condensation will form at that point. This is termed 'interstitial condensation'. Condensation may also form within voids (e.g. in redundant chimney flues).

The increased incidence of condensation in post-war years in the United Kingdom is due to changes in activities and patterns of use within buildings and changes in the nature of building fabric and installations.

One of the principal causes of condensation in buildings is that heating in lightweight modem constructions is typically provided only during the hours of occupation, thus raising the ambient temperature in a relatively short period of time. If the building is only heated intermittently, the fabric of the building tends to remain cold (i.e. thermal inertia). The air, although capable of holding moisture vapour generated by 
occupation whilst the heating system is on, quickly drops in temperature when the heating is turned off and deposits condensation on cold internal surfaces at dewpoint temperature.

In traditional constructions, walls and ground floors often have a high thermal mass and will therefore have a slow thermal response (i.e. warm and cool slowly). Where building fabric has a slow thermal response, constant low-output heating systems are preferable.

In addition, high levels of moisture vapour are generated on a daily basis by cooking (2-4 litres), bathing (0.5-1 litre), clothes drying (3-7.5 litres), and the use of flueless gas and paraffin heaters (1-2 litres during evening). Natural ventilation may be reduced by the installation of double glazing and draught-proofing, and the blocking of open flues and air bricks.

Some of the principal effects of condensation relate to health problems, deterioration of decorations (e.g. staining, mould growth), the breakdown of building fabric (e.g. fungal attack on timber, corrosion of metals), and impaired thermal performance.

It should be noted that standards of human comfort are not the same as those needed for the preservation of library and archive collections. The comfort range varies according to the $\mathrm{RH}$ of the air within the room, being between $20^{\circ}$ and $28^{\circ} \mathrm{C}$ at $30 \% \mathrm{RH}$ and between $18^{\circ}$ and $26.5^{\circ} \mathrm{C}$ at $70 \% \mathrm{RH}$. This compares with parameters for the storage of library and archive material given in BS 5454: $2000\left(16-19^{\circ} \mathrm{C} \pm 1^{\circ}\right.$ and $45-60 \% \mathrm{RH} \pm 5 \%$ for frequently-handled material, $13-16^{\circ} \mathrm{C} \pm 1^{\circ}$ and $45-60 \% \mathrm{RH}$ $\pm 5 \%$ for infrequently-handled material) and by the Historical Manuscripts Commission $\left(13-18^{\circ} \mathrm{C}\right.$ and $55-65 \% \mathrm{RH}$ ) (see section 3.1.3).

Remedial action relies largely on the use of increased ventilation to remove vapourladen air that might otherwise cause condensation. This might include the use of night vents, humidistat-controlled fans, built-in extraction ducts (e.g. use redundant chimney flues), roof void ventilation, and direct venting of vapour-producing appliances (e.g. tumble driers). Methods of controlled ventilation and heating have 
attracted particular attention in hot and humid climates, as they are typically costeffective and easy to install (Maekawa and Toledo 2002; Rodriguez de Carvalho et al. 2002). Considerable benefits may also be achieved in terms of internal comfort and reducing heating costs by upgrading the thermal properties of the external envelope, although attention must be given to the use of vapour barriers to restrict the transmission of water vapour through the structure. Heating and dehumidification also have important roles to play in reducing the risk of condensation.

\subsubsection{Mould}

Microorganisms - such as fungi, moulds and mildew - are always present in the air and thrive wherever conditions are favourable (i.e. warm, humid, dark, limited air circulation). These factors vary in relation to the specific demands of the microorganism, the nature of the material, and whether previous infection has been supported. Previous treatment regimes might also influence the growth of moulds (Florian 1993: 869).

\section{Taxonomy}

'Fungus' is an umbrella-term for moulds, mildew, mushrooms, and yeasts. These differ from the plant kingdom by a lack of chlorophyll and so cannot utilise energy directly from sunlight (Nittérus 2000:5). The taxonomy of fungi is continuously changing and accounts for considerable confusion within the relevant literature. The following taxonomy is commonly used in conservation literature and introductory botany textbooks.

Fungi are grouped into classes, which distinguish themselves by particular morphological characteristics - Phycomycetes, Ascomycetes, Basidiomycetes and Fungi imperfecti. The majority of fungi that develop on artefacts are Ascomycetes and Fungi imperfecti (i.e. fungi that produce sexual spores in sac-like asci and those without an observable sexual stage, respectively). Fungi that grow on the surface of materials such as paper, parchment, leather and wood are referred to as conidial 
fungi, because their growth is initiated by conidia (air spora) (Florian 1994: 3). The terms 'mould' and 'mildew' seem to be used interchangeably in the conservation literature, although pertaining to those fungi that grow on surfaces.

\section{Life Cycle of Conidial Fungi}

Although the life cycle of conidial fungi has been described many times before (e.g. Florian 1997), it seems necessary to recall the most important stages in the life cycle of fungi in order to understand its origin and prevention. The following summary of the life cycle of conidia fungi is based on that presented by Florian (1994).

The basic unit of vegetative growth of a fungus is the 'hypha'; a mass of hyphae is called the 'mycelium'. According to the species, the mycelium may take the form of a special structure or 'thallus' (e.g. mushroom). The material on which the fungus grows is referred to as the 'substrate'.

The life cycle of fungi starts with a spore, which germinates and produces vegetative stages on which are produced the spores (conidia) completing the cycle. Asexual spores are produced without cell fusion (i.e. they are genetically identical). They may be a single cell or a group of cells with low metabolic activity. They are formed on the surface of the mycelium and dispersed by air. Sexual spores, on the other hand, are produced by cell fusion followed by cell division, which allows for genetic variability. They are usually produced under adverse growing conditions. Sexual spores are commonly formed in the body of the thallus and are rarely airborne.

Maturation of conidia is the internal development required to become morphologically and physically complete. Maturation includes dehydration. The low metabolic state in which the conidia then stays prevents germination and is termed 'dormancy'. Conidia can remain dormant even under conducive environmental conditions. Dormancy may be broken through certain environmental events or conservation treatments. Once dormancy is broken, conidia will swell, form a germ tube and hyphae, and increase their metabolic activity. As soon as hyphae are produced, the fungus is referred to as in vegetative growth. The hyphae then secrete enzymes, which digest nutrients in 
the substrate into amino acids, simple sugars and fatty acids. The cycle ends with the production and maturation of conidia.

\section{Factors Supporting Mould Growth}

It is a well-known fact that humid environments support mould growth. High humidity is, however, not the only factor governing mould growth. Other factors include temperature and its fluctuation, light, the nature of nutrients on the substrate, moisture content and the moisture adsorption/desorption mechanism of the material, the physical properties of the object surface, osmotic pressure, air movement, and depth of penetration. The concentration of oxygen and carbon dioxide in the air also plays a vital role. The presence of micro-climates may induce condensation and dust. In addition, the exposure time to specific environmental conditions will influence the growth of mould (Valentín et al. 1998: 85-86).

When dealing with mould infections, it is important to keep in mind that high RH levels do not necessarily induce growth. The main reason for mould growth at high $\mathrm{RH}$ levels is the interrelationship between organic materials and water vapour in the air. All organic materials, if exposed to water vapour, will eventually arrive at a steady-state moisture content condition (i.e. equilibrium moisture content or EMC). The EMC depends on the RH and temperature, as well as the physical conditions of the material. Organic materials will absorb more moisture at low temperatures, withdrawing water vapour from the air. A decrease in temperature will therefore increase the EMC (and vice versa), whereas a decrease in $\mathrm{RH}$ will decrease the EMC (and vice versa). The EMC of a material can therefore only be maintained constant if both temperature and RH are altered at the same time (Florian 1997: 78).

Water in a substrate is expressed either as a quantitative amount (EMC) or as an activity (a). The activity is the effective concentration and is determined by the ratio of vapour pressure of water in a substrate $(p)$ and the vapour pressure of pure water $\left(p_{0}\right)$ at the same temperature and $\mathrm{RH}$ : 


$$
a=\frac{p}{p_{0}}
$$

The activity of pure water, $a_{w}$, is, by convention, equal to 1 . Hence the activity of water in a material will always be less than 1 (as it has been effectively diluted by the material). If the material is in equilibrium with its environment, the activity will be equivalent to $\mathrm{RH}$ (for example, at $75 \% \mathrm{RH}, a=0.75$ ).

Depending on how the water is 'attached' to the material, the moisture can be present in different forms (i.e. bound water, multi-layered water, free water). Bound water is characterised by strong chemical bonds to the molecules of the organic material (e.g. cellulose or protein), and hence no longer behaves like water: it has no solvent ability and cannot freeze. Since it is no longer available as 'water', its activity is near-zero. Multi-layered water is bound by weaker hydrogen bonds (i.e. electrostatic) to the surfaces of the molecules and hence is more available than bound water, but still has no solvent power and freezes only rarely. Accordingly, the activities of multi-layered water range from $0.2-0.7$. Since the bonds are fairly weak, it is multi-layered water that moves in and out of the material as environmental conditions vary. Loss and gain of this water is the cause of dimensional changes. Free or unbound water has no interaction with the material - it has simply been absorbed into the pores and capillaries or lumina of cells. Consequently the activities are always high (>0.7), it freezes readily, and is the water lost during drying. It is also the water most readily available for microorganisms (Florian 1997: 125-26).

The availability of water for fungal growth is determined by the bond strength between the material and water. Near $100 \% \mathrm{RH}$ the equilibrium moisture content reaches the material saturation point. At this point, the material will feel damp; it is not yet 'wet'. The EMC varies for different materials. Above the fibre saturation point, water will, however, be available for fungi. It is not clear if fungi can adsorb water vapour from air, or if they solely depend on moisture within the material (Florian 1997: 126-27). 
Fungi can be classified as hydrophilic or xerophilic (i.e. water loving or loving of dry conditions, respectively). The lower limits for xerophilic fungi lie at moisture activities of $0.70-0.75$. Where other environmental factors (e.g. nutrients, $\mathrm{pH}$, oxygen, temperature) are less favourable, the minimum required activity is higher. The internal moisture content (MC) of living organisms remains constant during life and is around $80 \%$. Fungi can maintain this moisture content by altering internal vapour pressure or by active osmosis. Fungi with a higher MC can germinate at lower substrate moisture activities than those conidia with a lower MC. Death due to dehydration occurs if the limits of their ability to control cell water is reached (Florian 1997: 127).

Many archive materials may have a reduced moisture activity due to their respective manufacturing processes. Paper, for example, contains, in addition to its basic constituent cellulose, different kinds of fillers, optical brighteners, and size. Leather, too, contains moisture-activity-lowering substances,'such as tanning chemicals, brighteners, chelators, and antioxidants. In addition, conservation treatments or chemical alteration due to oxidation may produce soluble products, both of which lower the moisture activity of the material (Florian 1997: 128).

In general, the MC of a material is dependent on its physical structure or porosity, inherent chemicals, deterioration, and sorptive history. ${ }^{15}$ Available hydrogen bonding sites, possible protein denaturation, the degree of crystallinity or amorphous regions, and the available surface area will all affect the MC of a material. Moreover, any chemical alterations (e.g. tannage, alkylation, acetylation, humectants) will also have some influence (Florian 1997: 10).

The $\mathrm{pH}$ of a material also has an influence on its ability to support fungal growth. Most microorganisms prefer conditions of neutrality (i.e. $\mathrm{pH}=7$ ). Although the full range of possible growth is between $\mathrm{pH} 2$ and 9, many fungi prefer slightly acidic

15 Over time, materials are exposed to many fluctuations in moisture gain and loss, mainly due to environmental fluctuations. Each time a loss occurs, some of the molecular bonds, which would normally hold water, crosslink. This results in a reduced regain ability, which might make the material more resistant to fungal attack (Florian 1997: 10). 
environments (Klotz-Berendes 2000: 51). ${ }^{18}$ Fungi are able to change the $\mathrm{pH}$ of a medium by generating certain metabolic products, such as organic acids (e.g. citric acid), which they secrete into the substrate (Florian 1997: 131). The resulting reduction of $\mathrm{pH}$ in the substrate will then condition the dynamics of bacterial or fungal growth in secondary attacks (Caneva et al. 1991: 57).

Furthermore, all living cells are dependent on osmotic pressure. The osmotic pressure of a solution is linked to the number of dissolved particles present. Osmotic pressure appears when solutions with different concentrations are separated by a semi-permeable membrane, which permits the passage of water but not of solutes. For biological cells, a higher concentration of solutions outside the cell (hypertonic) may be dangerous, since water will be extracted from within and will, ultimately, cause death. Only very few specialised organisms can tolerate a high osmotic pressure (Caneva et al. 1991: 11).

In addition, the concentration of oxygen and carbon dioxide influences mould growth (Valentin et al. 1998: 86). Oxygen is one of the main components of the atmosphere and is of basic importance for the respiration of living organisms. Carbon dioxide, on the other hand, is the product of respiration and subsequently used in photosynthetic reactions. It is therefore equally important since an increase in carbon dioxide concentration in the air, or in aqueous solutions, will give rise to higher growth of photosynthetic organisms (Caneva et al. 1991: 12-13).

The role of light in the germination and development of fungi is not clearly established. This might be due to the difficulty of distinguishing the effects of light from the effects of heat. In certain experiments it acted as a stimulator of growth, whilst in others it inhibited growth (Florian 1997: 131). It is generally agreed, however, that mould growth is more likely to appear in dark conditions (Caneva et al. 1991; Kowalik 1980a, b; Sclocchi et al. 1996).

18 On the contrary, the majority of bacteria prefer neutral or slightly alkaline conditions (Caneva 1991: 11). 
An outbreak of mould in a library or archive is one of the biggest threats to the stored material, as well as for staff and users. Opinions on the most commonly found species in libraries vary. Different species of the following fungi are, however, most frequently mentioned - Aspergillus, Penicillium, Cladosporium, Streptomyces, Epicoccum and Eurotium (McCrady 1999: 5). Different materials will be affected in different ways. The three most common materials in archives and libraries - paper, parchment, and leather - will be discussed separately. Following this, fungi affecting buildings will be considered.

\section{Interaction of Fungi with Paper}

Paper is primarily composed of cellulose and other substances depending on the origin of the raw material used in its manufacture. Among these are lignin, hemicellulose, proteins (size), and mineral constituents (fillers). Paper is a good source of nourishment for microorganisms, not only because of the organic nature of almost all of its components, but also because of its hygroscopicity. Fungi can utilise almost any naturally-occurring compound as a source of carbon and energy as long as availability of water is sustained. A high water content is therefore indispensable for microbial attack (Caneva et al. 1991: 56; Nittérus 2000: 29)

Paper, the most prevalent material in archives and libraries, can suffer damage by two means - it can be damaged structurally or aesthetically. Structural damage occurs through the interference of fungi with the structure of the media by various forms of attachment. In addition, some fungi develop fruiting bodies that are embedded in the paper, rupturing the paper felt. Most importantly, however, fungi will cause biodeterioration of paper by releasing enzymes (i.e. cellulase) in order to digest the cellulose. Aesthetic damage may be brought about by pigments produced within the fruiting bodies or in the mycelium. Often, pigments are secreted into the paper substrate. Colourless metabolic products can also react chemically with the substrate and evolve as stains. Pigmentation is possibly closely linked to metallic 
trace elements. ${ }^{17}$ Discolouration is a particular problem with objects of art on paper (Szczepanowska 1986: 31).

Fungi are able to attach to a substrate by the production of adhesive-like substances and/or anchor-like structures. Objects exhibiting physical damage, such as tears or abrasion, are more susceptible to fungal infestation as their surface area is generally increased, therefore accumulating spores and creating areas of easier attachment.

Papers with a high percentage of pure cellulose fibres (e.g. papers made from rags) are more resistant to fungal attack than lignin-containing papers. The former has a higher number of crystalline areas, which are more resistant than amorphous regions. Other contributing factors are the mode and length of beating. Certain pulping processes increase the surface area more than others, thereby increasing digestibility of cellulose. The addition of alkali during manufacture also results in an increased surface area, both by swelling and alteration of crystalline and amorphous structures. Once growth is established, acidity of the medium usually increases due to the accumulation of metabolic products (Szczepanowska 1986: 47).

\section{Interaction of Fungi with Parchment}

The main chemical components of leather and parchment are proteins or their monomers (amino acids) or partially-polymerised components such as polypeptides. Proteins are high molecular weight polymers composed of amino acids. They can be used by microorganisms as a source of organic nitrogen or carbon. Their utilisation depends, however, on the production of specific enzymes such as proteases and peptidases. The basic protein of skins is collagen. Collagen has a nearly-crystalline chemical structure and is therefore one of the proteins most resistant to microorganisms (Caneva et al. 1991: 61).

17 Trace elements include iron, copper, zinc, and manganese. They are thought to be introduced into paper during manufacturing processes or by having been in direct contact with these metals. 
The deterioration of leather and parchment is mostly due to fungi and actinomycetes. $^{18}$ Usually fungi predominate, but actinomycetes possess collagenases and chitinases as well. They are therefore able to break down the basic compound of hides. Fungi and actinomycetes mutually influence each other (Urzi and Krumbein 1994: 122).

Dry parchment is impervious to microbial attack. In addition, ink seems to have an inhibitory effect (Urzi and Krumbein 1994: 122). Certain treatments during the manufacture of parchment may, however, depolymerize the collagen, which in turn enables microorganisms to decompose the parchment more easily. Other components (e.g. lipids, carbohydrates, mineral constituents, impurities) contribute to its decay and the liability of parchment to biodeterioration depends upon the raw material as well as on its method of production and general condition. Environmental conditions (e.g. increased temperature, violent humidity changes, exposure to ultraviolet radiation) can also influence the stability of collagen. They can cause changes in structure and hence lower its resistance to microbial attack (Caneva et al. 1991: 63).

It has also been suggested that the slightly alkaline nature of parchment may induce bacterial growth (Valentin et al. 1998: 87). Furthermore, small amounts of ethylene glycol, a by-product of fumigation with ethylene oxide, may act as an activator for fungi on parchment (Florian 1994: 8).

18 Actinomycetes are distinguished from fungi by much smaller hyphae. They do not exhibit an apparent nucleus and their mycelium is formed by branched hyphae (Caneva 1991: 162). 


\section{Interaction of Fungi with Leather}

The chemical composition of leather is similar to parchment and it is therefore susceptible to similar microbiological species as parchment. Leather is produced by subjecting it to tanning, which causes chemical and physical changes of the skin. Different methods of tanning include vegetable tanning, mineral processes, smoking, and oil processes (Caneva et al. 1991: 63).

Principally, tanning causes a reduction of available water sites by crosslinking collagen; the EMC of tanned hides is therefore decreased compared to untanned skins (Florian 1994: 11). After tanning, leather has a pH of about 3 to 5 . It therefore provides better conditions for fungal growth than for bacteria. Fungi that attack leather usually use the fats present in leather as a source of carbon. In this case the proteins are not directly affected, but can be damaged by organic acids released as a metabolic waste product (Caneva et al. 1991: 63).

In general, microbial attack on leather depends on carbon and nitrogen sources (e.g. type of tanning, $\mathrm{pH}$, impurities, possible adhesives, some vitamins, presence of inorganic salts in small amounts). In addition, environmental factors (e.g. RH, temperature, moisture content) are important (Kowalik 1980b: 211). The susceptibility of leather to fungal attack is higher than for other materials as it will support mould growth at around $65 \% \mathrm{RH}$, conditions too dry for many other materials (Groom and Panisset 1933: 656; Kowalik 1980b: 210).

As for paper, the most serious damage caused by fungi on leather is due to germination. It includes swelling, cell-wall rupture, formation and germ tube emergence, which may cause fracturing and disruption of the substrate. It also increases the rate of metabolic activity (Florian 1994: 8). This, in turn, results in staining and structural weakening of the material. 


\section{Fungi Affecting Buildings}

Fungi that affect timbers in and around buildings are commonly referred to as either 'dry' or 'wet' rots. This terminology is confusing, as all such fungi require the timber to have a moisture content above $20 \%$. Wood-rotting fungi may be further designated as 'brown' or 'white' rots - the former consumes only the pale-coloured cellulose causing the affected wood to darken in colour, whilst the latter consumes both cellulose and lignin, giving a bleached appearance to the affected wood.

Another factor that comes into play in terms of timber decay is the type of timber being subjected to attack. Some timbers, such as oak, are highly resistant to some fungi (such as dry rot), whilst others (such as beech and pine) are distinctly 'perishable'.

There are four factors that are essential to fungal growth - moisture (i.e. timber with a moisture content in excess of $20 \%$ is susceptible), temperature (i.e. fungi are able to grow and attack timbers at temperatures ranging from $0-40^{\circ} \mathrm{C}$ ), oxygen, and a nutrient source.

Of the various fungi that might be present in buildings, the most common are dry rot (Serpula lacrymans) and various wet rots, including cellar fungus (Coniophora puteana), mine fungus (Antrodia vaillantii), and oak rot (Donkioporia expansa).

\section{Prevention}

Since mould spores are ubiquitous, specific circumstances must be present to allow germination and growth to proceed or not. As explained above, the environment plays a crucial role. It is important, however, to distinguish between macro- and micro-climates. Often, the micro-climate, which is the environmental condition within a certain type of enclosure (e.g. drawers, boxes, bottom shelves) or even the conditions close to a surface, are distinctly different from the conditions in the atmosphere. In the end, it is the availability of moisture immediately adjacent to the 
surface of an object that will determine whether growth will occur or not. The availability of moisture is therefore the critical limiting factor (Scott 1994, 1996).

Exterior walls, floors and cold surfaces should always receive special attention. A temperature difference of a few degrees can cause large variations in local RH levels (Strang and Dawson 1991: 2)..$^{19}$

There are several factors influencing the moisture content of an object. Apart from chemical and physical structure, one of the most important factors is the way air, and therefore water vapour, moves around a space. Conditions measured in the centre of a room might be different from those measured close to an object. Since ventilation changes the air next to the surface, changes in $\mathrm{RH}$ have the potential to alter the surface conditions of a material. Airflow around an object is, however, generally slowed down by friction. In still conditions, vapour will only move at the gaseous diffusion rate. The relative mass of water held in a hygroscopic object will therefore tend to dominate the conditions of the air around it. The more air movement, the less will be the influence of an object. In this respect, the temperature of an object relative to the adjacent air is also important. If a material is cool, vapour tends to move from the air into the surface layers as a result of differences in vapour pressure. The absorption can continue until either the capacity of the material is reached or the pressure gradient disappears. The opposite happens if the material is warmer than the surrounding air (Scott 1994, 1996). ${ }^{20}$ It is therefore crucial to maintain constant ventilation in every part of the collection, especially when humidity levels are above those recommended.

Since it is the moisture activity of an object that will ultimately determine the growth rate of mould, it is important to keep it below the favourable conditions for mould growth. Organic materials have specific moisture contents depending on their main component. If their natural moisture-holding capacity is exceeded, the material becomes wet and will readily support mould growth. There are some species of

19 Refer to section 7.1.2, where this is further explained in connection with the Bronte Parsonage Museum. 
Aspergillus and Penicillium, however, that are able to grow on paper having a moisture content of $7-8 \%$. This moisture content can readily be reached in conditions of around 65\% RH (Caneva et al. 1991: 56; Valentín et al. 1998: 86). If, under these conditions, parchment and leather exceed a moisture content of around $15 \%$, they, too, will support mould growth (Gallo et al. 1996: 178).

Different recommendations concerning ideal temperature and humidity conditions have been made over time in order to prevent mould growth. Although microorganisms are able to grow in a fairly wide range of conditions, they are best controlled if the temperature is between 16 and $20^{\circ} \mathrm{C}$ and relative humidity between 45 and 60\% (Florian 1997; Klotz-Berendes 2000; Sclocchi et al. 1996; Urzi and Krumbein 1994).

Objects should not be exhibited or stored directly against outside walls. These are often sites of high RH and condensation, especially if the walls are poorly insulated. At the same time, walls will convey water from leaks above the storage area (Strang and Dawson 1991: 2).

In order to prevent germination, materials should not be kept wet for longer than 24 hours after, for instance, the occurrence of a disaster. High RH levels, especially in still air pockets, must also be avoided. Even when RH is very high, germination will often only occur where condensation has formed. Condensation can form very quickly and takes a considerable amount of time to evaporate, even when conditions improve. The prevention of vegetative growth may be achieved by choosing dry cleaning methods rather than aqueous treatments (Florian 1994: 21; Strang and Dawson 1991: 2).

Due to the vastly increasing number of documents that have to be stored within archives and libraries, lack of space is a common problem. Within the same building, basements and attics are therefore commonly used. These are usually characterised by major climatic differences compared to the rest of the building. They are

20 The steeper the pressure gradient, the more rapid will the water vapour move; also, the longer the gradient is maintained, the deeper will be its effect (Scott 1996: 95). 
especially liable to mould infections, since they are generally dark and badly ventilated. They are also more likely to suffer damage in the case of natural disasters (e.g. floods or rupture of water and sewage systems). The lowest shelves and cabinets should therefore be raised at least $10 \mathrm{~cm}$ above the floor. These parts of the building should, wherever possible, be avoided for storing collections (Sclocchi et al. 1996: 150).

Many conservation treatments increase the susceptibility to growth. Commonly-used chemicals, such as lipid solvents or wetting agents (e.g. acetone, methanol, ethanol, ethylene glycol, glycerol, detergents, organic acids) penetrate the cell walls and may activate growth. Some acid or alkaline treatments may also be able to break dormancy (Florian 1994:7). ${ }^{21}$ Conservators must therefore be aware of these mechanisms in order to make appropriate compromises when treating objects.

Regular maintenance and cleaning of all storage facilities are also very important. Accumulating dust may form micro-environments by preventing normal airflow over surfaces and the large surface of dust particles will absorb moisture (i.e. forming a moisture reservoir). Most importantly, however, is the fact that dust particles themselves may be a source of nutrients for fungi. They contain human epithelial cells (i.e. skin debris), textile fibre fragments, starch grains, fungal conidia and spores, pollen grains, and carbon soot. Cleaning staff must be instructed to avoid splashing cleaning agents on to artefacts (Florian 1997: 11-12; Strang and Dawson 1991).

Most fungal growth is prevented below $70 \% \mathrm{RH}$. If it does occur, it may be due to the existence of micro-environments with high $\mathrm{RH}$ levels and materials with a moisture activity high enough to support mould or fungal species with low water tolerance (i.e. xerophilic fungi) (Florian 1997: 125).

21 It is known that treatments with calcium hydroxide are more likely to inhibit growth than treatments using magnesium hydroxide (Valentin 1986). Both substances are commonly used in aqueous conservation treatments in order to deposit an alkaline reserve into the paper. 


\section{Treatment of Infection}

Once a collection is infected with mould, any treatment or action should be directed towards the spores. Ideally, they should be erased or at least their amount lowered. In the past, conservators have been given advice by researchers from other fields, some of which was, for various reasons, not suitable for heritage collections. Many chemical sanitisers may react with proteins, cellulose, or other components in paper, such as fillers and sizing. These reactions may, for example, cause discolouration or embrittlement of the material. At the same time, many chemicals have posed a serious health hazard to staff and users. It is therefore important to be aware of possible remedies that have been used in the past (Nittérus 2000).

Chemical control of fungal problems should only be used after every effort has been made to solve the problem by removing the source of water and controlling the $\mathrm{RH}$. Since some fungicides interfere with analysis or conservation treatments (e.g. washing, bleaching, solvent cleaning), possible future treatments should be considered. Complete records of fungicide ingredients should always be made when documenting the treatment of artefacts (Strang and Dawson 1991: 4).

The following methods of eradication, past and current, have been summarised usefully by Nittérus (2000: $31-35$ ):

- Phenolic derivatives (e.g. orthophenylphenol, sodium orthophenylphenate, pentachlorophenol) ${ }^{22}$ have been in use in paper conservation for almost 60 years. They are moderately toxic. The reported results are, however, contradictory. They are known to be photo-oxidising and may therefore cause discolouration of paper over time.

- Formaldehyde is a powerful chemosteriliser. It is highly detrimental to proteins (i.e. leather, parchment, hide, glue). Formaldehyde is a known carcinogen and its use is therefore now restricted.

22 These substances are otherwise known as Dowicide 1 or Topane S, Dowicide A or Topane WS and Penta, Santobrite or Dowicide 7, respectively (Strang and Dawson 1991: 4). 
- Quaternary ammonium compounds have a disinfectant action. They contain reactive chlorine, are highly toxic, and have a detrimental effect on the immune system.

- Ethylene oxide is a powerful sterilant against both fungi and insects. It is also an explosive and toxic gas, and known to be carcinogenic. Treated material is more susceptible to microbial attack and it might also have an age-accelerating effect on paper.

- Current research is investigating the use of ultraviolet, gamma radiation and deep-freezing.

\subsubsection{Pests}

The term 'pest' is used to describe all animals that cause damage to a collection and includes insects (e.g. cockroaches, silverfish, termites) as well as mammals (e.g. rats, mice, squirrels) and birds. Pests are generally more efficient destroyers of collections than light, humidity, temperature, or any kind of contaminant.

\section{Insects Affecting Collections}

Insects typically pose the biggest threat to library or archive collections. This has been highlighted both by the media (e.g. Alberge 2001) and at recent conferences (such as Kingsley et al. (2001): A Pest Odyssey organised by English Heritage, the Science Museum and the National Preservation Office). Insects belong to the class of Phylum arthropoda, ${ }^{23}$ which are characterised by having three body segments (i.e. head, thorax and abdomen). They have three pairs of legs, which are attached to the thorax. The thorax also bears two pairs of wings. Not all stages of all species may exhibit all characteristics (Brenner 1991: 20). Each part of the insect body is covered with several plates or tubes that are connected with a flexible membrane. This outer shell is called the exoskeleton. Because the exoskeleton itself does not grow, insects

${ }^{23}$ The three major classes of Phylum Arthropoda include Arachnida (e.g. spiders, mites, scorpions, ticks), Crustacea (e.g. lobsters, shrimp, crawfish), and Insecta. Insects are the largest class in terms of number of species (Brenner 1991: 20). 
have to go through more or less complex metamorphoses based on periodic moulting. Growth proceeds in a series of steps until the adult stage is reached. A complete metamorphosis includes egg, larva, pupa and adult; an incomplete metamorphosis consists of egg, larva, nymph and adult (Bell 1988: 85; Wellheiser 1992: 4).

Different insect species have different food requirements, some even require different foods at different stages in their life. Generally, species can be either omnivorous (i.e. feed on everything) or have a specialised diet (e.g. cellulose materials, starches or proteins). Some are also encouraged by the development of fungi (Wellheiser 1992: 5). ${ }^{24}$ It is usually the larvae that cause most damage by feeding on certain collection materials. Insects not only consume materials, but they may also cause structural damage by tunnelling, burrowing, nesting activities, body secretions, and excrements (Child 1996; Wellheiser 1992: 4-5).

Insects are attracted to libraries and archives for two reasons - the collections provide food and the buildings offer shelter from harsh external environments. Compared to the challenges of nature, insects have only few predators in museum buildings (Bell 1988: 83; Wellheiser 1992: 7). Like mould, insects may tolerate a wide range of conditions, but need certain temperature and humidity levels for optimum development and reproduction. These are generally between 20 and $30^{\circ} \mathrm{C}$ and between $60 \%$ and $80 \% \mathrm{RH}$. Insects are ectothermic organisms (i.e. cold blooded). Their level of activity at any given moment is therefore proportional to the temperatures that lie between their high and low critical thermal limits. Because they are small (i.e. a high surface-to-volume ratio) they are prone to desiccation, and can rapidly loose moisture through the cuticle, respiratory spiracles, and other orifices. The regulation of water resources is therefore paramount to survival. As a result, insects prefer habitats with high temperatures and RH levels, low airflow and a supply of liquid water. They will usually find these conditions within the boundary layers of a building (Brenner 1991; Pinniger and Winsor 1998).

24 Recent research indicates that fungi alter the chemistry of wood, so influencing levels of beetle infestation (Ridout 2000: 39). 
The key to avoiding pests is to understand and deny the conditions under which they thrive (i.e. denial of food, warmth, humidity, and protection). Firstly, it is important to control the most common routes by which insects may enter the building. These can include (Bell 1988: 88-89):

- service entry points through walls (e.g. gas, water, exhaust, steam, heating)

- holes in walls for electrical wiring, light fixtures, and outlets

- spaces in door and window casings or thresholds

- air ducts from a central furnace or air-conditioning unit

- unused drains or drain-pipe openings

Often, these places are also prone to localised areas of dampness, caused by condensation or leaks. Importantly, they are areas that are undisturbed by human activity.

According to Strang (1996), there are five basic stages of controlling pests avoidance, blocking, detection, response, and recovering/treatment. Any decision that affects the collection, from building design via cabinet selection to staff training, should consider an integrated pest management system. Whilst this might often appear excessive, the benefits derived from pest management activities can help control other deleterious agents, primarily by increased sanitation and detection of problematic areas (Strang 1998). This is also true for historic buildings, where the exclusion of pests can be difficult due to the unacceptable appearance of some proofing methods (Pinniger and Winsor 1998).

\section{Insects Affecting Buildings}

Dead timber provides a good source of nourishment for a variety of insects whose larvae live within and consume the cellulose in the timber.

Wood-boring beetles attack different types and parts of timber. Virtually all such insects, however, require a minimum moisture content in the timber to survive and 
desiccation can prove effective treatment. In centrally-heated premises, where the moisture content falls below $10 \%$, insect attacks will usually die out.

Of the various wood-boring insects that might be present in buildings, the most common are the common fumiture beetle (Anobium punctatum), death watch beetle (Xestobium rufovillosum), house longhorn beetle (Hylotrupes bajulus), powderpost beetle (Lyctus brunneus and L. linearis), ptilinus beetle (Ptilinus pectinicormis), and wood-boring weevil (Pentarthrum huttoni and Euophryum confine). Other insects that can cause damage to structural and non-structural timbers used within a building include weevils, wasps and borers.

\section{Rodents}

Rodent infestations are usually detected quite easily. The most common rodents found within the British Isles are the black rat (Rattus rattus) and the house mouse (Mus domesticus). The occurrence of the brown rat (Rattus norvegicus) and grey squirrel (Sciurus carolinensis) is rare in museum collections. All of these rodents are omnivorous. They cause damage to objects by feeding, shredding for nesting material, and staining from urine and faeces. Their nests may contain organic detritus (e.g. fur, feathers, plant material), which in turn will attract insects (Pinniger and Winsor 1998: 11).

Typical signs of rodent problems are gnaw marks near the base of doors and cabinets, faecal droppings and urine stains, and nests made from shredded paper and textiles. In addition, there may be paw prints on dusty surfaces and noises of scampering or gnawing (Pinniger and Winsor 1998: 13).

\section{Birds}

Birds often roost or nest on window sills, ledges, and other architectural features, but do not usually enter buildings. Therefore, themselves, birds are of little direct threat to the collection. Their droppings, however, contain uric acid and are corrosive, causing staining and damage to the building fabric. As with rodents, bird nests attract 
insect pests, which may then move into the building (Rees 2001). Birds can also become trapped in chimney flues, where they die and become a source of food for some insect species. Bird corpses are one of the most common sources for insect pest infestations (Pinniger and Winsor 1998: 14).

\section{$\underline{\text { Treatment }}$}

If control mechanisms and integrated pest management strategies have failed to prevent pest infestation, there are several methods of treatment. These will not be elaborated in this thesis, since there are many excellent reviews on possible treatment strategies (e.g. Pinniger and Winsor 1998; Pinniger 1994; Strang 1996; Wellheiser 1992). 


\subsection{Relationship between Humidity and Paper}

In the following section, an overview over sorption mechanisms of paper, and its influence on properties, degradation, and buffer capacity is given in order to make scope and results of the subsequent sections more readily accessible.

The relationship between water and cellulose is the most important relationship in paper chemistry, as it affects several important properties of paper. In conservation, sorption mechanisms and moisture content of paper has been looked at from different points of view. It is generally agreed upon that the presence of water plays a major role in degradation chemistry. Dimensional changes are also considered problematic in library and archive collections. The following section will look at sorption mechanisms and possible consequences in more detail.

\subsubsection{Degradation}

Cellulose can undergo many different forms of transformation; however, not every transformation that can occur to cellulose, occurs in the ageing of paper. With respect to paper, the most important cellulose degradation chemistries are those that break the cellulose molecules, since these are the reactions that cause a loss in strength properties of paper. There are three principal ways of chain scission: hydrolysis, oxidation and elimination (Whitmore 1994).

- Hydrolysis inserts a water molecule into the chain, thereby breaking the connection between the glucose rings. As the name implies, this reaction requires water. At the same time, it is catalysed by acids ${ }^{25}$.

- Oxidation begins with the abstraction of a hydrogen atom by some oxidising agent, e.g. from a bleaching agent or through light exposure. Once a carbon

${ }^{25}$ Possible sources of acidity in paper are: the papermaking process itself, particularly the use of alum-rosin sizing, atmospheric contamination, and miscellaneous causes such as e.g. writing inks. 
radical is formed on the glucose, molecular oxygen can attach itself to form a hydroperoxide. Hydroperoxides, in turn, decompose to split off hydroxyl radicals, which continue the reaction. Oxidation occurs randomly on the chains and is known to proceed very slowly in pure cellulose.

- Elimination breaks the chain next to the carbonyl groups. It therefore affects only the chain ends and is also termed peeling. It is generally catalysed by bases.

Other ingredients of paper, such as lignin and sizes may alter the degradation mechanisms by affecting the rates of other possible reactions. In addition to the composition of paper, the specific stress acting upon it in particular environments will determine, which of the different reactions are important for paper degradation. Despite the elaborate effort in recent years, it is still not known which cellulose scission chemistries dominate the ageing of papers of specific composition in a specific environment (Whitmore 1994: 38).

\subsubsection{Influence of Moisture Content on Paper Properties}

The moisture content of paper has effects on all physical properties of the material. While the amount of water held within the individual fibres affects their strength and flexibility, the overall moisture content of paper affects weight, strength, dimensional stability and permanence. Many of these properties are vital in archive and library collections. It is well known that strength properties of paper increase to a certain point with increasing moisture content, and will rapidly decrease afterwards. Therefore, extremes on either end of the humidity scale will endanger an object while being handled. Especially high moisture content in combination with stress (i.e. handling) can cause relaxation and thus irreversible changes in physical structure. (Brandon 1981)

The dimensional stability of paper is a particular concern in the case of maps, since the accuracy of scale is jeopardised. Composite objects, on the other hand, such as most books, may structurally suffer. This is due to the varying degree of response of the different materials to changes in relative humidity. 
Other detrimental effects on library and archive material are known, e.g. embrittlement of glues and inks, or the offsetting of soluble inks. These issues will not be further addressed here, since they are not solely linked to the effects of moisture on paper.

\subsubsection{Sorption Mechanisms}

A paper sheet is considered as a composite structure of fibres and voids through which moisture is transported by diffusion. The moisture is transported within the fibres, along the fibre surfaces, or through the pores of the paper. It initially diffuses through the pores and then from the pores into the fibres. During moisture uptake paper swells, which may alter the pore sizes and subsequently change the diffusivity of the material (Hägglund et al. 1999: 71).

Paper is able to absorb and desorb moisture in changing environments. At steady conditions, paper seeks to reach equilibrium with the environment. In this state, the amount of water evaporating from fibres per unit time is exactly counterbalanced by that condensing on them. The curve that expresses the relation between the amount of water in the fibre and its concentration outside, at any given temperature, is called sorption isotherm (Urquhart 1960: 14).

As long as the RH of the environment is higher than that of the material, moisture transfers into the material. The transfer takes place in three distinct stages. Firstly, moisture moves from the surrounding air to the surface. The moisture then enters from the surface to the interior. It does so by diffusion, mainly through the air between the fibres, though some air may pass along the fibres. Thirdly, the individual fibres absorb the moisture from the air between them, since moisture diffuses radially. These stages are in practice simultaneous (Crank 1960: 87).

The fibre structure, i.e. molecular composition and arrangement (the number of hydrophilic groups and their accessibility) are therefore the most important factors 
determining the general pattern of moisture sorption in fibres (Hearle 1960: 13). In cellulose, only the amorphous parts and hemicellulose are hygroscopic. The higher the crystallinity, the lower is the moisture permeability, since the tightly bound chains resist the penetration of fluids. This explains, why papers with a high $\alpha$-cellulose content tend to have a lower moisture content than papers containing many impurities $^{26}$. The cellulose isotherm is characteristic of a multimolecular sorption, where the attractive forces between sorbing (cellulose) and sorbed substances (water) are greater than those between the molecules of the sorbed substance in the liquid state. In fact, dry cellulose is one of the most hygroscopic substances known (Urquhart 1960: 16).

In general, sorption isotherms obtained from reducing humidity are higher than the corresponding adsorption isotherms. This phenomenon, where different paths between adsorption and desorption exist, is called hysteresis. For hysteresis to occur, a molecular rearrangement is necessary. The effect can be equated to differences in the degree of relaxation of cohesive forces within the substrate between fibres conditioned by adsorption or desorption at a particular humidity. It is supposed that hysteresis arises because some sites become available for adsorption only in the highly swollen state. These sites then continue to bind water molecules as the water vapour pressure is lowered (Watt 1979: 311).

\subsubsection{Cycling Conditions / Air Circulation}

Despite the many comprehensive efforts in recent years on the ageing behaviour of paper (Porck and Teygeler 2000), only few studies investigate the effects of cycling conditions on the ageing of paper. Typically, these experiments are carried out at constant elevated temperature and varying RH (Käßberger 1998; Shahani et al. 1988).

${ }^{28}$ Raw material having a high content of pure cellulose, is technically referred to as $\alpha$ cellulose. The $\alpha$-cellulose content of a material is measured by the amount of cellulose 
It is known that transient variations in moisture content caused by cyclic humidity changes have dramatic effects on paper. Käßberger proved that artificial ageing using cycling conditions leads to more significant losses regarding properties such as e.g. brightness, tear strength, fold endurance and breaking length, compared to the conventionally used method of ageing at steady conditions. In addition, the test papers exhibited optical properties similar to naturally aged papers. However, his work did not examine the effects of cycling conditions on paper stacks (i.e. resembling a book block) (Käßberger 1998). Justification for cycling conditions during accelerated ageing is usually seen in the fact that documents in storage do not experience constant conditions either. Whilst this is certainly true, it must be kept in mind that single test sheets in a test chamber are readily able to adjust to three hour cycles, whereas tightly stacked books in storage are not. Other studies in this area usually focus on the durability of paper, rather than on its permanence (e.g. Ramarao 1999).

Recently, further studies employing cycling conditions have been performed (Bigourdan and Reilly 2002; Bogaard and Whitmore 2002). However, their results are contradicting. Bigourdan and Reilly (2002) investigated the possibility of faster decay when cycling humidity or, alternatively, temperature conditions, as compared to steady conditions at the upper limit of humidity or temperature, respectively. Bogaard, on the other hand, researched cycling humidity conditions at steady room temperature conditions (2002). These studies aimed to detect different mechanisms of decay or accelerated deterioration compared to current thermodynamic models. While the former study demonstrated deterioration rates after cycling conditions to be no worse than those of samples having experienced steady conditions at the upper limit, Bogaard proved cycling $\mathrm{RH}$ at room temperature to accelerate degradation. However, this could possibly be due to the short cycling intervals, which is likely to have hindered the paper to desorb its moisture completely before being exposed to elevated conditions again. The paper therefore was likely to have had raised moisture content levels over the entire time.

that remains undissolved in $18 \%$ sodium hydroxide solution. (McGinnis and Shafizadeh 1980: 25) 
These studies show that there is still a lot of uncertainty as to the effects of cycling conditions. In addition, all studies so far were carried out under laboratory conditions and may not necessarily resemble real life conditions.

Studies within the textile science have investigated the factors that influence the conditioning rates of cotton fibres packed as a tight bale (Crank 1960). These studies have shown the moisture content to increase rapidly at first and then more and more slowly as the final equilibrium is approached. In this, the time taken to reach equilibrium is directly proportional to the square of the linear dimensions. The other major factor is the density of the package, since the density governs its permeability to water vapour. Therefore, the more compressed the material is, the lower the permeability, the longer will be the conditioning times. These factors are important with respect to the storage of books, as they are typically stored fairly tight. This not only increases the density of the material but also affects the exposed surface area, as the covers of adjacent books usually touch each other (with the exception of the two books at either end of the shelf).

In practice, diurnal fluctuating relative humidity may therefore be negligible, as the stacked paper needs several days to adjust to changing humidity levels (Rodrigues de Carvalho 2002). It is therefore usually only the surface areas that fluctuate in their moisture content with fluctuating ambient conditions, whereas the interior reacts much more slowly (Greaves 1985: 343; Panshin and de Zeeuw 1980: 206). However, in climates where high humidity levels are experienced within internal accomodation, hygroscopic material, such as paper, will exhibit increased moisture content. A high moisture content over a long period of time will shorten the overall life-expectancy of paper (Bégin and Kaminska 2001).

The circulation of air and its temperature is also of importance: as the material takes up moisture, the air in contact will be denuded of water. The conditioning of the material will therefore be delayed unless the air current is sufficient to maintain a supply of moist air to the surface. The larger the exposed surface of the material is, the more important this effect becomes (Crank 1960: 86). 
Generally, the rate of moisture absorption decreases during humidity uptake due to changes to the physical structure of paper (i.e. swelling) as it absorbs moisture. In addition, the absorption of humidity itself results in changes to the direct environment of the paper. Until equilibrium is reached, the paper increasingly deprives the air of its water content.

\subsubsection{Buffer Capacity of Paper}

Previous researchers have identified the ability of paper (and other material) to absorb and desorb excess moisture and therefore act as an environmental buffer, which in tum may be of advantage for building finishes and fabric. (Christoffersen 1995; Jedrzejewska 1985; Padfield 1988, 1998) The term 'buffering' has been introduced in this context, referring to the ability of the material to respond to and moderate changes in ambient $\mathrm{RH}$.

In addition, some researchers have investigated specific behaviour of library materials to changing environments. (Bigourdan et al. 1997; Christoffersen 1995; Reilly et al. 1995) Their observations have shown that the time for an object to reach equilibrium with its surroundings depends on the material, its mass, shape, surface area, and the velocity of air circulation around it. $\mathrm{RH}$ equilibration is not only much slower than temperature equilibration, but also a much more complex process.

Since the capacity of air to hold water is extremely low compared to paper, it is concluded that, within a reasonably tight space its temperature and the moisture content of the material control the $\mathrm{RH}$ of air. The smaller the volume of air compared to the volume of hygroscopic material, the more significant this effect will be. This is important, since a repository with large and active surface areas (e.g. museum repository) is therefore able to moderate short-term fluctuations, whereas strongrooms with a high density of material (e.g. library or archive) have a small exposed surface area, which tends to affect long-term fluctuation. In an archive, the stored material typically occupies approximately $40 \%$ of the available space (volume), whereas museum objects take about $10-15 \%$ of the volume. However, the exposed 
surface areas are not necessarily active surfaces. The material could for example be painted or varnished, or in the case of libraries, books may be covered with less hygroscopic book cloth. Moreover, under certain circumstances (e.g. high air exchange rate), air leakage may have more influence on indoor climate than the buffer capacity of paper. (Christoffersen 1995)

Due to the comparatively slow response of stacked paper to changes in humidity, its moisture content is affected by seasonal rather than weekly or even diumal changes (Bigourdan et al. 1997). This had been proven by a study by Reilly (Reilly et al. 1995), where conditions inside a book were compared with ambient conditions within the library. However, this experiment did not look at a full year's cycle, nor did it take outside conditions at the time into account.

It is in view of this latter experiment that more comprehensive environmental monitoring was performed at the two selected case studies (see section 6). 


\subsection{Predictive Tools for Environmental Analysis}

The complexity of buildings in general, and that of historic buildings and monuments in particular, has made it extremely difficult to assess the impact of climatic and other environmental factors on building fabric as well as internal environment. This is partly due to the heterogeneous nature of materials and forms of construction, and partly due to the continuous adaptation of buildings to new forms of usage during its lifetime.

However, attempts have been made to model environmental impact on various aspects of buildings, including their material, environmental control system or the material housed within them. These predictive tools are typically based on mathematical models and focus on one or several aspects. Their applicability for preservation purposes is therefore often limited.

The most recent of these focus either on factors goveming mould growth (Clarke et al. 1999), infiltration of particulate pollutants, vapour and/or air (Michalski 1994; Papakonstantinou et al. 2000), or the influence of relative humidity on specific objects (Di Pietro and Ligterink 1999). Recently, Knight (2002) has made attempts to assess potential risks to collections under fluctuating relative humidity employing statistical methods. It is interesting to note that many of these projects have approached the problem in an interdisciplinary effort.

All of these models have given further scientific insight into particular areas of concern. However, they can usually not easily be used by a professional within the conservation or museum area for predicting the impact of a certain environmental condition on particular parts of their collections.

To date, no tool for environmental analysis in museums, archives or libraries is commercially available. However, the development of a web-based tool for predicting occurrence and effects of pollutants within museums is under way at University 
College London (UCL) $)^{27}$. This tool, called 'IMPACT' has also been developed in an interdisciplinary approach. Its aim is to provide a free and user-friendly tool that complements pollution measurements, or helps in the design of new buildings or refurbishment (Blades et al. 2002).

Since late 2000, a program developed by the Image Permanence Institute (IPI) at Rochester Institute of Technology in Rochester (NY, USA) has gone on a field trial within the United States ${ }^{28}$. The developed tool is called 'Climate Notebook'.

This computerised system is based on a battery-powered data logger and a Windows-based software system. The data logger monitors $\mathrm{RH}$ and temperature and was developed with a view of preservation issues within a wide variety of collections. The data logger is user-friendly and has the ability to recall past conditions for up to the previous 90 days. Data can be transferred onto a computer either by direct cable connection or with the help of a memory card that can be read by most conventional laptops and desktop computers. Alternatively, a card reader accessory can be purchased. Users will be able to have printed reports about their storage conditions within minutes of downloading data due to the fast data-organising features of the Climate Notebook software.

In addition, the data loggers have the ability to display values reflecting decay rates of organic materials stored in that location. These values have been developed and refined over the past decade by IPI and are known as Preservation Index (PI) and Time-weighted Preservation Index (TWPI). These indices show how temperature and $\mathrm{RH}$ combine over time to influence deterioration processes. This research had been carried out with a view of assessing long-term environmental effects on library and archive collections (Reilly et al. 1995). The basic theory behind these indices is that the amount of time spent at very bad conditions accounts for more damage than the same amount of time at very good conditions can make up for. This fact has since been supported by further studies within IPI (Bigourdan and Reilly 2002). As

27 More information can be found on www.ucl.ac.uk/sustainableheritage (10 October 2002) 
these values are displayed alternating with temperature and $\mathrm{RH}$ values on the data loggers, no computer is needed to evaluate current conditions.

The software is also able to retrieve information from other dataloggers commonly used within the US ${ }^{29}$ and offers to work with any data as long as they can be saved as Comma Separated Value file (CSV) within Excel.

The software for analysing the collected data is designed to extract all necessary information and report them in several formats. Climate Notebook uses a database of environmental parameters required for storage of various types of objects. Among other things, it contains numerical limits, which alert the software to warn users of harmful conditions. This database can be altered or extended by users at any time to take local conditions into account or allow specialist knowledge to be incorporated in the program.

The different prepared formats in which Climate Notebook is able to report on environmental conditions include a report aimed at an engineer in order to assist communication with facilities personnel. A report for a collections manager, analysing conditions and reporting them in easy to understand language, and a report aimed at a conservator, with all available details in numerical values and graphs. The conservator is also able to retrieve a figure showing the risk of mould growth within the measured space. In addition, the software allows to compare conditions measured at different locations at once. All these reports can be formatted according to a preferred lay-out in terms of colour, fond, scale, size and other such features. It allows to manipulate data by cutting out certain parts or to look at phenomena in more detail by stretching the scale.

28 Specifics about the field trial and more detail concerning the model can be obtained via the internet at http://www.rit.edu/ 661www1/sub_pages/8page21.htm (25 September 2002).

29 Supported data logger types include ACR, Rotronic, Hobo, Spectrum, and Trak-R. 
Additional features of the program include the so-called Preservation Calculator, a tool also developed by IPI showing how changes made to temperature or RH are likely to affect the longevity of the collection.

Once the software is installed and data are downloaded, the user has the possibility to specify the kind of material that is housed within the collection. From the flexible database, the program can then alert the user to specific problems, such as mechanical deformation, metal corrosion, possible mould problems, etc.

Due to specifics given by the sponsoring body of this work, the program so far is only used by institutions within the United States. The stored database within it therefore also aims at North American climate conditions. However, due to the fact that the program allows different users to modify the database, it can be used under different circumstances, given the used computer installs the software correctly. 


\section{SURVEY OF RECORD REPOSITORIES IN THE UNITED KINGDOM}

\subsection{Methodology}

In order to qualitatively and quantitatively assess different environmental and anthropogenic factors influencing mechanisms of deterioration in buildings and collections, a survey of selected British libraries and archives (excluding Northem Ireland) was carried out between March and September 2000. This survey was based on a comprehensive questionnaire designed to acquire information on three interrelated subjects - building, environment and collection (Appendix B). The survey focused on buildings built before the Second World War housing paper-based collections. It sought to address different building types (e.g. cathedrals, churches, industrial buildings, large and small domestic as well as purpose-build buildings). In addition, different climatic situations were taken into account (e.g. buildings experiencing mountainous or sea climate)

Questionnaires were sent to 194 libraries and archive repositories (Appendix C). This survey achieved a $75 \%$ response and sought answers regarding the age and construction of the building, occurrences of dampness, building services, environmental monitoring, size and type of collection, number and type of users, and disaster preparedness ${ }^{30}$. In order to rule out buildings or collections of low interest to this particular project, and also to improve the response rate, representatives of every collection were contacted by telephone beforehand. In addition, the layout of the questionnaire was kept as simple as possible (most questions could be answered by ticking the appropriate boxes).

The questionnaires were analysed employing basic statistics, that is, by looking at the results by way of percentage. In addition, analysis was carried out using Minitab $^{\mathrm{TM}}$ (for Windows, Version 13, developed by Minitab Inc.), in order to find

so Respondents to the questionnaire were informed of the main results of the survey in October 2002. 
whether the occurrence of mould can be related to any particular features of the building or environmental monitoring systems ${ }^{31}$.

Furthermore, the results of the survey were used to identify 11 case studies for further investigation ${ }^{32}$, two of which were used for in-depth monitoring of environmental conditions (see section 6).

Specific libraries or archives have not been named within this thesis in order to maintain the confidentiality of individuals and organisations consulted during the course of this research program.

\subsection{Results and Discussion}

\subsubsection{Building}

As explained above, only buildings built before World War II were considered for this survey. A good third (37\%) of the investigated buildings were from the $20^{\text {th }}$ century and another $31 \%$ were constructed during the $19^{\text {th }}$ century. It is therefore not surprising that most buildings considered in this study $(87 \%)$ are constructed from load-bearing brick or stone, which was the prevalent building material in the United Kingdom during this period (Figure 3 ). Although there is no significant statistical evidence, it appears that $20^{\text {th }}$ century buildings investigated during the course of this survey suffered somewhat less from mould problems. A possible reason for this is that many of the $20^{\text {th }}$ century buildings are not listed buildings and it may therefore have been possible to employ more sophisticated monitoring and control equipment than in listed buildings. No correlation, however, was found between the occurrence of mould and the principal form of construction.

\footnotetext{
${ }^{31}$ All results calculated using Minitab ${ }^{\mathrm{TM}}$ are based on a significance level of $5 \%$.

32 More specific comments on particular case studies can be found in Appendix D
} 


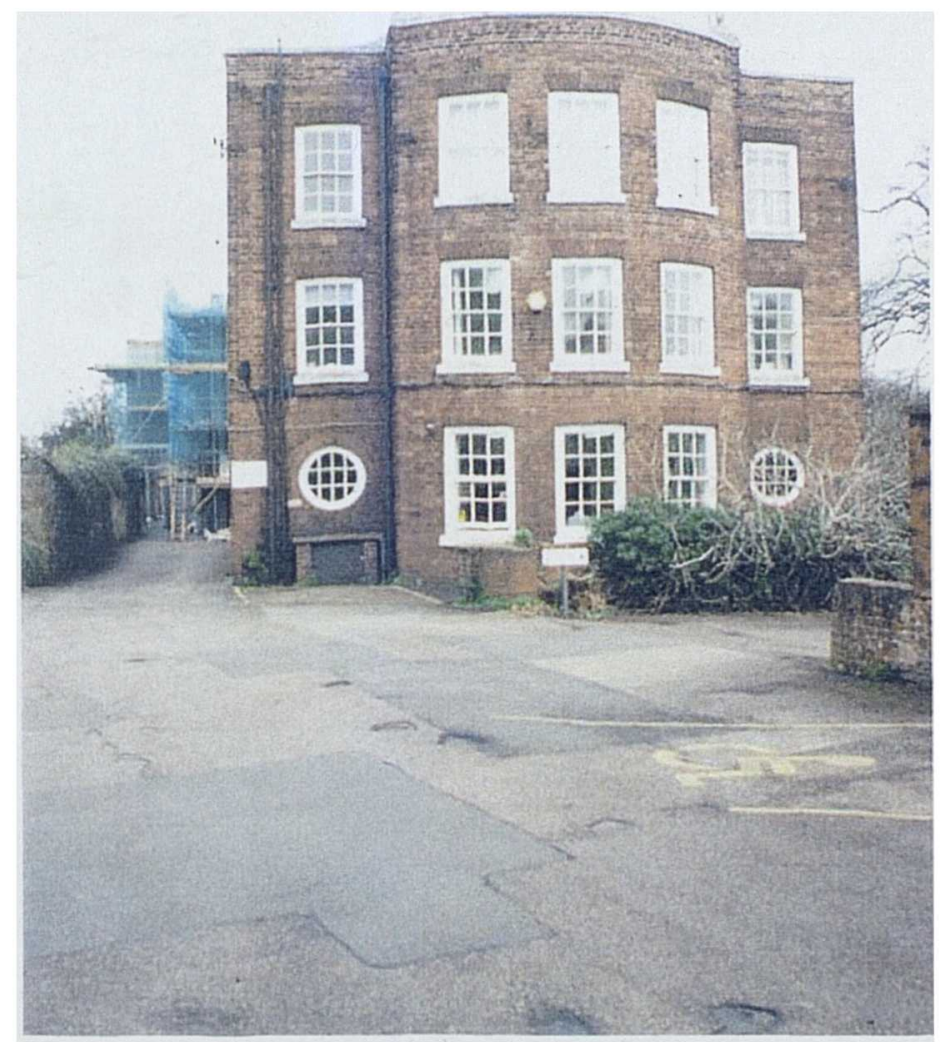

Figure 3: Typical example: converted rectory (Flintshire Record Office)

More than half of the surveyed buildings used as record repositories have three stories or more. Nearly two thirds have basements, of which almost half are used for storage purposes. In contrast, $59 \%$ have attics, but only $22 \%$ of these are used as storage rooms (Figure 4). There is no statistical evidence for an increased risk of mould growth for collections that house part of their collection in either the basement or attic. However, this result may be due to the layout of the questionnaire in which no question was posed as to the exact place of occurrence of mould within the collection or building. 


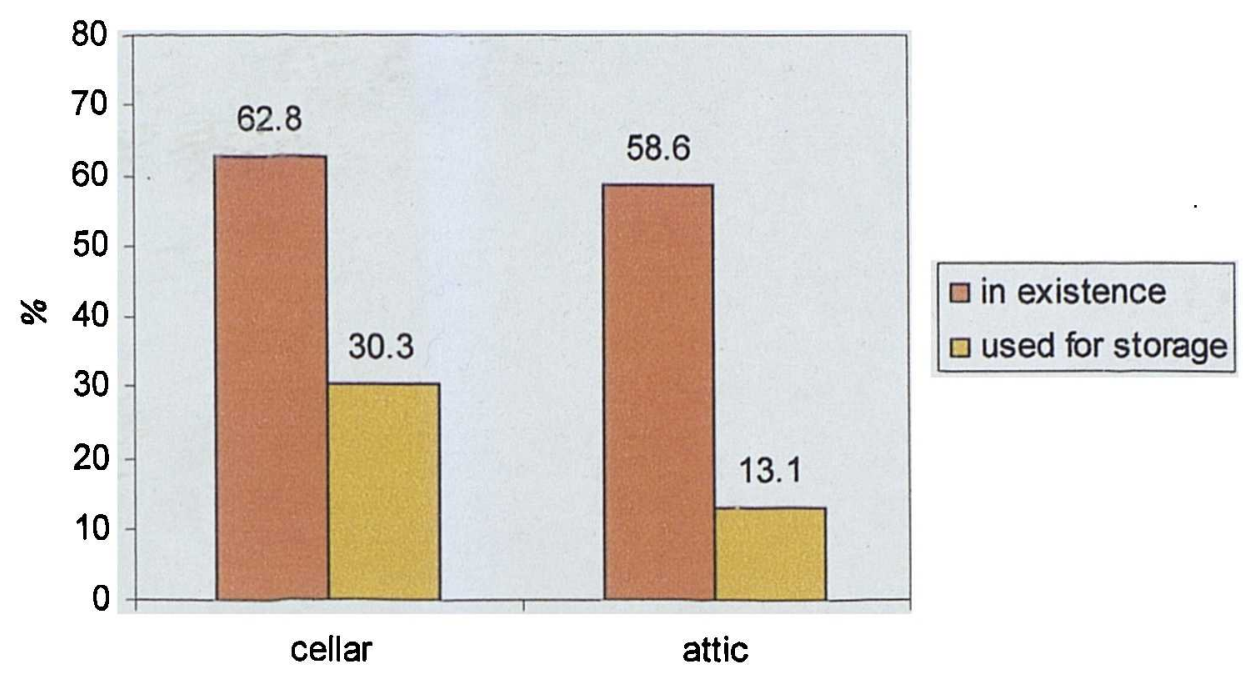

Figure 4: Cellars and attics in use for storage

In addition, $31 \%$ of all sampled buildings have flat roofs, which may typically lead to problems associated with leakage. However, as with other issues discussed previously, no link could be proven between the presence of mould and the construction of the roof.

Although the questions tried to correlate the appearance of mould with problems of dampness, some questionnaires were answered such, that the occurrence of mould was declared, whereas any damp problems were not acknowledged. However, since mould can only thrive in damp conditions, these buildings must, by nature, suffer form dampness. Collections suffering from mould growth may not always have obvious dampness problems, but rather a very poor ventilation rate in certain areas, which may cause high localised levels of RH.

Trying to statistically relate the presence of mould to a particular cause of dampness was unsuccessful, as there are too many variables involved (e.g. staff may not be very familiar with causes of dampness in buildings or the particular layout of the questionnaire that made it impossible to relate one to another). Nonetheless, almost half of the respondents $(46 \%)$ reported past or present problems with dampness. The main causes of dampness have been identified as penetrating damp and 
dampness arising from leakage (Figure 5). The existence of mould occurrence was declared by $38 \%$ of the questionnaire respondents.

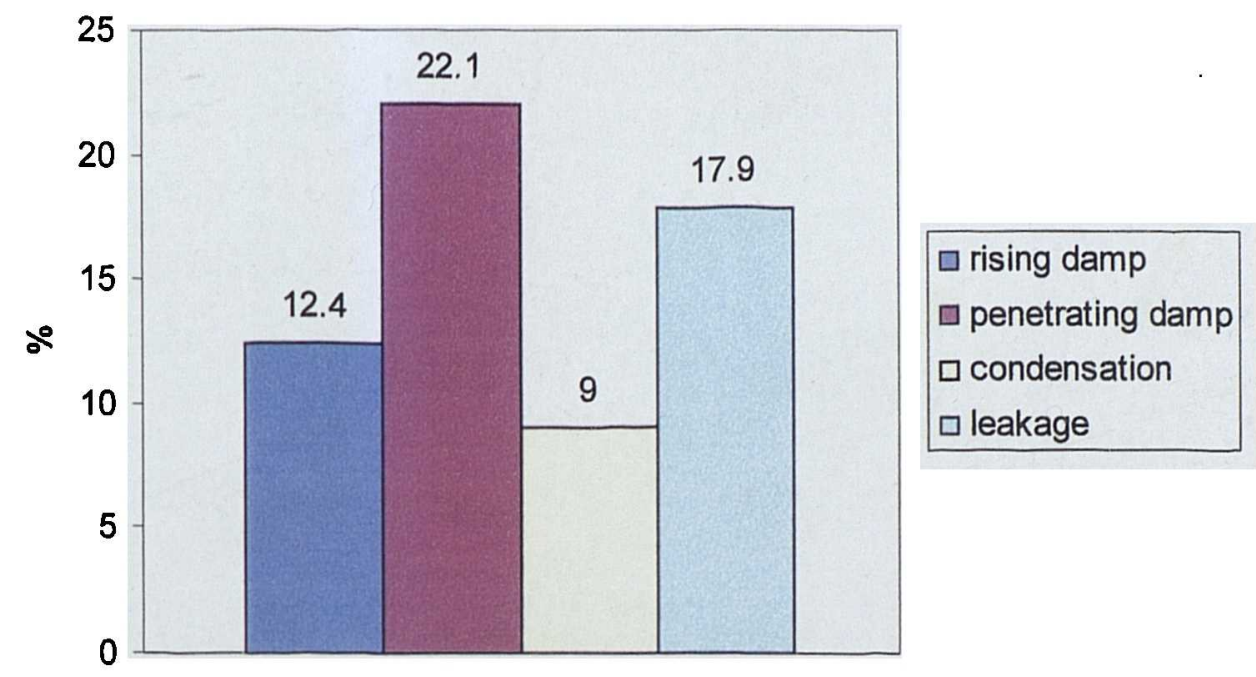

Figure 5: Cause of dampness

\subsubsection{External / Internal Environment}

The internal environment of most buildings is controlled by means of central heating $(90 \%)$ and buildings are usually ventilated naturally $(75 \%)$. However, some $30 \%$ employ mechanical ventilation to aid air exchange. The type of ventilation could not be proven to make a significant difference in terms of mould occurrence. Obviously, the rate of air exchange is more important than the method employed for this.

Air conditioning is present in $33 \%$ of all buildings and is mostly used either partial or individually. The survey results indicate that slightly less repositories with air conditioning in place suffer from mould than those without any air conditioning: $34 \%$ of collections with air conditioning suffer from mould growth, whereas $42 \%$ without air conditioning do or have experienced mould growth. This, however, cannot be seen as significant enough a difference to prove air conditioning systems beneficial. In practice, these systems bear the danger of breaking down, leaving the collection and building with a sudden change of environmental conditions that could easily trigger 
the outbreak of mould. Air conditioning only makes sense if staff are sufficiently trained to operate and maintain the system.

Environmental conditions are monitored in $87 \%$ of the surveyed buildings. As can be seen from Figure 6, temperature and $\mathrm{RH}$ are the parameters most monitored. In addition, most repositories count their visitor or user numbers. Out of those buildings that monitor internal environmental conditions, $80 \%$ monitor conditions within their storage areas. Significantly less interest is shown for reading rooms and display areas (39\% and $30 \%$, respectively). Monitoring is mostly carried out using thermohygrographs.

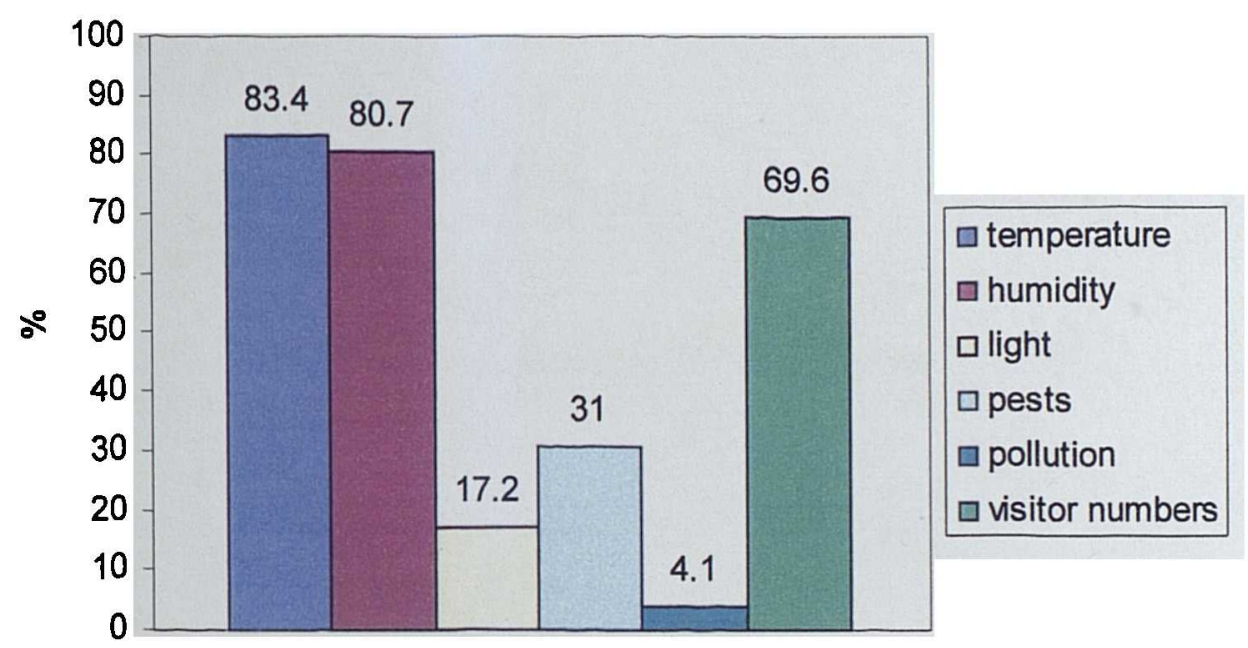

Figure 6: Environmental monitoring

As could be expected, high RH levels are controlled by heating and dehumidification. However, more than $24 \%$ of all participating repositories do not control their internal environmental conditions at all (Figure 7). Data retrieved from the questionnaire prove central heating to be most effective in reducing the presence of mould in comparison with individual heaters or no heating at all. However, it must be kept in mind that the survey questionnaire was not sufficiently detailed to pinpoint where exactly mould occurred within the buildings. 


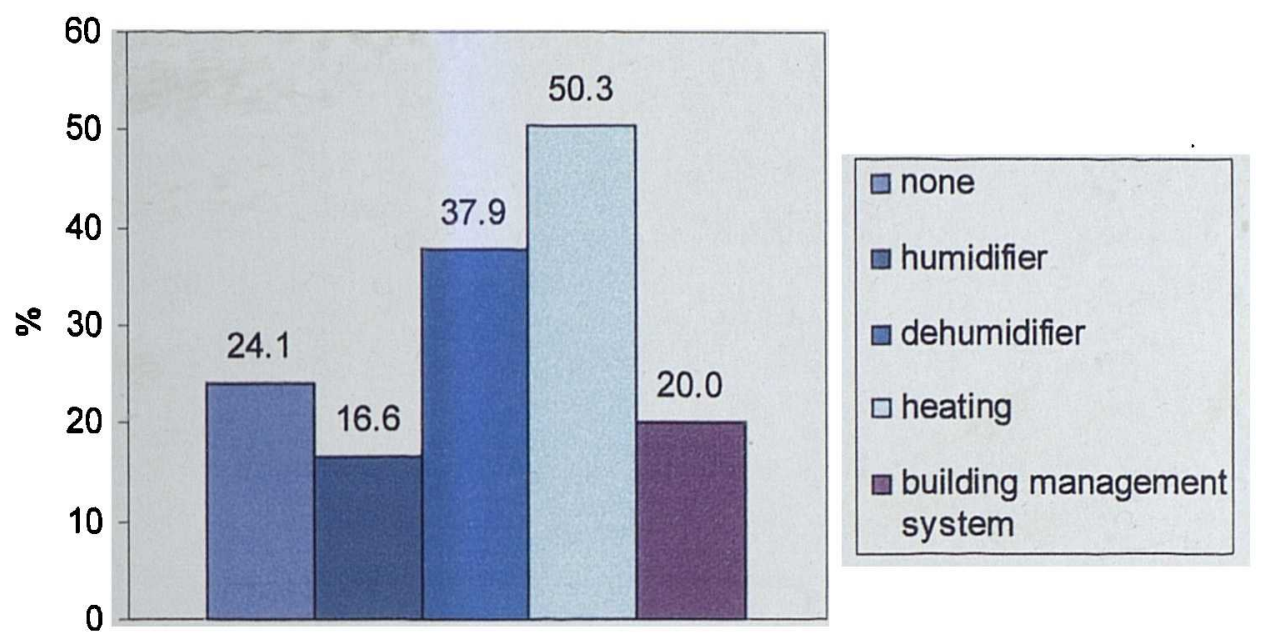

Figure 7: Environmental control

On the whole, heating and building management systems have proven to prevent the occurrence of mould best, whereas dehumidification alone was not successful. Employing no control also seemed to be a good option for historic buildings, where often the building fabric alone functions very well as a means of climate control.

\subsubsection{Library / Archive Collection}

This research program focuses on collections that mainly contain organic material, such as paper, parchment, and vellum. The main emphasis therefore relates to books. However, the storage of single sheets (e.g. paper or parchment manuscripts, art on paper and maps) has to be taken into account. It is inevitable that these materials will often consist of several materials, including wax seals and metal bosses. 


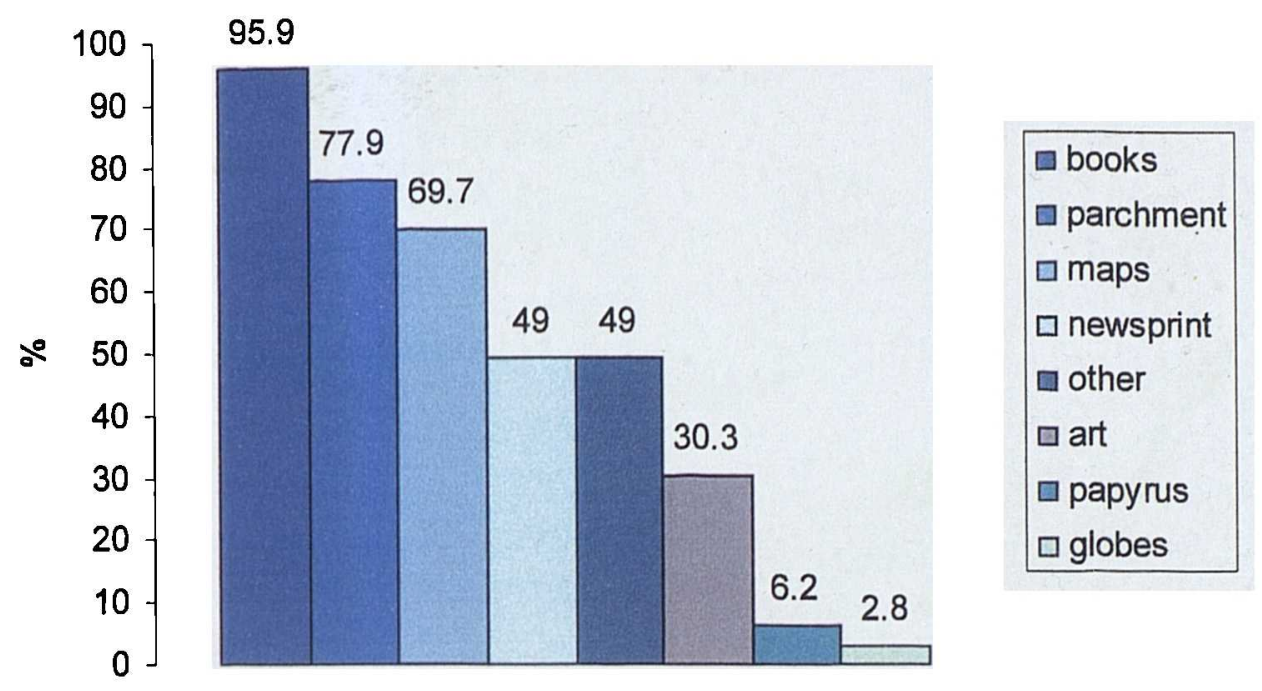

Figure 8: Nature of collections

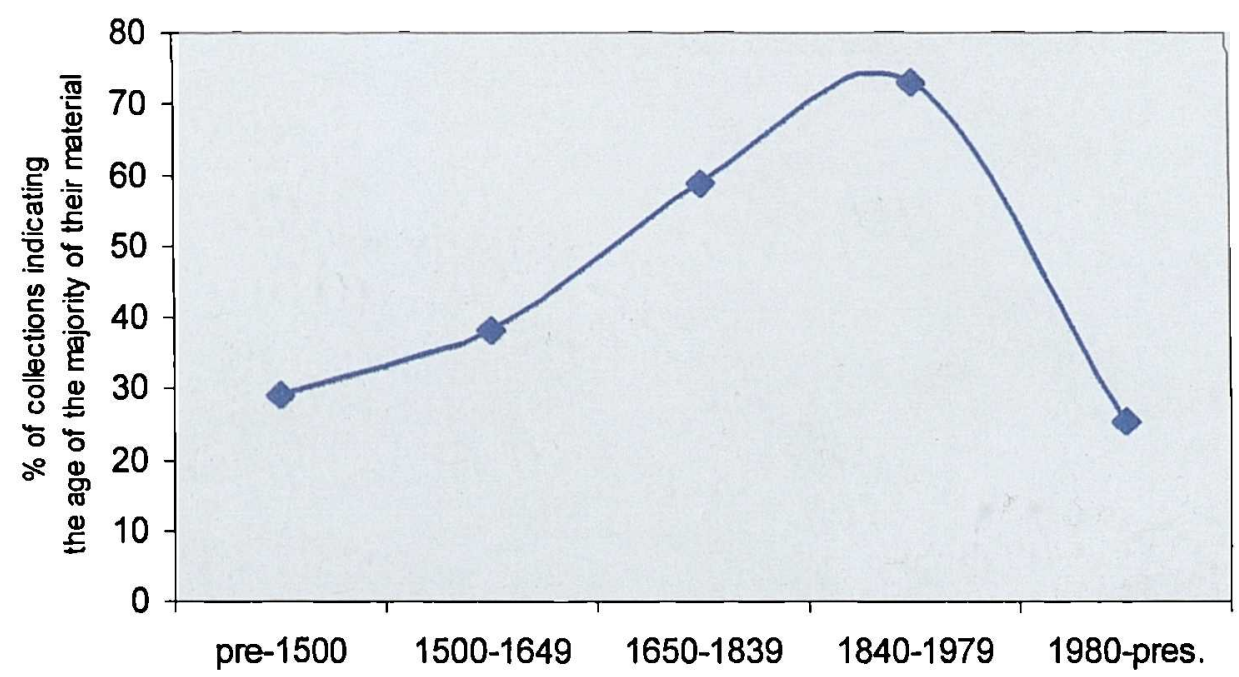

Figure 9: Age of collections

Figure 8 and Figure 9 show the range and distribution of different collection materials and give indications as to the age of collections investigated. The age of the collection is of interest, since raw material and therefore the quality of paper changed over the last two centuries, which in turn influences rates of decay (see section 3.1). 
The survey undertaken as part of the overall research program revealed that the collections are mostly used for research $(95 \%)$, whereas an additional third of the surveyed collections are also used for display purposes. Few objects seem to go on loan: only $12 \%$ claim to give objects for such purpose. This, however, is largely due to the fact that the majority of surveyed collections were record repositories rather than libraries. Because of the very nature of archives (as opposed to libraries) it is not common practice to give items on loan.

User and visitor numbers vary widely, from some reported twelve users per year, up to more than ten thousand. However, in this it must be kept in mind that some collections are solely used for exhibition (such as e.g. formerly libraries within buildings owned by the National Trust or the Historic Houses Association). Some librarians reported difficulties with small user numbers, as regular handling of the objects would make it easier to detect potential problems early.

Although most record repositories have only manual fire extinction equipment (96\%), $90 \%$ have a fire detection system and are directly linked to the local fire fighting unit.

Many of the surveyed repositories complained about a distinct lack of space, with only $9 \%$ anticipating a move or any other form of improvement in the near future. This conforms well with the findings of other UK surveys (see section 5.3 )

\subsection{Existing Surveys within the United Kingdom}

Many of the issues and concerns noted above overlap with those expressed in the recent mapping exercises for archive services in England, Scotland, and Wales. 


\subsubsection{English Archives}

The mapping project of English archive services raises a number of interesting issues relating to the use of existing (but not necessarily historic) buildings for storing archive collections (1998c: 23-32):

- $11 \%$ of local archives are in buildings that fail completely to meet relevant standards

- an additional $54 \%$ of local archives are in buildings that fail to meet basic standards

- $38 \%$ of local archivists reported that entire holdings are kept in conditions that fail to meet the main British Standard (i.e. BS 5454)

Based on a questionnaire survey of 123 head archivists in local record offices, the mapping project report highlighted the following issues:

- archive services suffering from a lack of accommodation will only achieve full potential by moving to new premises (i.e. purpose built or conversion)

- converted premises (i.e. designed originally for different uses) have either never been successful or have severe limitations (e.g. one London borough service housed within a sixteenth-century listed building next to the river poses a significant risk to its collections)

- listed building status prevents the installation of modern security systems

- the location of a local record office in a former army barracks is described as a 'vintage building not built for [the] present purpose', with none of the records stored in appropriate conditions

- the costs of alteration and refurbishment are considered prohibitive

- investment in unsuitable premises is not a costeffective use of Heritage Lottery Fund (HLF) awards

- local authority re-organisation has added to the pressures on storage space

- the siting of archive services are often not conducive to developing links with local communities 
In relation to the storage of records (1998c: $28-32$ ), the following issues and actions were identified:

- a very high proportion of records are at risk from water damage (e.g. leaking roofs, poor drainage, service pipes running through stores, use of basement storage)

- $32 \%$ of head archivists reported that the risk of water damage to their holdings is high or fairty high

- holdings at risk of water damage would benefit from early waming detection systems

- fire protection in $18 \%$ of main buildings is considered to be poor or fairly poor (e.g. in one record office internal support columns are of unprotected timber)

- installation of sophisticated fire detection systems (e.g. Very Early Smoke Detection Alarms or VESDA) in main buildings and out-stores would be worthy of HLF support

- $42 \%$ of head archivists reported that environmental conditions are poor or fairly poor

- environmental control described as 'a constant battle...a number of strongrooms experiencing enormous [temperature] fluctuations'

- lack of environmental control resulted in 'temperature and humidity...vary from BS 5454 by up to $50 \%$ in hot summers and dry winters'

- a package of environmental monitoring and control equipment may help to improve storage conditions to an acceptable level in the short to medium term

- 'all the storage is for library books...none of it was designed with an archive in mind'

- there is a clear need for customised archival shelving

\subsubsection{Scottish Archives}

The findings of the mapping project of Scottish archive services makes similarly sorry reading (2000a: $v, 4-8)$ : 
- accommodation for archives and archive services generally described as appalling

- in the majority of cases BS 5454 is very far from being met

- basic physical safeguards are, in many instances, not in place

- $85 \%$ of local authority archive accommodation is reported as poor or very poor

- $60 \%$ of health board archive accommodation is reported as poor

- $55 \%$ of university archive accommodation is reported as poor

- $40 \%$ of national institution archive accommodation is reported as poor

Based on a questionnaire survey of public and private sector archive services (with a $67 \%$ overall response rate to 95 questionnaires), responses to questions concerning the site/location of the main building, soundness of structure, fire protection, flood/water damage risk, security and storage conditions, included the following statements:

- 'attic not renovated and remains a fire hazard'

- 'the building is adjacent to the fleet maintenance garage'

- 'area is susceptible to occasional flooding'

- '...running battle over many years with the Property Department (concerning roofing and gutters)'

- '...high power cabling running across the ceiling'

- 'the system of fire protection is now obsolete and requires considerable expenditure to upgrade'

- 'water leaks after heavy rain are not uncommon'

- 'engineers had advised that a new roof was required in 1989 but the cost was too prohibitive for temporary accommodation'

In summarising the data from this questionnaire survey, the following issues were identified:

- consistent pattern of difficulties regarding security and internal access arrangements, summed up as a conflict between archival storage and other functions of the building 
- records not being held under recognised British Standard for storage of archival records in main buildings

- many problems with environmental controls (e.g. 'environmental controls inadequate', 'fluctuations in temperature and RH outside recommended guide', 'no temperature or humidity control or monitoring', historic building...heating, solar gain, ventilation all very limited control)

- problems with existing shelving

- typical lack of funding for upgrading facilities

- standards of storage of archival records in outstores far worse

- conditions in outstores well below minimum standards (e.g. 'entirely unsatisfactory...damp, and too cramped', 'environmental controls are not anywhere near BS 5454')

\subsubsection{Welsh Archives}

The recently-published report of the Welsh mapping project is based on a survey of all archives in Wales (i.e. it includes those that are run by local authorities such as museums, libraries and universities, and those run by governmental bodies [2001]).

The main findings, based on a questionnaire survey of 22 archives, all of whom responded, were (2001: 8-9):

- Nearly two thirds of all record repositories in Wales occupy accommodation that falls significantly short of recommended standards

- Most archives have serious arrears of cataloguing

- Few archives are sufficiently equipped to make use of computers and networking

- Provision of conservation and preservation facilities is restricted in many places

- The biggest asset of Welsh archives is the provision of access and the quality and ability of staff

With regards to the accommodation of archival collections the report highlighted the following issues (2001: 10-14): 
- $59 \%$ of record offices provide accommodation which is designated either poor or fairly poor

- record office buildings in Wales range from converted buildings to purpose-build structures; typical comments conceming the buildings structure included 'in need of overhaul', and 'requires much maintenance'

- precautions against natural disasters need upgrading; $64 \%$ have no automated systems of fire detection and extinction

- $27 \%$ of record offices have basement storage areas which are liable to flood

- $27 \%$ are at risk from water damage through roof leaks

- $82 \%$ have no early warning system for water detection

- $77 \%$ have no means of draining water from their repositories once water has infiltrated

- only $45 \%$ have good or fairly good environmental control

- there is an ever increasing problem with space: $93 \%$ of all archives have only sufficient space for less than five years worth of accrual

- $71 \%$ of out stores are being assessed as poor or fairly poor ('records urgently need to be removed from this building')

In terms of conservation and preservation the following points were raised through the survey (2001: 31-33):

- $63 \%$ of record offices' provision for conservation is rated poor or fairly poor

- a need for office- and national-level strategies for the co-ordination of preservation efforts has been highlighted

- there is a considerable backlog in conservation work: $41 \%$ reported that $5 \%$ or more of their collection is entirely unfit for use; however, only $23 \%$ have carried out collections surveys in order to prioritise the material in need of conservation

- only $14 \%$ felt able to say that they had sufficient staff to address their collections' preservation needs

Although many of the findings of this research program overlap with those from existing surveys within the United Kingdom, some issues must be highlighted from 
the current project. The main problems of library and archive collections in historic buildings arise from adverse environmental conditions deriving from unsuitable buildings or long-term neglect of maintenance. Whilst this is recognised, historic buildings often do not allow for improvements requiring changes to the building. The option of moving the collection into purpose-built repositories, on the other hand, causes ambiguities, as it destroys the integrity of collections and buildings within their historic site of a city as well as their integrity as a historic entity (Figure 10).

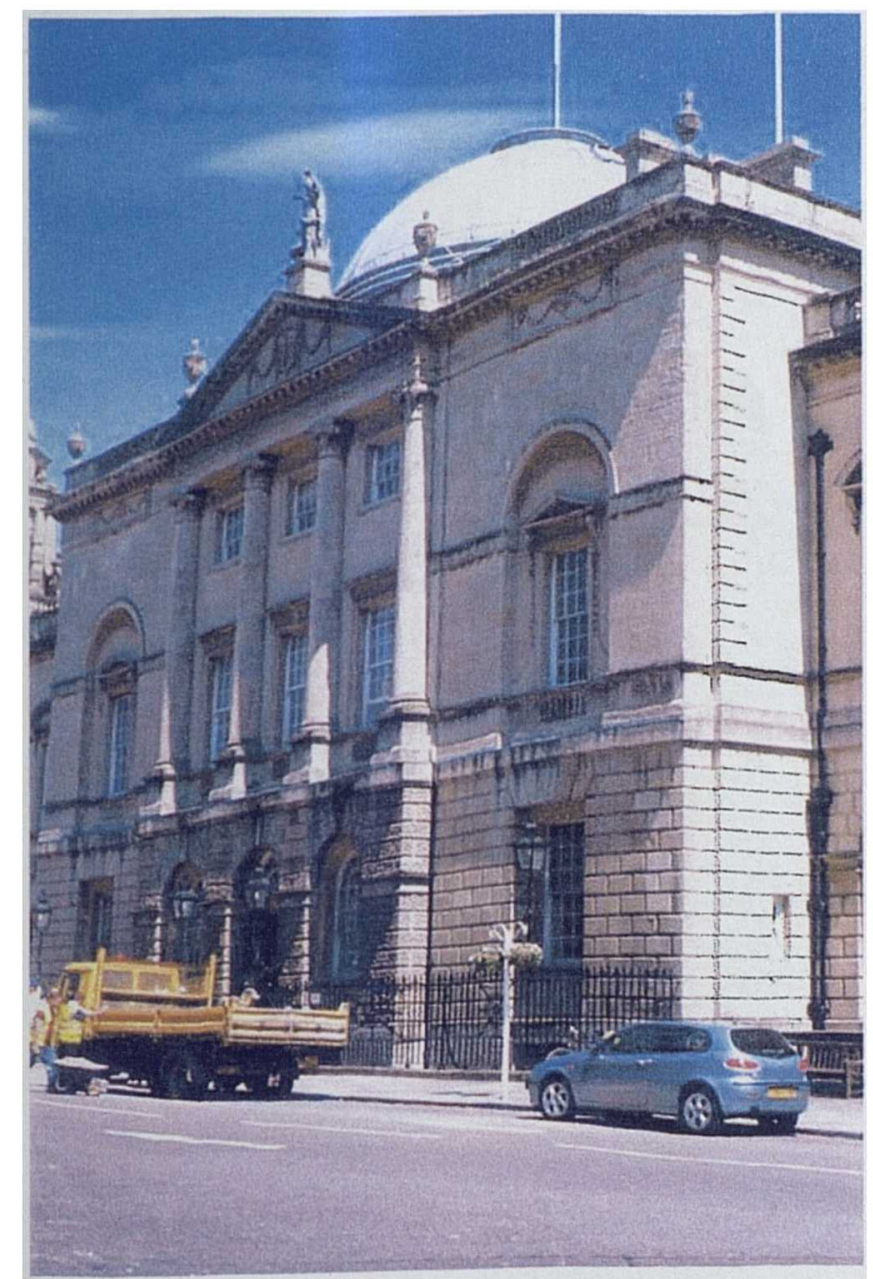

Figure 10: Bath and North East Somerset Record Office at Bath Guildhall

Many problems relate to a lack of storage space. An outstore for housing parts of a collection may be a solution, however, it will create its own problems, when items from the outstores are needed within the main building. There is a risk attached to moving items from different sites, not only due to environmental changes, but also 
due to safety issues. Only a few sites are fortunate enough to have available space adjacent to the historic site, where modern storage accommodation may be built (Figure 11).

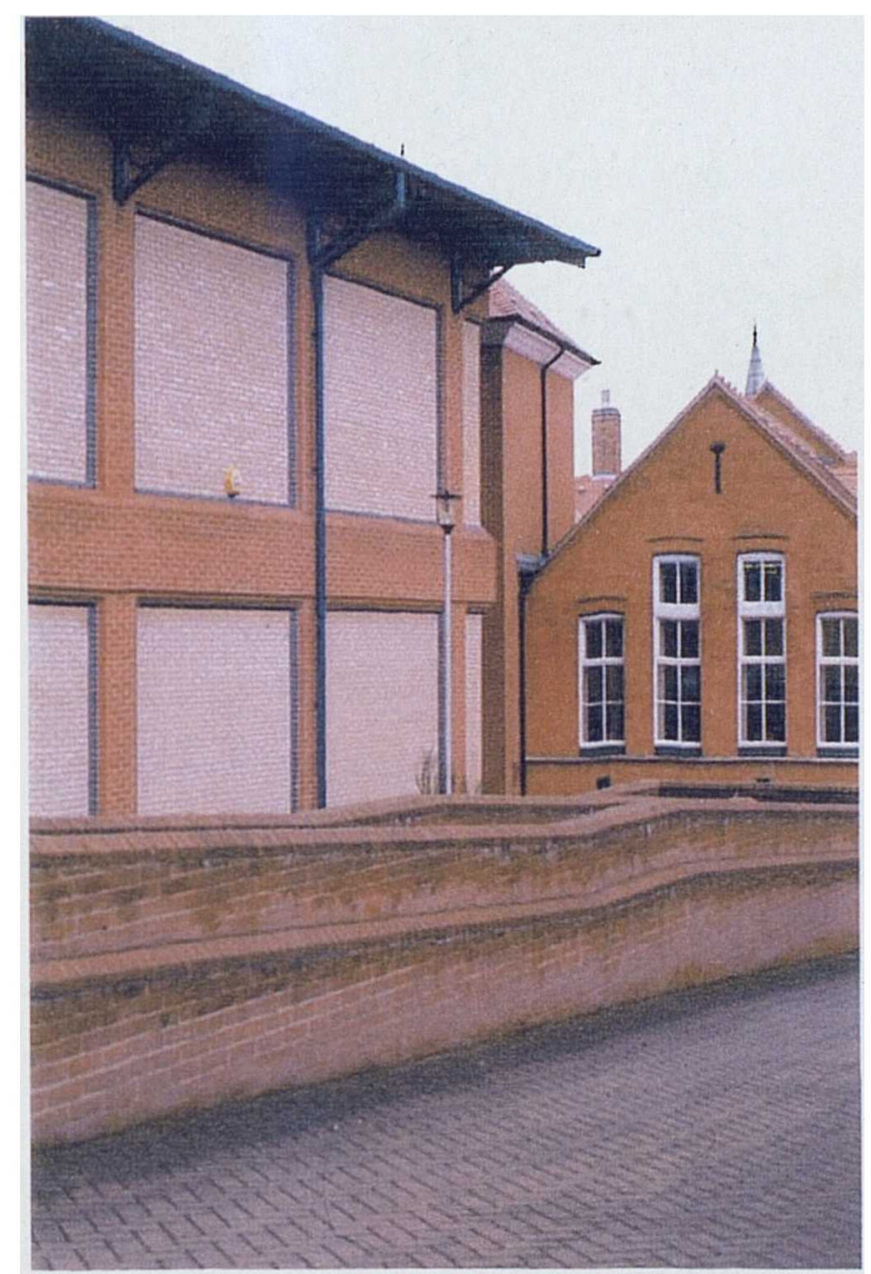

Figure 11: Leicestershire Record Office: modern storage facility built behind historic school

The libraries and archives visited during this research also revealed concerns with respect to different levels of preventive maintenance. Since many archives and libraries are administered by local authorities or other large organisations, confusion often occurs over responsibilities between the authorities and staff. A lack of regular, planned preventive maintenance is common.

Often, historic buildings may not be suitable for the needs of modern archives or libraries, as it may not be possible to install lifts, or may require staff to carry items by 
hand instead of on trolleys (Figure 12). Converted industrial buildings may pose difficulties in providing appropriate storage, as original floor levels may have to be altered (Figure 13) or historic machinery integrated (Figure 14).

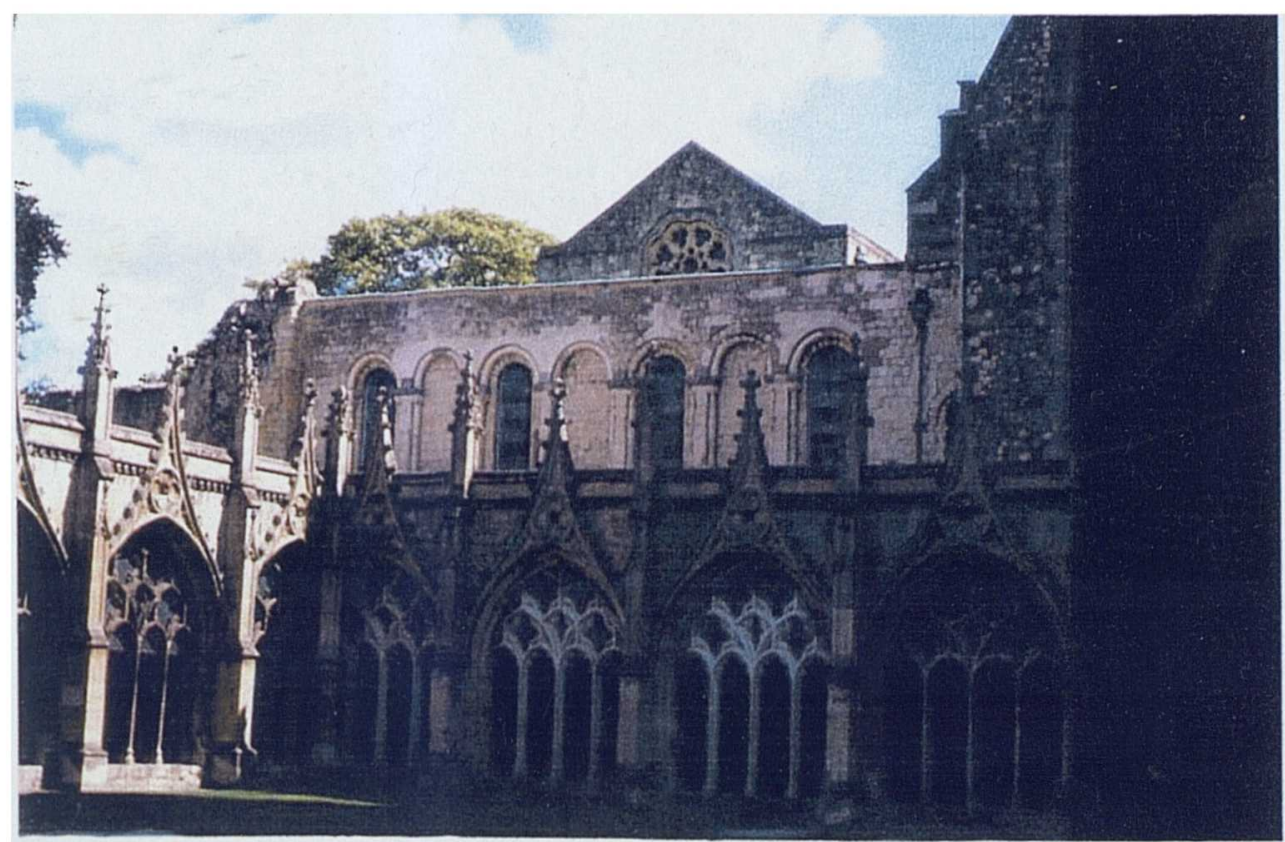

Figure 12: Canterbury Cathedral Library and Archives: extension integrated with cloister (first floor)

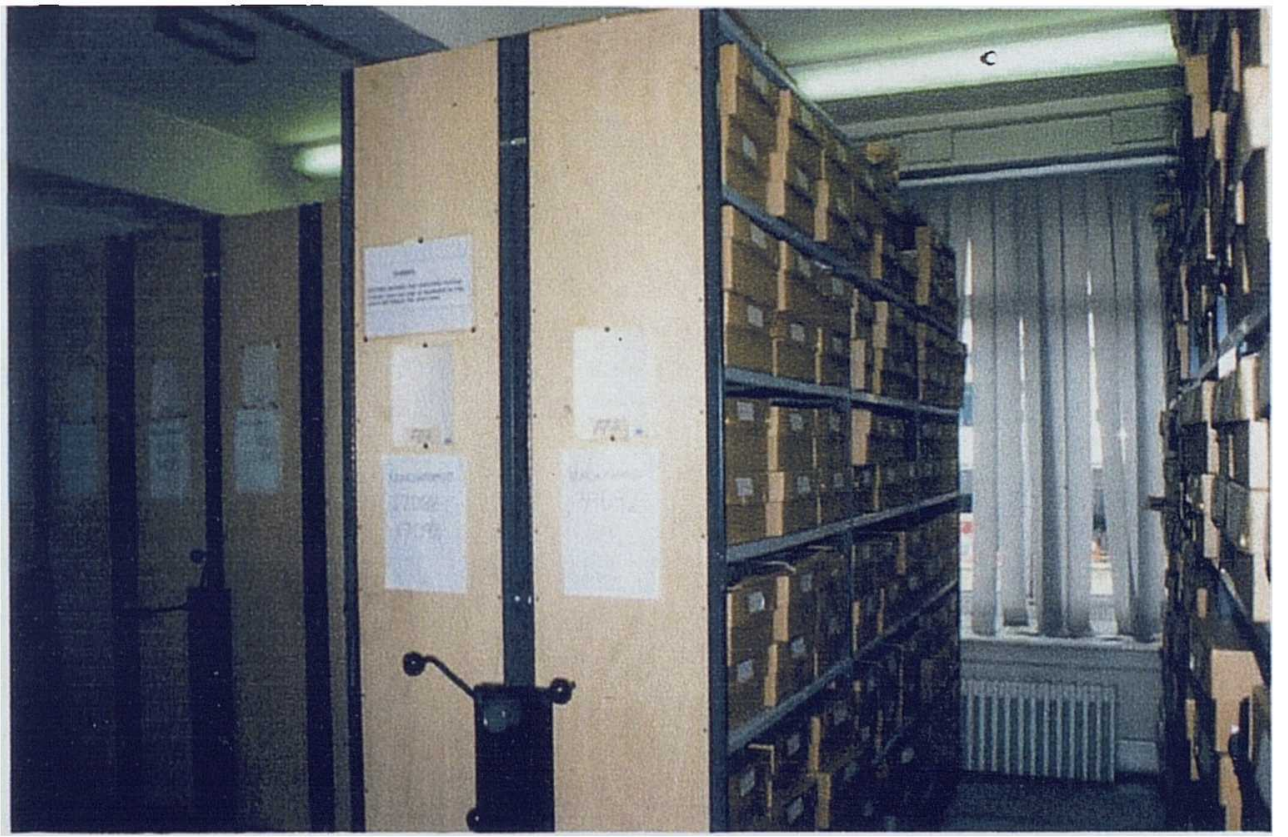

Figure 13: West Yorkshire Archive Service, Bradford: raised floor level across radiator 
Many members of staff are aware of the needs for improvements. There is, however, a distinct lack of funding within the library and archive sectors. Applications to grant awarding bodies often need a great deal of expertise, time and effort, which can often not be spared by part-time staff running a small repository. In addition, the assessment of a collection itself will require careful planning. Exacerbating this is the fact that investments, in unsuitable premises is not cost-effective and funding applications are therefore often rejected.

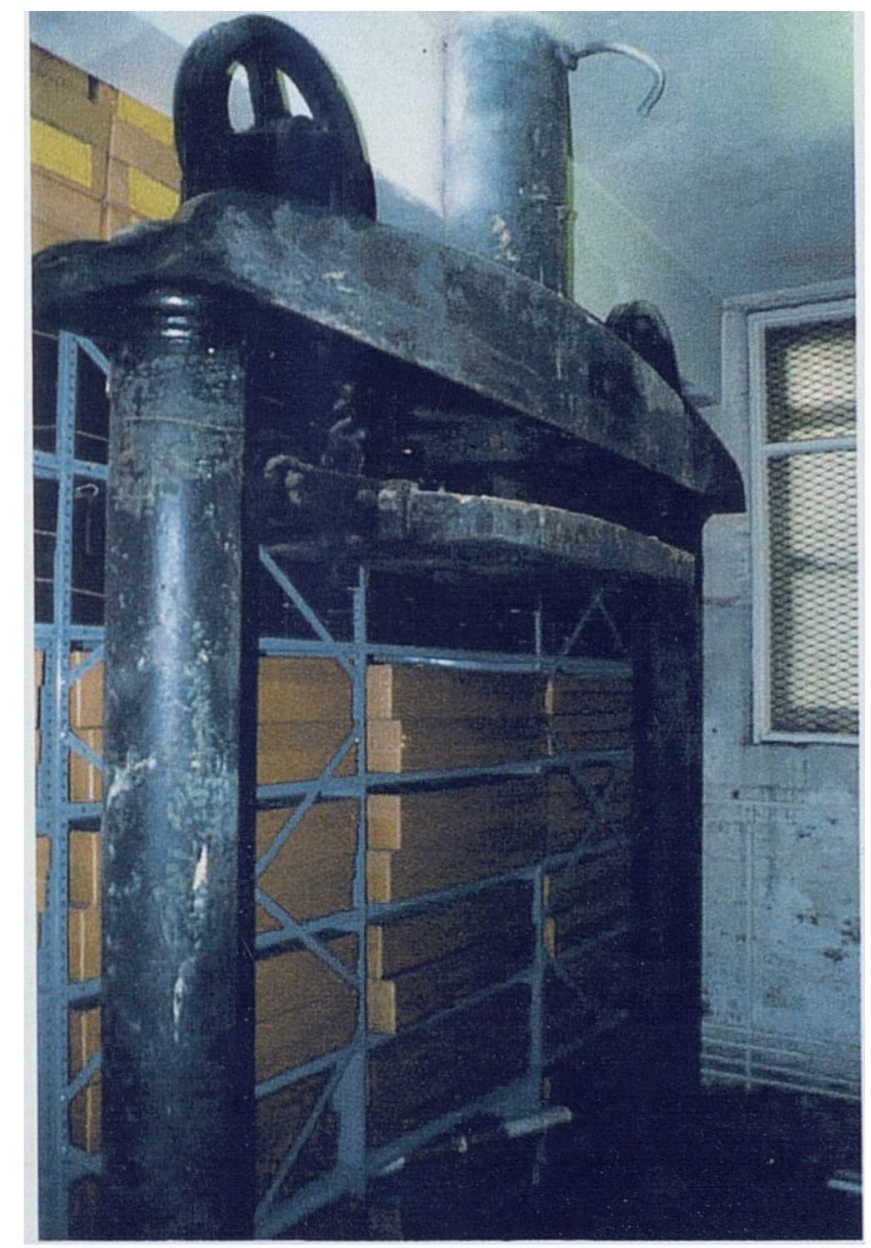

Figure 14: West Yorkshire Archive Service, Bradford: industrial machinery within strongroom

Historic buildings do, however, have the potential to work for the advantage of the collection, as their often substantial fabric can provide a relatively stable internal environment (especially if the collection is housed away from outside walls). It is important to note that conditions may not always conform to current standards. 
Nevertheless, historic buildings can provide stable environment, which is of great importance, even if the parameters set in recognised standards are not met in all aspects. Storing items in rooms without windows also has the advantage of reduced light levels within the strongrooms. In addition, natural ventilation in historic buildings may contribute to the well-being of buildings and collections.

This survey made it evident that historic buildings may be used effectfully for paperbased collections, as long as specialists from the different fields are involved (e.g. architectural conservators and conservators caring for the particular collection). The overall outcome of this research is in close line with the recent report by Hughes (2001), commissioned by the Council for Museums, Archives and Libraries (Resource). 


\section{EXPERIMENTAL}

\subsection{Case Studies}

Two very different case studies were chosen for in-depth monitoring of environmental conditions. Data collection was carried out in order to identify relationships between external and ambient conditions in a room, and those experienced within glass-fronted bookcases:

- Unstable environment (Guildhall Museum, Leicester (Leicestershire): small library, frequently visited, external door often open).

- Stable environment (Brontë Parsonage Museum, Haworth (West Yorkshire): small strongroom, infrequently visited).

The studies focussed entirely on humidity and temperature conditions. In this, the atmospheric moisture is expressed as relative humidity, since it expresses the thermodynamic activity of water ${ }^{33}$. Materials, which react reversibly with water, such as cellulose, absorb water according to the relative humidity of its surroundings, with only a slight temperature dependence. It is probably because of this, that $\mathrm{RH}$ is the most commonly used unit among professionals in conservation. (Padfield 1998: 12)

\subsubsection{Guildhall Museum, Leicester}

The oldest part of the Guildhall, or Old Town Hall, is a fourteenth-century cruckframed hall. Built for the Corpus Christi Guild (founded in 1343 and dissolved in 1548), the hall was extended in the mid-fifteenth century to accommodate a larger membership (this explains the two different forms of timber-frame construction apparent in the building), and east and west wings added in c.1490 (with floors

33 Water vapour concentration can also be expressed in units of $\mathrm{kg}$ per $\mathrm{kg}$ of dry air. This is useful when dealing with the heat that needs to be added, or removed, but it is confusing 
inserted into the west wing in c.1563). The use of the building saved it from destruction during the Reformation and it retained its function, including the insertion of police cells beneath the library in c.1836, until the new Town Hall was built in 1876. Despite standing empty and being considered for demolition after this time, it was used briefly as a cookery school before being restored and opened to the public as a museum in 1922. A major conservation programme, including works to the library, was undertaken in 1991-93. The Guildhall is now in the care of Leicester City Council.

The Guildhall library is located in the east wing at first-floor level, in a room likely to have originally been living accommodation for chantry priests associated with the Corpus Christi Guild. This was extensively remodelled in c.1632 and further enriched in 1645. Two external walls (north and south) are of timber-framed construction, 75 $\mathrm{mm}$ in thickness, with infill panels of wattle-and-daub, whilst that to the east is of 265 $\mathrm{mm}$ solid brick construction. There are windows, with leaded lights, to north and east, and an extemal door opening on to a part-enclosed external stairway to the south. The internal west wall divides the library from the upper part of the hall. The room is $\sim 16.8 \mathrm{~m}^{2}$ in area with its ceiling formed at the assumed collar level of the pitched roof. The volume of the space is $-62.9 \mathrm{~m}^{3}$. Heating is by an electric storage heater fixed to the east wall, which is thermostatically controlled. The Guildhall is open to the public on 361 days per year and for much of this time both internal and external doors remain open. It attracts c.50,000 visitors per year.

The library contains many seventeenth-century books that were moved from St Martin's Church (now Leicester Cathedral) in 1632. First mentioned in 1587, these formed the third oldest public library in the United Kingdom, being pre-dated only by libraries in Bristol and Norwich. By 1650 a catalogue of 876 volumes had been compiled. The library fell into decline, with few additions after the seventeenth century. Many volumes were stolen or damaged and, in 1919, the remaining books were catalogued - apart from theology, there are works on history, poetry, philosophy, medicine and mathematics. The rarest books have since been moved to

when dealing with moisture equilibria between materials and the surrounding space, where the air plays no role at all. (Padfield 1998: 12) 
the Leicestershire Record Office, including the fifteenth-century New Testament in Greek known as the Codex Leicestrensis. There is also a New Testament translated into an American Indian language, which was printed in Cambridge, Massachusetts, in 1661.

The books are housed within three fixed timber bookcases - to south, east and west walls (i.e. two backing on to external walls). Each is shelved and fitted with paired glazed doors. For the purposes of the project, the bookcase to the east wall, adjacent to the north-east corner (i.e. two external walls), was chosen for study.

\subsubsection{Brontë Parsonage Museum, Haworth}

The parsonage at Haworth was built in 1778-79 and became the lifelong home of the Brontë family. The house was opened as the Brontë Parsonage Museum in . 1928 , and displays the furniture and belongings of the Brontë family. The Museum is owned and administered by the Brontë Society and open to the public on 332 days per year, attracting $c .75,000$ visitors per year.

The two-storey eighteenth-century building is constructed of local sandstone beneath a stone-slated roof and was extended to the north in 1878. In addition, there is a rear (west) extension dating from the late 1950 s/early 1960 s.

The Brontë Parsonage Museum provides research facilities and access to collections, and offers both permanent and temporary interpretative exhibitions and educational events. The research library is housed within the 1878 extension to the main building. The library is the focal point for the largest collection of Bronte material in the world (including personal books, first editions, manuscripts, drawings, and other rare material) and provides a key resource for academic scholars. The library also contains a comprehensive collection of secondary source material (including facsimiles of primary material, books, articles, the Brontë Society Transactions from 1898 to the present (to be re-named Brontë Studies from 2002), 
photographs, and other related material) for use by post-graduate students and other researchers.

The most vulnerable primary material is housed within a strongroom to the rear extension. The construction of this room is of cast concrete with an external stone facing; sloping ground to the south covers the lower parts of the walling. There are no windows and a security door provides an airtight seal; there is no heating or mechanical ventilation. The strongroom is accessed on average 3 times per week, with an entry/exit log recording the duration of visits. The room is $\sim 6.2 \mathrm{~m}^{2}$ in area and has a volume of $\sim 12.2 \mathrm{~m}^{3}$. The material is stored on open metal shelving, within timber and metal bookcases, and in conservation-quality boxes on metal racking. Environmental monitoring is undertaken using a fixed thermohygrograph positioned on the external rear wall of the room.

In October 2000, mould was discovered on temporary exhibition picture frames standing in front of the rear wall. Concern has since been expressed that conditions might be conducive to the formation of condensation and mould growth on certain surfaces. For the purposes of the project, a shelved metal bookcase with sliding glass doors standing to the south wall in line between a taller metal bookcase and a metal racking with boxed items was chosen for study. This bookcase holds 93 books and pamphlets on three shelves, with 36 items on the lower subject shelf.

\subsection{Methodology}

Environmental monitoring was carried out at both the Guildhall Museum (commencing 25 June 2001) and the Brontę Parsonage Museum (commencing 16 July 2001), using a total of eight dataloggers (Hanwell Humbugs). Each site was monitored for a twelve-month period. All eight dataloggers have an accuracy of $\pm 2 \%$ $\mathrm{RH}$ over a range of 5 to $95 \% \mathrm{RH}$, and $\pm 0.3^{\circ} \mathrm{C}$ over a range of -25 to $50^{\circ} \mathrm{C}$. One data logger was an instrument for monitoring external conditions only, the other seven loggers were standard Humbugs for internal use. 
The two dataloggers within the two dummy books were precision calibrated, resulting in an accuracy of $\pm 1 \% \mathrm{RH}$ over a range of 5 to $95 \% \mathrm{RH}$, and $\pm 0.3^{\circ} \mathrm{C}$ over a range of -25 to $50^{\circ} \mathrm{C}$.

\subsubsection{Datalogger Locations}

Six dataloggers were placed within the Guildhall Museum Library. These were situated in the following locations:

- External. One logger (Hanwell External Humbug, unit number 24222) to east face of external stairway, $2.3 \mathrm{~m}$ above landing level. Intended to provide data on external conditions as a reference for intemal data.

- Internal accommodation. One logger to east wall above subject bookcase, 2.3 $m$ above floor level (Hanwell unit number 3227). Intended to provide data on internal conditions as a reference for data collected within bookcase.

- Bookcase. Two loggers inside the bookcase: one to upper shelf of $\sim 97,000 \mathrm{~cm}^{3}$ volume containing eight books (including two dummy books) and one to lower shelf of $\sim 93,000 \mathrm{~cm}^{3}$ volume containing no books (Figure 15a) (Hanwell unit numbers 3213 and 3214 , respectively). Intended to provide data on buffering capability of bookcase and influence of books on conditions within sealed shelves.

- Dummy books. Two loggers inside dummy books: one inside a seventeenthcentury book made of rag paper (384 x $245 \times 50 \mathrm{~mm}$, 'big book') and one inside a nineteenth-century book made of lignin-containing paper $(235 \times 165 \times 44 \mathrm{~mm}$, 'small book')(Hanwell unit numbers 3209 and 3210 , respectively $\left.{ }^{34}\right)^{35}$. Intended to provide data on buffering capabilities of books and humidity levels within lignincontaining and lignin-free papers in relation to shelved micro-environments (Figure 15b). Both loggers used inside the two dummy books were subject to

34 The two datalogger within the dummy books were precision calibrated by Hanwell. Hanwell calibration certificate numbers are 1502 and 1503, respectively; the certificates were issued 12 June 2001)

${ }^{35}$ For a more detailed fibre analysis of the two dummy books refer to Appendix F. 
certified humidity and temperature calibration to improve operating efficiency $\left(-25-50^{\circ} \mathrm{C}\left[+/-0.3^{\circ}\right]\right.$ and $5-95 \%[+/-1 \%]$ relative humidity).

Two dataloggers were installed within the Brontë Parsonage Museum, in addition to the existing monitoring system. These were placed in the following locations:

- Internal accommodation. One logger to rear wall adjacent to existing monitoring system, $1.1 \mathrm{~m}$ above floor level (Hanwell unit number 3311). Intended to provide data on internal conditions as a reference for data collected within the bookcase and as a control for the existing monitoring system.

- Bookcase. One logger on the lower shelf of the metal bookcase, intended to provide data on buffering capability of bookcase and determine conditions favourable to condensation (Hanwell unit number 3310 ).

\subsubsection{Positioning the Dataloggers within the Dummy Books}

The standard Humbug datalogger for intemal monitoring was used to measure conditions within the dummy books. These dataloggers have dimensions of $45 \mathrm{~mm}$ (width) $\times 90 \mathrm{~mm}$ (length, excluding sensor; $97 \mathrm{~mm}$ including sensor) $\times 16 \mathrm{~mm}$ (thickness).

The loggers were placed in the centre of the books, as the main aim was to monitor how the centre of a book is influenced by fluctuating conditions in its surroundings. In order to accommodate the loggers within the books, holes the size of the logger were cut to fit the units snug, and leave as little air space as possible. In order to facilitate downloading with as little interruption as possible, these dataloggers were fitted inside the books with the cables attached and their plugs easily accessible (see Figure 15b). It was therefore necessary to also cut a small channel to fit the cable. As the books stood directly on the shelf and air exchange was therefore minimised, sealing of cable and dataloggers was considered unnecessary. 


\subsubsection{Placing the Dataloggers within the Bookcases}

The gaps between the leading edges of the shelves and glazed doors of the bookcase were sealed using a closed-cell polyethylene foam gasket to isolate the shelved micro-environments from one another. Shelves and vertical divisions inside the bookcase are of $19 \mathrm{~mm}$ thick sealed hardwood.

\subsubsection{Data Collection}

The dataloggers were set to collect data hourly. Monitoring at the Guildhall Museum commenced on 25 June 2001, with downloads on 11 July 2001, 18 September 2001, 10 December 2001, 4 March 2002 and 8 July 2002.

Monitoring at the Bronte Parsonage Museum commenced 16 July 2001, with downloads on 19 October 2001, 7 May 2002 and 14 August 2002.

All data were transferred into Excel to allow for in-depth analysis. 


\section{RESULTS AND DISCUSSION}

\subsection{Environmental Monitoring}

\subsubsection{Guildhall Museum Library}

\section{External Environment}

Over the observed time (July 2001 until June 2002) the external environmental conditions in Leicester varied between 23 and $96 \% \mathrm{RH}$, with an average $\mathrm{RH}$ of $73 \%$ for the entire year. These $\mathrm{RH}$ conditions correlate well with official data published by the Met Office (UK) (see below). Temperatures ranged from -5 to $29^{\circ} \mathrm{C}$, with an average of $12^{\circ} \mathrm{C}$. As can be expected in temperate climates, $\mathrm{RH}$ conditions in winter were higher than in summer, while temperatures were lower in winter and higher during the summer months. According to official data from the Met Office, the minimum RH in winter (January) in the Midlands, on a daily average, is around $85 \%$ $\mathrm{RH}$. In summer (July), the minimum relative humidity has a daily average of around $65 \% \mathrm{RH}$ (Figures 16a and 16b). This highlights the fact that observed data with much lower values were temporary peaks.

\section{Internal Environment}

From Figure 17 it can be seen, that the internal conditions follow the external conditions very closely. Over the observed time, ambient conditions reached from 31 to $91 \% \mathrm{RH}$, with temperatures between 3 and $28^{\circ} \mathrm{C}^{30}$. There is, however, a general trend for the ambient $\mathrm{RH}$ conditions to lie approximately $10 \%$ below the external conditions. While the $\mathrm{RH}$ within the room follows the external conditions very closely, there is a very small time lag between the two conditions. The building itself does hardly act as a buffer for internal conditions, which is demonstrated in Figure 18, 
using the months of August and September 2001 as an example ${ }^{37}$. It is not surprising then that internal temperatures are also very close to external conditions, though generally $c .2^{\circ} \mathrm{C}$ higher. It is noteworthy that the time lag for the ambient temperature to adapt to external conditions is slightly bigger than for the adaptation of RH conditions, six to twelve hours as compared to less than six (Figure 20). This can possibly be attributed to a slight cooling effect of the thermal mass of the three extemal walls surrounding the library.

The similarity of outside and inside conditions must be attributed to the presence of the external door, which is often left open by visitors to the museum and staff alike. This results in an extremely high level of air exchange within the library.

\section{Environment within the shelves}

As can be seen from Figure 21, both bookshelves, the full one and the empty one, respectively, have conditions of over $65 \% \mathrm{RH}$ for the entire observed time. Comparing the conditions within those shelves with the conditions in the room, it is obvious, that the Victorian bookpresses considerably dampen the fluctuation of ambient conditions (Figure 22). Conditions within the bookshelf therefore remain reasonably constant $(\sigma<2 \%)^{38}$. Both shelves are fairly similar to each other compared to both, extemal and ambient conditions. However, the fully packed shelf experiences slightly less RH fluctuation than the empty shelf (Figure 21). This means, the relative conditions reverse twice a year: in winter the conditions in the empty shelf are more humid, in summer the conditions within the full shelf are more humid. Although the differences between the shelves are no more than $2 \%$, Figure

36 The RH data were collected hourly. However, the data plotted in Figure 17 are based on a seven day average.

${ }^{37}$ In Figure 18, the RH was plotted as a rolling seven day average. This means, a seven day average was calculated. For every new reading the oldest reading was discarded and the newest inserted for the calculation of every following average. This approach evens out short-term fluctuations, while still monitoring minute changes closely. For direct comparison of the two methods of averaging data, refer to Figure 19. From this, it can be seen that the two methods produce different results. However, during the course of this research, both methods were found to be valid as long as the same method was applied within one graph.

${ }^{39} \sigma$ is the standard deviation and indicates the 'spread' of the data. 
21 shows two distinct points where the lines intersect: once in early October and once in March.

As mentioned above, the ability of paper (and other materials) to absorb and desorb excess moisture and therefore act as an environmental buffer has been described previously. The phenomena described here confirm this buffering capacity. As paper typically absorbs moisture more readily than it desorbs, moisture is given off to the surrounding environment after the ambient $\mathrm{RH}$ conditions have dropped. Thus, during the warmer months, the books acted as a 'moisture reservoir' within their surrounding environment. This will be further explained below.

The temperature within the shelves generally follows the ambient temperature very closely. The shelves tend to be somewhat cooler than the ambient temperature $\left(c .2^{\circ} \mathrm{C}\right)$, which again can be attributed to the thermal mass of the outer walls adjacent to the bookshelves.

\section{Dummy books}

The nature of this on-site experiment did not allow for measurement of the actual moisture content of paper. Instead, precision-calibrated data loggers were fitted inside the two dummy books, measuring equilibrium relative humidity and expressing the partial moisture vapour pressure generated by paper in a closed system (for example, stack). In other words, it measures the portion of water that is readily responsive to environmental changes. This technique is widely applied in the paper industry using sword hygrometers (Brandon 1981; Greaves 1985).

Looking at the RH data of the two dummy books, one can see that both books needed roughly five weeks to adapt to their surrounding conditions (Figure 23). Once they had equilibrated, they reacted in much the same way, indicating that different paper types, as well as the different book sizes, do not influence the overall interaction with humidity in the air. It is generally agreed upon that the rate of moisture uptake depends not so much on the size and volume of the book, but on 
the exposed surface area. As both books were shelved within a row of books, the exposed surface areas of both books were fairly similar.

Conditions in the books proved to be similar to their immediate surroundings (i.e. the fully packed shelf). Measured data revealed the $\mathrm{RH}$ to be above $65 \%$ over the entire observed time once the two books had adapted. However, the magnitude of fluctuation was much smaller within the books as compared to the conditions within the shelf (Figure 24). These data therefore confirm a considerable amount of time to be necessary for paper to adapt to changes in humidity.

Di Pietro and Ligterink (1999) defined the half-time ${ }^{39}$ for the $\mathrm{RH}$ response of backboard-protected canvas paintings as:

$$
t_{1 / 2}=\ln 2 \frac{M \alpha}{P A P_{s a t}}
$$

where $M$ is the total mass of hygroscopic material, $\alpha$ is a mean desorption isotherm gradient for cellulosic material, $P$ is the permeance of the canvas, $A$ is the surface area of the canvas, and $P_{\text {sat }}$ is the saturation vapour pressure.

As discussed previously, the equilibrium moisture content (EMC) of a hygroscopic material, as a function of $\mathrm{RH}$, is defined by an isotherm. Both the adsorption and desorption isotherms are linear within the range of interest $(40-80 \%$, since this is considered to cover normal ambient conditions found in UK libraries and archives). Comparison of the desorption isotherms for a variety of different paper types reveals a great similarity, a fact reflected in the various gradients, $\alpha$ (Table 1).

\begin{tabular}{|l|l|}
\hline Paper type & $\alpha$ \\
\hline Mechanical printing paper & 0.1447 \\
Wall paper & 0.1471 \\
\hline
\end{tabular}

Table 1: Comparison of desorption isotherm gradients $(\alpha)$ for $\mathrm{RH}=40-80 \%$ for a variety of paper types

${ }^{30}$ The half-time is the time taken for the $\mathrm{RH}$ to reach half its initial value in decreasing $\mathrm{RH}$ conditions, or the time taken to reach the half-way point between initial and final RH values in increasing $\mathrm{RH}$. 


\begin{tabular}{|l|l|}
\hline Paper type & $\alpha$ \\
\hline Blotting paper & 0.1357 \\
Bible tissue & 0.1303 \\
Chart paper & 0.1364 \\
Wove paper & 0.1546 \\
Kraft paper & 0.1638 \\
MG Kraft paper & 0.1642 \\
MG W/S Kraft & 0.1374 \\
Manilla & 0.1657 \\
Index card & 0.1195 \\
Chipboard & 0.1298 \\
\hline Mean $\alpha( \pm \sigma)$ & $\mathbf{0 . 1 4 4 1} \pm \mathbf{1 0} \%$ \\
\hline
\end{tabular}

Table 1 (continued): Comparison of desorption isothem gradients $(\alpha)$ for $\mathrm{RH}=40$ $80 \%$ for a variety of paper types ${ }^{40}$

For any given system, assuming a mean $\alpha$ value, the half-time response should be proportional to the mass of hygroscopic material present (i.e. $t_{1 / 2} / M$ should be constant for any book on a given bookshelf). Figure 25a shows the different response rates of the small and big dummy books in reaching equilibrium with their new environment within the bookcase. The small book reaches equilibrium at a faster rate than the big book and consequently their half-times differ accordingly. The half-times can be determined empirically from the data (see Figure 25b). The observed relationship between the half-time and the total mass for each book is given in Table 2. The agreement between the two ratios $\left(t_{1 / 2} / \mathrm{M}\right)$ is well within the inherent error due to the assumption that $\alpha$ is the same for both paper types.

\begin{tabular}{|l|l|l|l|}
\hline Book & $\mathrm{t} 1 / 2$ (h) & $\boldsymbol{M}(\mathbf{g})$ & $\mathrm{t} 1 / 2 / \boldsymbol{M}$ \\
\hline Big book & 56 & 2,644 & 0.0212 \\
Small book & 27 & 1,223 & 0.0221 \\
\hline
\end{tabular}

Table 2: Empirical relationship between the half-time and mass of the dummy books 
The measured half-time responses for the big and small dummy books to adapt to changes in the RH are considerable (56 and $27 \mathrm{~h}$, respectively) and hence become irrelevant when changes in the local environment are on a much faster time scale.

In general, the $\mathrm{RH}$ inside the book fluctuated by approximately $\pm 3 \%$. This amount of fluctuation does not necessarily affect paper adversely, as, generally, it is the level of moisture content that has the potential to cause damage.

During the observed time, the $\mathrm{RH}$ conditions within the book rose steadily until the middle of April, when the conditions slowly started to decline again. Comparing the dummies with the shelf conditions it can be seen that, from the middle of winter on, the dummy books are damper than their surroundings. They remain damper until the end of the observed time (June 2002) (Figure 26). This phenomenon can not entirely be explained at this point. Possible reasons could be the remarkable moisture retention capacity of paper, or an unknown moisture source, such as e.g. condensation between the bookpress and the building wall and therefore high local $\mathrm{RH}$ behind the books, where no monitoring took place.

The RH conditions within the books drifted slightly apart from each other in early March. However, they are still less than 2\% different and the discrepancy can therefore not be called significant. It remains to be seen, whether or not the lines meet again or will react parallel to each other for the remaining time. At this point there are two possible explanations for this phenomenon. It could either be an instrumental error, where the calibration went slightly off during downloading of data (data had been downloaded on 4 March 2002; similar 'decalibration' in connection with downloading had previously been observed with this type of instrumentation). Or the conditions within the book did in deed drift apart. This question will be answered during the next phase of this research.

40 The desorption isotherm gradient ( $\alpha$ ) for a variety of paper types has been derived from data kindly provided by the Printing Industry Research Association International (PIRA) in Crook and Bennett (1962). 
As explained above, it was impossible to measure moisture content of paper within the set-up of this project. Most figures shown here therefore relate to $\mathrm{RH}$ measurements. With respect to the measured relative humidity within the dummy books, it is, however, interesting to compare the absolute humidities $(\mathrm{AH})$. $\mathrm{AH}$ data for the dummy books show similar effects with regard to the splitting $\mathrm{RH}$ lines in early March (Figure 27). However, when comparing $\mathrm{RH}$ data of one of the dummies and its shelf environment with the equivalent $\mathrm{AH}$ data, it can be seen that the measured $\mathrm{AH}$ in both locations resulted in the same line, whereas the RH of shelf and dummy are different (Figure 28). This clearly emphasises the influence of temperature in the determination of $\mathrm{RH}$. The temperature difference between book and shelf may have been sufficient to result in differing $\mathrm{RH}$ data, since $\mathrm{RH}$ decreases with rising temperatures and increases with falling temperatures.

At the outset of the project, it was expected that the conditions within the shelves would be driven by the ambient conditions in the room. Data show, however, that the conditions within the shelves are much closer in line to the conditions within the dummy books (Figure 29). This raised the question of how ambient, shelf and book conditions are related. Taking the months of August and September 2001 as an example, it is obvious that the conditions within the fully packed shelf follow those of the dummy. Thus, the environmental conditions within this confined space are dictated by the paper rather than the books reacting to their immediate environment (Figure 30 ). This conforms with previous findings of other researchers stating that, within a reasonably tight enclosure the organic (and hygroscopic) material governs the inner $\mathrm{RH}$ by exchanging moisture with the micro-environment. Because these moisture changes are rather small compared to the total moisture content of the material, the latter can be dominant in controlling the micro-environment. The buffering of humidity changes depends in part on the characteristics of the enclosure (e.g. materials, level of air tightness, its situation within the room), and in part on the moisture capacity of the enclosed material (Bigourdan and Reilly 1997).

Further illustrations were prepared in order to determine to which condition exactly the books react. Since the ambient RH follows the external RH directly, external conditions were not considered. As has been demonstrated previously, however, the 
ambient RH seemed to be rather different from any of the inner humidities measured, i.e. shelves and dummies, which is why the observed phenomenon must be related to ambient temperature. In fact, plotting the RH conditions of the fully packed shelf and one of the dummies against the ambient temperature demonstrated that, the RH within the dummy follows the ambient temperature fairly closely, whereas the shelf $\mathrm{RH}$, although following the same trend, shows a certain time lag. In other words, as the ambient temperature rises, the $\mathrm{RH}$ within the book rises, and falling temperatures cause a decrease of RH within the book (Figure 31).

This fact has very important implications in practice and has been described by previous researchers as 'positive feedback effect' (Christoffersen 1995; Padfield 1998). The RH of the fully packed shelf rises slightly when the temperature is increased, because the exchangeable water within the books is vastly greater than the amount of moisture the surrounding air is able to hold. As the temperature rises, the paper with its nearly constant moisture content of ca. $6 \%$ forces the surrounding air to a higher $\mathrm{RH}$ value. In doing so, the books have released a negligible amount of moisture. Yet, this released moisture has a significant impact on the RH of the shelf, since the ability of air to hold water is extremely small compared to the moisture retention capacity of paper.

Very recently, Curteis reported similar observations within historic churches, therefore validating that observations made within confined spaces can also be relevant on a larger scale (i.e. a building) (Curteis 2002).

Furthermore, it was attempted to determine the amount of time the books needed to adapt to their immediate environment. As has been stated above, the mechanisms with respect to $\mathrm{RH}$ equilibration between books and the surrounding air are fairly complex. While certain short term equilibration can be observed, on the whole, significant changes in $\mathrm{RH}$ tend to be seasonal.

Temperature equilibration, however, happens much more readily. The temperature within the books follows the ambient temperature within a few hours (Figures 32a, $32 \mathrm{~b}$ and $32 \mathrm{c}$ ). Three figures were prepared in order to determine differences 
between winter and summer conditions. In these, random weeks during July, March and December were chosen. It becomes apparent that, the higher the ambient temperature the more similar are the books in temperature. While there is roughly a $2^{\circ} \mathrm{C}$ difference between book and room temperature in winter, there is hardly any in July.

From these graphs it can also be seen that, in terms of temperature, the book size does make a difference. The rag paper dummy, which is the bigger book, follows exactly the same temperature equilibration as the smaller book, but is two to four hours behind. Since the data logger placed within the bigger book is buried farther inside, and therefore away from the surface, the logger and consequently the centre of the book, takes slightly longer to equilibrate with outside conditions.

\subsubsection{Brontë Parsonage Museum}

The Brontë Parsonage Museum at Haworth has much more stable conditions compared to the Guildhall in Leicester, as can be seen from Figure $33^{41}$. The comparatively stable $\mathrm{RH}$ condition within the strongroom also results in a fairly stable $\mathrm{RH}$ within the glass-fronted bookshelf. In addition, this figure shows the overall RH within the room to be higher at the Brontë Parsonage Museum than at the Guildhall.

Comparing the shelf conditions at the two different sites in more detail, it is obvious that, while conditions at the Bronte fluctuate much less on the whole, they are about $10 \%$ higher than at the Guildhall, i.e. $75 \%$ and more (Figure 34 ). As official data from the Met Office confirm, conditions in West Yorkshire are on average damper than in Leicestershire throughout the year (Figures 16a and 16b). In addition, two more factors need to be considered when interpreting these data. Firstly, similar phenomena as observed in the Guildhall may be occurring, i.e. the moisture content of the books within the glass-fronted shelf acts as a moisture reservoir and pushes the surrounding RH to higher levels. Secondly, the metal bookshelf, backing onto an

41 The data logger at the Bronte Parsonage Museum ran out of memory during the month of April 2002. 
outside wall, experiences lower temperatures. Although the temperature gradient may not be significant on the whole, it is enough to raise the $\mathrm{RH}$ within the shelf by 5$10 \%$ (Figure 35).

The Brontë Parsonage Museum was chosen as a case study for its very stable conditions throughout the year. However, staff had noticed a severe mould outbreak in October 2000. The in-depth monitoring of environmental conditions within the strongroom made it possible to explain the infestation. While the measured conditions within the room seemed stable and the level of humidity fairly acceptable throughout the year, the micro-climate within the shelf was conducive for mould growth, in particular with the additional lack of ventilation due to the glass-fronted book case.

There are several possible solutions for avoiding future mould outbreak:

- to avoid stagnant air within shelves by exchanging closed shelves for open shelves,

- to aid air movement by employing a small fan, and/or

- to reduce humidity with the help of a local dehumidifier.

The latter solution would be the preferred one. However, it is only advisable, if staff is able to check and maintain the performance of a dehumidification device. This would include emptying the water-collecting unit regularly and without failure to avoid local flooding within the room. Ideally, such a unit could be linked to a nearby drain to avoid this problem. In addition, an eye must be kept on the internal temperature, as the strongroom is very small, and a dehumidification unit could raise the temperature within it, which is not desirable with a view to the longevity of the material.

The library at the Guildhall Museum in Leicester, although experiencing large fluctuations, both in temperature and $\mathrm{RH}$, is in very good condition to date. Environmental monitoring made clear that the original Victorian bookpresses, though not ideal, stabilise the immediate environment significantly. No member of staff can remember any problems with respect to either mould or pest infestations. 
Because the Guildhall is of special architectural and historic interest, any changes to the building fabric that affect the character or appearance of the building would require specific approval. However, the large fluctuation of environmental conditions could easily be mitigated, e.g. if staff and visitors kept the external door to the library closed.

While hygroscopic material is able to buffer physical responses of other material in its surroundings, these data have shown that in a climate such as England, the overall $\mathrm{RH}$ within the dummy and therefore its moisture content is almost constantly raised. It is this, not necessarily the amount of fluctuation itself, which will shorten the life-expectancy of the books. In addition, there is a potential mould problem if the temperature was to rise for prolonged periods of time at high relative humidities, as well as mechanical problems while handling items.

However, many libraries in the United Kingdom are, like the Guildhall library in . Leicester, 'passive', rather than actively used libraries and issues of handling therefore do not often arise. 


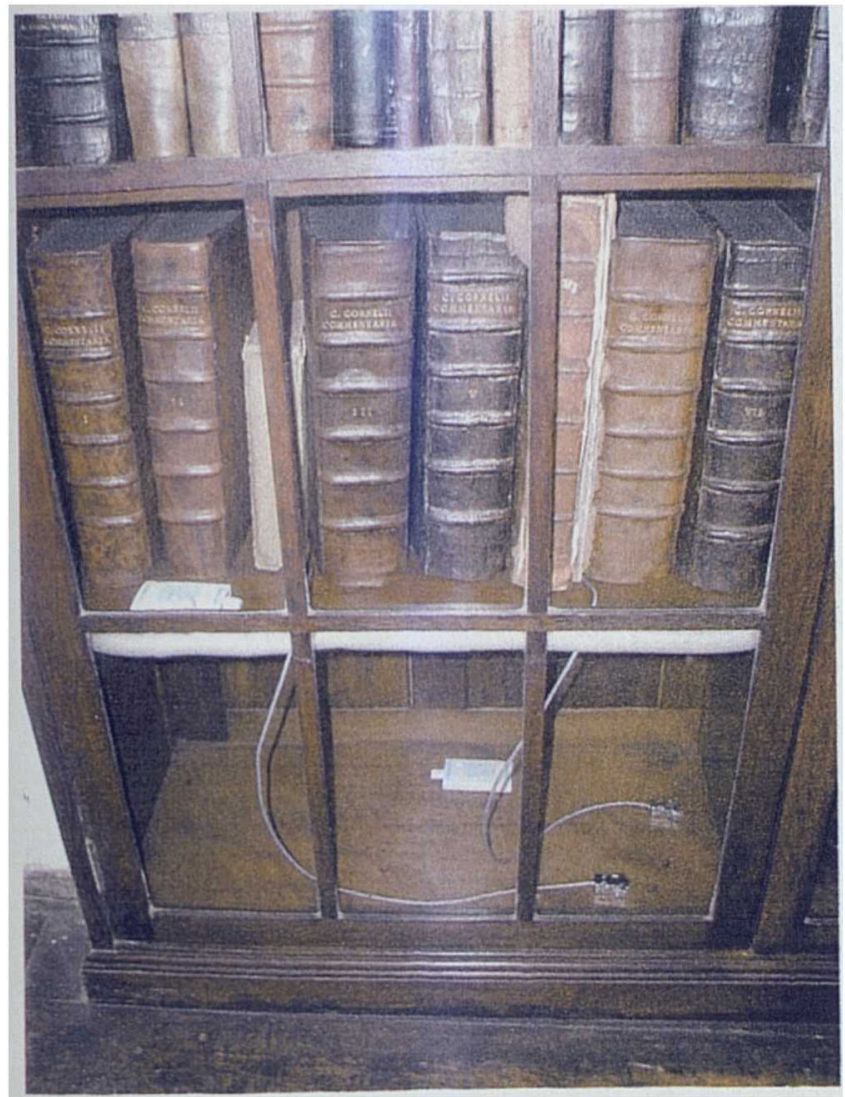

1: lignin-containing dummy

2: rag paper dummy

3: data logger in fully packed shelf

4: data logger in empty shelf

5: poly-ethylene foam gasket for isolation of shelf micro-

environments

Figure 15a: Experimental set-up at Guildhall Museum

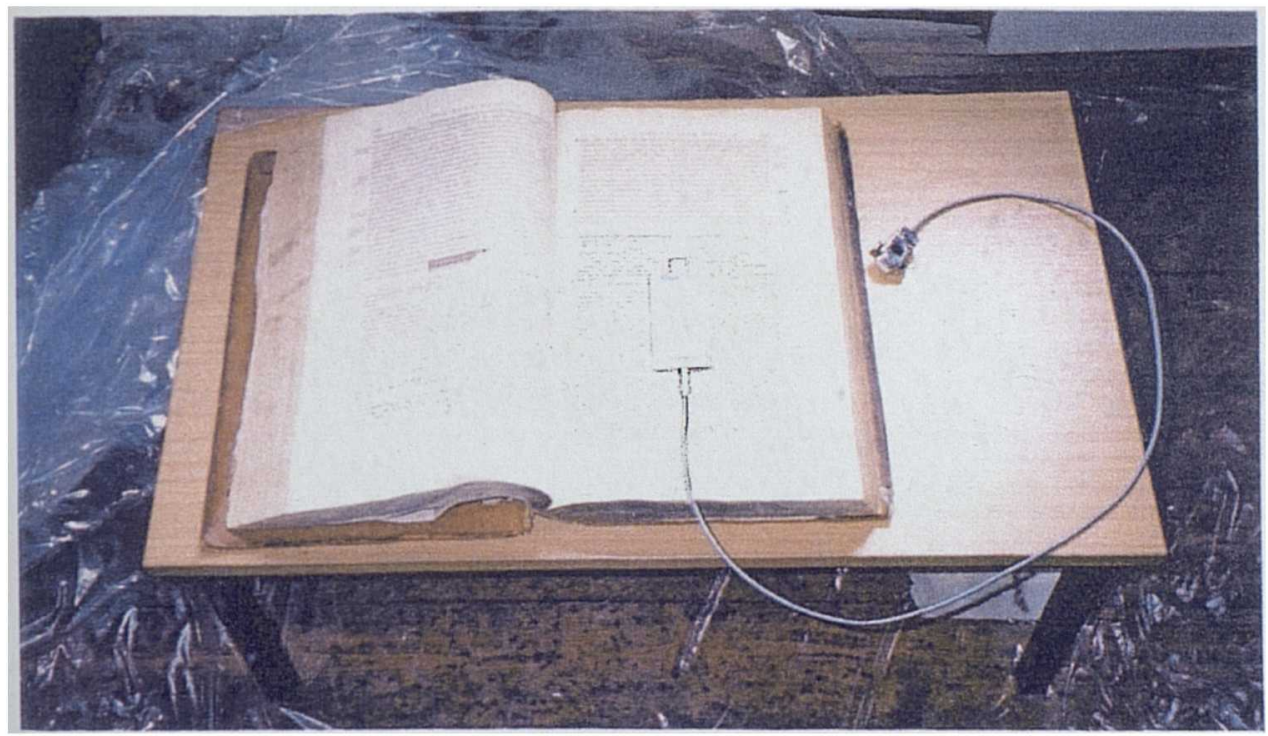

Figure 15b: Position of datalogger within dummy book 

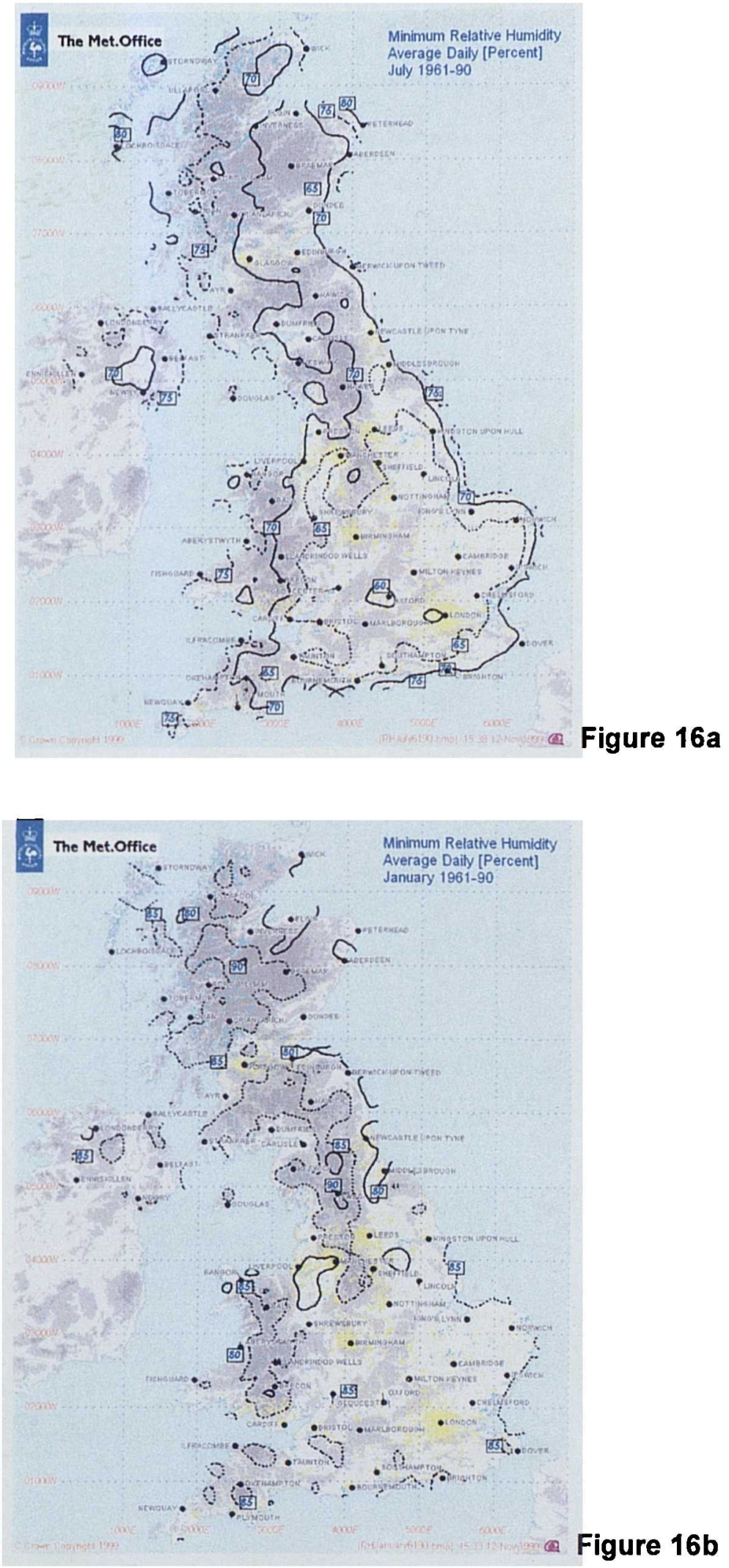


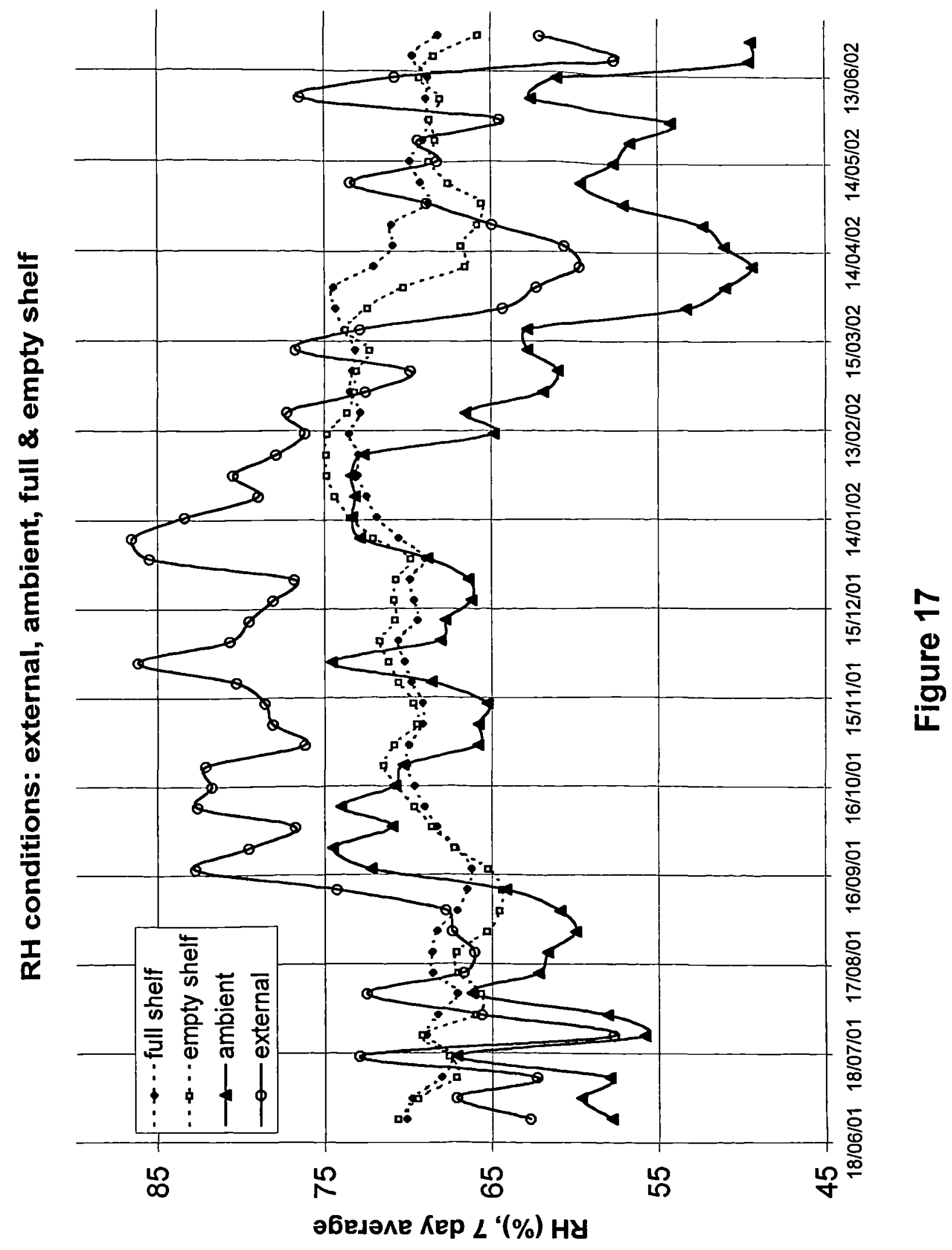




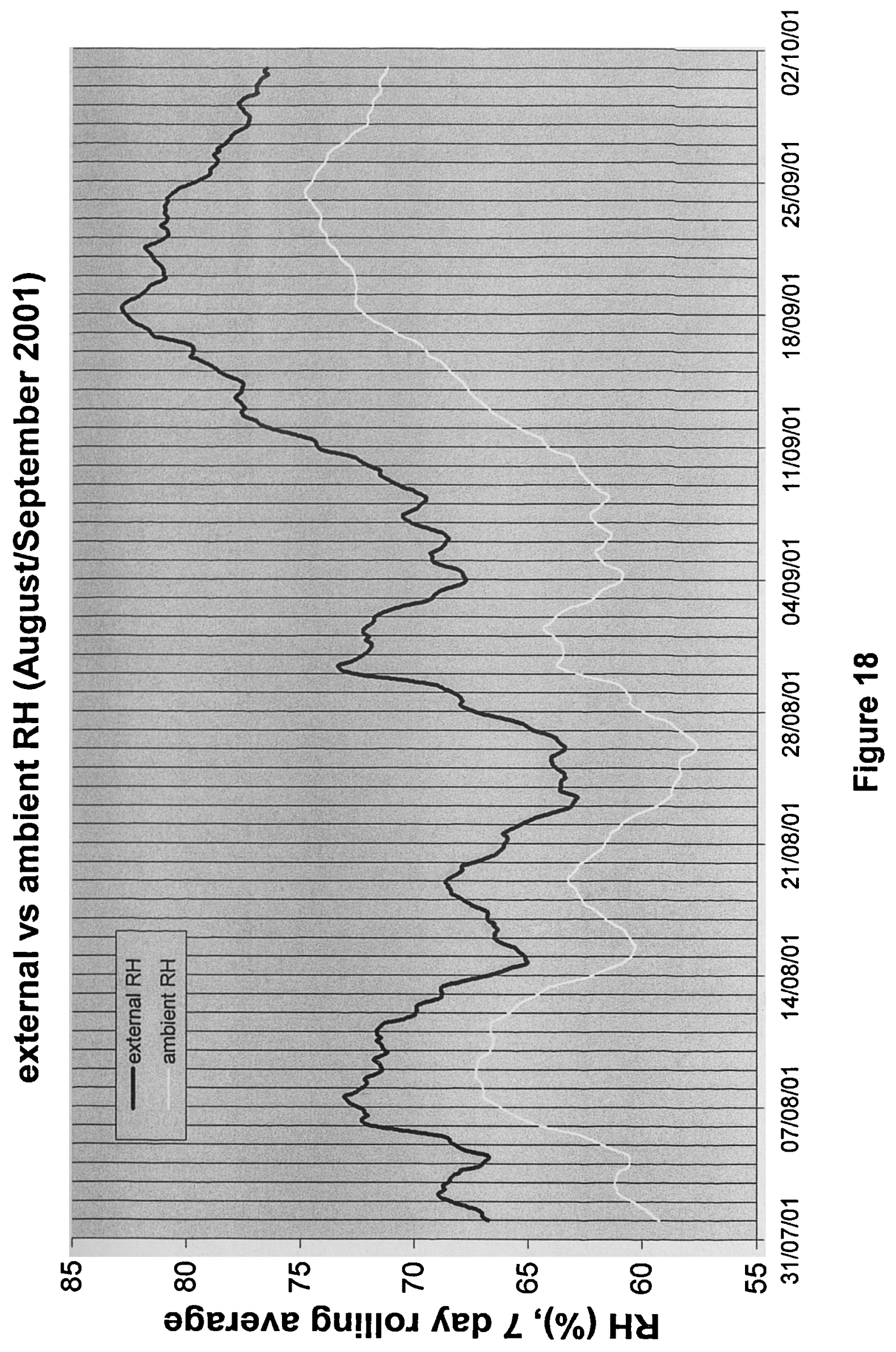




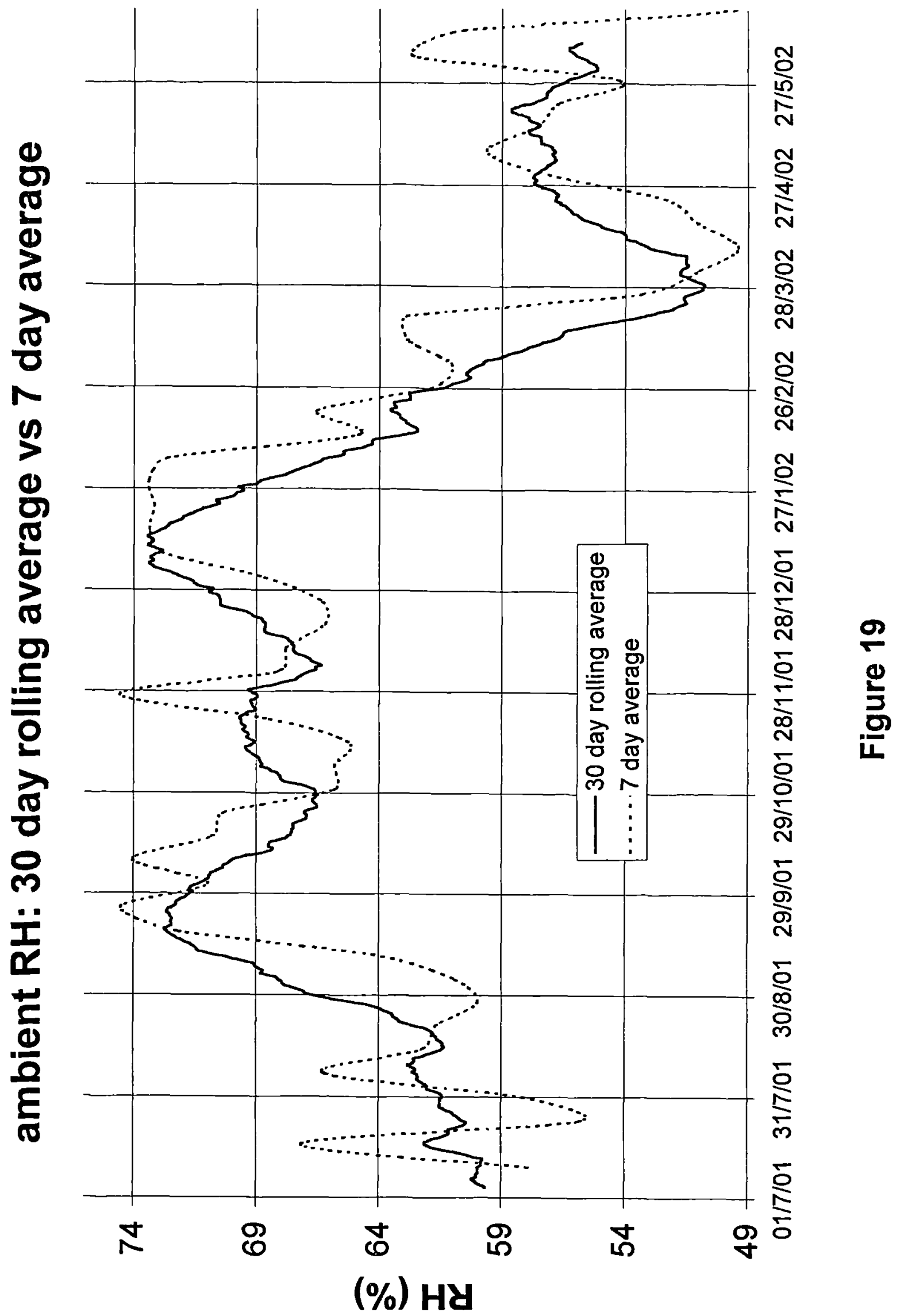




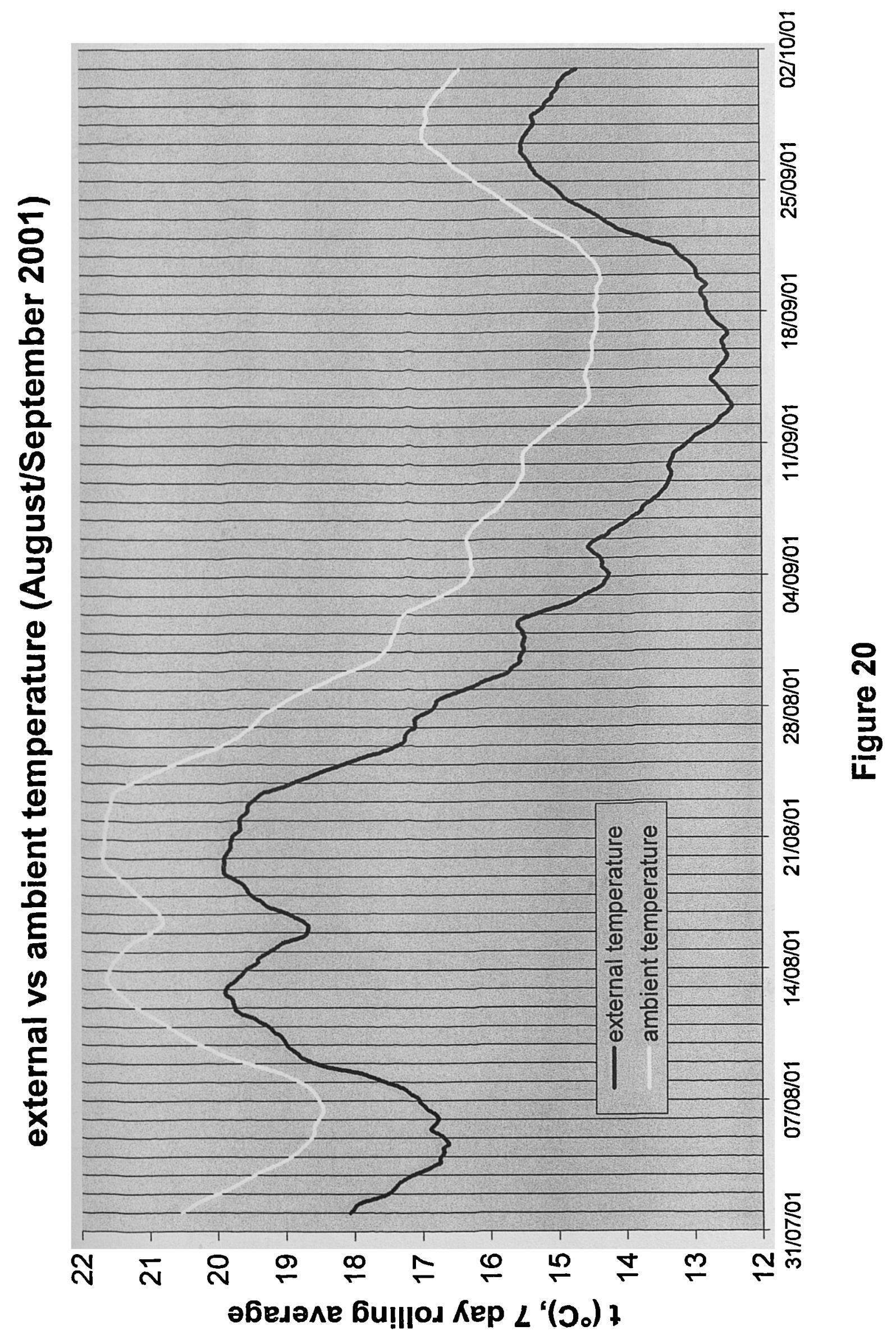




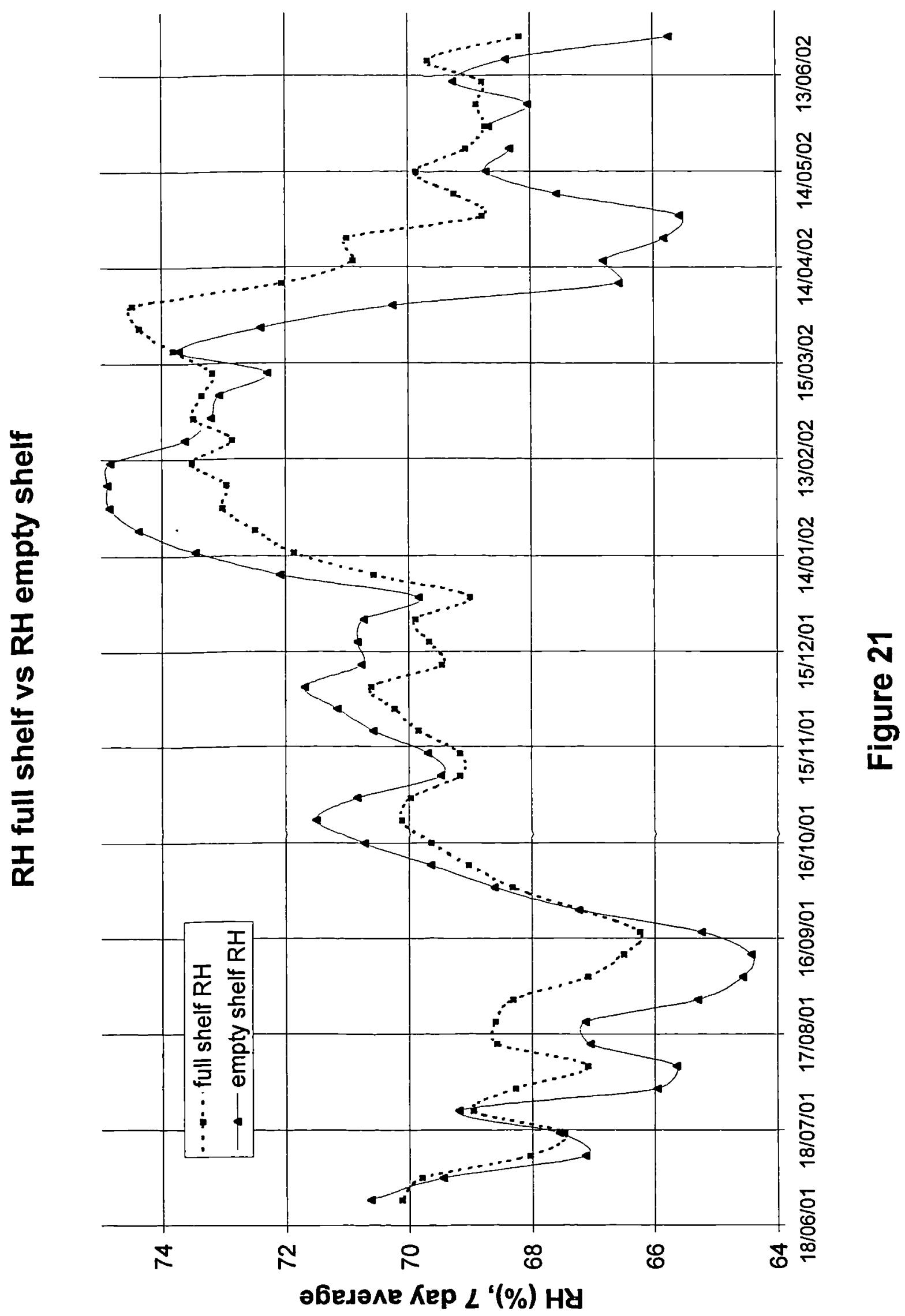




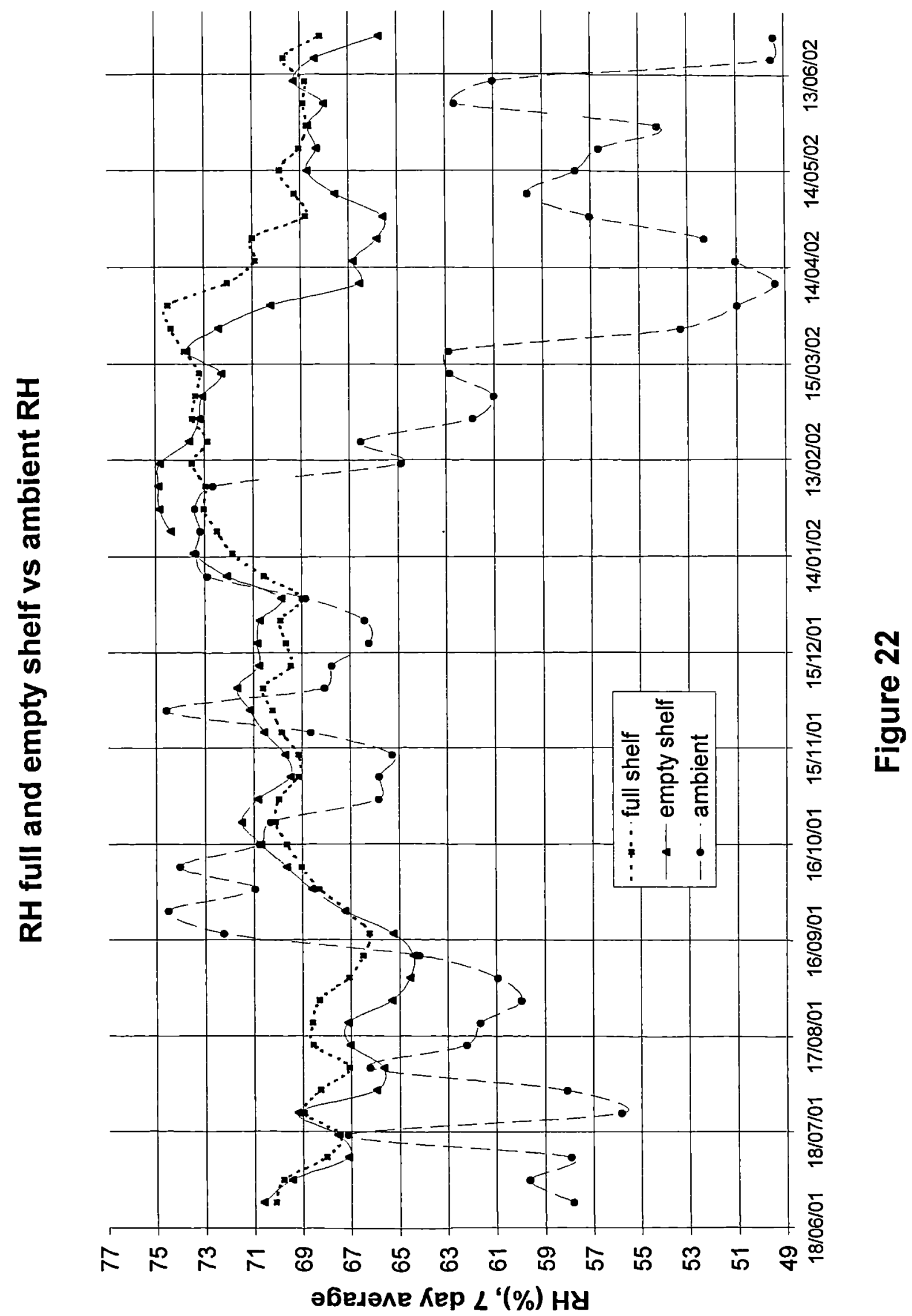




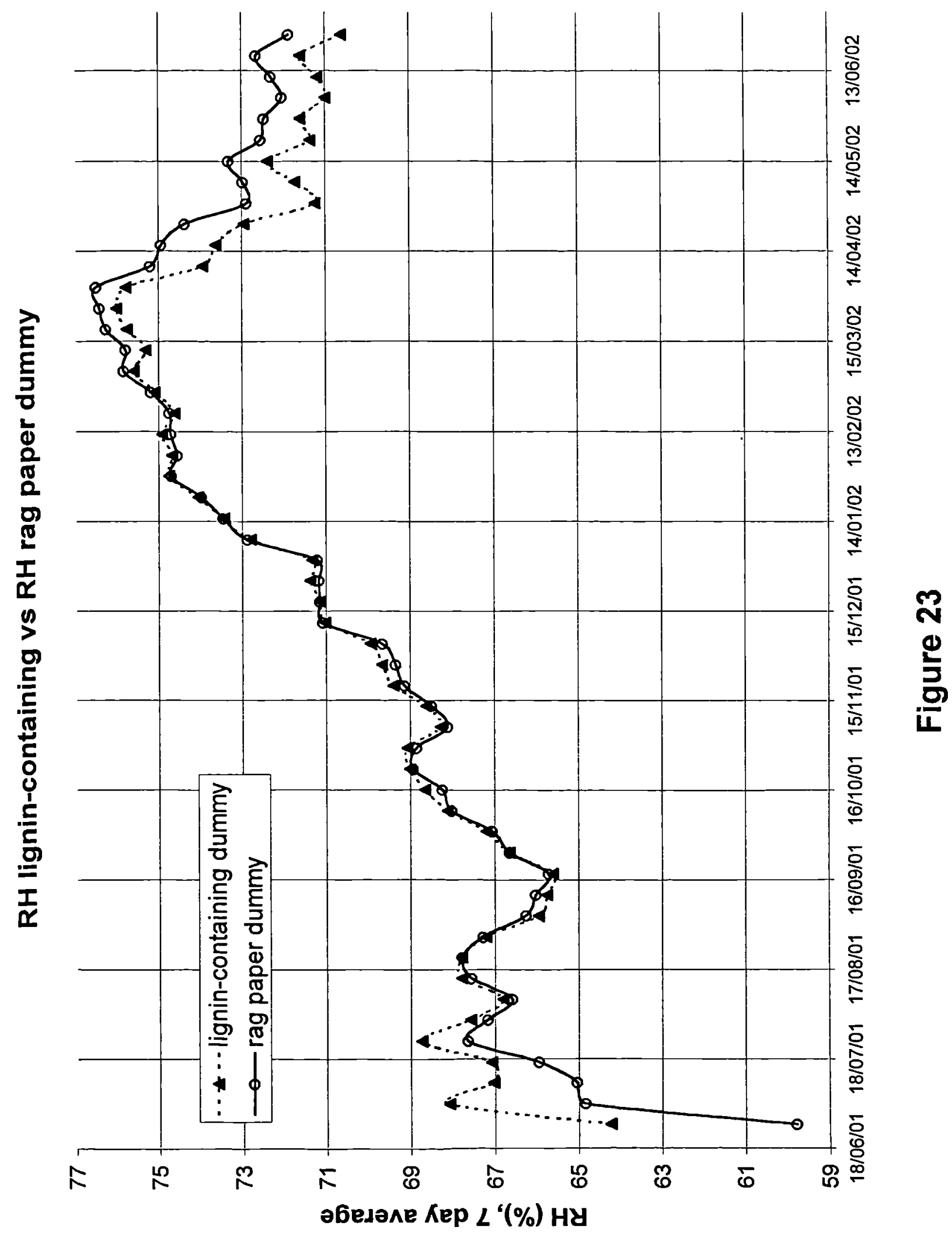




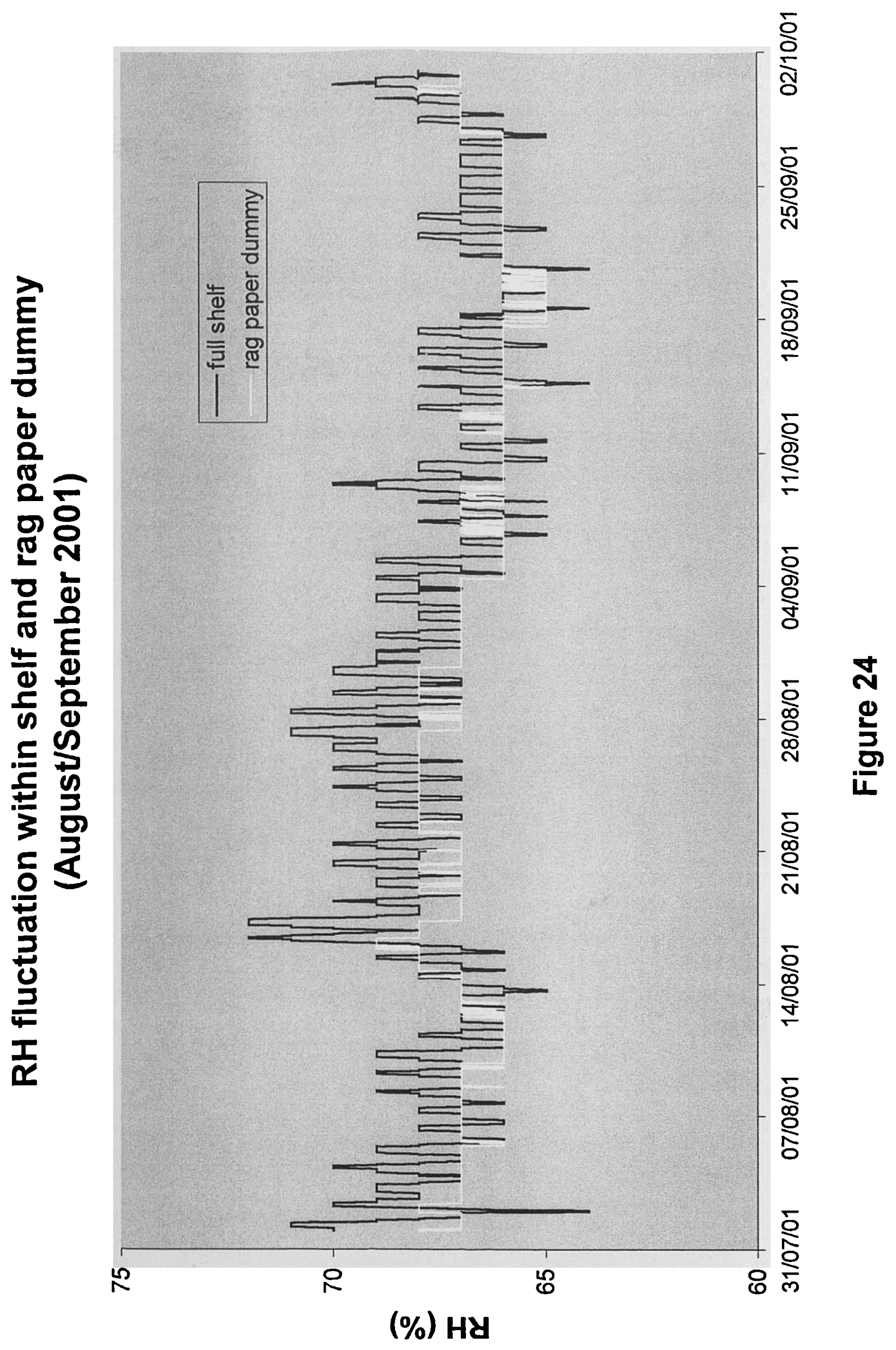


Determining the half-time for RH equilibration in the small and big book

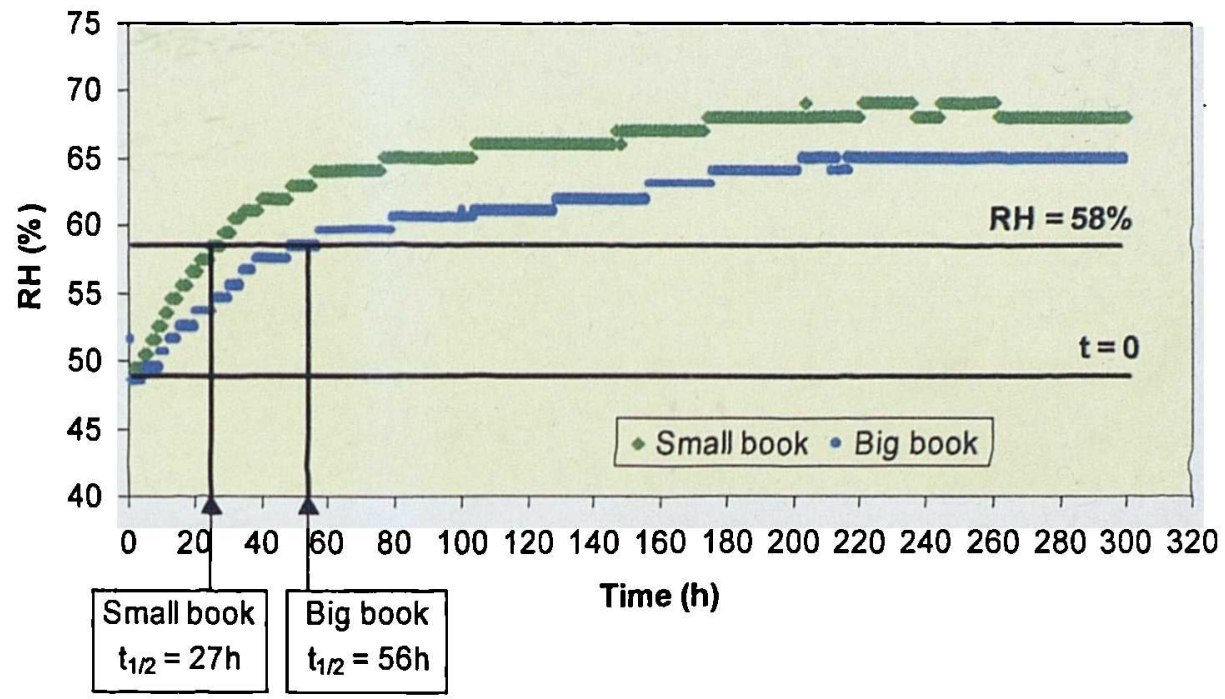

Figure 25a

Comparison between the RH equilibration of the small and big books within the bookcase at the Guildhall Library

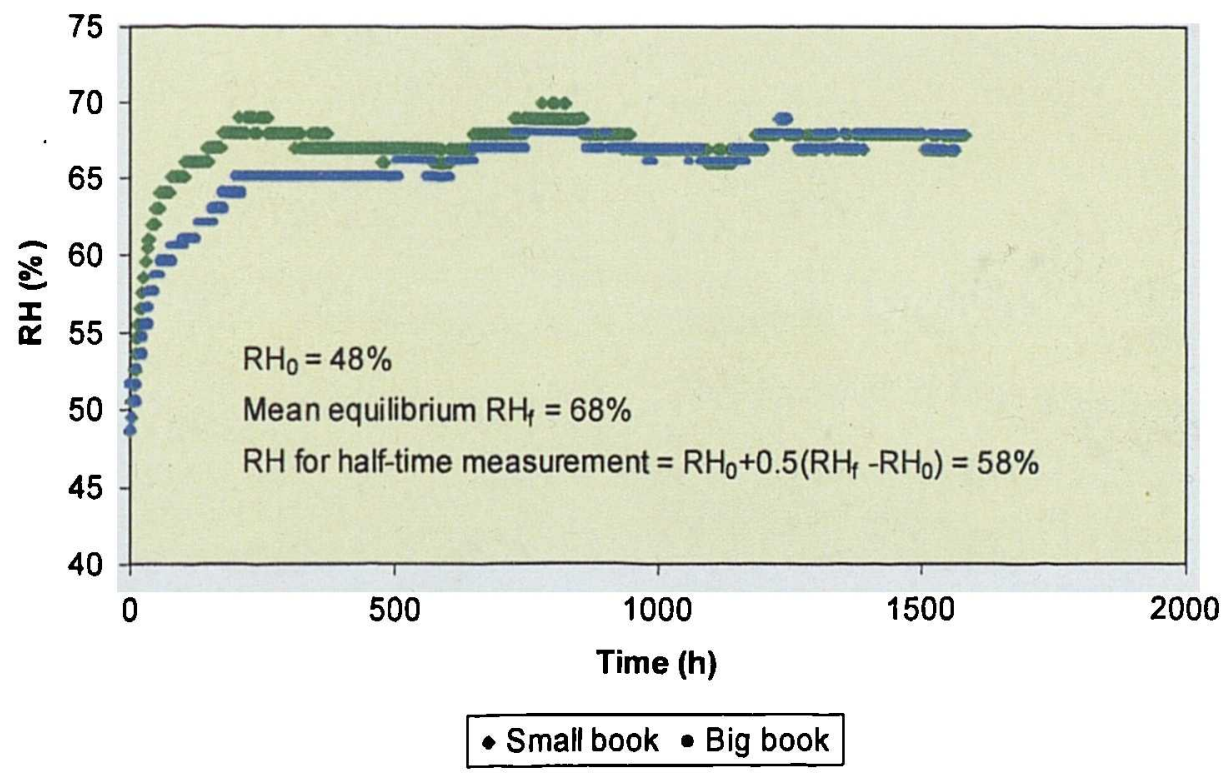

Figure 25b 


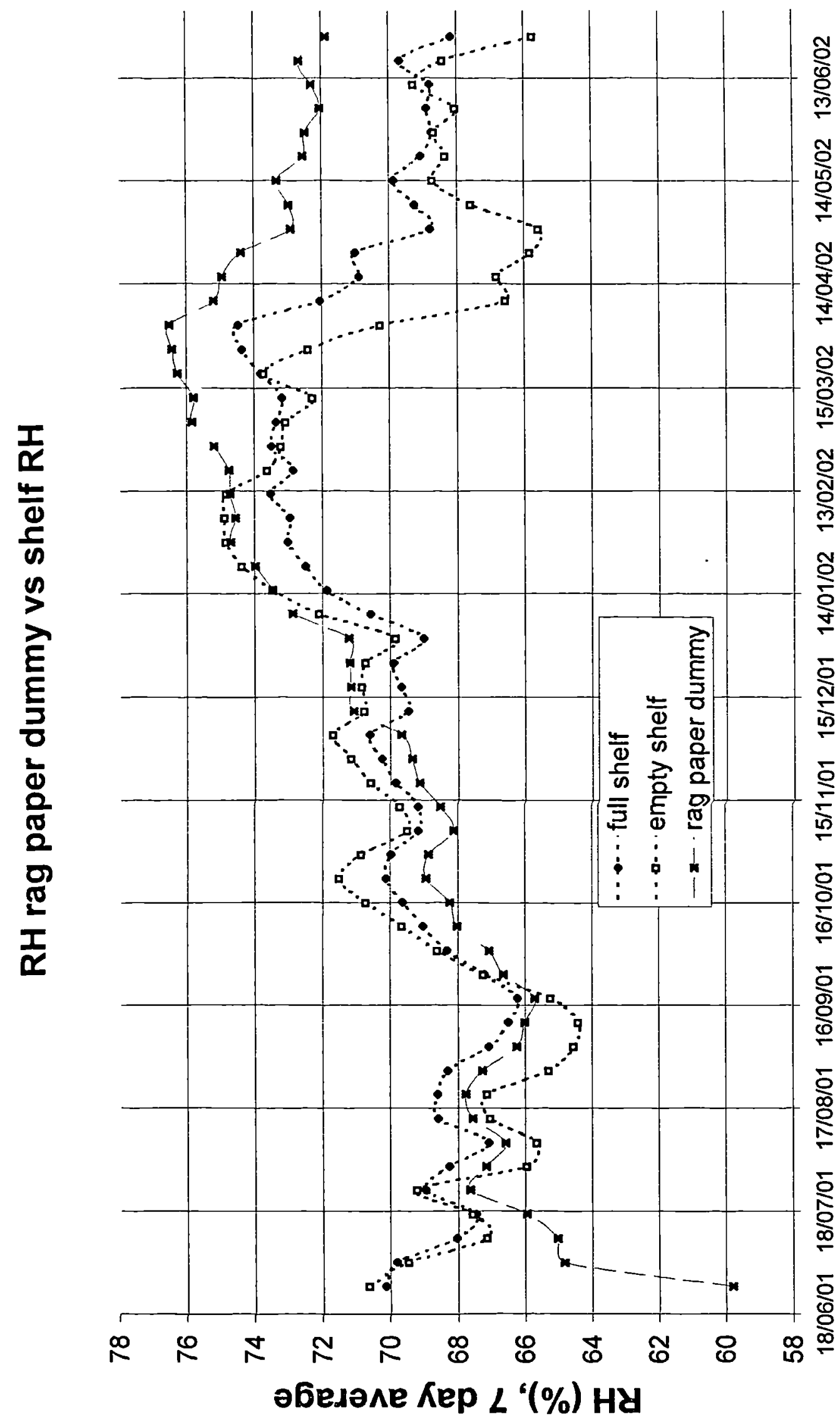

온 


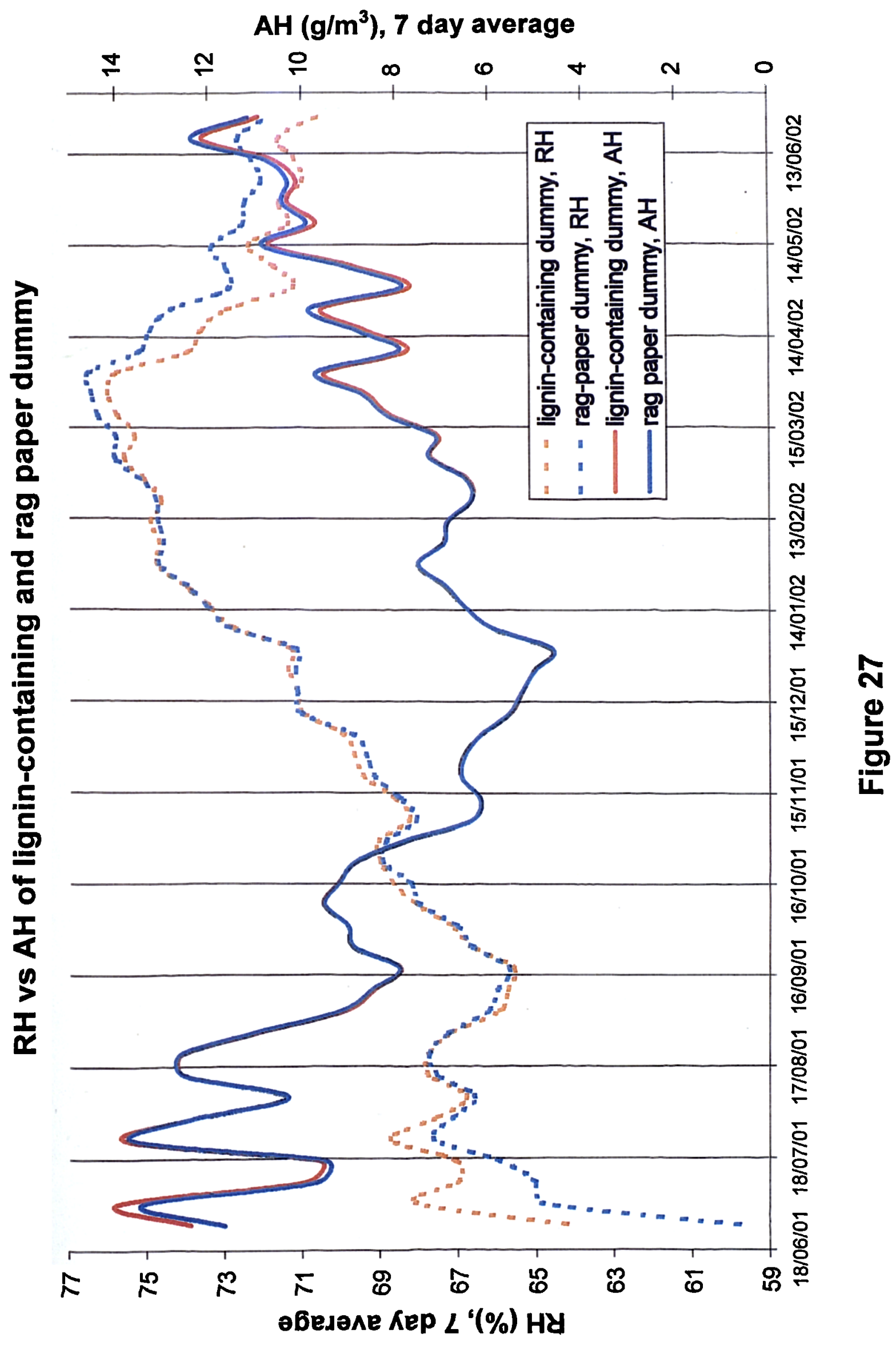




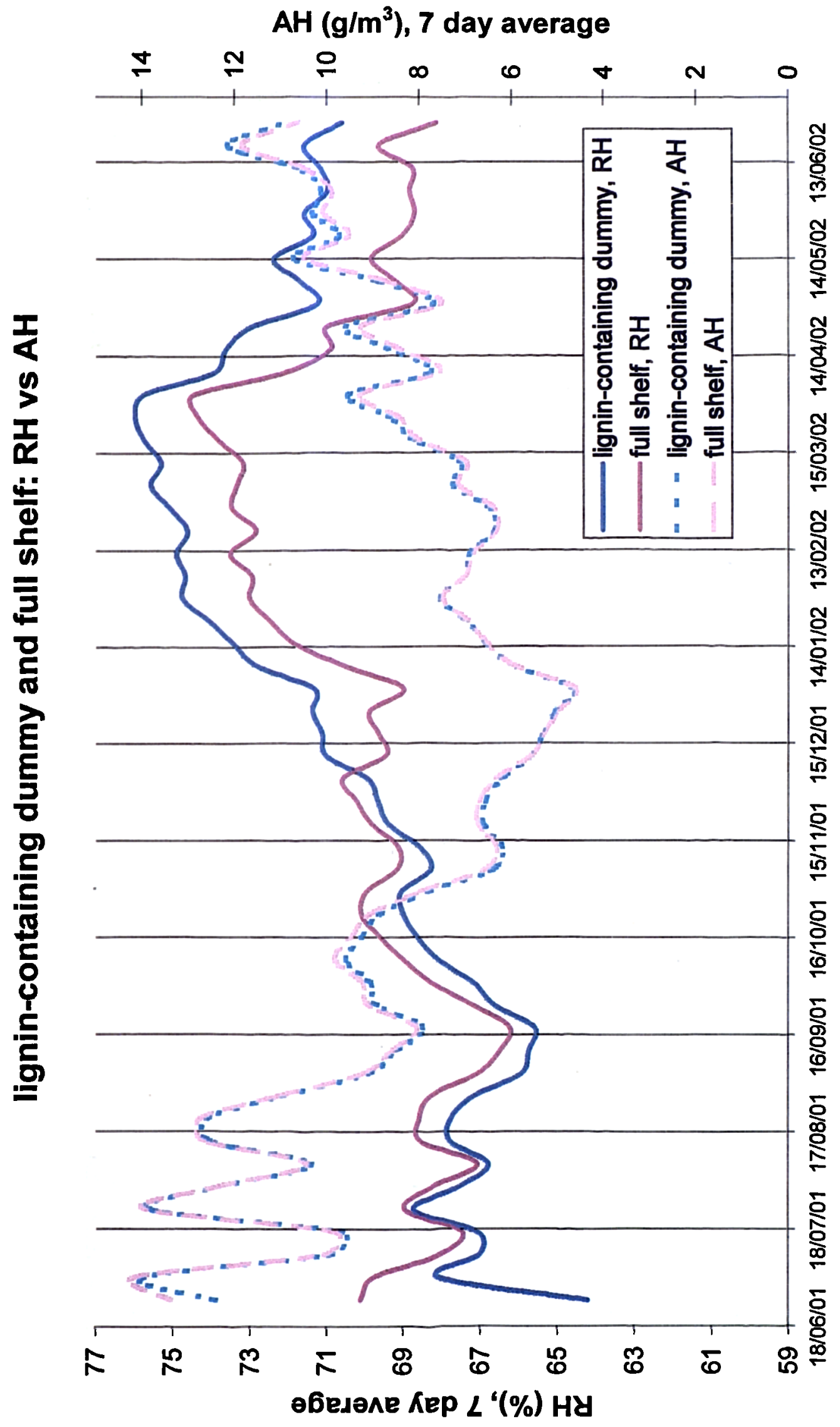

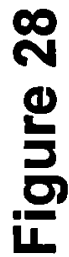




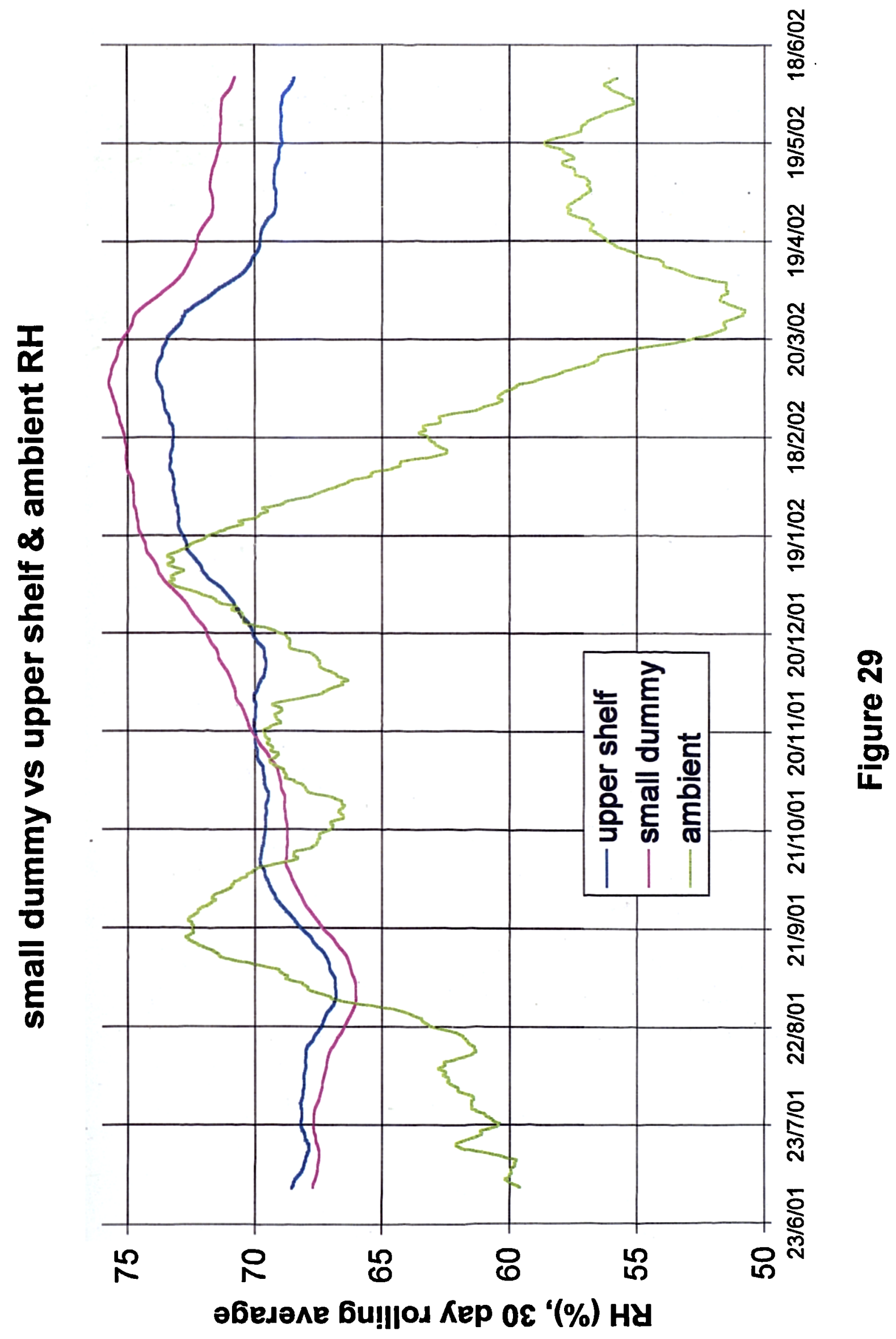




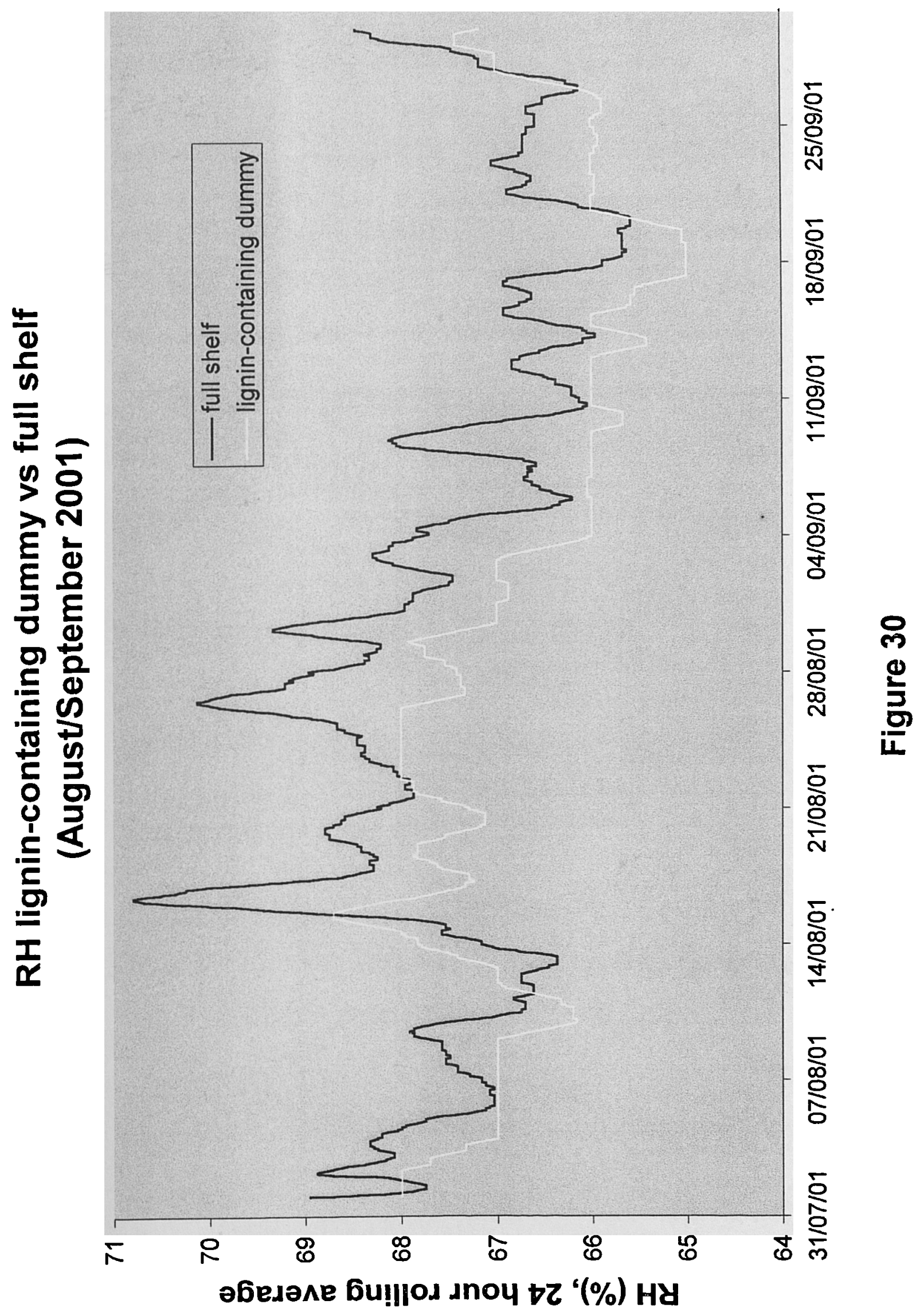


$\mathrm{t}\left({ }^{\circ} \mathrm{C}\right), 7$ day rolling average

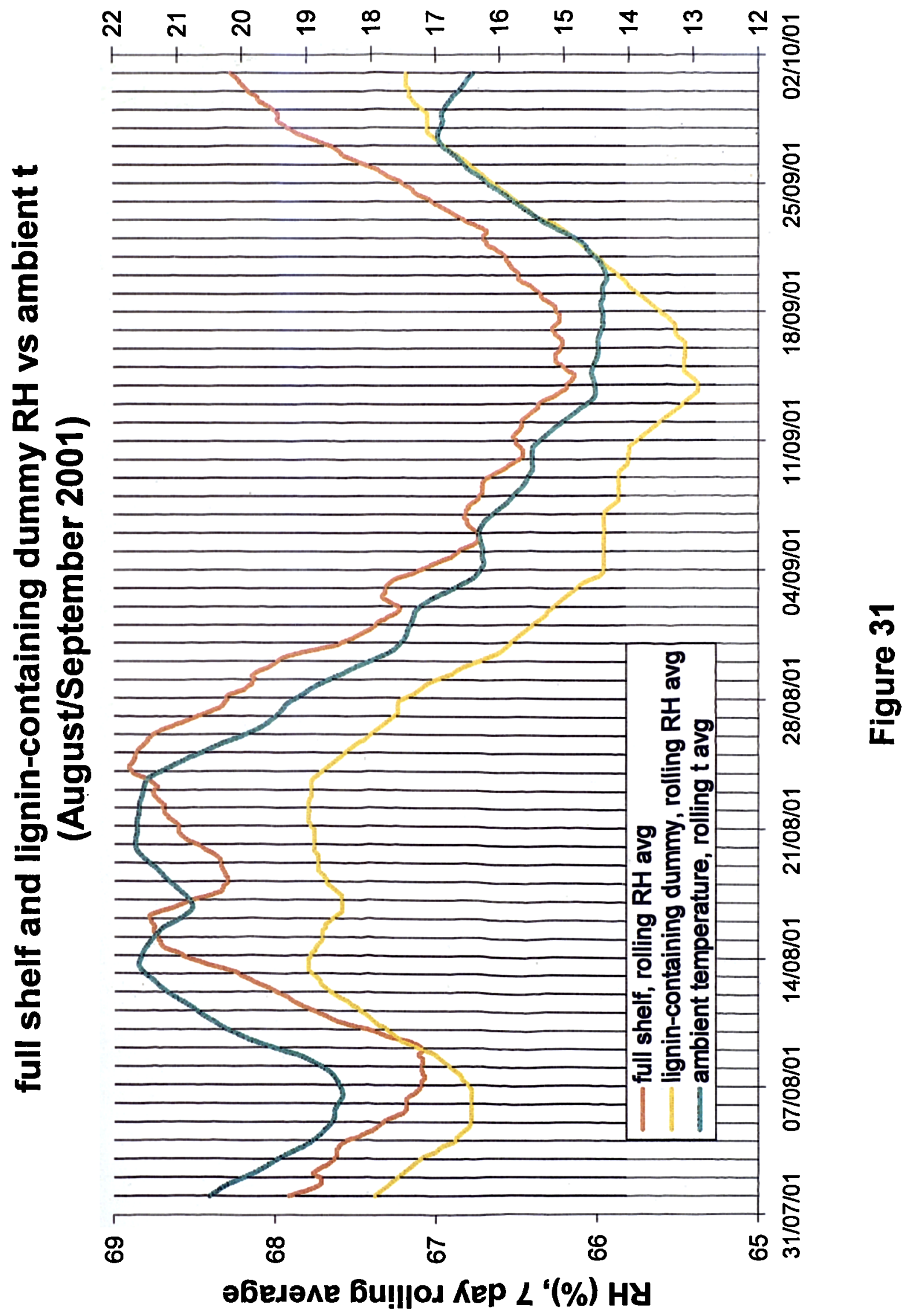




\section{$\mathrm{T}$ and $\mathrm{RH}$ of guild upshelf}

For the 12 Month Period Sunday Jul. 08, 2001 to Monday Jul. 08, 2002

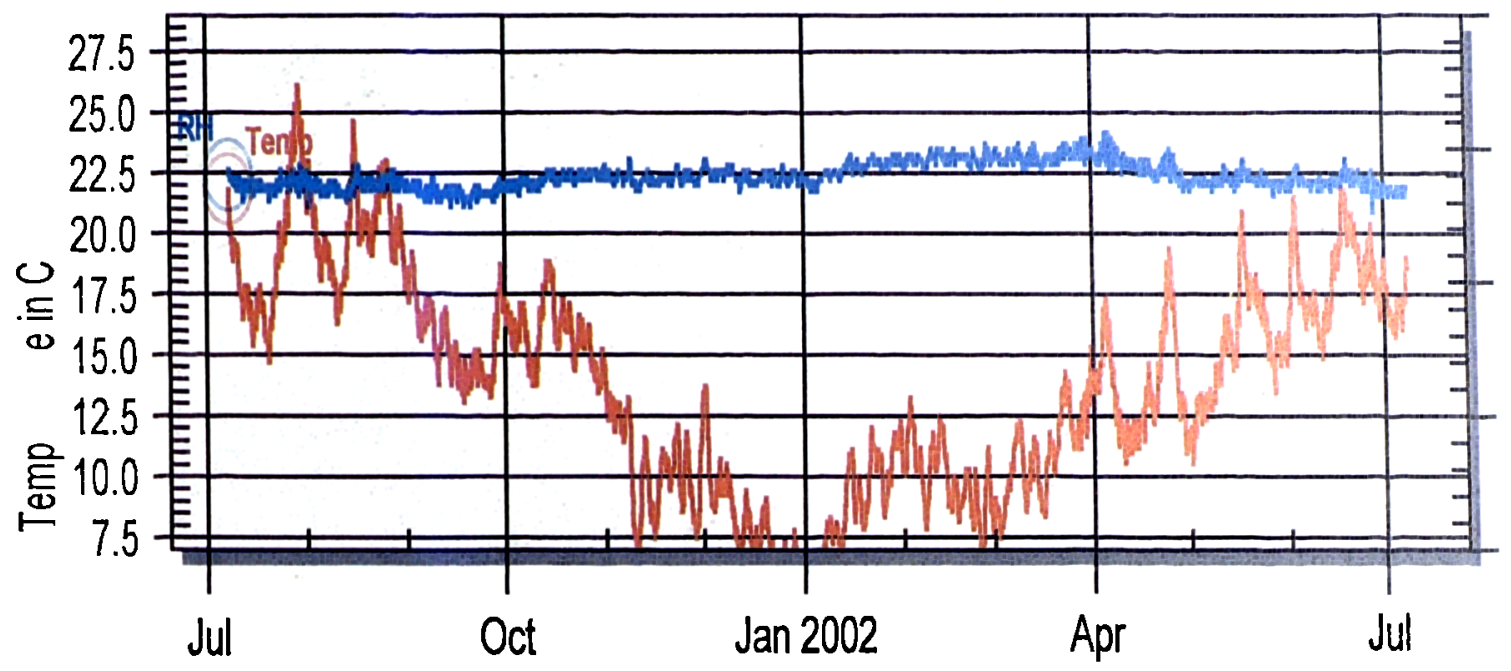

2001

PI and TWPI of guild_upshelf

TWPI for the 12 Month Period 08/07/01 to 08/07/02 = 49 Years

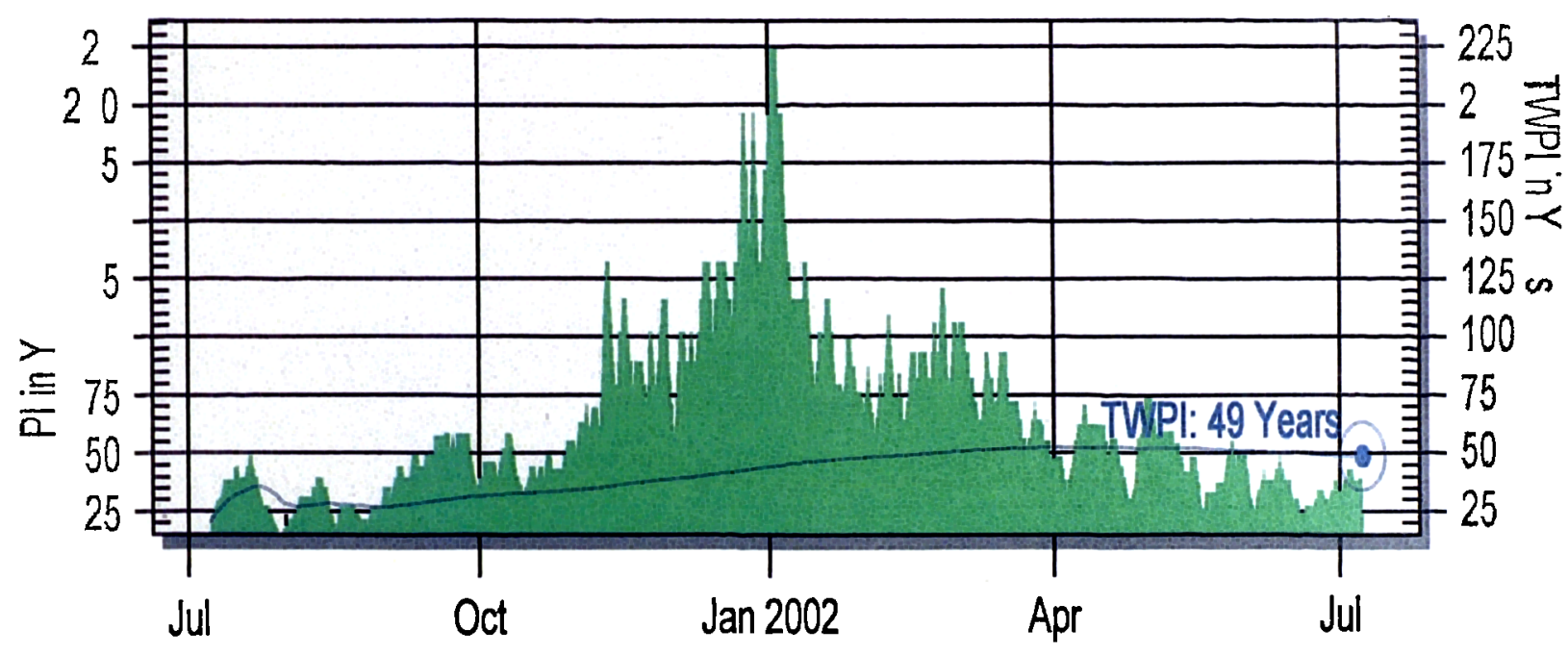

2001

Mold Risk Analysis of guild_upshelf

Maximum Mold Risk Factor for the 12 Month Period 08/07/01 to 08/07/02 $=0.36$

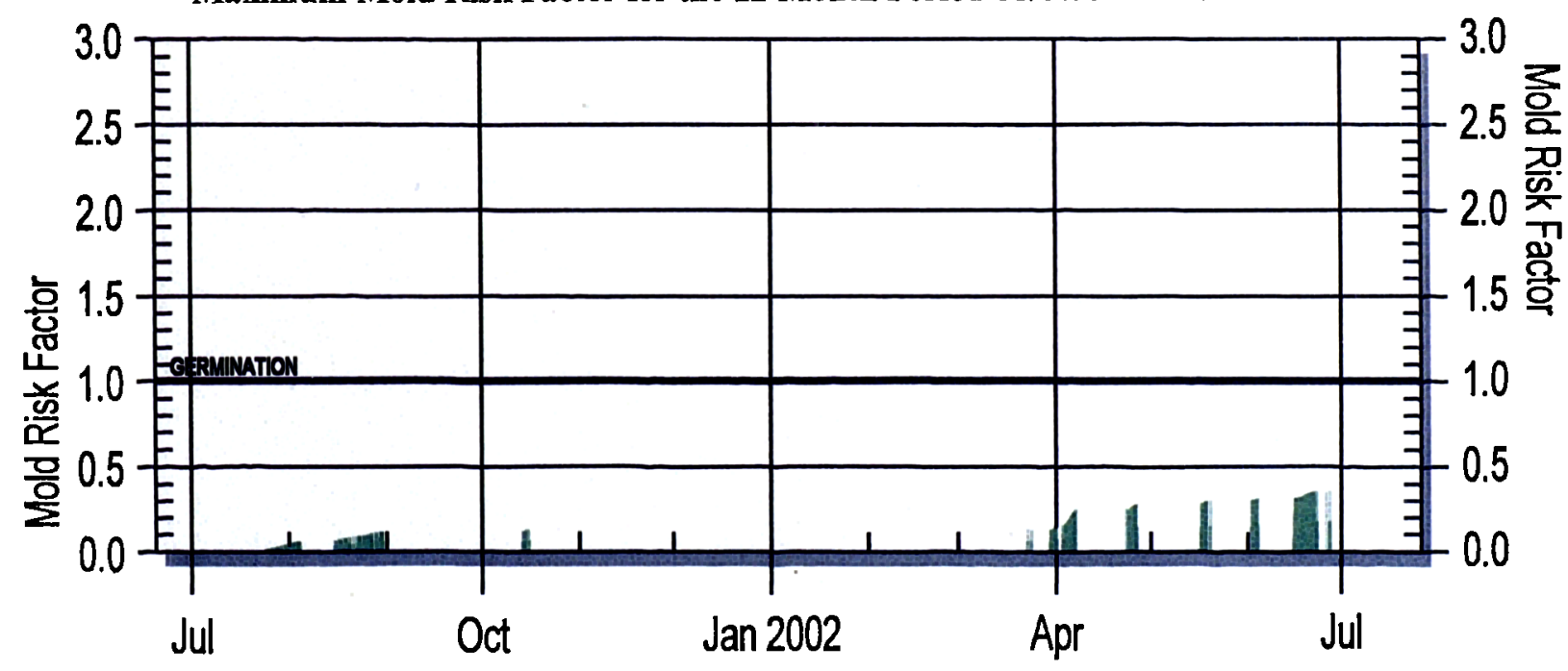




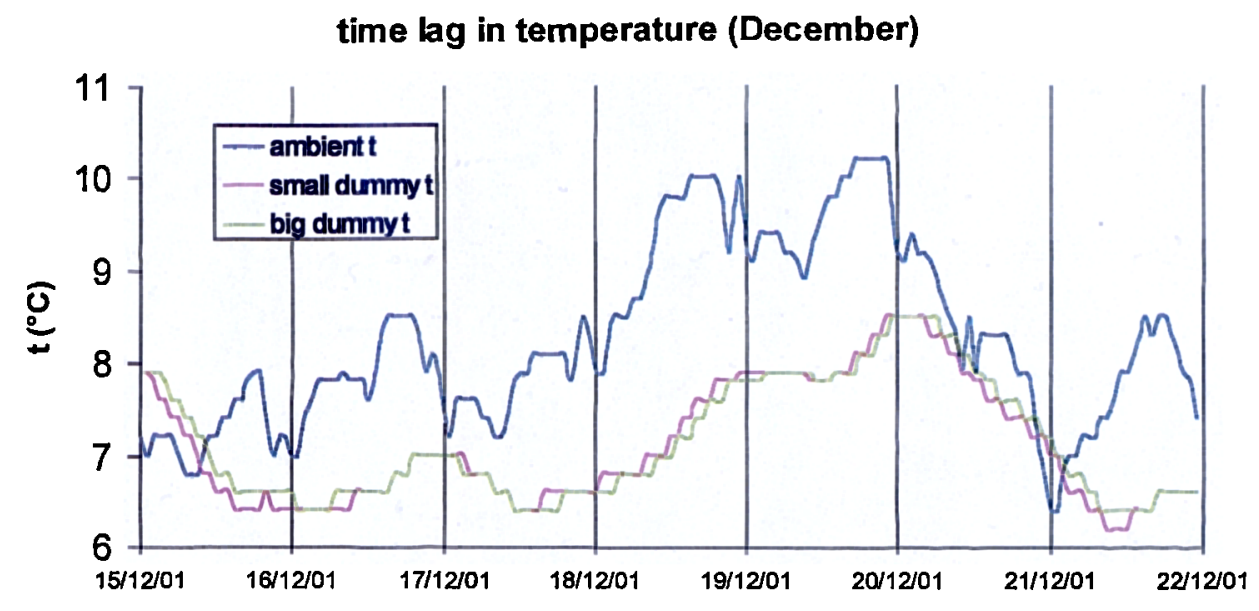

Figure 32a

time lag in temperature (March)

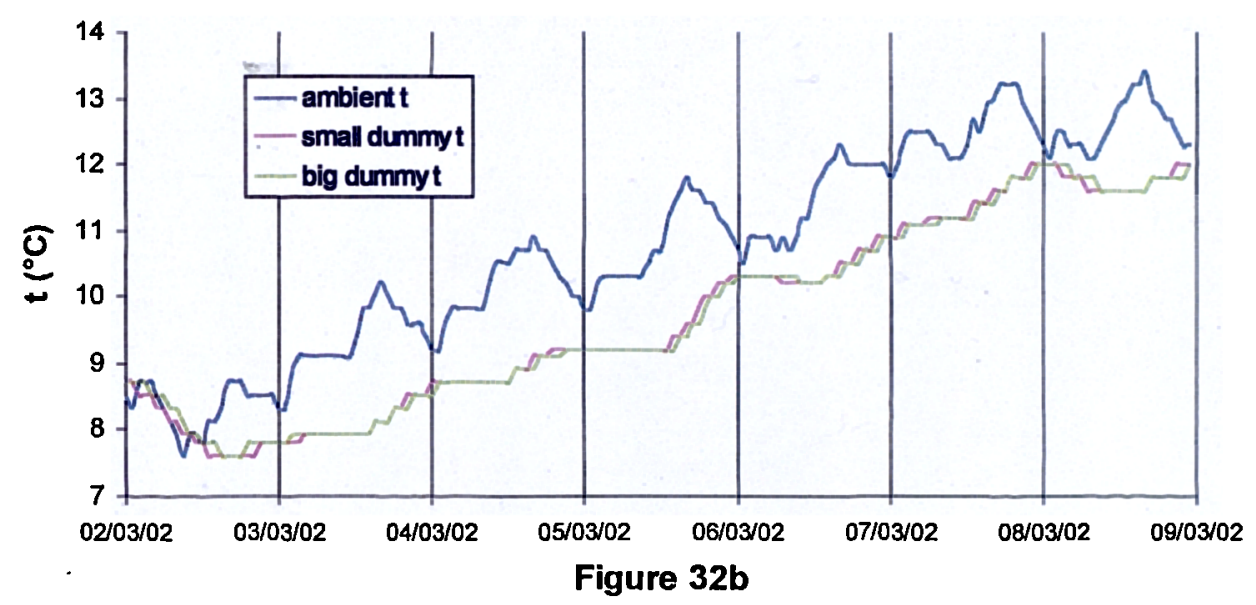

time lag in temperature (July)

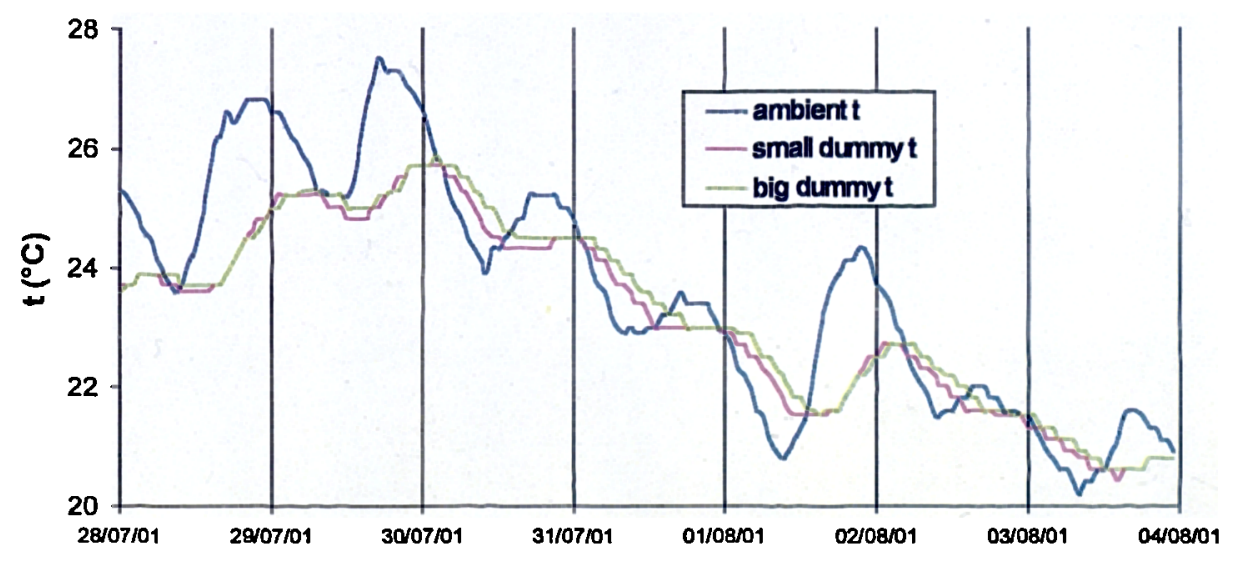

Figure 32c 


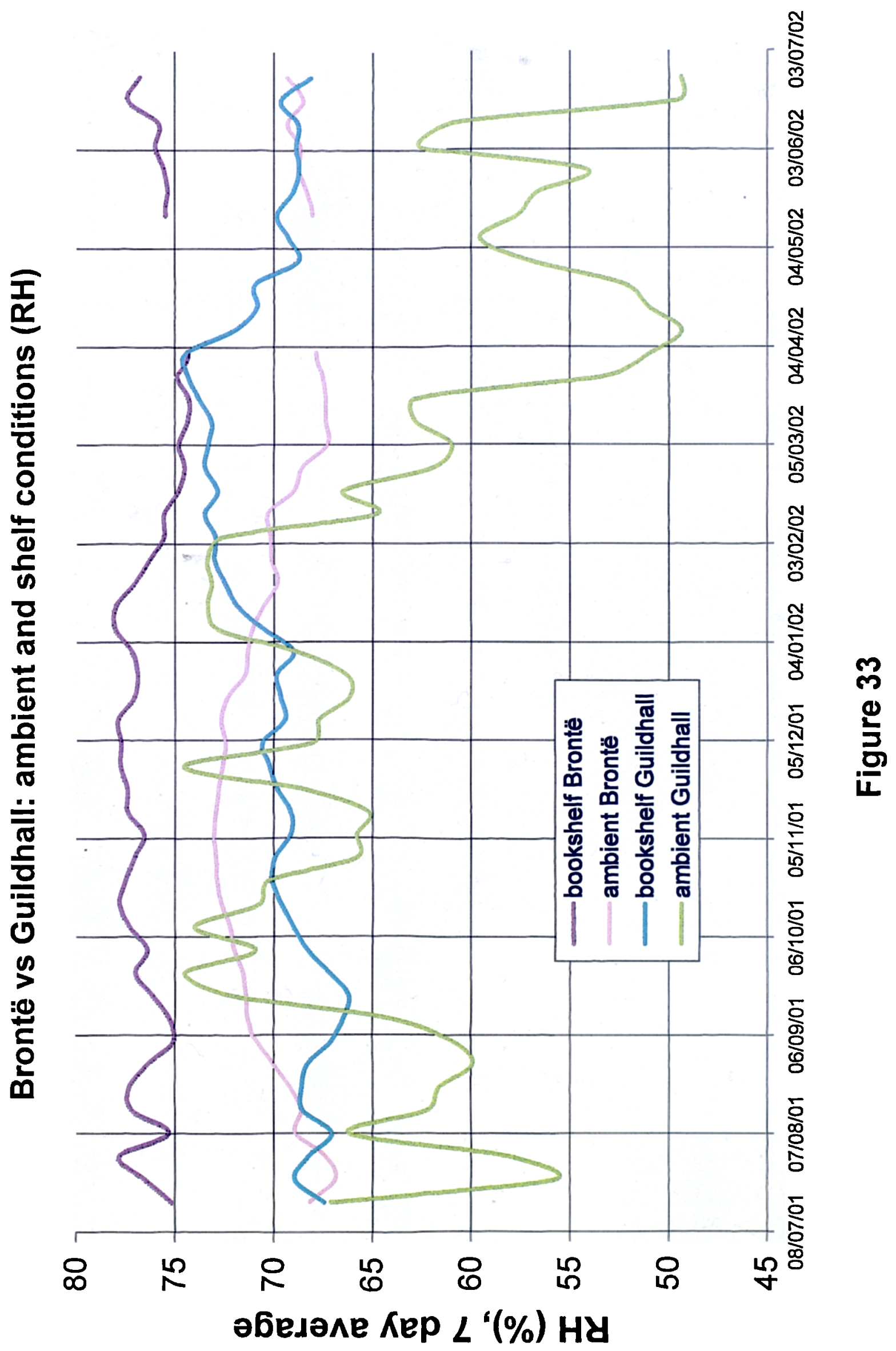




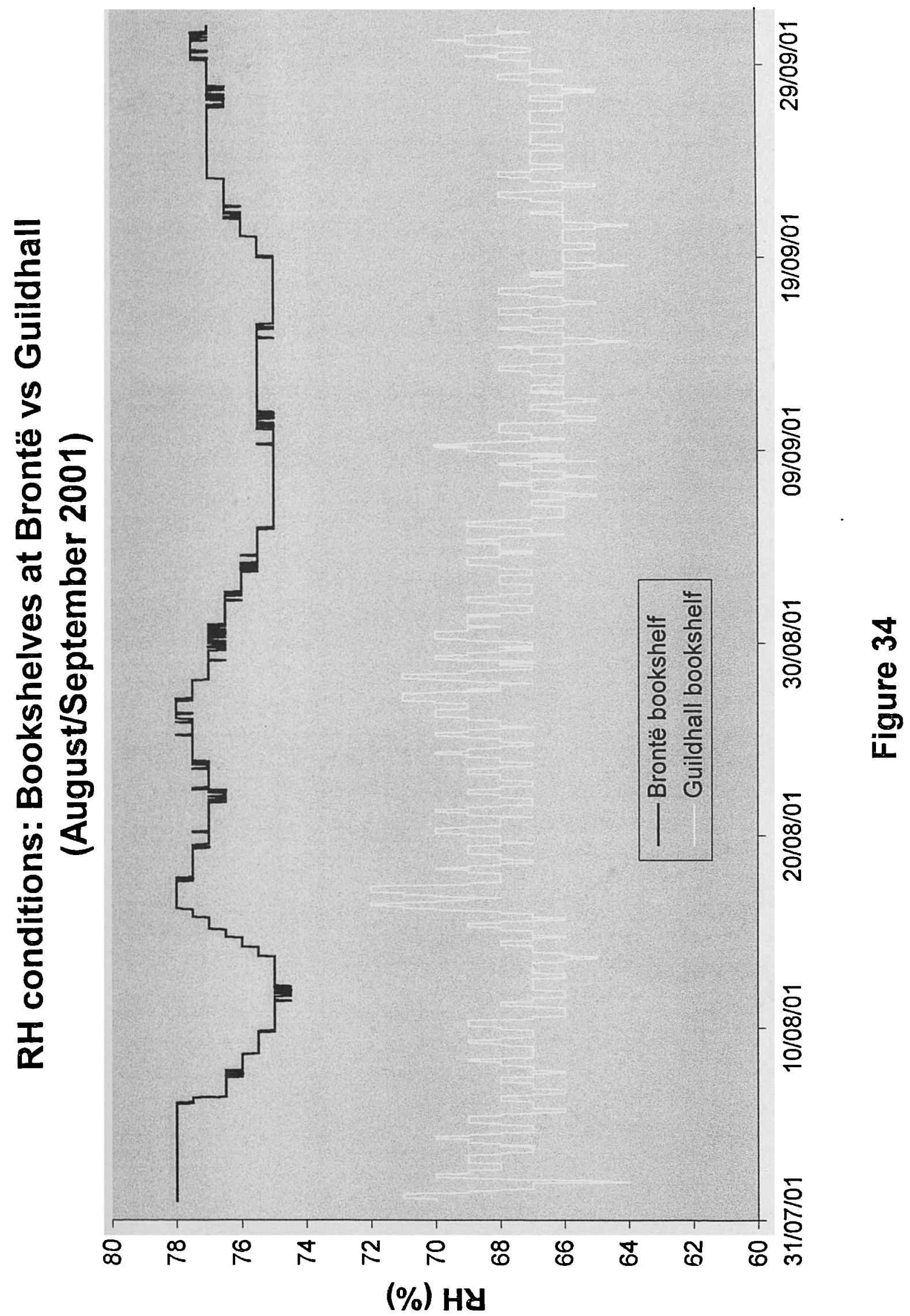




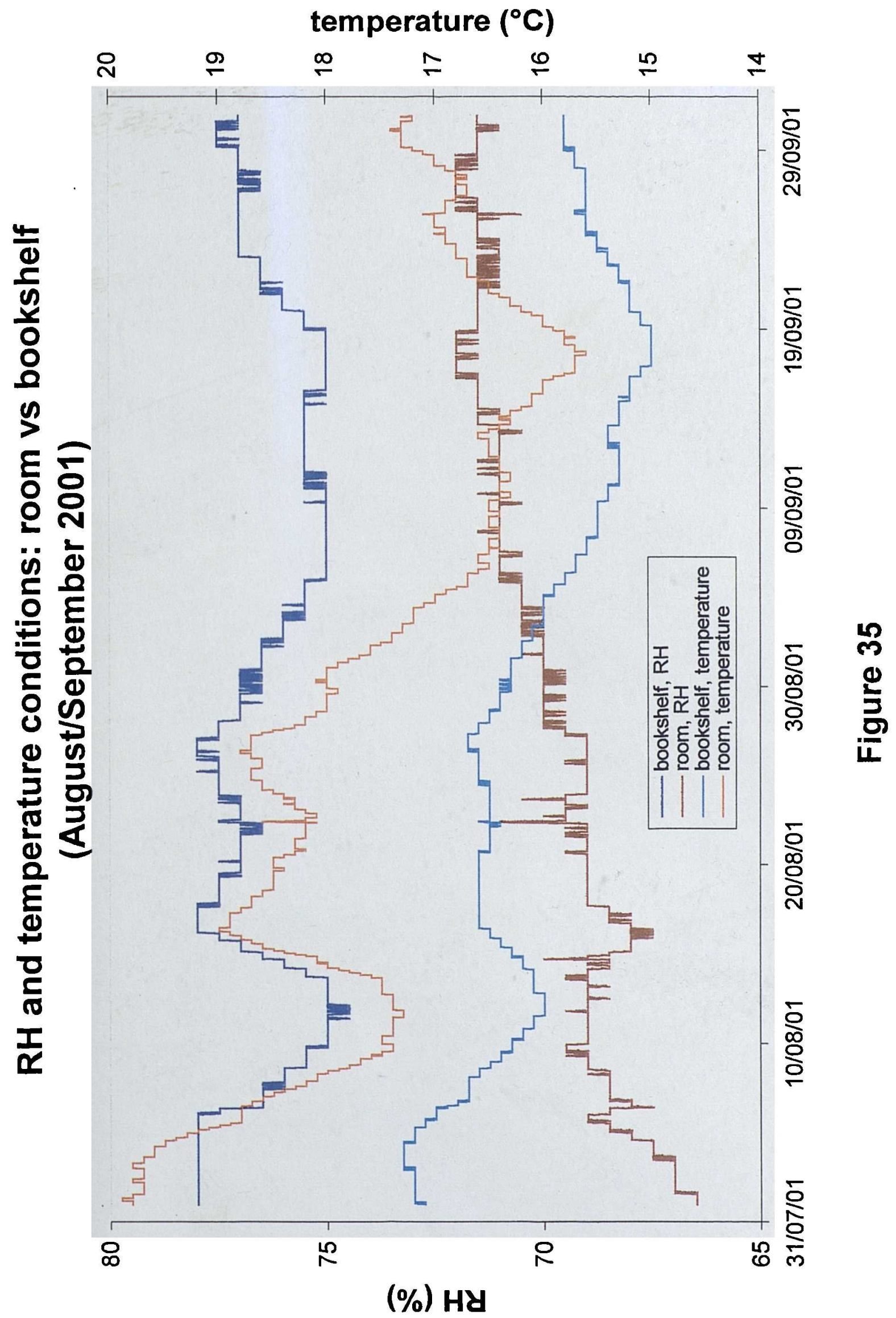




\subsection{Modelling}

\subsubsection{Climate Notebook}

Data obtained from the Brontë Parsonage Museum and the Guildhall Museum Library were successfully analysed using Climate Notebook. It has been the first time the program was run with data from outside the United States and thus, its ability to correctly analyse data has been independently validated.

Hanwell Humbug data were stored as CSV file on Excel and subsequently converted into the necessary format for the program. Difficulties arose with the different formats for dates between Europe and the US (i.e. day/month/year versus month/day/year) as well as from the fact that Hanwell software stored date and time together in one column. These problems were overcome with the help of additional software ${ }^{42}$. Although there still remain some basic problems when running the program from a UK computer, the principle of how the program works can still be seen.

Apart from allowing to compare different sets of data in one report ( $p .145)$, Climate Notebook is able to produce three different reports:

1. The conservator's report;

2. The engineer's report; and

3. The collections manager's report.

For the conservator's report, the data obtained from the bookshelf in the Brontë Parsonage Museum have been used. This shows the high mould risk within the measured space (p. 146). Climate Notebook was programmed to report on any mould risk factors, setting the limit at 1.0 (i.e. any value below would be of no risk, values above 1.0 would refer to a risk as 1.0 represents the point of germination). In the case of the Brontë Parsonage Museum, an extremely high mould risk factor of

42 Free Hex, a free binary file editor for Windows, available from http://www.kibria.de /frhed.html (24 September 2002) 
7.13 was determined. In deed, practice had proven a mould outbreak within the shelf in question in October 2000 , although no mould was apparent during the monitoring period. This report also gives indications of decay rates using PI and TWPI. The values are fairly low, thereby indicating a fast decay rate in the case of the Bronte Parsonage Museum, which is mainly due to the extremely high relative humidity.

Comparing this report with one generated from data from the Guildhall, it can be seen that the conditions look much worse due the large fluctuations (p. 147). However, the low temperatures in winter as well as the slightly lower RH result in better life-expectancy values. At the same time, the risk for mould germination is much lower (0.36).

The engineer's report confirms a lower risk of mould growth at the Guildhall Library (p. 148). While at this point the North American RH target of $35 \% \pm 5 \%$ was not altered due to technical problems, it is still clear that the average $\mathrm{RH}$ is far too high. Since the room is not temperature controlled, it experiences immediate changes in temperature. The overall temperature is rather cool. The report given for the collection manager summarises the conditions within the measured space (in this case, the fully packed shelf at the Guildhall Library) and gives general recommendations for improvements within the collection (p. 149).

The analysis of the Guildhall Library data with Climate Notebook revealed far from ideal conditions, with the temperature variation being wide and the average $\mathrm{RH}$ high. However, the mould risk factor within the Guildhall is negligible, which has been proven correct, as no member of staff can remember any mould outbreak in past years.

Climate Notebook is not yet completely developed and hence, not commercially available at this point. It is anticipated to incorporate results and observations of participating institutions within the United States and refine the programming before its official launch. In time, it is envisioned to make the program internationally available. However, many problems are yet to be overcome. 
Climate Notebook is able to analyse data and pinpoint specific problem areas, such as incorrect $\mathrm{RH}$ or temperature values for certain material. It does, however, not predict particular conditions within a space that is not being monitored. It is therefore reliant on actual data.

This problem was addressed within the course of this research by developing a mathematical model, which is able to predict $\mathrm{RH}$ conditions in storage spaces using data obtained from ambient measurements. 


\section{Temp Comparison}

\section{Temperature in $\mathrm{C}$}

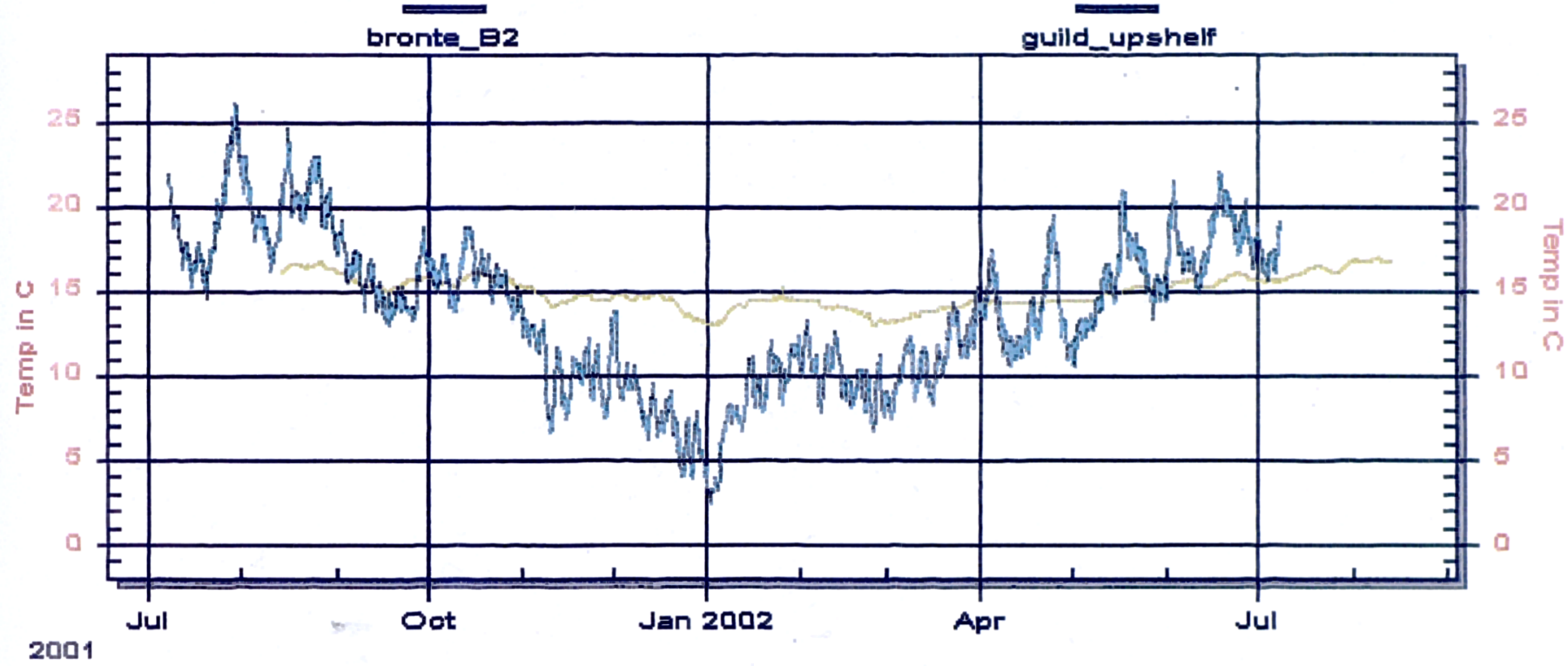

\section{RH Comparison}

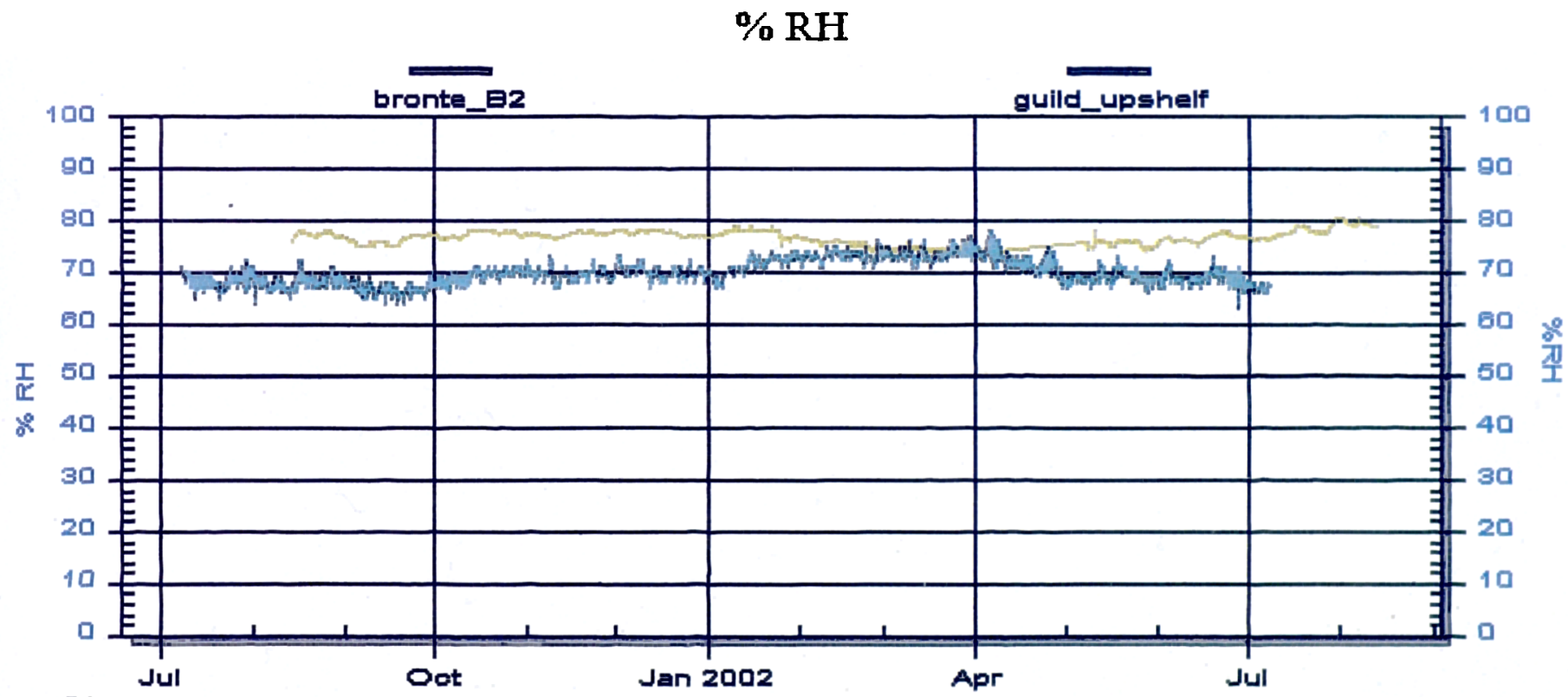

2001 
$\mathrm{T}$ and $\mathrm{RH}$ of bronte $2 \mathrm{~b}$

For the 12 Month Period Tuesday Aug. 14, 2001 to Wednesday Aug. 14, 2002

2001

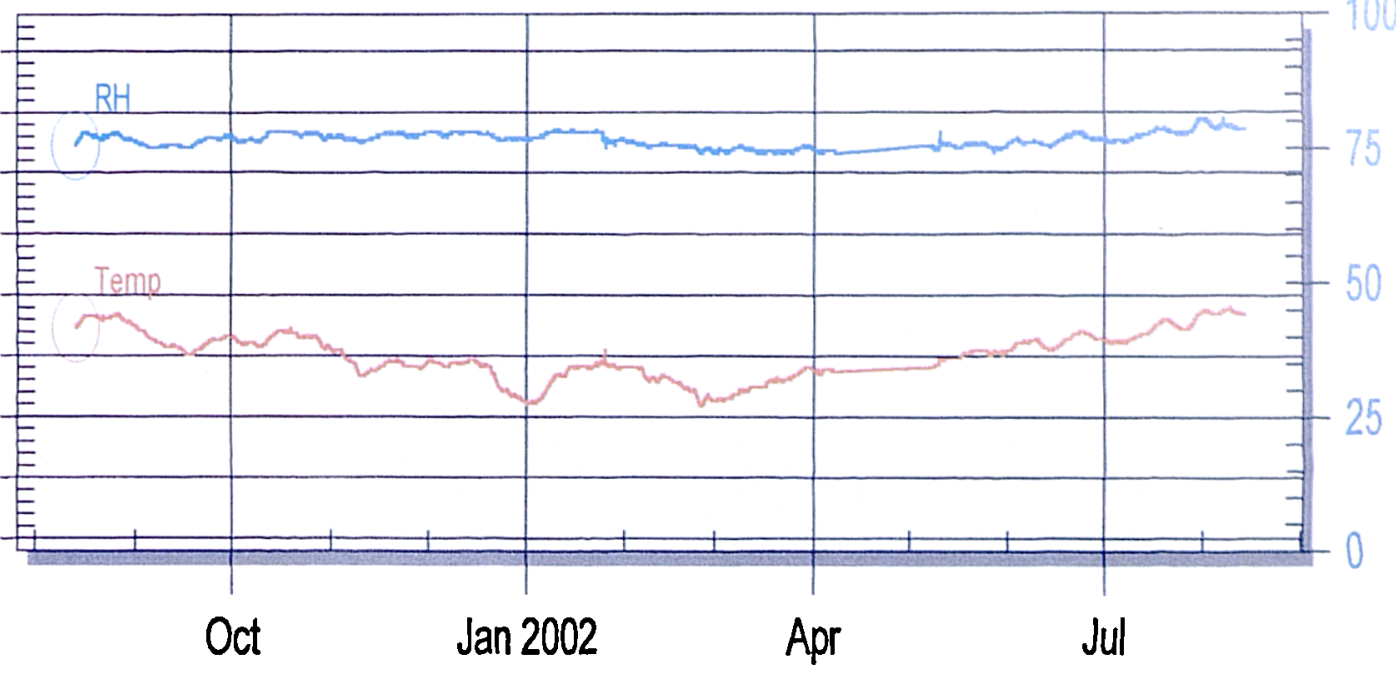

PI and TWPI of bronte $2 b$

TWPI for the 12 Month Period 14/08/01 to 14/08/02 = 40 Years

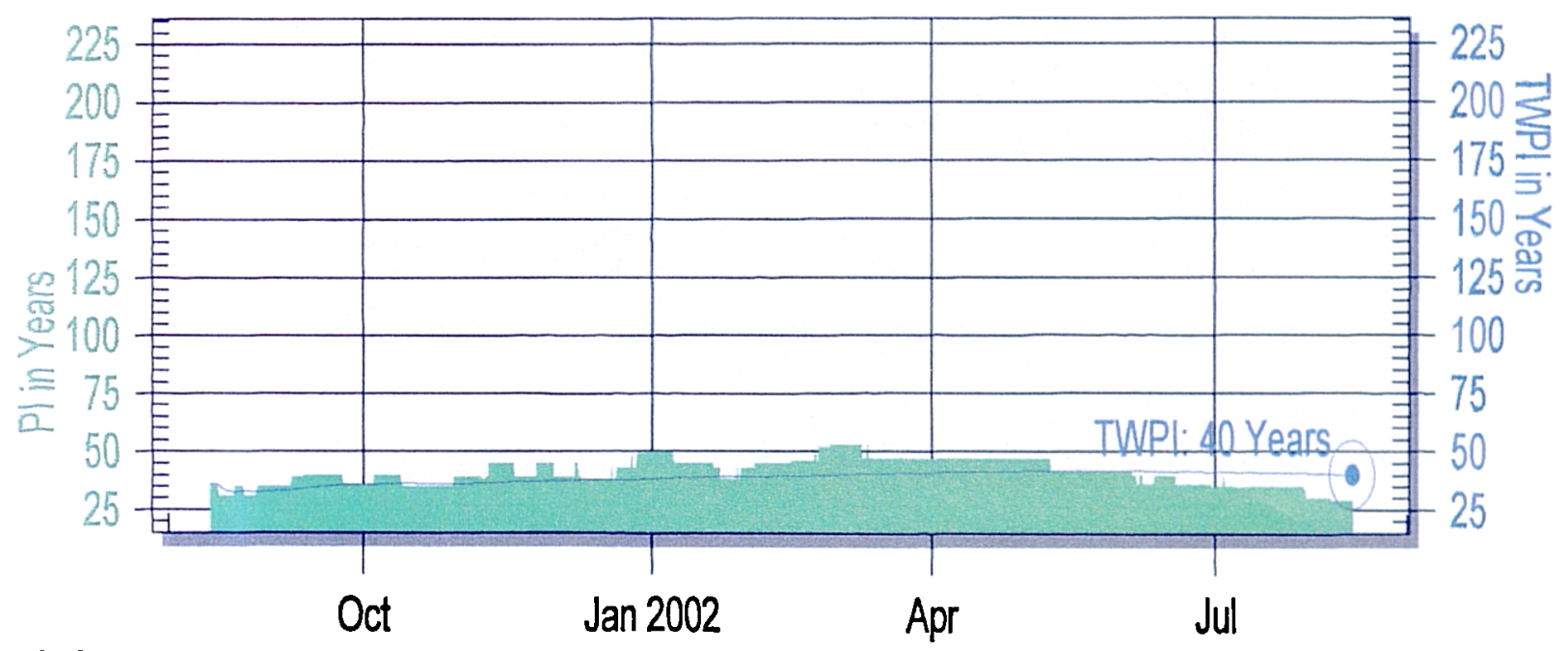

2001

Mold Risk Analysis of bronte $2 b$

Maximum Mold Risk Factor for the 12 Month Period 14/08/01 to 14/08/02 = 7.13

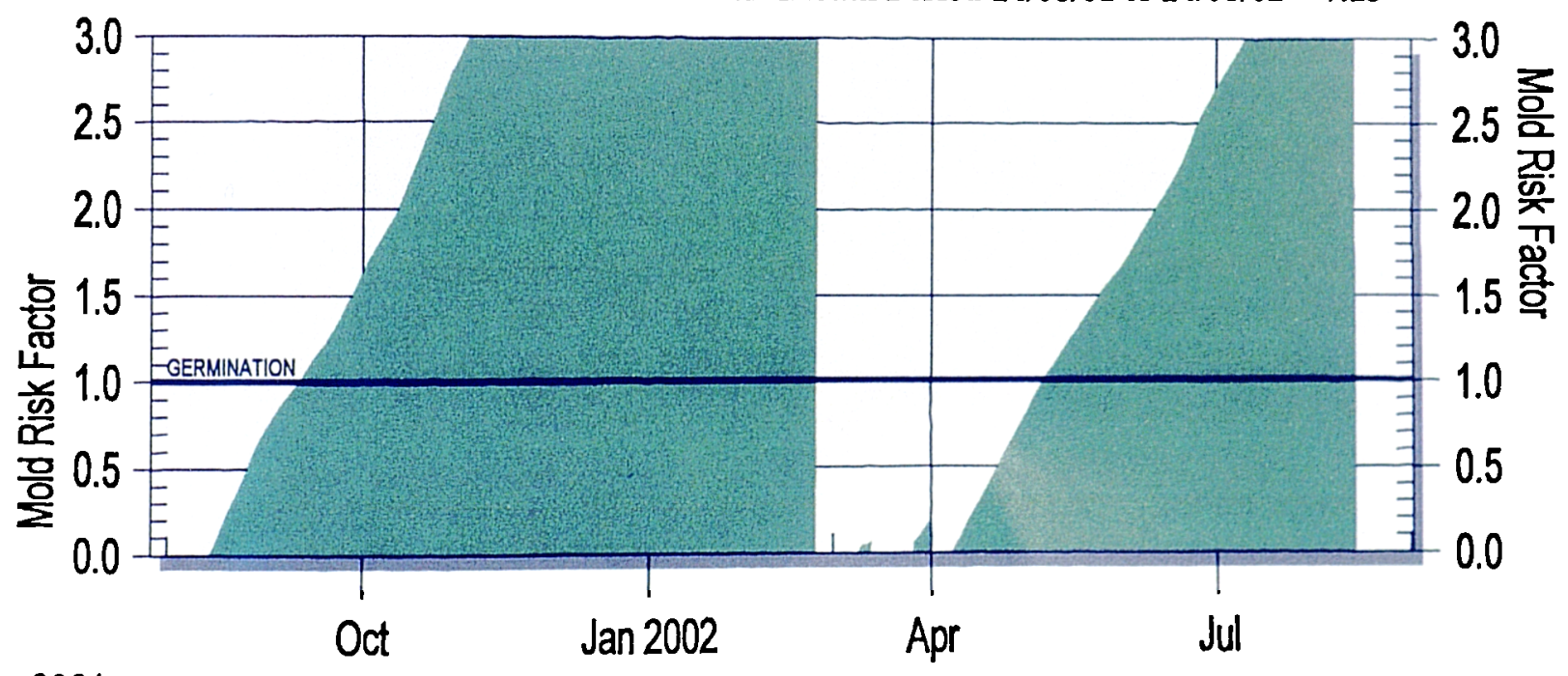


$\mathrm{T}$ and $\mathrm{RH}$ of guild_upshelf

For the 12 Month Period Sunday Jul. 08, 2001 to Monday Jul. 08, 2002

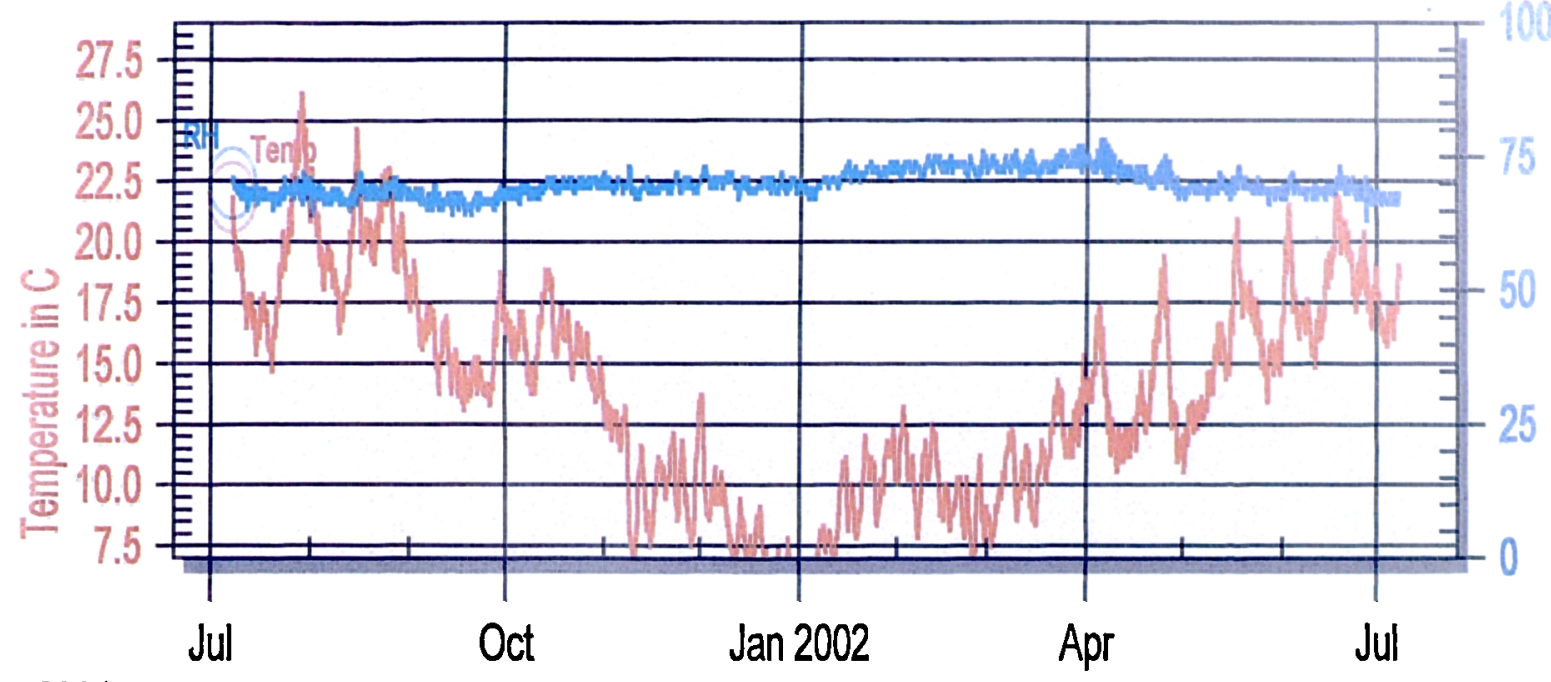

2001

\section{PI and TWPI of guild_upshelf}

TWPI for the 12 Month Period 08/07/01 to 08/07/02 = 49 Years

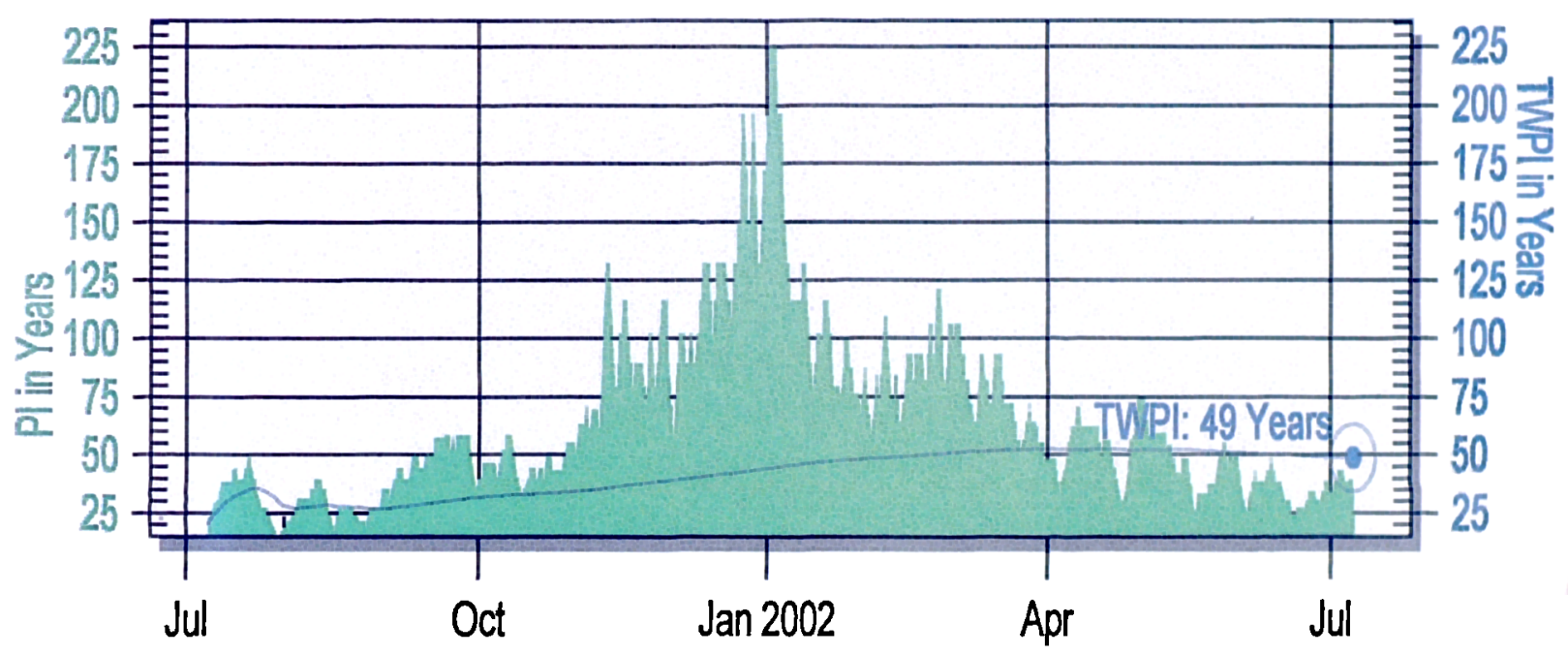

2001

Mold Risk Analysis of guild_upshelf

Maximum Mold Risk Factor for the 12 Month Period 08/07/01 to 08/07/02 $=0.36$

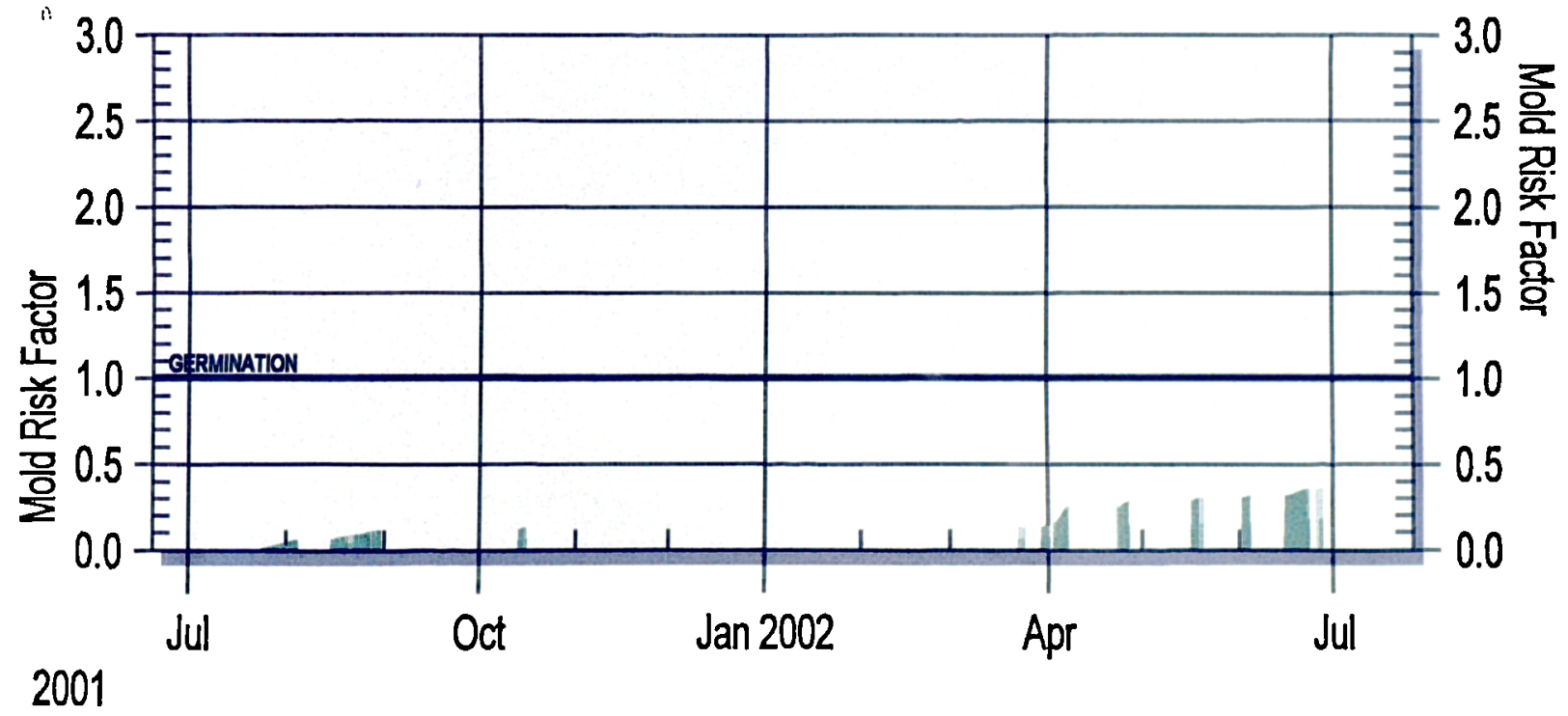




\section{Temperature}

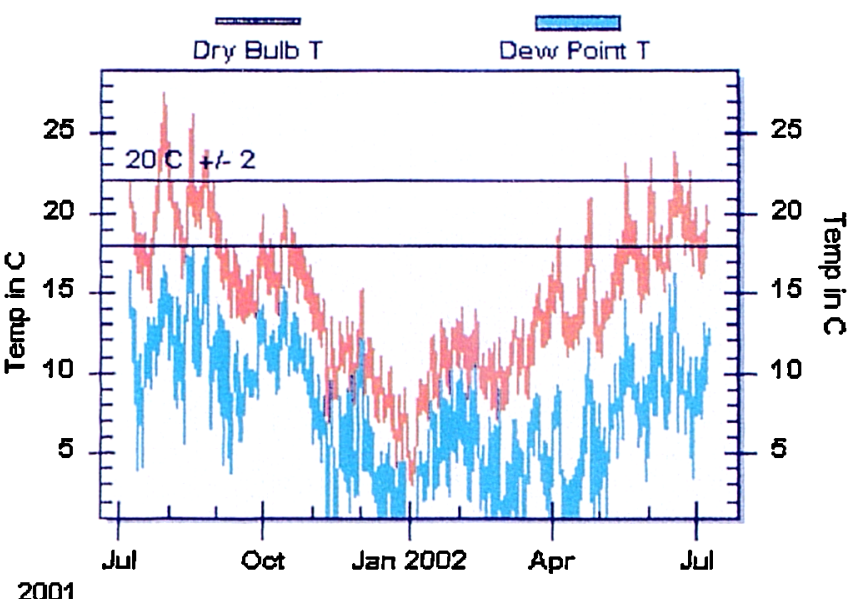

Temp Performance Target : $20 \mathrm{C}+/-2 \mathrm{C}$
Relative Humidity

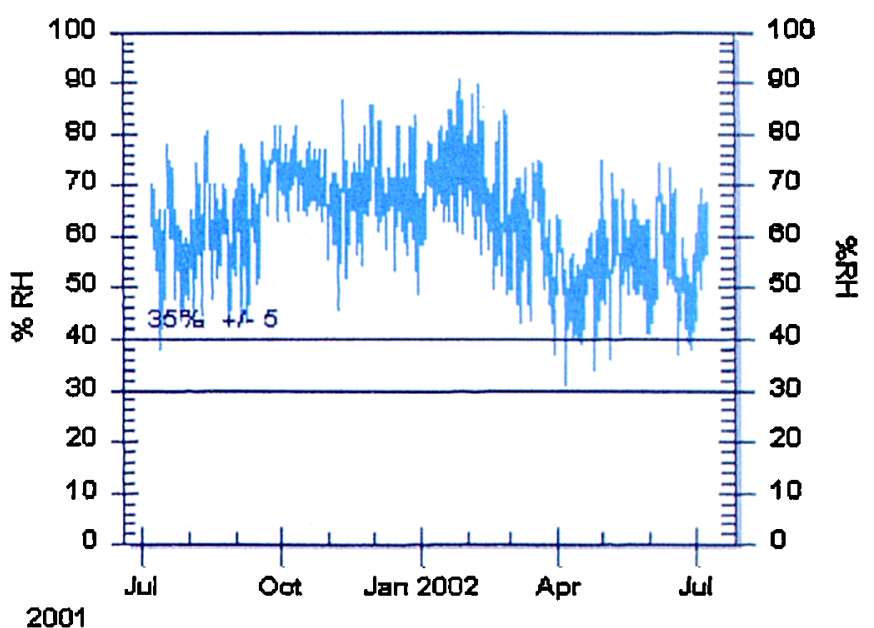

RH Performance Target: $\quad 35 \%$ RH $+/-5 \%$
Actual Temp vs Target

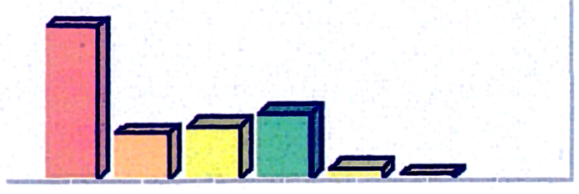

$<14$

18-22

$>26$

T Min : $3 \mathrm{C}$

T Max : $28 \mathrm{C}$

T Range : $25 \mathrm{C}$

T Mean: $14 \mathrm{C}$

T Std Dev : $4.5 \mathrm{C}$

Temp is within tolerances of 18 to $22 \mathrm{C}$ for 20 $\%$ of the time
Actual RH vs Target

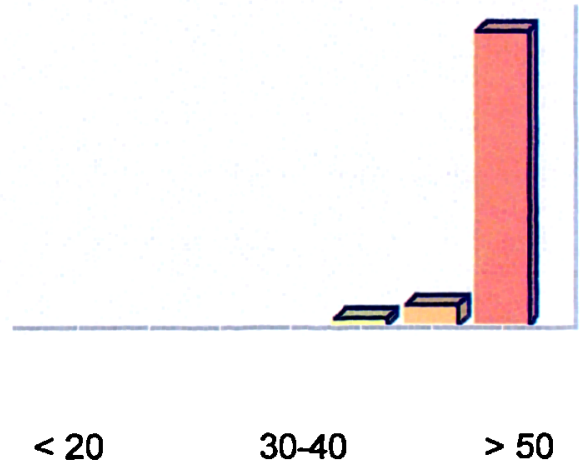

RH Min : $31 \%$

RH Max : $90 \%$

RH Range : $60 \%$

RH Mean: $63 \%$

RH Std Dev : $9 \%$

$\% \mathrm{RH}$ is within tolerances of 30 to 40 for $\%$ of the time

\section{E. Engineer's Summary REILLY}




\section{Room Conditions}

\begin{aligned} & Temperature is COOL Average temperature: $14 \mathrm{C} \\ &$ Temp variation is WIDE T Variation: $+1-9 \mathrm{C} \\ &$ RH is HIGH Average RH: $70 \% \\ &$ aging rate is MODERATE RH Variation: $+1-5 \% \\ &$ Mold risk is NONE TWPI: 49 years \\ & \hline\end{aligned}

\section{General Alerts}

WIDE Temperature variation

$\mathrm{HIGH}$ Average $\mathrm{RH}$

\section{General Recommendations}

Reduce Temperature variation to +/- $4 \mathrm{C}(7 \mathrm{~F})$. Adjust Average Relative Humidity to 10 to $55 \%$.

\section{Collection Materials}

\section{ALERT}

MATERIAL LEVEL REASON FOR ALERT

\section{OK}

\section{Graphs of Room Conditions}

Temperature

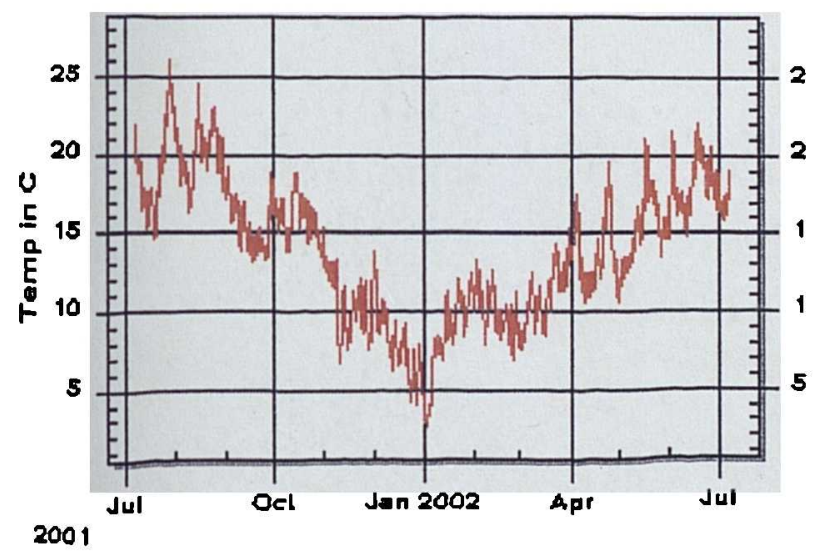

Relative Humidity

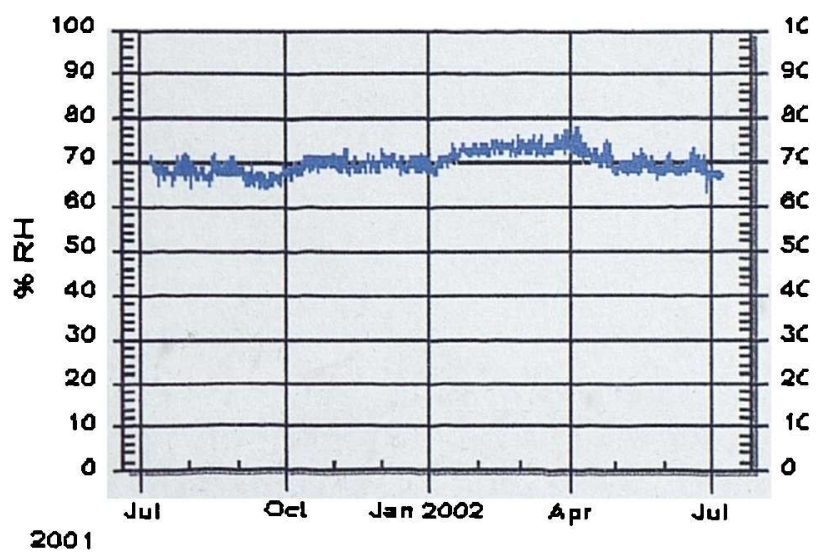




\subsubsection{Developing a Mathematical Model}

\section{Methodology}

The success of any mathematical model is dependent upon the quality of the data used. In order to predict how changes in the environment affect paper-based collections, it is necessary to establish the relationships between various microenvironments (e.g. in the room, on a bookshelf, within a bookcase, and within a book). Since these relationships are generally not known, existing modelling packages are currently of limited application.

The various relationships of interest can be readily defined at an empirical level, and hence a mathematical model can be established. Once the relationships have been defined, the effects of any change in environmental conditions have to be understood in terms of collection care (i.e. if a change in $\mathrm{RH}$ is predicted, what effect will this have on a sensitive collection housed within the room?). Hence, the design and construction of a comprehensive database is paramount, and has constituted one of the main components of this project. The majority of the required data has been collected and collated from the literature, but only those data quantifying the effects of dampness on building fabric and paper-based collections have been incorporated into the database (Appendix $G$ ). ${ }^{43}$

Regarding the safe storage of paper-based collections, perhaps the most difficult situation within which to predict and control detrimental changes in environmental conditions is where storage is effected using enclosed bookcases (i.e. shelves behind glass-fronted doors). Although continual monitoring within a bookcase would remove any such difficulties, the monitoring would have to be undertaken on every shelf in every bookcase. Although it is acknowledged that there are many benefits to using enclosed bookcases (e.g. protection from particulate pollution), a potential problem is that, by their very nature, there will be certain micro-environments set up within the enclosed space(s). This will have a direct impact on the storage conditions

43 Information on the storage of other types of collections can be found in Appendix G. 
of the books, and may or may not be affected by changes in the ambient conditions within the room. Furthermore, books on part-filled shelves may experience different micro-environments to those on filled shelves. Similarly, the micro-environments could be affected by the construction material, the form of the shelf, the size of the books, the prevalent paper-type, the buffering capacity of the materials, the binding material, and how well the doors fit.

As a consequence to these considerations, the relationships between various microenvironments had to be established. This included the collection of data within the room, a closed bookshelf, and within books. Two books have been included for study, varying in size as well as paper type ${ }^{44}$. Different data sets between fully packed shelves and empty shelves have also been obtained. The conditions at Brontë Parsonage Museum and Guildhall Library, respectively, have been found ideal for data collection, as they represent two distinctly different environments: one very stable, and one very unstable.

It is unlikely that a single model can be used for every situation. It should, however, be possible to approximate according to the general environmental conditions.

\section{Defining the model}

In order to develop the mathematical model, the bookcase system has to be initially defined. Since the aim of the model is to make predictions on the basis of the ambient $\mathrm{RH}$ alone, the system has to be simple, with minimum variables. Consequently, a number of assumptions have to be made.

A book within an enclosed bookcase can be considered to be a closed system (assuming the door fits well and is not continually being opened), with local $\mathrm{RH}$ driven by the equilibrium with the enclosed hygroscopic material. The internal $\mathrm{RH}$ should follow the ambient fluctuations within the room, although the extent of this correlation will be subject to the performance of the bookcase doors. Any direct 
correlations would not be expected to be immediate, and the delay would be dependent upon the amount of hygroscopic material, its buffering capacity, and the damping effect of the door.

The system described above is analogous to a showcase. The behaviour of RH inside showcases is well documented (Padfield, 1966; Thomson, 1977; Kamba, 1994), and has been shown to respond to changes in ambient RH in an exponential manner. This is not surprising, as the absorption and desorption of water should be described by first-order kinetics. Consequently, the response of the material or air to a sudden change in ambient $\mathrm{RH}$ can be defined by a half-time (as discussed previously) which is a characteristic of the defined system, and will not change unless the system is varied (e.g. books removed or replaced).

Since most collections are invariably mixed - containing different paper types, different binding materials and books of different sizes - it is important to establish whether these factors show significantly different responses to changes in RH.

It has been shown above that the paper type will not affect the overall collection response to changes in ambient $\mathrm{RH}$, since all $\alpha$ values fall within $10 \%$ of each other. Furthermore, the size of the book was shown empirically to have little influence on the overall collection response to changes in ambient $\mathrm{RH}$. Although the size of the book affects the half-time response (where $t_{1 / 2} / M$ is constant), the half-time response was shown to be too slow to allow the books to respond to fluctuations in ambient $\mathrm{RH}$.

A simple model can, therefore, be defined to describe the system of interest, as outlined above: 45

1. The bookcase is considered to consist of a number of isolated, glass-fronted boxes, with all sides being impermeable to moisture transport (i.e. each shelf is a

44 For detailed information on the two dummy books refer to Appendix $F$.

45 Very similar parameters have previously been validated for a mathematical model by $\mathrm{Di}$ Pietro and Ligterink (1999). 
closed system). Corrections will need to be made to account for leakage and other air infiltration.

2. Inside each box there is a fixed mass (M) of buffering (i.e. hygroscopic) material.

3. The $\mathrm{RH}$ of the enclosed air is considered to be in equilibrium with the hygroscopic materials at all times.

4. Books of all sizes behave the same.

5. All paper types exhibit the same response to rapid changes in $\mathrm{RH}$ - this can be described by $\alpha$, the gradient of the desorption isotherm, where $\alpha=0.14$.

6. No temperature gradients are present within the enclosed system.

7. The total mass of water $(W)$ in the system is given by the sum of the moisture in the enclosed air and the moisture content of the hygroscopic material.

\section{Modelling an unstable environment}

The ambient conditions within the Guildhall Museum library were extremely erratic, ranging from $31 \%$ to $90 \%$ during a one-year period. By comparison, the environment within the bookcase was much more stable, ranging from $63 \%$ to $78 \%$.

In order to model the environment within the bookcase from the ambient $\mathrm{RH}$ data, mathematical expressions had first to be derived for each system. Due to the spread in ambient data, it was necessary to determine the average values before defining the mathematical equation - monthly values were used for this purpose (Figure 36). By defining the equations for both ambient variations and those inside the bookcase, two mathematical expressions were derived (Figure 37). Since the variation in RH on the full shelf, empty shelf, and inside the big and small books was fairly similar (generally within 1-2\% $\mathrm{RH}$ ), the data from inside the (smaller) lignin-containing book was used for this purpose. 


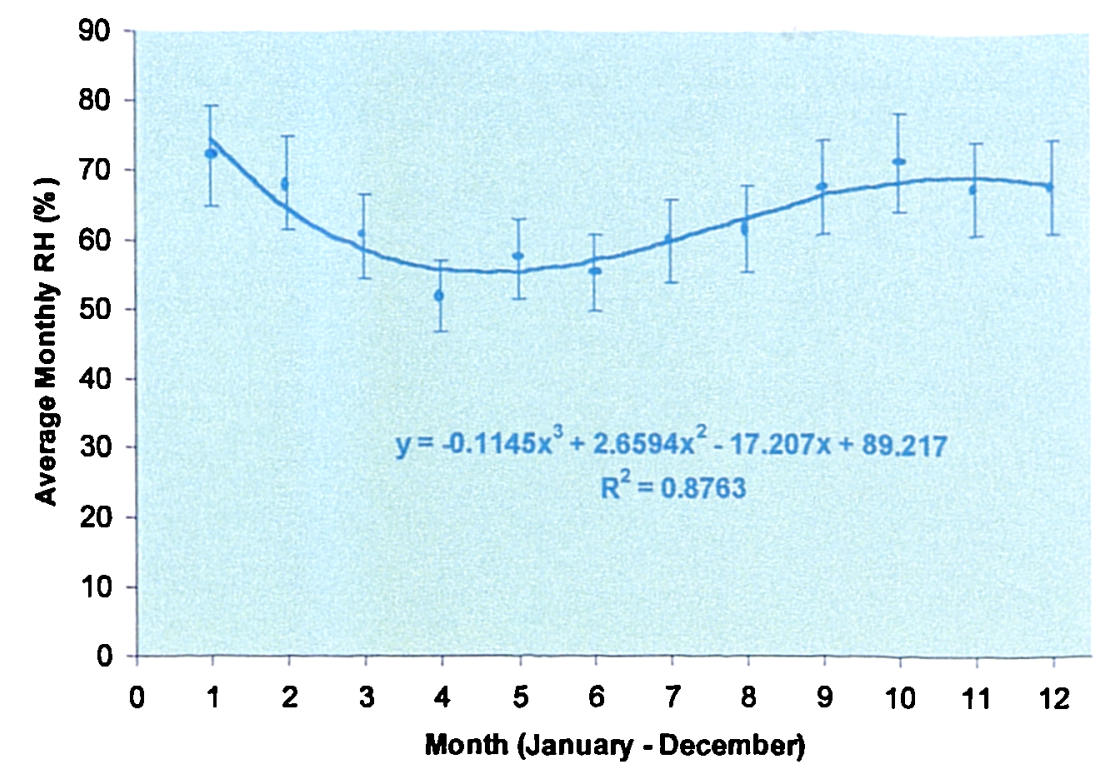

Figure 36: Variation in ambient RH (monthly average values)

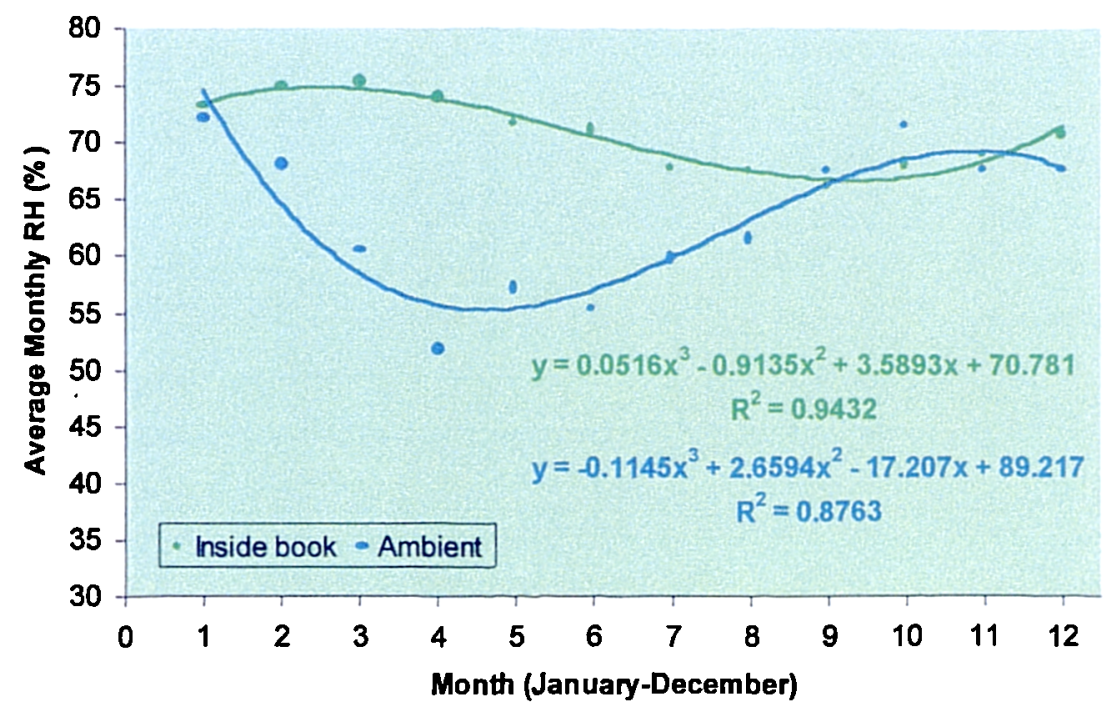

Figure 37: Comparison of the variation in RH between the lignin-containing book and ambient conditions 
Solving these equations provided the mathematical relationship between the ambient $\mathrm{RH}$ and that inside the bookcase (Figure 38 ). This gives the required model for the Guildhall Museum library.

For ambient $\mathrm{RH}, \mathrm{y}$ :

$y=-0.1145 x^{3}+2.6594 x^{2}-17.207 x+89.217$

For the small book $(\mathrm{RH}=\mathrm{y})$ :

$y^{\prime}=-0.0516 x^{3}-0.9135 x^{2}+3.5893 x+70.781$

where $x=$ month of year (January $=1$, December $=12$ )

Re-arranging (1):

$x^{3}=(1 / 0.1145)\left(-y+2.6594 x^{2}-17.207 x+89.217\right)$

Re-arranging (2):

$x^{3}=(1 / 0.0516)\left(y^{\prime}+0.9135 x^{2}-3.5893 x-70.781\right)$

Equating (3) and (4) and re-arranging gives the model:

$y^{\prime}=-0.451 y+0.2847 x^{2}-4.165 x+110.99$

where $\quad y^{\prime}$ is the predicted $\mathrm{RH}$ inside the book

$y$ is the ambient $\mathrm{RH}$ (measured)

$x$ is the month of year (January=1, December $=12$ )

Figure 38: Deriving the mathematical model for the Guildhall Museum library

By applying the model to ambient $\mathrm{RH}$ data, it should be possible to reproduce the measured RH within the bookcase. Figure 39 illustrates how well the model works using monthly average data - the measured and predicted values should, ideally, be the same. A plot of one against the other should therefore be a straight line of 
equation $y=m x$, with a gradient $m=1$. From Figure 40 it can be seen that the data produces a straight line of gradient $m=0.9993$. Although the data points are fairly wide spread $\left(R^{2}=0.8317\right)$, the model works well considering the erratic nature of the ambient data.

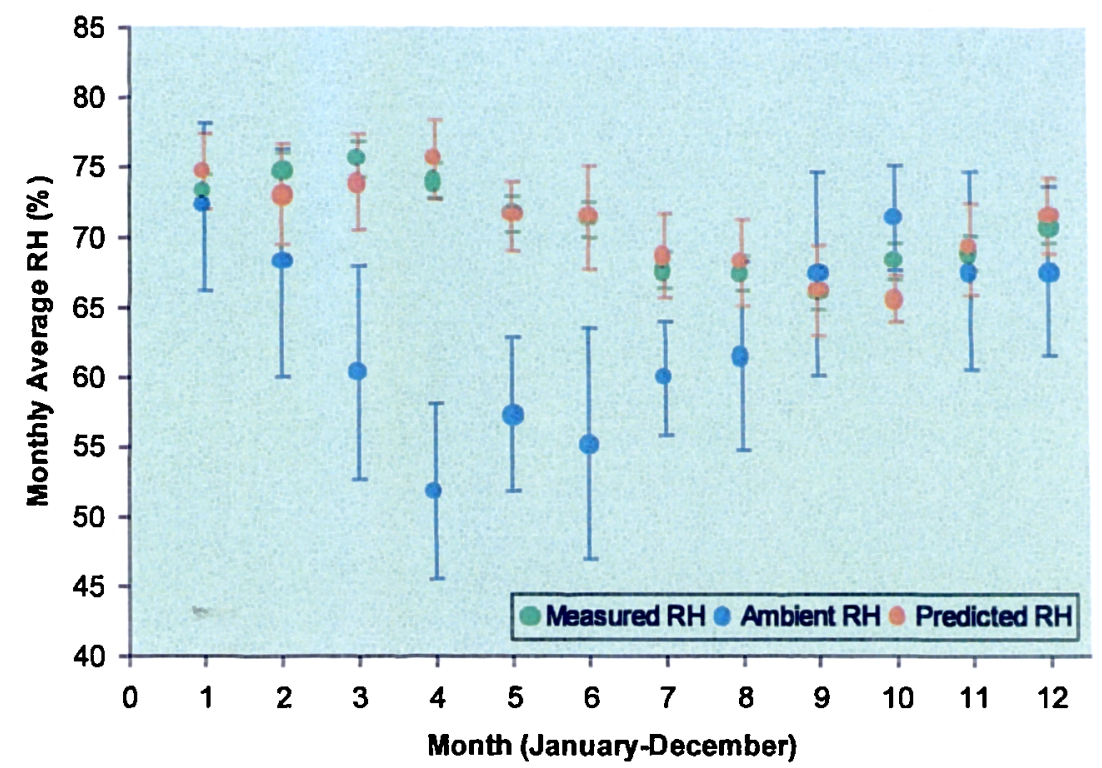

Figure 39: Modelling the changes in $\mathrm{RH}$ inside a bookcase from ambient $\mathrm{RH}$ measurements

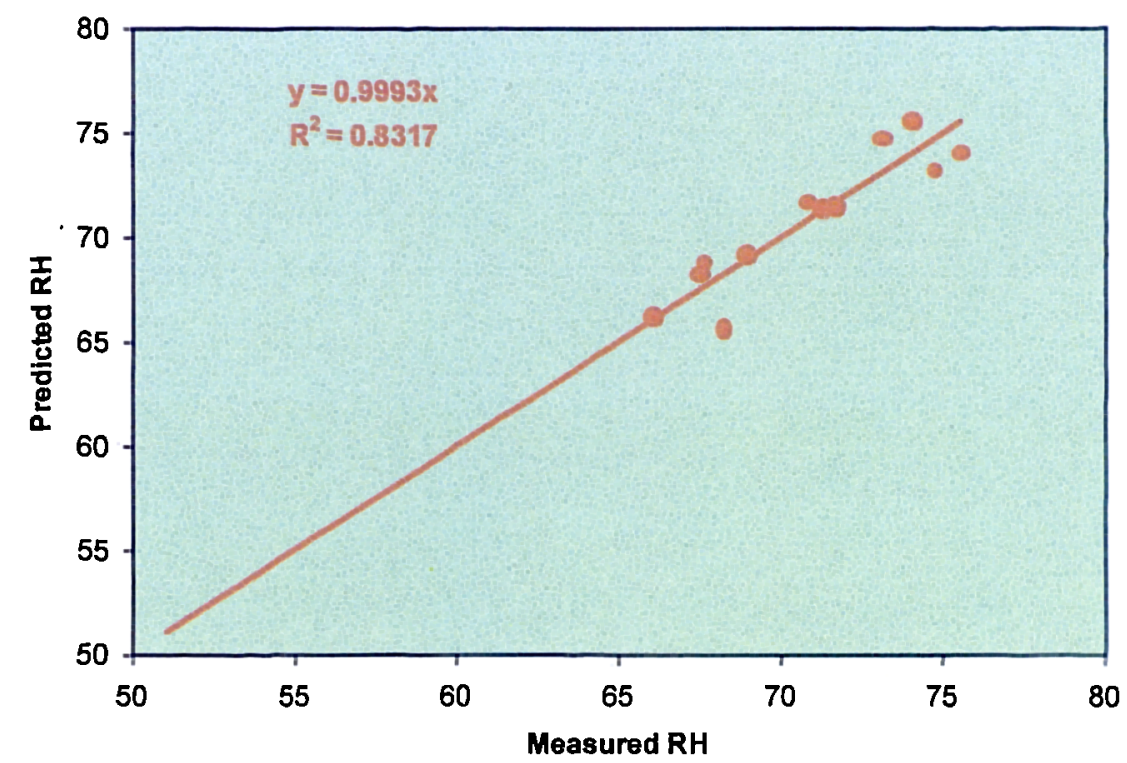

Figure 40: Correlation between the measured and predicted RH values in the bookcase 
When applying the model to the hourly ambient data (Figure 41), it can be seen that the predicted RH follows the trend well. Unfortunately, the large spread of the ambient data remains present in the predicted values. This means that the model can only define a safe RH 'band' of about $\pm 8-10 \%$.

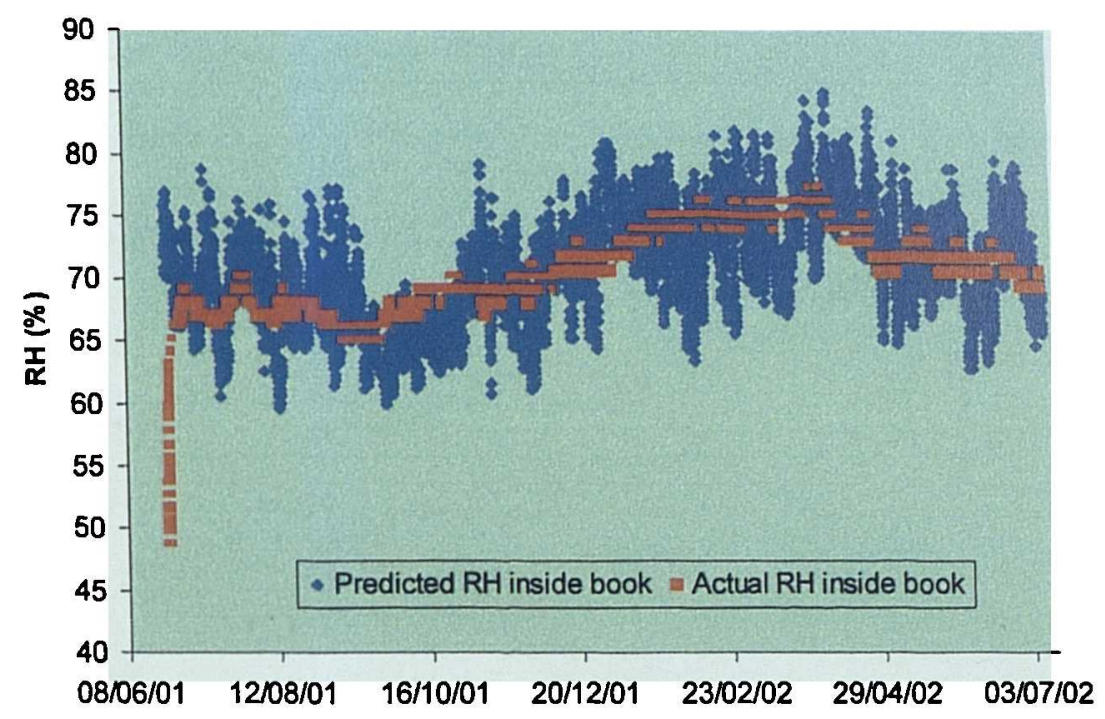

Figure 41: Using hourly monitoring to predict RH inside the lignin-containing book

Given that some collections within historic buildings will experience similar unstable conditions, the model was applied using data formed through a rolling average. This method evens out large fluctuations without loosing any information and has been explained in section 7.1. (Footnote 37). Applying this method reduced the error margin to about $5 \%$ and therefore proved very useful. However, it must be kept in mind that the model is developed with a view to being used by conservation staff and an easy method of averaging data is preferable. 


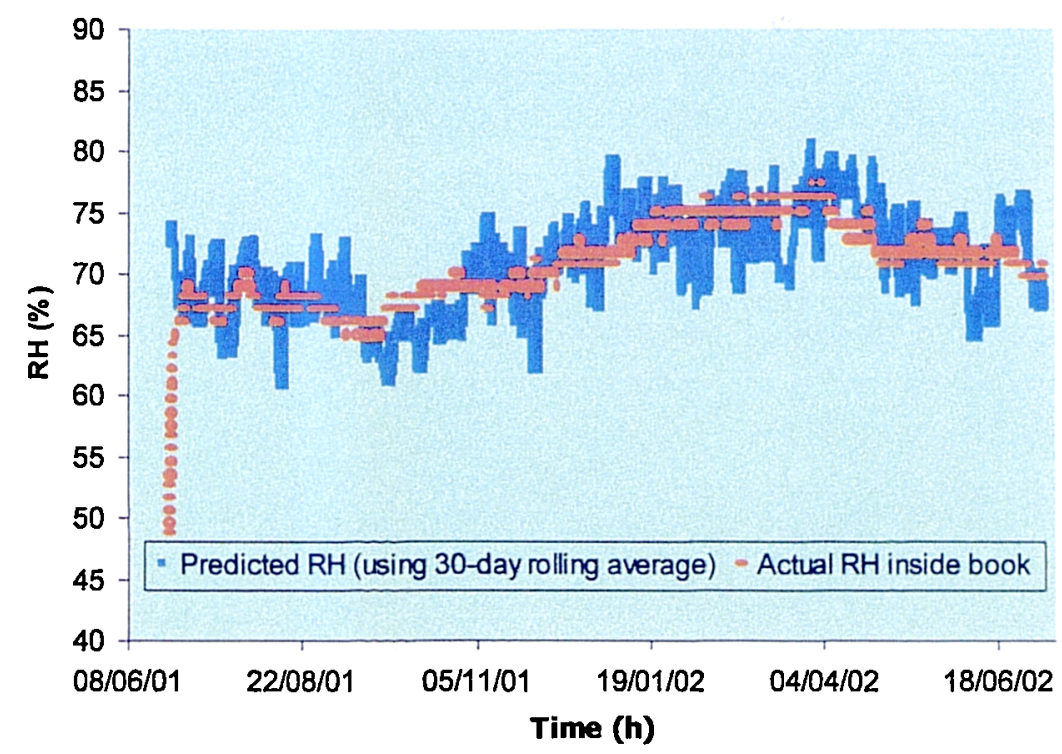

Figure 42: Modelling the RH inside the lignin-containing book using ambient RH values (30-day rolling average)

\section{Modelling a stable environment}

The ambient conditions within the strongroom at the Bronte Parsonage Museum were very stable (in general $66-73 \%$ ). ${ }^{46}$ Figure 43 illustrates the great difference between the ambient conditions at the Brontë Parsonage Museum and the Guildhall Museum library.

48 The RH dropped to $61 \%$ when the strongroom door was left open to allow easy staff access when the museum was closed. 


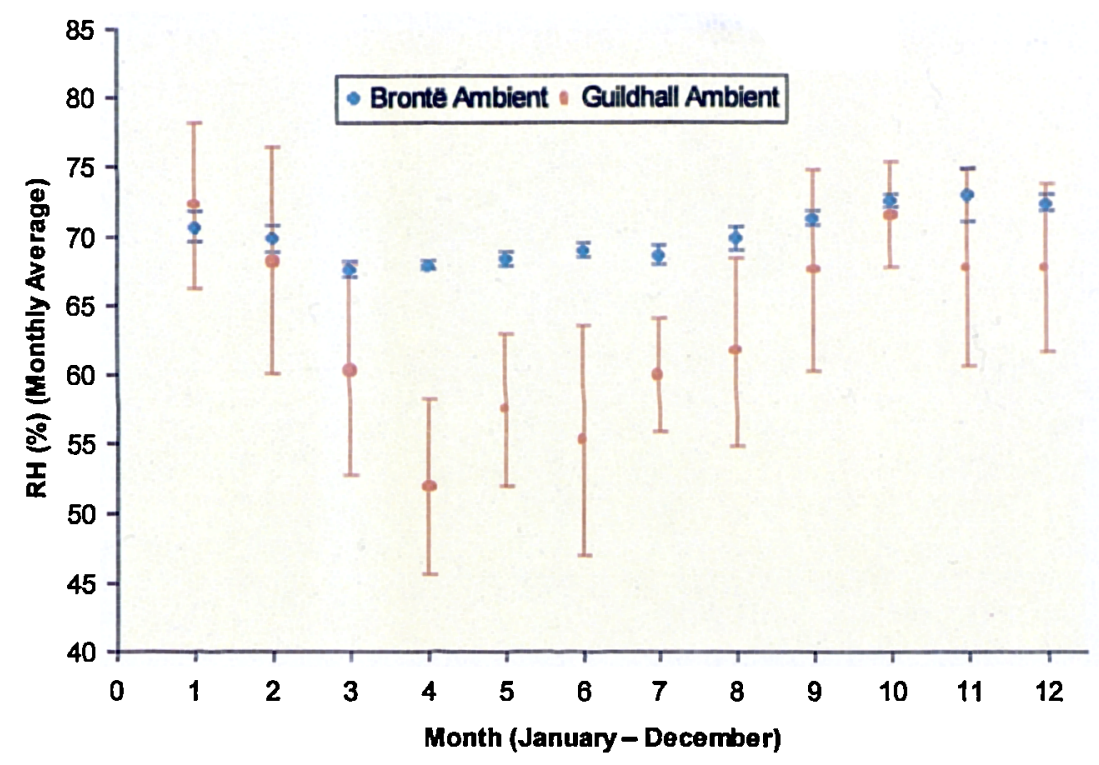

Figure 43: Comparing the ambient conditions within Brontë Parsonage Museum and Guildhall

As discussed previously, unlike the Guildhall Museum library, the environmental conditions within the bookcase follow those within the room very closely, although the bookcase is always at a significantly higher $\mathrm{RH}$ (Figure 44 ). ${ }^{47}$ Since the RH profiles are very different, due, perhaps to the different bookcases involved, the Guildhall model could not be applied to the Brontë data. Consequently, a different model had to be determined.

The methodology for defining the model for these stable conditions is the same as adopted for the Guildhall Museum, above. Figure 45 shows the mathematical expressions for the variation in RH within the room (ambient) and the bookcase. These are solved in Figure 46.

47 Some of the data was lost during April 2002 due to the Humbug's memory being full. 


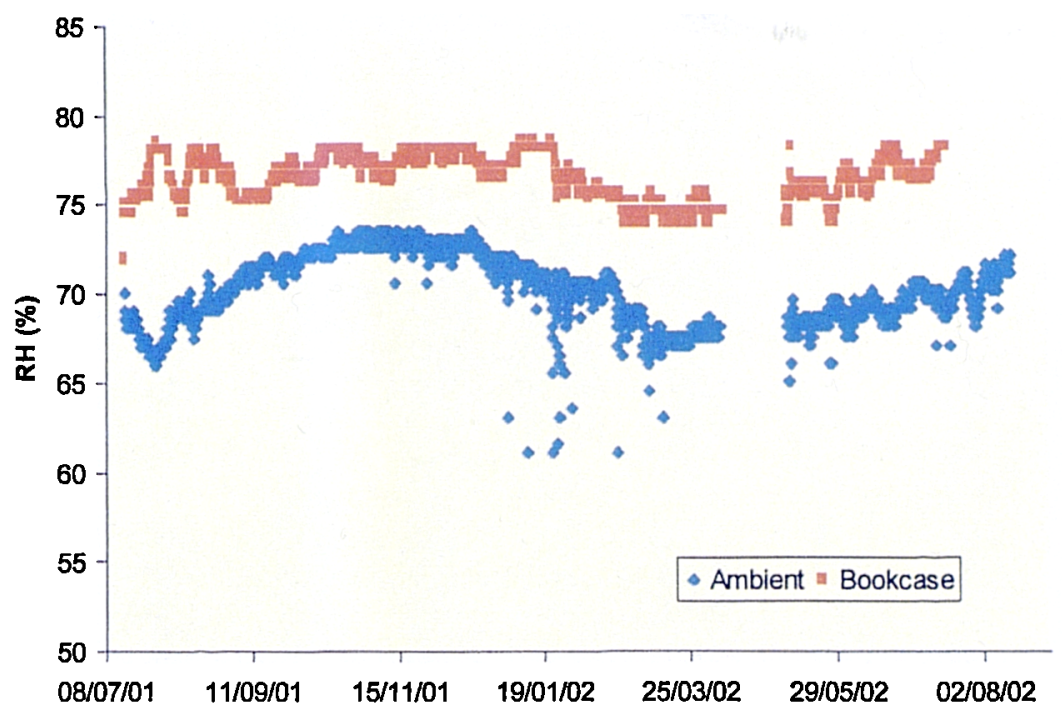

Figure 44: Comparing the ambient RH and the RH within the bookcase at Brontë Parsonage Museum

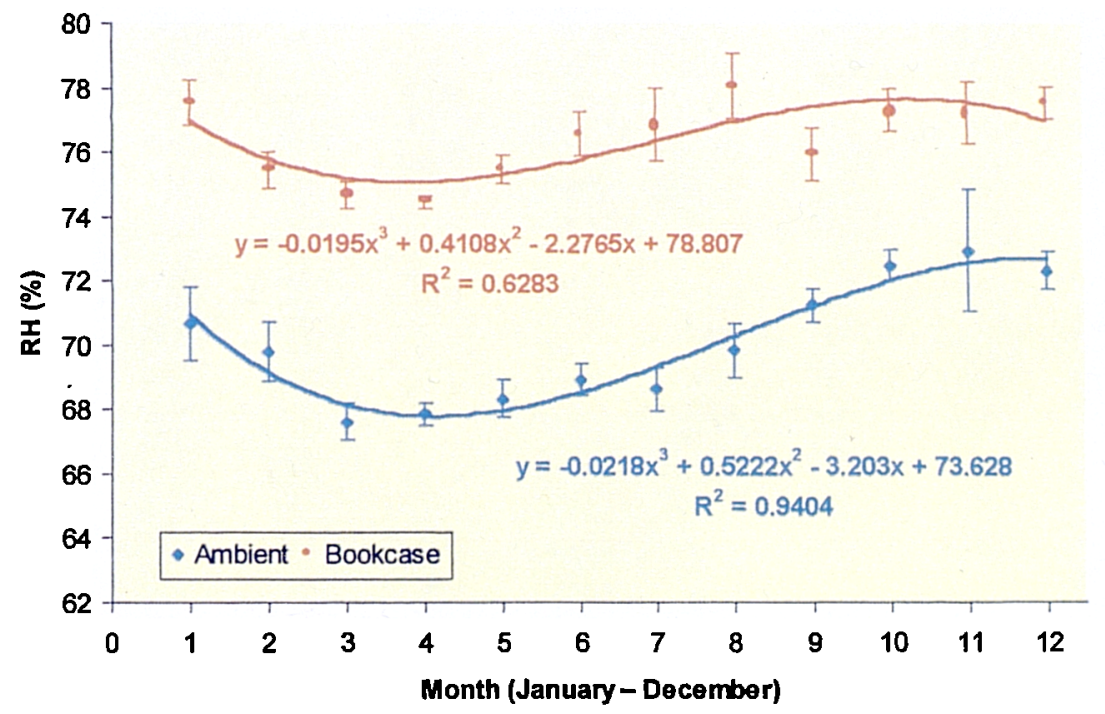

Figure 45: Ambient and bookcase variation in RH (monthly averages) 
For ambient $\mathrm{RH}, \mathrm{y}$ :

$y=-0.0218 x^{3}+0.5222 x^{2}-3.203 x+73.628$

For the bookcase $\mathrm{RH}, \mathrm{y}$ :

$y^{\prime}=-0.0195 x^{3}+0.4108 x^{2}-2.2765 x+78.807$

where $x=$ month of year (January $=1$, December $=12$ )

Re-arranging (1):

$x^{3}=(1 / 0.0218)\left(-y+0.5222 x^{2}-3.203 x+73.628\right)$

Re-arranging (2):

$x^{3}=(1 / 0.0195)\left(-y^{\prime}+0.4108 x^{2}-2.2765 x+78.807\right)$

Equating (3) and (4) and re-arranging gives the model:

$y^{\prime}=0.894 y-0.055 x^{2}+0.592 x+12.95$

where; $\quad y$ is the predicted $\mathrm{RH}$ inside the book

$y$ is the ambient RH (measured)

$x$ is the month of year (January $=1$, December $=12$ )

Figure 46: Deriving the mathematical model for the Bronte Parsonage Museum

This model was far more easily validated since the ambient conditions were very stable. Using the model with monthly averages proved to trace irregularities within the room (i.e. when the door was left open for easier access during the month of January), which actually had not been experienced by the bookshelf. It was therefore found useful to run the model with a rolling 30-day average, as has been done with the data obtained from the Guildhall. 
The developed model for the Bronte Parsonage Museum, using a rolling average, was able to reproduce the environment experienced within the bookcase with far less uncertainty than observed at the Guildhall (Figure 47).

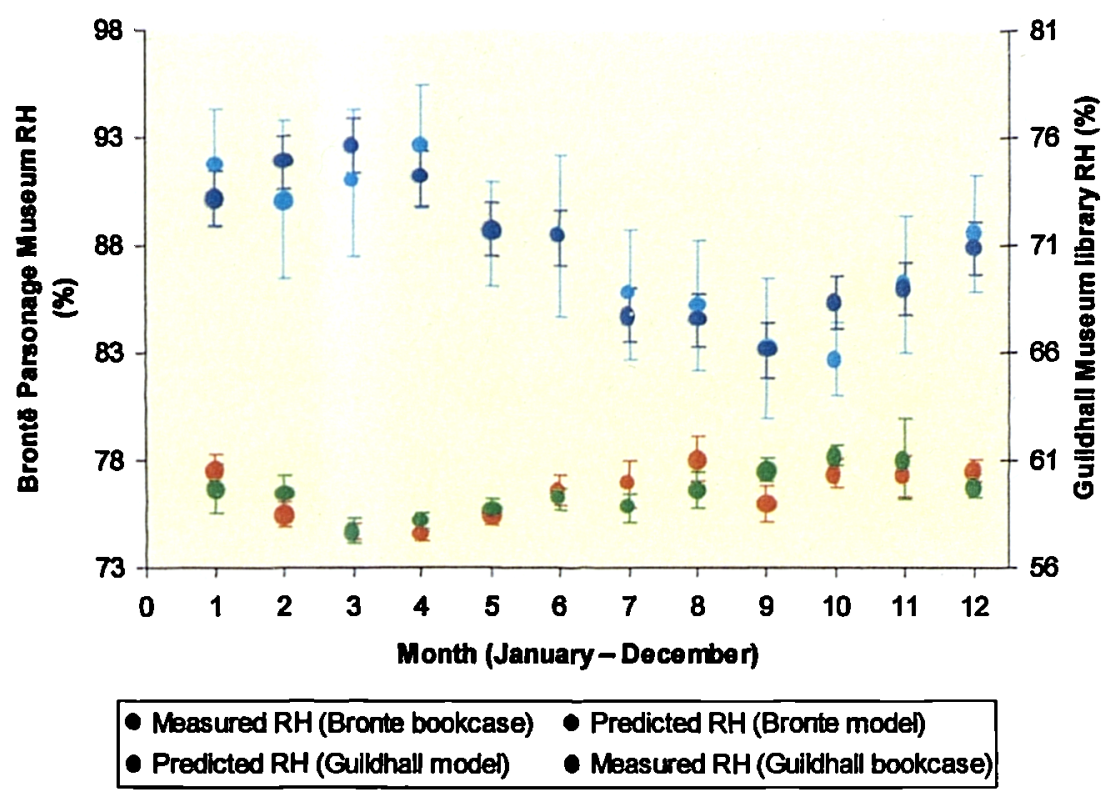

Figure 47: Comparing predicted and measured RH values in the bookcases of both Brontë Parsonage Museum and Guildhall Library

These modelling studies have shown that it is possible to model environmental conditions within refined spaces using ambient data. The model developed within this study has successfully used and predicted conditions experienced within an extremely unstable as well as a very stable environment. The stable conditions produced predicted values within $\pm 1 \%$. Data from the unstable site produced data within $\pm 10 \%$, using raw data, and $\pm 5 \%$ using rolling averages. 


\section{CONCLUSIONS AND FURTHER WORK}

This research project involved an extensive literature review, a survey among libraries and archives within the British Isles, and in-depth environmental monitoring at two case-study sites. This work was aimed at developing a simple model to be used as a predictive tool for analysing storage conditions from ambient $\mathrm{RH}$ measurements.

Although the literature available for both the preservation of paper and the preventive conservation of historic buildings and monuments is extensive, there is evidently a lack of guidance on issues relating to the interface between the two. An attempt has been made in this thesis to draw particular attention to this problem.

During the course of this study it has become clear that an interdisciplinary approach to the preservation of collections housed within historic buildings is paramount to success. Traditional training within the museum profession typically focuses only on certain aspects. Therefore, conservators, whilst having in-depth knowledge of their particular area, often lack the understanding of problems concerning the historic building that houses their collection. The same is true for those professionals dealing with buildings. Engineers, building managers and surveyors often have limited knowledge of the needs of a collection. This is exacerbated by the fact that professionals involved may not be given the chance to work as a team on the often broad issues relating to their situation.

While it was found that there is generally an awareness of the problems associated with housing collections within historic buildings, the dissemination of information on an interdisciplinary level is not easy. However, where a holistic approach has been taken, a clear benefit to collections, as well as to buildings, was apparent. It is therefore important that professional institutions, such as the International Centre for the Study of the Preservation and the Restoration of Cultural Property (ICCROM) or the European Commission on Preservation and Access (ECPA) support research and disseminate guidance on such issues. 
During the study of micro-and macro-environments at selected case studies, important insight has been gained into the interaction between buildings, enclosed bookshelves and the books housed within them. While the experiment did not allow for the monitoring of the actual moisture content of paper, it did reveal its great impact on the immediate environment surrounding the books. As the ability of paper to hold moisture is far greater than the ability of air, books within a confined shelving system may act as a moisture reservoir, releasing water to the air, whenever the RH drops. Depending on circumstances, this may hold true for much of the year. There is thus a tendency for enclosed bookshelves to experience a higher $\mathrm{RH}$ than the ambient condition in the room. Both case studies, representing stable and unstable environments, confirmed this interaction.

Often, paper-based collections within historic buildings are restricted in terms of storage and display, which makes it important to monitor the conditions and control the environment, wherever possible. Often, rather simple solutions may be achieved in increasing the air circulation or controlling the RH by local dehumidification. Historic buildings can often work to the advantage of a collection as their thermal mass retards or 'evens out' extreme fluctuations through their often massive building fabric.

It has also become clear that seemingly adverse conditions, as observed at the Guildhall Library in Leicester, do not necessarily have a negative impact on the collection, as the books housed within the Guildhall, for centuries in some cases, are in good condition. Stable conditions on the other hand, as seen at the Brontë Parsonage Museum, can still be held responsible for detrimental effects, if their overall temperature or $\mathrm{RH}$ is too high, especially when creating additional microclimates within enclosed spaces.

Currently, tools for environmental analysis are either not commercially available, or do not address the particular problems faced by museum staff. A special tool for predicting conditions within refined spaces from measured ambient data has therefore been developed. It has been shown that both stable and unstable ambient 
conditions can be modelled successfully, although two very different models are required to reproduce respective environments within the bookcases. It was shown that this might well be a function of the material of the bookcase, rather than the stability of the ambient conditions, since books at the Guildhall library were housed within wooden cases, whereas the bookshelves at Brontë Parsonage Museum were made of metal. Further work would need to be done to clarify this. It is anticipated that this tool will give professionals further insight into micro-climates within their collections and aid in making decisions with respect to environmental control.

At present, the predicted environmental data can be analysed using the IPI 'Climate Notebook' (when available), to determine the suitability of the environmental conditions with respect to the care of the collection. However, in the future, it is intended to incorporate the database of cause and effect into the model developed during this research program, so that conservation information can be accessed more readily.

Future work should emphasise the distribution of information on the care of collections housed within historic buildings. The information and guidance should be derived from an interdisciplinary approach to the subject and disseminated by professional bodies. This is of particular importance for libraries and archives, which increasingly have to deal with modern media, such as magnetic tapes and various forms of digital media.

Future surveys should therefore focus on the amount of modern media present, as well as anticipated growth of these types of collections. Their particular problems have attracted increasing attention in recent times. However, much work remains to be done, including life expectancy of such records and recovery after various disasters.

Although the project has given further insight into the interrelationship between macro- and micro-climates, certain issues remain unknown. Future research therefore needs to be carried out to determine the exact role certain enclosures play. For example, much archival material is stored within cardboard boxes and/or within 
various kinds of wooden or metal drawers. As this research has not taken any materials other than paper into account, the specific effects of leather, book-cloth or other cover material on the absorption and desorption of moisture has not been looked at. This clearly should be addressed in further research.

Future research should also seek to answer whether the material in a fully packed strong-room has a positive effect on building fabric, and how detrimental such buffering would be to the collection (i.e. to determine whether or not the observations made in this study can also be seen on a larger scale within library and archive collections). Further attention should also be given to changes in actual moisture content of paper during an experiment with a similar set-up.

Studies in this direction should be carried out with a view to other volatile compounds present in the air, such as particulate pollutants, or those off-gassing from the enclosure material itself.

Research of this kind would also be valuable in further developing the predictive model, as the derived data so far do not fully answer questions of micro-climates other than the ones described. In addition, it is important to ascertain whether the models can deal with extreme changes in environmental conditions and to determine its limits of function. 


\section{REFERENCES}

\subsection{Guidelines and Reports}

(1995): Guidance on Schemes for the Care, Presenvation and Management of Records under Section 60 of the Local Government (Wales) Act. Welsh Office.

(1996a): Circular 61/96: Planning and the Historic Environment: Historic Buildings and Conservation Areas. Welsh Office (since 1999 National Assembly for Wales), Cardiff.

(1996b): Historic Buildings: The Conservation of their Fixtures, Fittings, Decorations and Contents. National Trust Policy Paper. National Trust, London.

(1998a): Circular 1/98: Planning and the Historic Environment: Directions by the Secretary of State of Wales. Welsh Office (since 1999 National Assembly for Wales), Cardiff.

(1998b): Memorandum of Guidance on Listed Buildings and Conservation Areas. Historic Scotland, Edinburgh.

(1998c): Our Shared Past: an Archival Domesday for England. Archival Mapping Project Board. Local Authority Archive Services in England: Funding Opportunities and Development in England. Public Record Office, Kew.

(1999): National Planning Policy Guideline: Planning and the Historic Environment. NPPG 18. Scottish Executive, Edinburgh.

(2000a): An Archival Account for Scotland. Public and Private Sector Archive Services in Scotland: Funding Opportunities and Development Needs. National Archives of Scotland, Edinburgh.

(2000b): Guidelines for the Protection of the Architectural Heritage. Council of Europe Publishing, Strasbourg.

(2000c): Guidelines for the Protection of the Movable Heritage. Council of Europe Publishing, Strasbourg.

(2000d): Power of Place: The Future of the Historic Environment. English Heritage Power of Place Office, London.

(2001b): Archival Mapping Project for Wales - A Survey of Archival Provision in Wales. Archive Council Wales, Aberystwyth. 


\subsection{References}

ADCOCK E.P. (1998): IFLA Principles for the Care and Handling of Library Material. International Preservation Issues, 1. International Federation of Library Associations and Institutions (IFLA), Paris.

ALBERGE D. (2001): Alarm as Bookworms Devour Historic Museums Collections. The Times, no. 67246, 17 September, p. 18.

ANDRÉ L. (1996): Machines à papier: innovation et transformations de l'industrie papetière en France: 1798-1860. Éd. de l'Écoledes hautes études en sciences sociales, Paris.

APTIAIC (1992): New Oreans Charter for Joint Preservation of Historic Structures and Artifacts.

BANKS P.N. (1988): Environmental Conditions for Storage of Paper-based Records. In: Proceedings of Conservation in Archives. International Council on Archives and National Archives of Canada, Ottawa, 10-12 May 1988, pp. 7788.

BANSA H. (2001): Personal Communication, 6 November.

BARROW W.J. (1967): Permanence / Durability of the Book - V. W.J. Barrow Research Laboratory, Richmond, Virginia.

BÉGIN P. and KAMINSKA E. (2001): ASTM/ISR Research Program on the Effects of Ageing on Printing and Writing Papers: Thermal Accelerated Ageing Test Methods Development. In: European Materials Research Society, Spring Meeting. Strasbourg, France, 6-7 June 2001, pp. K-11.4.

BeLL W.J. (1988): Cockroaches in the Museum Environment. In: A Guide to Museum Pest Control (L. A. Zycherman and J. R. Schrock, eds.), Foundation of the American Institute for Conservation of Historic and Artistic Works and the Association of Systematics Collections, Washington DC, pp. 83-97.

BigOURDAN J.-L., ADELSTEIN P.Z. and REILLY J.M. (1997): Moisture and Temperature Equilibration: Behaviour and Practical Significance in Photographic Film Preservation. In: La conservation: une science en évolution - bilans et perspectives. (C. Chahine, F. Daniel, F. Flieder, B. Lavédrine and S. Monod, eds.), ARSAG, Paris, 21-25 April 1997, pp. 154-164.

BIGOURDAN J.-L. and REILLY J.M. (1997): Environment and Enclosures in Film Preservation. Final Report to the Office of Preservation, National Endowment for the Humanities. Image Permanence Institute, Rochester Institute of Technology, Rochester, NY.

BIGOURDAN J.-L. and REILLY J.M. (2002): Effects of Fluctuating Environments on Paper - Stability and Practical Significance for Preservation. In: La 
conservation à l'ère du numérique. ARSAG, Paris, 27-30 May 2002, pp. 180192.

BlADES N., KRUPPA D. and CASSAR M. (2002): Development of a Web-based Software Tool for Predicting the Occurence and Effect of Air Pollutants inside Museum Buildings. In: 13th Triennial Meeting. ICOM-CC, Rio de Janeiro, Brazil, 22-28 September 2002, Vol. 1, pp. 9-14.

BOGAARD J. and WHITMORE P.M. (2002): Explorations of the Role of Humidity Fluctuations in the Deterioration of Paper. In: Works of Art on Paper Techniques and Conservation. $(\mathrm{V}$. Daniels, A. Donnithorne and P. Smith, eds.), IIC, Baltimore, MD, USA, 2-6 September 2002, pp. 11-15.

BRANDON C.E. (1981): Properties of Paper. In: Pulp and Paper - Chemistry and Chemical Technology (J. P. Casey, ed.), John Wiley \& Sons, New York, Chichester, Brisbane, Toronto. Vol. 3, pp. 1715-1972.

BRENNER R.J. (1991): Insect Pests, Construction Practices and Humidity. In: Bugs, Mold \& Rot, a Workshop on Residential Moisture Problems, Health Effects, Building Damage, and Moisture Control. (E. Bales, ed.) National Institute of Building Sciences, Washington, DC, 20-21 May 1991, pp. 19-26.

BRIGGS J.R. (1987): Environmental Control of Modern Records. In: Conservation of Library and Archive Materials and the Graphic Arts (G. Petherbridge, ed.), Butterworths, London.

BRIMBLECOMBE P. and RAMER B. (1983): Museum Display Cases and the Exchange of Water Vapour. Studies in conservation, Vol. 28, no. 4, pp. 179-188.

BSI (1988): Repair and Allied Processes for the Conservation of Documents. BS 4971. British Standard Institution, London.

BSI (1998): Guide to the Principles of the Conservation of Historic Buildings. BS 7913. British Standards Institution, London.

BSI (2000): Recommendations for the Storage and Exhibition of Archival Documents. BS 5454: 2000. British Standards Institution, London.

BüLow A.E. (1999): Migration of Volatile Compounds from Paper Stacks during Accelerated Ageing. MAC Thesis, Department of Art, Queen's University, Kingston, ON, Canada.

Caneva G., Nugari M.P. and Salvadori O. (1991): Biology in the Conservation of Works of Art. ICCROM, Rome, Italy.

CHILD R.E. (1996): Detection, Monitoring and Control of Instect Pests. In: Pest Attack \& Pest Control in Organic Materials. (A. Neher and D. Rogers, eds.), UKIC, London, 18 November 1996, pp. 4-6. 
ChRISTOFFERSEN L.D. (1995): Zephyr - Passive Climate Controlled Repositories. unpublished thesis, Department of Building Physics, Lund University, Lund, Sweden.

Clarke J.A., Johnstone C.M., Kelly N.J., Mclean R.C., Anderson J.A., Rowan N.J. and SMITH J.E. (1999): A Technique for the Prediction of the Conditions Leading to Mould Growth in Buildings. Building and Environment, Vol. 34, no. 4, pp. 515-521.

Cox H. (1999): The Application and Use of Standards in the Care and Management of Libraries and Archives. National Preservation Office, London.

CRANK J. (1960): Rate of Change of Moisture Content. In: Moisture in Textiles (J. W. S. Hearle and R. H. Peters, eds.), The Textile institute / Butterworths Scientific Publications, Manchester / London, pp. 83-93.

CROOK D.M. and BENNETT W.E. (1962): The Effect of Humidity and Temperature on the Physical Properties of Paper. The British Paper \& Board Industry Research Association, Kennley, Surrey.

CULVERHOUSE J. (2001): Personal Communication with D.S. Watt, 28 November.

CURTEIS T. (2002): Working Buildings: The Effect of Building Use on the Conservation of Wall Paintings and other Sensitive Polychrome Surfaces. In: Where Conservation Meets Conservation. (D. S. Watt, ed.) Donhead Publishing Ltd, De Montfort University, Leicester, UK, 9 September 2002, in press.

Daniel V. and MAekawa S. (1993): Hygrometric Half-lives of Museum Cases. Restaurator, Vol. 14, no. 1, pp. 30-44.

DAVENPORT C. (1908): The Book - Its History and Development. D. Van Nostrand Company (republished by Tower Books, Detroit, 1971), New York.

DAWIDOWSKY F. (1884): A Practical Treatise on the Raw Materials and Fabrication of Glue. Henry Carey Baird \& Co., Philadelphia / London.

DE TORRES A.R. (1995): Preventive Conservation: Global Trends. In: The Conservation and Preservation of Islamic Manuscripts. (Y. Ibish, ed.) AlFurqan Islamic Heritage Foundation, London, 18-19 November 1995, pp. 185-194.

DI PIETRO G. and LIGTERINK F. (1999): Prediction of the Relative Humidity Response of Backboard-protected Canvas Paintings. Studies in Conservation, Vol. 44, no. 4, pp. 269-277.

DIEHL E. (1980): Bookbinding - Its Background and Technique. Dover Publications, New York. 
DNH (1995): Guidance on the Care, Preservation and Management of Records Following Changes Arising from the Local Government Act 1992. Department of National Heritage.

DOE (1990): Planning Policy Guidance: Archaeology and Planning. PPG 16. Department of the Environment, London.

DoE/DNH (1994): Planning Policy Guidance: Planning and the Historic Environment. PPG 15. Department of the Environment / Department of National Heritage, London.

Douglas R. (1990): The Evolution of the Library: Antique and Medieval Storage Systems. unpublished research paper, Department of Art, Queen's University, Kingston (ON).

ECCO (1993): E.C.C.O. Professional Guidelines: The Profession and the Code of Ethics. European Confederation of Conservator-Restorers' Organisations, http://palimpsest.stanford.edu/byorg/ecco/, 1 October 2001

EMMS (2001): The EMMS Emergency Manual for Historic Buildings and Collections. East Midlands Museum Service, Nottingham.

ERHARDT D. and MECKLENBURG M. (1994): Relative Humidity Re-examined. In: Preventive Consenvation: Practice, Theory and Research. (A. Roy and P. Smith, eds.), IIC, Ottawa, 12-16 September 1994, pp. 32-38.

ESPY H.H. (1990): The Genesis of Alkaline Sizing and Alkaline-curing Wet-strength Resins. Alkaline Paper Advocate, Vol. 3, no. 3, pp. 28-29.

FLORIAN M.-L. (1993): Conidial Fungi (Mould) Activity on Artifact Materials - a New Look at Prevention, Control, and Eradication. In: 10th Triennial Meeting. (J. Bridgland, ed.) ICOM-CC, Washington DC, 22-27 August 1993, Vol. 2, pp. 868-874.

FLORIAN M.-L. (1997): Heritage Eaters. James \& James, London.

FLORIAN M.-L.E. (1994): Conidial Fungi (Mould, Mildew) Biology: a Basis for Logical Prevention, Eradication and Treatment for Museum and Archival Collections. Leather Conservation, Vol. 10, pp. 1-29.

FOoT M. (1997): Britain's Written Heritage: a Struggle for Survival. In: La conservation: une science en évolution - bilans et perspectives. (C. Chahine, F. Daniel, F. Flieder, B. Lavédrine and S. Monod, eds.), ARSAG, Paris, 21-25 April 1997, pp. 256-258.

FоOт M. (2001): Building Blocks for a Preservation Policy. National Preservation Office, London. 
FOSTER S., RUSSEL R., LYALL J. and MARSHALL D. (1995): Memory of the World: General Guidelines to Safeguard Documentary Heritage. Cll-95NS-11. UNESCO, Paris.

Gallo F., Valenti P., Colaizzi P., Pasquariello G., Scorrano M., Sclocchi M.C., MAGGI O. and PERSIANI A.M. (1996): Research on the Viability of Fungal Spores in Relation to Different Microclimates and Different Materials. In: International Conference on Conservation and Restoration of Archive and Library Materials. Istituto centrale per la patologia del libro (Roma), Erice, Italy, 22-29 April 1996, Vol. 1, pp. 213-230.

GIROUARD G. (1980): Life in the English Country House. Penguin Books, Harmondsworth.

GRANT J. (1937): Books \& Documents - Dating, Permanence and Presenvation. Grafton \& $\mathrm{Co}$, London.

GREAVES P. (1985): The Practical Measurement of Paper Condition (Why Bother with Quality Control when the Paper is Wavy). In: Taga Proceedings, pp. 337358.

GROOM P. and PANISSET T. (1933): Studies on Penicillium Chrysogenum Thom, in Relation to Temperature and Relative Humidity. Annals of Applied Biology, Vol. 20, pp. 633-660.

HAGGLUND R., WESTERLIND B., GULLIKSSON M. and NORDSTRAND T. (1999): Diffusion of Water Vapor in Paper. In: AlChE Symposium Series No. 322: Fundamental Advances in the Pulp and Paper Industry, Vol. 95, pp. 71-79.

HANSEN E.F., LEE S.N. and SOBEL H. (1992): The Effects of Relative Humidity on Some Physical Properties of Modern Vellum. JAIC, Vol. 31, no. 3, pp. 325342.

HEARLE J.W.S. (1960): The Structure of Fibres. In: Moisture in Textiles (J. W. S. Hearle and R. H. Peters, eds.), The Textile Institute / Butterworths Scientific Publications, Manchester / London, pp. 10-13.

HENDERSON C. (1996): Environmental Standards for Exhibiting Library and Archival Materials; the Work of NISO Committee MM. In: International Conference on Conservation and Restoration of Archive and Library Materials. Istituto centrale per la patologia del libro (Roma), Erice, Italy, 22-29 April 1996, Vol. 1, pp. 125-131.

HENDRIKS K.B. (1984): The Preservation and Restoration of Photographic Materials in Archives and Libraries: a RAMP Study with Guidelines. PGI-84MS/1. UNESCO, Paris.

HMC (1997): HMC Publications: Standard for Record Repositories. $2^{\text {nd }}$ ed, Public Record Office, Royal Commission on Historic Manuscripts and the Scottish Record Office. 
HMC (1999): Archives at the Millenium - The 28th Report of the Royal Commission on Historical Manuscripts. The Stationary Office, London.

HUGHES S. (2001): Preserving Library and Archive Collections in Historic Buildings. The Council for Museums, Archives and Libraries (Resource), University College London.

HUNTER D. (1978): Papermaking - The History and Technique of an Ancient Craft. Dover Publications Inc, New York.

ICA (2000): General International Standard Archival Description: ISAD(G). International Council on Archives, http://www.ica.org/ISAD(G)E-pub.pdf., 15 October 2001

ICOM-CC (1986): Code of Ethics of the ICOM Committee for Conservation. International Council for Museums, Committee for Conservation (ICOM-CC), http://cecor.eba.ufmg.br/icom-ccl, 5 October 2001

ICOMOS (1964): The Venice Charter: International Charter for the Conservation and Restoration of Monuments and Sites. International Council on Monuments and Sites, Paris.

ICOMOS (1999): The Burra Charter: The Australia ICOMOS Charter for the Conservation of Places of Cultural Significance. International Council on Monuments and Sites, Paris.

JACKSON-STOPS G. and PIPKIN J. (1993): The English Country House: A Grand Tour. Weidenfeld \& Nicholson, London.

JEDRZEJEWSKA H. (1985): Some Simple Consideration on the Problem of Relative Humidity Inside Buildings. In: Common Responsibilities and Tasks of the Restorer, Scientist and Museologist in Storing and Exhibiting the Objects of Art, with Particular Regard to the Problems of Exhibit Installations and Showcases. 5th Intermational Restorer Seminar. National Centre of Museums, Veszprém, Hungary, 29 June - 9 July 1985, pp. 19-25.

Kamba N. (1994): Performance of Wooden Storage Cases in Regulation of Relative Humidity Change. In: Preventive Conservation - Practice, Theory and Research. (A. Roy and P. Smith, eds.), IIC, Ottawa, 12-16 September 1994, pp. 181-184.

KAßBERGER M. (1998): Vorgänge im Papier bei dynamisch beschleunigter Alterung. unpublished PhD Thesis, Fakultät für Maschinenbau, Technische Universität Graz, Austria.

KIngsley H., PINNiger D., XAVIER-ROWE A. and WINSOR P. (eds.) (2001): Integrated Pest Management for Collections: Proceedings of 2001: A Pest Odyssey, 1-3 October 2001, James \& James, London. 
KITCHING C. (1993): Archive Buildings in the United Kingdom, 1977-1992. HMSO, London.

KLOTZ-BERENDES B. (2000): Schimmelpilzbefall in Bibliotheken - Vorkommen, Gefährdung, Bekämpfung. Bibliotheksdienst, Vol. 34, no. 1, pp. 47-59.

KNIGHT B. (2002): Predicting the Unpredictable: How does the Museum Environment Fluctuate? In: 13th Triennial Meeting. ICOM-CC, Rio de Janeiro, Brazil, 22-28 September 2002, Vol. 1, pp. 45-50.

KOWALIK R. (1980a): Microbiodeterioration of Library Materials. Part 1, chapters 1-3. Restaurator, Vol. 4, no. 2, pp. 99-114.

KOWALIK R. (1980b): Microbiodeterioration of Library Materials. Part 2. Microbiodecomposition of Basic Organic Library Materials, chapter 4. Restaurator, Vol. 4, no. 3/4, pp. 135-219.

MAEKAWA S. and TOLEDO F. (2002): Controlled Ventilation and Heating to Preserve Collections in Historic Buildings in Hot and Humid Regions. In: 13th Triennial Meeting. ICOM-CC, Rio de Janeiro, Brazil, 22-28 September 2002, Vol. 1, pp. 58-65.

MASSARI G. and MASSARI I. (1993): Damp Buildings, Old and New. Trans. C. Rockwell. ICCROM, Rome.

MAYS D. (2001): Personal Communication with D.S. Watt, 4 December.

MCCRADY E. (1999): Mold: the Whole Picture. Pt. 1. Abbey Newsletter, Vol. 23, no. 4, pp. 1-6.

MCGINNIS G.D. and SHAFIZADEH F. (1980): Cellulose and Hemicellulose. In: Pulp and Paper - Chemistry and Chemical Technology (J. P. Casey, ed.), John Wiley \& Sons, New York, Chichester, Brisbane, Toronto. Vol. 1, pp. 1-38.

MCINTYRE J., KIRTLEY T., BARRETT A. and JONES I. (2000): Guidance for Exhibiting Archive and Library Materials. National Preservation Office, London.

MGC (1996): Code of Practice on Archives for Museums. Museums \& Galleries Commission, London.

MICHALSKI S. (1993): Relative Humidity: a Discussion of Correct/Incorrect Values. In: 10th Triennial Meeting. (J. Bridgland, ed.) ICOM-CC, Washington DC, 22-27 August 1993, Vol. 2, pp. 624-629.

MICHALSKI S. (1994): Leakage Prediction for Buildings, Cases, Bags and Bottles. Studies in Conservation, Vol. 39, no. 3, pp. 169-186.

NEEDHAM P. (1979): Twelve Centuries of Bookbindings: 400-1600. The Pierpont Morgan Library, New York and Oxford University Press, Oxford. 
NITTÉRUS M. (2000): Fungi in Archives and Libraries. Restaurator, Vol. 21, no. 1, pp. $25-40$.

NPO (1992): Security Matters: Carrying out a Library Security Survey and Drafting a Security Policy. National Preservation Office, London.

NPO (1994): Security Matters: How to Deal with Criminal and Anti-social Behaviour. National Preservation Office, London.

NPO (1996): Security Matters: Designing Out Crime. National Preservation Office, London.

NPO (2000): Good Handling Principles and Practice for Library and Archive Materials. National Preservation Office / British Library Collection Care and Handling Team, London.

PADFIELD T. (1966): The Control of relative Humidity and Air Pollution in Show-cases and Picture Frames. Studies in Conservation, Vol. 11, pp. 8-30

PADFIELD T. (1988): Climate Control in Libraries and Archives. AlCCM Bulletin, Vol. 14 , no. $1 / 2$, pp. $49-68$.

PADFIELD T. (1998): The Role of Absoment Building Materials in Moderating Changes of Relative Humidity. unpublished PhD Thesis, Department of Structural Engineering and Materials, The Technical University of Denmark, Lyngby, Denmark.

PANSHIN A.J. and DE ZEEUW C. (1980): Textbook of Wood Technology. 4 ed. (M. D. Provenzano and S. Wagley, eds.). McGraw-Hill, New York / Montreal I London.

PAPAKONSTANTINOU K.A., KIRANOUDIS C.T. and MARKATOS N.C. (2000): Mathematical Modeling of Environmental Conditions inside Historical Buildings. The Case of the Archaeological Museum of Athens. Energy and Buildings, Vol. 31, no. 3, pp. 211-220.

Paxman J. (1999): The English: A Portrait of a People. Penguin Books, Harmondsworth.

PICKFord C., RhYS-LeWIS J. and WeBer J. (1997): Best Practice Guideline 4: Preservation and Conservation. Society of Archivists, London.

PINNIGER D. and WINSOR P. (1998): Integrated Pest Management. Museums \& Galleries Commission, London.

PINNIGER D.B. (1994): Insect Pests in Museums. $3^{\text {rd }}$ ed. Archetype Conservation Monograph. Archetype Publications Ltd, London. 
PORCK H.J. and TEYGELER R. (2000): Preservation Science Survey. Council on Library and Information Resources / European Commission on Preservation and Access, Washington, DC.

PRO (2002): A History of the Public Records. http://www.pro.gov.uk/about/history/ history1.htm, Public Record Office, 9 October 2002

RAMARAO B.V. (1999): Moisture Sorption and Transport Processes in Paper Materials. Studies in Surface Science and Catalysis, Vol. 120, no. A, pp. 531560.

REES S. (2001): Feral Pigeons: A Forgotten Pest? In: Integrated Pest Management for Collections: Proceedings of 2001: A Pest Odyssey. (H. Kingsley, D. B. Pinniger, A. Xavier-Rowe and P. Winsor, eds.), James \& James, London, 1-3 October 2001, pp. 106-113.

REILLY J.M. (1997): Preservation and the Economics of Information Access in Institutions, Libraries, and Archives. In: La conservation: une science en évolution - bilans et perspectives. (C. Chahine, F. Daniel, F. Flieder, B. Lavédrine and S. Monod, eds.), ARSAG, Paris, 21-25 April 1997, pp. 70-76.

REILlY J.M., NISHIMURA D.W. and ZINN E. (1995): New Tools in Preservation Assessing Long-term Environmental Effects on Library and Archives Collections. The Commission on Preservation and Access, Washington, DC.

RIDOUT B. (2000): Timber Decay in Buildings: The Conservation Approach to Treatment. E. \& F.N. Spon, London.

RITZENTHALER M.L. (1993): Preserving Archives and Manuscripts. Archival Fundamental Series. Society of American Archivists, Chicago, IL.

Rodrigues DE CARVAlHo C.S., Joly M.C. and Lopes TAVARES L. (2002): House of Rui Barbosa Museum: a Preventive Conservation Plan Based on an Environmental Control Strategy. In: 13th Triennial Meeting. ICOM-CC, Rio de Janeiro, Brazil, 22-28 September 2002, Vol. 1, pp. 86-89.

RYDHOLM S.A. (1985): Pulping Processes. Robert E. Krieger Publishing Company, Malabar, Florida.

SClocChI M.C., Ruschioni E., CAVAllinI F. and Persia F. (1996): Research on Biodeterioration of Archival Assets. In: Intemational Conference on Consenvation and Restoration of Archive and Library Materials. Istituto centrale per la patologia del libro (Roma), Erice, Italy, 22-29 April 1996, Vol. 1, pp. 175-190.

ScotT G. (1994): Moisture, Ventilation and Mould Growth. In: Preventive Conservation - Practice, Theory and Research. (A. Roy and P. Smith, eds.), IIC, Ottawa, 12-16 September 1994, pp. 149-153. 
ScoTT G. (1996): Mould Growth in Tropical Environments: a Discussion. In: 11th Triennial Meeting. ICOM-CC, Edinburgh, Scotland, 1-6 September 1996, Vol. 1, pp. 91-96.

SHAHANI C.J., HENGEMIHLE F.H. and WEBERG N. (1988): The Effect of Variations in Relative Humidity on the Accelerated Aging of Paper. In: Historic Textile and Paper Materials II: Conservation and Characterization. Developed from a symposium sponsored by the Cellulose, Paper and Textile Division at the 196th National Meeting of the American Chemical Society. (S. H. Zeronian and H. L. Needles, eds.), American Chemical Society, Los Angeles, CA, 2530 September 1988, pp. 63-80.

SINGH J. (1994): The Built Environment and the Development of Fungi. In: Building Mycology: Management of Decay and Health in Buildings (J. Singh, ed.), E. \& F.N. Spon, London, pp. 1-21.

SoA (2001): Code of Practice for Archivists and Records Managers under Section 51 (3) of the Data Protection Act 1998. Society of Archivists and Records Management Society.

SPAB (1877): Manifesto. Society for the Protection of Ancient Buildings, London.

StRANG T.J.K. (1996): Museum Pest Management. Seminar Notes, Canadian Conservation Institute. Ottawa.

STRANG T.J.K. (1998): Another Brick in the Wall. In: 3rd Nordic Symposium on Insect Pest Control in Museums. (M. Ákerlund, J.-E. Bergh, A. Stenmark and I. Wallenborg, eds.), PRE-MAL and ICOM, Stockholm, Sweden, 24-25 September 1998, pp. 10-29.

StRANG T.J.K. and DAWson J.E. (1991): Controlling Museum Fungal Problems. Technical Bulletin, 12. Canadian Conservation Institute, Ottawa.

SZCZEPANOWSKA H. (1986): Biodeterioration of Art Objects on Paper. The Paper Conservator, Vol. 10, pp. 31-39.

TÉtREAUlt J. (1999): Coatings for Display and Storage in Museums. Technical Bulletin, 21. Canadian Conservation Institute, Ottawa.

THOMSON G. (1964): Relative Humidity - Variation with Temperature in a Case Containing Wood. Studies in Conservation, Vol. 9, no. 4, pp. 153-169.

THOMSON G. (1977): Stabilization of RH in Exhibition Cases: Hygrometric Half Time. Studies in Conservation, Vol. 22, pp.85-102

URQUHART A.R. (1960): Sorption Isotherms. In: Moisture in Textiles (J. W. S. Hearle and R. H. Peters, eds.), The Textile Institute / Butterworths Scientific Publications, Manchester / London, pp. 14-32. 
URZI C. and KRUMBEIN W.E. (1994): Microbiological Impacts on the Cultural Heritage. In: Durabiltiy and Change: the Science, Responsibility, and Cost of Sustaining Cultural Heritage (W. E. Krumbein, P. Brimblecombe, D. E. Cosgrove and S. Staniforth, eds.), John Wiley \& Sons, London, pp. 107-135.

VALENTÍN N. (1986): Biodeterioration of Library Materials Disinfection Methods and New Alternatives. Restaurator, Vol. 10, no. 1, pp. 40-45.

VALENTín N., GaRcía R., dE LUIS O. and MaEKAwa S. (1998): Microbial Control in Archives, Libraries and Museums by Ventilation Systems. Restaurator, Vol. 19 , no. 2, pp. 85-107.

WATT D.S. (1999): Building Pathology: Principles and Practice. Blackwell Science, The University Press, Cambridge.

WATT D.S., COLSTON B.J. and BOLLOW A.E. (2002): Libraries and Archives in Historic Buildings: Predicting the Effects of Dampness. Library and Information Commission Research Report No. 138. Council for Museums, Libraries and Archives (Resource), De Montfort University, Leicester.

WATT I.C. (1979): Water Vapour Sorption Hysteresis in Swelling Substrates. In: Physics of Materials (D. W. Borland, L. M. Clarebrough and A. J. W. Moore, eds.), Griffin Press, Melboume, pp. 305-313.

Wellheiser J.G. (1992): Nonchemical Treatment Processes for Disinfection of Insects and Fungi in Library Collections. IFLA Publications (C. Henry, ed.), 60. IFLA, The Hague, The Netherlands.

WHITMORE P.M. (1994): The Mechanisms of Chemical Deterioration of Paper. In: Workshop on the Effects of Aging on Printing and Writing Papers, ASTM/ISR, Philadelphia, PA, pp. 31-40.

WILSON W.K. (1995): Environmental Guidelines for The Storage of Paper Records. NISO TR01-1995. National Information Standards Organization, Annapolis Junction (MD).

WINSOR P. (1999): Conservation of Books. Fact Sheet. Museums \& Galleries Commission, London.

WITHAM G.S. (1920): Modem Pulp and Paper Making. The Chemical Catalog Company Inc., New York.

Zou X., Uesaka T. and GuRnagul N. (1996): Prediction of Paper Permanence by Accelerated Aging 1. Kinetic Analysis of the Aging Process. Cellulose, Vol. 3, pp. 243-267. 


\subsection{Key Texts}

\subsection{Paper and Paper-based Collections}

ADCOCK E.P. (1998): IFLA Principles for the Care and Handling of Library Material. International Preservation Issues, 1. International Federation of Library Associations and Institutions (IFLA), Paris.

BSI (2000): Recommendations for the Storage and Exhibition of Archival Documents. BS 5454: 2000. British Standards Institution, London.

DIEHL E. (1980): Bookbinding - Its Background and Technique. Dover Publications, New York.

HUNTER D. (1978): Papermaking - The History and Technique of an Ancient Craft. Dover Publications Inc., New York.

\subsection{Historic Buildings and Monuments}

WATT D.S. (1999): Building Pathology: Principles and Practice. Blackwell Science, The University Press, Cambridge.

WATT D.S., COLSTON B.J. and BÜLOW A.E. (2002): Libraries and Archives in Historic Buildings: Predicting the Effects of Dampness. Library and Information Commission Research Report No. 138. Council for Museums, Libraries and Archives (Resource), De Montfort University, Leicester.

\subsection{The Interface between Paper-based Collections and Historic Buildings}

GIROUARD G. (1980): Life in the English Country House. Penguin Books, Harmondsworth. 
HMC (1999): Archives at the Millenium - The 28th Report of the Royal Commission on Historical Manuscripts. The Stationary Office, London.

PRO (2002): A History of the Public Records. http://www.pro.gov.uk/about/history/ history1.htm, Public Record Office, 9 October 2002

\subsection{Specific Damp-related Problems}

ERHARDT D. and MECKLENBURG M. (1994): Relative Humidity Re-examined. In: Preventive Conservation: Practice, Theory and Research. (A. Roy and P. Smith, eds.), IIC, Ottawa, 12-16 September 1994, Vol., pp. 32-38.

FLORIAN M.-L. (1997): Heritage Eaters. James \& James, London.

MASSARI G. and MASSARI I. (1993): Damp Buildings, Old and New. Trans. C. Rockwell. ICCROM, Rome.

StRANG T.J.K. and DAwson J.E. (1991): Controlling Museum Fungal Problems. Technical Bulletin, 12. Canadian Conservation Institute, Ottawa. 


\subsection{Relationship between Humidity and Paper}

HeARle J.W.S. and PETERS R.H. (eds.)(1960): Moisture in Textiles. The Textile Institute / Butterworths Scientific Publications, Manchester / London.

ReILly J.M., NishimURA D.W. and ZINN E. (1995): New Tools in Preservation Assessing Long-term Environmental Effects on Library and Archives Collections. The Commission on Preservation and Access, Washington, DC.

\subsection{Predictive Tools for Environmental Analysis}

http://www.rit.edu/ 661www1/sub_pages/8page21.htm (5 November 2001) 
APPENDICES 


\section{APPENDIX A - MEChanISMS OF DETERIORATION AND DECAY (BUILDINGS)}

\section{Human Factors}

- Inherently poor design

- Poor workmanship

- User activities

- wear and tear

- impact and vibration

- inappropriate cleaning routines

- unexpected user activity (e.g. additional floor loading)

- failure to carry out routine maintenance

\section{Chemical, Physical and Biological Action}

- Chemical and/or physical change

- corrosion (e.g. oxidation, electrolytic)

- electromagnetic radiation (e.g. ultraviolet, infrared, visible)

- frost damage

- salt crystallisation

- Incompatible materials

- Biological agencies

- fungi, moulds

- wood-boring insects

- bird droppings

- mosses, lichens

- rodents (e.g. mice, rats, squirrels)

- plants (e.g. climbers, trees)

\section{Atmospheric and Climatic Action}

- Weathering and staining

- Wind/snow loading

- Frost

- Temperature $\left({ }^{\circ} \mathrm{C}\right)$ and humidity $(\% \mathrm{RH})$

- maximum, minimum and fluctuations

- dewpoint and surface/interstitial condensation

- Sunlight

- Air infiltration

- extemal pollution (e.g. $\mathrm{SO}_{2}, \mathrm{NO}_{\mathrm{x}}, \mathrm{CO}_{2}$, particulates)

- indoor air quality (e.g. dusts, fibres, spores, allergens, VOCs, radon)

- Atmospheric gases and pollutants

- Lightning

\section{Moisture}

- Rain (e.g. penetrating damp)

- Groundwater (e.g. rising damp)

- Construction process

- Condensation (e.g. surface, interstitial) 
- Water supply

- Faulty services

- Maintenance and cleaning (e.g. spillage)

Movement

- Loading

- on the structure

- on the ground

- Thermal movement

- Moisture movement

- Soil movement

- deformation due to loading

- volume changes (e.g. clay soils)

- mass movement (e.g. subsidence, landslip)

- Vibration

- Physical change

- loss of volatiles

- ice or crystalline salt formation (e.g. spalling masonry)

- Chemical change

- corrosion (e.g. expansion of embedded cramps)

- sulphate attack (e.g. leaning chimney stacks)

- carbonation

Fire

- Loss of strength of structural materials

- Expansion (e.g. restrained members suffering deformation/cracking)

- Decomposition

- Burning

- Fire-fighting (e.g. water, fungal infestation) 


\section{APPENDIX B - OUTLINE QUESTIONNAIRE}

\section{Library and Information Commission}

Preservation of and Access to the Recorded Heritage

Predicting damp-related problems in historic buildings and monuments used for library and archive purposes

Would you please answer all questions and either tick the most appropriate box(s) or specify information for each of the following:

\subsection{BUILDING}

1.1 What is the age of your building?

$$
\text { Pre-18 century } \square 18^{\text {th }} \text { century } \square 19^{\text {th }} \text { century } \square 20^{\text {th }} \text { century } \square
$$

1.2 What is the principal form of construction?

Timber frame $\square$ Brick/stone walls $\square$ Concrete/steel frame $\square$ Other (please specify) $\square$

1.3 What is the principal roof type?

Pitched roof $\square$ Flat roof $\square$

1.4 How tall is your building?

One storey $\square$ Two storeys $\square$ Three storeys $\square$ More than three storeys $\square$

1.5 Does your building have a basement/cellar?

Yes $\square$ No $\square$

1.6 If yes, is it used in relation to your collection?

Yes $\square$ No $\square$

1.7 Does your building have an attic/roof space?

Yes $\square$ No $\square$

1.8 If yes, is it used in relation to your collection?

Yes $\square$ No $\square$

1.9 Does your building suffer from dampness?

Yes $\square$ No $\square$

1.10 If yes, what is the cause of the dampness?

Rising damp $\square$ Penetrating damp $\square$ Condensation $\square$ Leakage $\square$

1.11 Does (or has) your building been subject to fungal or mould growth?

Yes $\square$ No $\square$ 


\subsection{EXTERNAL / INTERNAL ENVIRONMENT}

2.1 How is your building heated?

No heating $\square$ Central heating $\square$ Individual room heaters

2.2 How is your building ventilated?

No ventilation $\square$ Natural ventilation $\square$ Mechanical ventilation

2.3 Does your building have an air conditioning system?

Yes $\square$ No $\square$

2.4 If yes, what type of system is used?

Full system $\square$ Partial system $\square$ Individual room units

2.5 Do you monitor environmental conditions within your building?

Yes $\square$ No $\square$

2.6 If yes, do you monitor?

Temperature $\square$ Humidity $\square$ Visible/UV light $\square$ Pests $\square$ Pollution $\square$ Visitor/user numbers $\square$

2.7 If yes, where are environmental conditions monitored?

Storage areas $\square$ Display areas $\square$ Reading rooms $\square$

2.8 What equipment do you use for temperature and humidity monitoring?

Spot meters $\square$ Thermohygrographs $\square$ Data loggers $\square$ Telemetry $\square$

2.9 How do you control environmental conditions within your building?

No control $\square$ Humidifier $\square$ Dehumidifier $\square$ Heating $\square$ Building management

system $\square$

\subsection{LIBRARY I ARCHIVE COLLECTION}

3.1 How large is your collection? Please specify.

3.2 What is the nature of your collection?

Books $\square$ Parchment $\square$ Papyrus $\square$ Newspapers $\square$ Maps $\square$ Globes $\square$ Art on paper $\square$ Other $\square$

3.3 How old is the principal part(s) of your collection?

Pre-1500 $\square$ 1500-1649 $\square$ 1650-1839 $\square$ 1840-1979 $\square$ 1980-present $\square$

3.4 How is your collection used?

Display $\square$ Research $\square$ Loan $\square$ Other $\square$

3.5 How many visitors/users do you have per annum?

Less than $50 \square$ 50-500 $\square$ 501-1,000 $\square$ 1,001-5,000 5,001-10,000 $\square$ More than $10,000 \square$ 
3.6 Are visitors/users given instruction and/or observed in handling items?

Instruction $\square$ Observation $\square$ None

3.7 Are staff members given instruction on how to handle different items?

Yes $\square$ No

3.8 Do you have conservation expertise on site?

Yes $\square$ No $\square$

3.9 Does your building have a fire detection system?

Yes $\square$ No

3.10 What firefighting equipment does your building have?

Manual extinguishers $\square$ Sprinkler system $\square$ Other (please specify)

3.11 Does your building have an intruder detection system (you do not have to answer this question)?

Yes $\square$ No $\square$

3.12 Do you have a current disaster plan?

Yes $\square$ No $\square$

\subsection{ADDITIONAL QUESTIONS}

4.1 Would you be interested in completing a future detailed questionnaire?

Yes $\square$ No $\square$

4.2 Would you be willing to allow us to visit you and your library/archive collection?

Yes $\square$ No $\square$

4.3 Would environmental monitoring data be available for reference within the project?

Yes $\square$ No $\square$

4.4 Do you have any specific problems or concerns that relate to the use of your building for library or archive purposes? Please specify.

Thank you for completing this outline questionnaire

Dr David Watt, Centre for Conservation Studies

Dr Belinda Colston, Department of Chemistry

Anna Bülow, Junior Researcher

De Montfort University, The Gateway, Leicester, LE1 9BH 


\section{APPENDIX C - LIBRARIES AND ARCHIVES CONTACTED DURING THE SURVEY}

\section{England}

Avon

Bristol

Bristol Record Office

Bedfordshire

Wobum

Wobum Abbey

Berkshire

Windsor

St George's Chapel

Buckinghamshire

Middle Claydon

Claydon House

Cambridgeshire

Cambridge

Huntingdon

Peterborough

Wisbech

Cambridge University Library (CURL)

Fitzwilliam Museum

Cambridgeshire County Record Office

Peterborough Cathedral Library

Peterborough Central Library

Wisbech and Fenland Museum

Cheshire

Chester

Chester Archives

Chester Cathedral Library

Warrington

Cheshire Record Office

Warrington Library

Cleveland

Middlesbrough

Teesside Archives

Cornwall

Truro

Royal Institution of Cornwall

Cumbria

Barrow

Barrow

Carlisle

Cumbria Record Office and Local Studies Library,

Carlisle Cathedral Library

Hutton-in-the-Forrest

Cumbria Record Office, Carlisle Headquarters

Thwaitehowe

Kendal

Cumbria Record Office, Kendal

Derbyshire

Bakewell

Matlock

Chatsworth House

Derbyshire Record Office 
Devon

Exeter

Exeter Cathedral Archives

Exeter Cathedral Library

Exeter University Library

Dorset

Sherborne

Sherborne Castle

Durham

Durham

Durham Cathedral Archives

Durham Cathedral Library

East Riding of Yorkshire

Beverley

East Riding of Yorkshire Archive Office

East Sussex

Lewes

East Sussex Record Centre

Essex

Chelmsford

Chelmsford Cathedral Library

Gloucestershire

Badminton Estates

Badminton House

Gloucester

Gloucester Cathedral Library

Gloucestershire Record Office

Tewkesbury

Tewkesbury Abbey

Greater London

Bexley Local Studies and Archives Centre

British Library of Political \& Economical Science

(CURL)

Chiswick Public Library, Local Studies Department

Corporation of London, Guildhall Library

Duchy of Cornwall

Enfield Local History Unit

Greenwich Local History Library

Haringey Archive Service

Harrow Museum

HM Tower of London

Imperial College Libraries (CURL)

Lambeth Palace Library

Newham Local Studies Library

Tower Hamlets Local History Library and Archives

University College London (CURL)

University of London Library (CURL)

Waltham Forest Archives and Local Studies Library

Westminster Abbey Library 


\section{Greater Manchester}

Bolton

Irlam

Leigh

Manchester

Oldham

Rochdale

Sale

Stalybridge

Hampshire

Brockenhurst

Portsmouth

Winchester

Herefordshire

Hereford

Hertfordshire

Hatfield

Hertford

St Albans

Humberside

Kingston upon Hull

Isle of Wight

None

Kent

Canterbury

Maidstone

Rochester

Lancashire

None

Leicestershire

Leicester

Wigston Magna

Lincolnshire

Grimsby

Lincoln
Bolton Archive and Local Studies Service

Salford City Archives

Wigan Archives Service

Greater Manchester County Record Office

John Rylands Library

Oldham Archives Service

Rochdale Libraries, Local Studies Department

Trafford Local Studies Centre

Tameside Archive Service

Beaulieu Abbey

Portsmouth City Museums and Archive Service

Portsmouth Diocesan Library

Winchester Cathedral Library

Herefordshire Record Office

Hatfield House

Hertfordshire Archives and Local Studies

Gorhambury Archives

Hull City Archives

Canterbury Cathedral Library and Archives

Centre for Kentish Studies

Rochester Cathedral Library

Guildhall Museum

The Record Office for Leicestershire, Leicester and Rutland

North East Lincolnshire Archives

Lincoln Cathedral Library

Lincolnshire Archives 
Merseyside

Liverpool

St Helens

Norfolk

Norwich

Wells-next-the-Sea

Northamptonshire

Kettering

Northampton

Northumberland

None

North Yorkshire

York

Nottinghamshire

Nottingham

Southwell

Oxfordshire

Oxford

Upton

Woodstock

Rutland

None

Shropshire

Shrewsbury

Somerset

Bath

Wells
Liverpool Cathedral

St Helens Local History and Archives Library

Norfolk Record Office

Norwich Cathedral Dean and Chapter Library

Holkham Hall

The Drayton Estate

Castle Ashby

Northamptonshire Record Office

Castle Howard

York City Archives Department

York Minster Library

Nottinghamshire Archives

Nottingham University (Department of Manuscripts and Special Collections)

Southwell Minster Library

Bodleian Library

Corpus Christi College

Magdalen College

Merton College

Oxford University Archives

Oxfordshire Archives

Queen's College

Highelere Castle

Blenheim Palace

Lower Wallop Farm

Shropshire Records and Research Centre

Bath and North East Somerset Record Office

Wells Cathedral Library 
South Yorkshire

Doncaster

Sheffield

Staffordshire

Burton upon Trent

Lichfield

Stafford

Stoke-on-Trent

Suffolk

Ipswich

Surrey

Hampton Court Palace

Kingston-upon-Thames

Tyne and Wear

Newcastle-upon-Tyne

Warwickshire

Stratford-upon-Avon

Warwick

West Midlands

Birmingham

Warley

Wolverhampton

West Sussex

Arundel

Chichester

West Yorkshire

Bradford

Haworth

Leeds

Wakefield

Headquarters

Wiltshire

Calne

Salisbury
Doncaster Archives Department

Sheffield Archives

Sheffield University (Special Collections and Library

Archives Department)

Staffordshire and Stoke-on-Trent Archive Service

Lichfield Cathedral Library

Lichfield Record Office

Sandon Hall

Staffordshire and Stoke-on-Trent Archive Service

William Salt Library

Staffordshire and Stoke-on-Trent Archive Service

Suffolk Record Office, Ipswich Branch

Kingston Museum and Heritage Service

Northumberland Record Office

Tyne and Wear Archives Service

Shakespeare Birthplace Trust, Centre Library Shakespeare Birthplace Trust, Records Office Warwickshire County Record Office

University of Birmingham (CURL)

Sandwell Community History and Archives Service Wolverhampton Archives and Local Studies

Arundel Castle

Chichester Cathedral Library

West Yorkshire Archive Service

Brontë Parsonage Museum

Leeds University, Brotherton Library (CURL)

West Yorkshire Archive Service, Wakefield

Bowood House

Salisbury Cathedral Library 
Warminster

Worcestershire

Dudley

Malvern

Severn Stoke

Worcester

\section{Scotland}

Argyll and Bute

Inveraray
Lochgilphead
Millport (Isle of Cumbrae)
Mount Stuart (Isle of Bute)
Central
South Queensferry
Stirling
Dumfries and Galloway
Dumfries

Thornhill

Falkirk

Falkirk

Fife

None

Grampian

Aberdeen

Highland

Inverness

Wick

Lothian

Edinburgh
Longleat House

Dudley Archives and Local History Service Madresfield Court

Croome Court

Worcester Cathedral Library

Worcestershire Record Centre (City Centre Branch)

Worcestershire Record Centre (Headquarters Branch)
Argyll Estates

Argyll and Bute Council Archives

Cumbrae Collegiate Church of the Holy Spirit

Mount Stuart Trust

Hopetoun House

Stirling Council Archives Service

Dumfries and Galloway Archives

Dumfries and Galloway Libraries

Drumlanrig Castle

Falkirk Museums History Research Centre

Aberdeen City Archives

Aberdeen City Archives (Old Aberdeen House Branch)

Highland Council Archive

Inverness Cathedral

North Highland Archive

Advocate's Library

Edinburgh City Archives

Edinburgh University Library (CURL)

National Library of Scotland

Orkney

None 
Scottish Borders

Lauder

Selkirk

Shetland

Lerwick

Strathclyde

Cumbernauld

Glasgow

Centre

Tayside

Dundee

Montrose

Pitlochry

Wales

Anglesey

Llangefni

Cardiff

Cardiff

Carmarthenshire

Carmarthen

Ceredigion

Aberystwyth

Lampeter

Conwy

None

Denbighshire

Ruthin

Flintshire

Hawarden

Gwynedd

Bangor
Thirlestane Castle

Scottish Borders Archive and Local History Centre

Shetland Archives

North Lanarkshire Archives

Glasgow City Archives

Glasgow University Archives and Business Record

Glasgow University Library (CURL)

Dundee City Archives

Angus Archives

Blair Castle

Anglesey County Record Office

Cardiff Castle

Glamorgan Record Office

Carmarthenshire Record Office

Ceredigion Archives

National Library of Wales

Founders' Library

Denbighshire Record Office

Flintshire Record Office

St Deiniol's Library

University College of North Wales

University of Wales 
Monmouthshire

None

Pembrokeshire

Haverfordwest

Pembrokeshire Record Office

St David's

St David's Cathedral Library

Powys

Brecon

Brecon Cathedral Library

Llandrindod Wells

Powys County Archives Office

Vale of Glamorgan

Penarth

Llandarff Cathedral Library

Wrexham

None

Ireland

Dublin

Trinity College (CURL) 


\section{APPENDIX D - CASE STUDIES}

\section{CASE STUDY PROFORMA: Atholl Estates}

Case study identification

No. 156a (archives) + b (library)

Site

Blair Castle

Atholl Estates Office

Pitlochry

Perthshire PH18 5TH

Tel. $01796 / 481207$

\section{Building or monument}

Pre-18 ${ }^{\text {th }}$ century, oldest parts from 1269.

$18^{\text {th }}$ century addition houses archives.

\section{Collection}

Archives hold estates records, oldest document from 1180; mostly single sheets and maps.

Library holds mostly books from 1650 till 1970s.

Castle gets around 130,000 visitors per year, but only 50 users of library or archive. Scottish Museums Council has made complete survey of collection.

\section{Specific issues}

Blair Castle is still family property.

There is in house staff for maintenance.

Archivist is in charge of complete collection (i.e. not only archive and library, but also weapons, paintings, other artifacts).

Few conservators on contract, part-time.

General problems in use of building/monument

Archive building is partly built within a hill, which results in localised dampness.

Amount of visitors can be a threat, but has decreased in last years.

Finding balance between amount of visitors (income through entrance fees) and preservation of collection.

Very small budget for conservation work.

Damp-related problems affecting building/monument and/collection

Damp-related problems only in archive building.

Leaking roof will be repaired by in house staff.

Good/bad practice

Due to only few people with conservation expertise, emphasis is being laid on preventive measures rather than conservation of objects.

Some objects are restored by conservation staff of Dundee University. 
Conclusions

Archive and Library are usually of little interest to general public, since mainly estates records.

Very small budget for conservation is sensibly spend.

\section{References}

http://www.great-houses-scotland.co.uk/blair/pages/blair.htm 


\section{CASE STUDY PROFORMA: Bath and North East Somerset Record Office}

Case study identification

No. 22

Site

Bath and North East Somerset Record Office

Guildhall, High Street, Bath BA1 5AW

Tel 01225 / 477421

\section{Building or monument}

Grade I listed building within conservation area.

Built in $19^{\text {th }}$ century, with additions in the $20^{\text {th }}$ century.

Built as guildhall, has always been in use as such.

Brick/stone walls, solid.

Dehumidifiers, central heating.

Maintenance through County Council, planned maintenance.

\section{Collection}

Predominantly paper-based, very few films.

c. 3,000 users a year, mainly genealogists.

Collection used to be 'Bath City Archives', was renamed to Bath and North East

Somerset Record Office five years ago.

Has been made accessible to the public in 1967.

Collection is exclusively housed within the guildhall.

\section{Specific issues}

Very small record office, one full-time, one part-time staff.

No conservator on site; objects in need for conservation will be conserved by conservators of the Wiltshire Record Office.

General problems in use of building/monument

Space problem; archivist likes to keep the collection together in the guildhall for practical reasons (not enough staff), therefore refused offers for outstores.

Difficulty in allocating new space within the building.

No sprinkler system.

Hot water pipes above shelves.

Bad communication between city council and archivist.

Damp-related problems affecting building/monument and/collection

Only one storage room has very high humidity, dehumidifiers need to be emptied several times a week.

There have been problems with rising damp in the past, today these patches are dry and according to archivist have not changed in many years.

Occurrence of mould in one room; unknown whether infestation is active or not (did not change in past years).

\section{Good/bad practice}

Due to archive mainly underground there are very stable conditions. 
Thermohygrographs have not been calibrated in 17 years (no expertise on site); however, recording sheets are changed regularly.

Disabled access through elevator.

Direct link with fire brigade.

No burglar alarm, not felt necessary.

Conclusions

Repository with major space problems and few staff.

Due to the space problems and comparatively few users per year, there might be areas within the storage rooms, that are never accessed or objects moved.

There seems to be no current damp problems; however, there is an area with mould infestation, probably inactive.

\section{$\underline{\text { References }}$}

none 


\section{CASE STUDY PROFORMA: Brontë Parsonage Museum}

Case study identification

No. 189

Site

Brontë Parsonage Museum

Haworth, Keighley, BD22 8DR

Tel. $01535 / 6423$

Building or monument

Grade I listed building.

Built in 1778 of local stone, with additions from the $19^{\text {th }}$ and $20^{\text {th }}$ century.

Building and collection is owned by Brontë Society.

Collection

Predominantly paper-based, books and art on paper.

$c .75,000$ visitors to the museum per year, $c .500$ users of library material; by appointment only.

Users are given photocopies if possible.

Most important part of collection is held in 1960s annex, strongroom, concrete floors and walls.

Conservation carried out by private conservators (funded by Yorkshire Museums

Council).

Occasional loans of objects (will be accompanied and their conditions checked throughout).

\section{Specific issues}

Brontë Society is responsible for structural maintenance and cosmetic changes. museum has maintenance budget for smaller tasks; various different ways of funding (e.g. Lottery fund).

General problems in use of building/monument

Finding compromises between display and preservation; especially within the museum, light is considered a problem.

Curators feel general lack of understanding the building.

Zoned heating not possible due to museums concept.

Curators try to keep $17^{\circ} \mathrm{C}$ throughout the building, which leads to staff complaints.

Wind is problematic in keeping constant temperature.

Damp-related problems affecting building/monument and/collection

Recent problems with mould (detection due to smell).

Books in metal cupboard feel colder.

\section{Good/bad practice}

There is a staged audit in place for the collection; beginning of each year the museum is closed for 4 weeks, every item (display and storage) is checked then.

Pest control company checks building and collection once a month.

Direct link to fire brigade.

No flood detectors. 


\section{Conclusions}

Control of visitor numbers through ticket prices.

Difficulty in finding right balance between public museum, creating enough income for sustaining the collection and preservation issues.

Will be chosen as second monitoring site: strongroom suggests interesting phenomena in terms of microenvironment.

\section{References}

http://www.bronte.org.uk 


\section{CASE STUDY PROFORMA: Cambridgeshire County Record Office}

\section{Case study identification}

No. 24

Site

Cambridgeshire County Record Office

Grammar School Walk, Huntingdon, Cambridgeshire, PE18 6LF

Tel $01480 / 375842$

Building or monument

Not listed.

Built 1820.

Built as a chapel. Later uses: warehouse, cinema, school. In use as a record office since the early 1980 s.

Brick/stone walls, solid.

No double glazing.

New roof in the 1990s.

Dehumidifiers, central heating.

Maintenance through County Council.

Collection

Predominately paper-based; some Victorian glass-plate negatives, photographs, video, fiche and film.

c. 3,500 users a year, mainly genealogists.

Collection has never been in purpose-built building.

\section{Specific issues}

Offices shares one thermohygrograph with main office (located in Cambridge).

Main office and Huntingdon office share one conservator, who drops by about every six weeks.

Oil patch on floor.

All furniture is second hand, including storage boxes and shelving.

Incoming petrol fumes from adjacent public car park occasionally set off fire alarms.

General problems in use of building/monument

No access for disabled people, changes would require major changes to building.

Storage area can be directly accessed via outside door. This causes not only safety problems, but also damp problems (leakage).

Reading room tends to heat up due to people (laptop, body heat).

Building has reached its capacity; unclear responsibilities over which type of records must be stored at this site.

Damp-related problems affecting building/monument and/collection

Localised damp problems (penetrating damp); this area is being monitored.

Mould problems did not increase in recent years.

Mouldy objects get send to main office and are being treated by conservator there. 
Good/bad practice

UV filters on all lights and all windows except office windows.

Fire detectors are connected with local fire brigade; the building does not have its own fire suppression system.

Readers are always under supervision.

No gloves are used (financial problems?).

Instructive posters in reading room concerning handling of objects.

No automatic light switches.

Generally no temperature control and only localised $\mathrm{RH}$ control (archivist not familiar with BS standards).

\section{Conclusions}

The idea of using second hand furniture and boxes is good. However, care needs to be taken to chose items of good quality, which is a potential problem as the quality is often the main reason for these items to be on the market.

This repository is aware of its problems and deals with them according to their financial abilities.

\section{References}

Guide to the Huntingdonshire Record Office, 1958

www.cambridgeshire.gov.uk follow links: heritage - archives - HRO 


\section{CASE STUDY PROFORMA: Flintshire Record Office}

\section{Case study identification}

No. 74

Site

Flintshire Record Office

The Old Rectory, Hawarden, Flintshire, CH5 3NR

Tel 01244532364

Building or monument

Grade II listed building.

Built in $18^{\text {th }}$ century as Rectory.

Problem with downstand beams.

\section{Collection}

Flintshire Record Office established in 1951 and moved to Old Rectory in 1956 Oldest record office in north-east Wales.

Historic archive includes records of the Church in Wales; non-conformist chapels; schools; county, district and parish/community councils; poor law unions, Flintshire Quarter sessions; magistrates' courts; families and estates; antiquarian collections; hospitals; police; shipping; businesses and industries; clubs and societies; trades unions; political parties.

Record provide 'legal memory' of community.

Gladstone Collection - political papers housed in British Library, private papers housed in Flintshire Record Office.

\section{Specific issues}

Semi-rural location, most users are therefore known.

Public visits for whole day possible (by prior appointment [unlike library]).

High level of support (i.e. social inclusion).

Archive is a unique resource.

Only 9 seats in reading room (working at capacity).

Current need for new strong-room and special media accommodation.

First record office to apply for Heritage Lottery Fund grant to control environmental conditions ( $£ 110,000$ application).

Work started late 1997; completed summer 1998.

All work undertaken whilst building in use.

General problems in use of building/monument

Not able to plan use of building when Flintshire Record Office moved in Old Rectory in 1956.

Has grown within building as space becomes available.

Know what is needed, but lack of investment.

Shape and configuration of building problematic - search room and storeys divided so all items have to be carried.

Limited disabled access/egress and facilities (no disabled WC).

Light levels (impact on records versus good illumination for disabled persons) - legal responsibility for records.

Cannot read to blind persons in limited accommodation (i.e. noise pollution). 
Lockers for personal bags and coats (apply best practice in inappropriate accommodation).

Perhaps have to use basement in future.

Marriages and meeting held in building (uses not conducive/clash of uses).

Damp-related problems affecting building/monument and/collection

None

Good/bad practice

Review of service delivery led to 4-prong approach (talked to conservators to Nonwich Library fire and HMC).

Public search room and external strong-room still weak.

24-hour fire link to emergency services.

Regular fire drills and familiarisation visits from fire service every 6 months.

Automatic fire suppression system in use within storage areas.

Former carbon dioxide fire suppression system switched off during working day due to potential health risks.

Automatic environmental control used in strong-room and conservation studios (as BS 5454).

Environmental monitoring based on Hanwell telemetric system in strong-rooms (controlled by conservation staff).

Flood detection system in use for pipework in or near strong-rooms (wires placed close to pipes).

Conclusions

An example of how best practice can be applied in the use of a historic building. Innovative use fire suppression and flood detection systems.

Problems with limited space, possibly forcing future use of basement.

\section{References}

None 


\section{CASE STUDY PROFORMA: Glasgow University Archives and Business Records Centre}

Case study identification

No. 194

Site

Glasgow University Archives and Business Records Centre

13 Thurso Street

Glasgow, G11 6PE

Tel. $0141 / 3305515$

Building or monument

$20^{\text {th }}$ century building, built as tram depot, later used as flour mill (groundfloor is still used as a garage).

not a listed building, not within conservation area, no restraints in terms of changes to the building.

used to be five storey building, top storey has been removed now, results in flat roof. building has always been used for storage.

Collection

Predominately paper-based, books and parchment.

Various collections, came together five years ago.

Specific issues

High humidity is seen as a problem rather than dampness.

Only the second and the third floor are used for archive purposes.

Building is shared with museum.

Part of collection is within outstorage.

University maintains building regularly.

General problems in use of building/monument

Building is very dry, RH is rather too low than to high, BS5454 is not met.

There are heating devices, but no cooling (no means to shut off the system to improve staff comfort).

Not enough office space for 24 members of staff.

Building affected by concrete cancer.

No access for disabled persons.

Damp-related problems affecting building/monument and/collection

Drains are frequently blocked by plastic bags or dead birds, which may lead to an overflow on the flat roof.

Good/bad practice

Due to a lack of conservation expertise on site, staff undertakes preventive measures.

Single items are being restored by private conservators. 
Conclusions

There are possibilities for improvements that are restrained due to finances.

The archives are hoping to be bale to move within the next 5 to 10 years.

References

Kitching (1997): Archive Buildings in the United Kingdom 1977-1992, HMSO, London, pp. $97 / 98$

Anon. (2000): An Archival Account of Scotland. Public and Private Sector Archive Services in Scotland: Funding Opportunities and Development Needs. National Archives of Scotland, Edinburgh 


\section{CASE STUDY PROFORMA: Guildhall Museum}

Case study identification

No. 192

Site

Guildhall Museum

Guildhall Lane, Leicester LE1 5FQ

Tel $0116 / 2532569$

Building or monument

Grade I listed building.

Built in $14^{\text {th }}$ century, with later additions.

Built for Corpus Christi Guild, various uses since, including Town Hall, school, police cells.

Electric storage heater, thermostatically controlled.

Maintenance through Leicester City Council.

Collection

Mainly leather bound books, one of the oldest public libraries in Britain.

c.50,000 museum visitors per year; no library users.

Collection used to be housed at St Martin's Church (now Leicester Cathedral).

Most valuable items have been moved to Leicestershire Record Office.

Collection is not growing.

Security system in place throughout the building.

Specific issues

Collection is housed within Victorian timber bookcases, with paired glazed doors.

No conservation expertise on site; advice through staff of Leicestershire Record

Office.

Collection is virtually never used, which may make detection of problems difficult.

Building is used as a venue for concerts, etc..

General problems in use of building/monument

Most visitors leave outside door open upon leaving, resulting in outside conditions within library, which the electrostatic heater is unable to control.

Alterations to building or fumiture is almost impossible due to integrity of building. Access to all parts of the building for disabled impossible.

Damp-related problems affecting building/monument and/collection

Despite high $\mathrm{RH}$ presently no problems with dampness.

Good/bad practice

No control of outside doors, visitors are not urged to close them.

Library is regularly inspected by staff of Leicestershire Record Office.

Visitors are observed by staff throughout the building.

No environmental monitoring. 


\section{Conclusions}

Despite adverse conditions, the collection is in very good condition.

Changes to any parts of the building are difficult to implement due to the building being listed.

It would be fairly easy to put monitoring and control systems in place.

\section{References}

Bryan, P. and Cooper, S. (n.d.): The Leicester Guildhall. Leicester City Council, Leicester. 


\section{CASE STUDY PROFORMA: The Record Office for Leicestershire, Leicester and}

Rutland

\section{Case study identification}

No. 1

$\underline{\text { Site }}$

The Record Office for Leicestershire, Leicester and Rutland

Long Street, Wigston Magna, Leicestershire LE18 2AH

Tel $0116 / 2571080$

Building or monument

Built in $19^{\text {th }}$ century, with recent additions for storage.

Built as school house, in use as record office since early 1990 s.

Brick/stone walls, solid.

Storage building built of brick / concrete with insulation in-between.

Dehumidifiers, central heating.

Maintenance through County Council, planned maintenance.

\section{Collection}

Predominantly paper-based, but also some other media.

$12-15,000$ users a year, mainly genealogists.

Sometimes small exhibitions in foyer.

No valuable objects on display.

Facsimile of certain objects may go on loan as teaching material.

\section{Specific issues}

Conservation studio on site, with three members of staff.

Staff is also responsible for other collections within Leicestershire (e.g. Guildhall

Library in Leicester).

Collection used to be housed in different locations throughout Leicester, including

New Walk Museum (experienced rodent and insect pests).

All media stored together (including modem media such as film and photographs).

General problems in use of building/monument

Compromises due to space and money.

Difficulties allocating new space.

Conditions in reading rooms according to user comfort (conflict of interest between readers and objects).

Heat build-up in reading rooms due to rather small size and use of electronic media (laptop, microfiche reading equipment, etc.).

Difficulties in providing comfortable environment for staff in various parts of building.

Damp-related problems affecting building/monument and/collection

Minor problems with rising dampness in local areas of old part of building.

Currently no mould problems.

\section{Good/bad practice}

Direct link with fire brigade.

Emergency kit in dominant position (plus instructions for use). 
Psychrometric records since 1952 (hand-written).

Digital environmental records since in this location (early 1990s).

Use of dehumidifiers to aid dehumidification after construction.

Most parts of collection is in good condition and well looked after.

Users are being observed by staff.

Users are encouraged to use microfiche.

Mew objects are housed in temporary space to check for mould, pests, etc.; all incoming material is cleaned before permanently stored.

\section{Conclusions}

Considered common financial and space problems, this repository is in good conditions and deals with its problems well.

Improvements could be made by paying attention to some details, such as the rising damp and roof form, accumulating snow in certain corners that are not accessible.

\section{References}

none 


\section{CASE STUDY PROFORMA: Westminster Abbey}

Case study identification

No. 129

$\underline{\text { Site }}$

Westminster Abbey Muniment Room and Library

East Cloister, London SW1P 3PA

Tel $020 / 72225152$

Building or monument

Grade I listed building within conservation area.

Library housed in $16^{\text {th }}$ century part of the building, former dormitory.

Brick/stone walls.

Collection

c. 16,000 books, 70,000 archives (manuscripts and muniments); some modern books on history of abbey.

Up to 5,000 visitors per year, but no more than 1,000 users.

\section{Specific issues}

No access for disabled people.

Library and reading room on different levels.

No conservation staff on site, three members of staff working as curator.

Conservation work gets contracted outside abbey.

General problems in use of building/monument

Space problem (collection is completely housed within the library), no possibility of extension.

Adaptation of existing space for collection and use.

Due to the buildings function as an abbey no alterations possible.

Accessibility of collections.

Damp-related problems affecting building/monument and/collection

Previous problems with leakage.

No current problems with dampness.

Good/bad practice

Environmental monitoring started in 1999.

Direct link with fire brigade.

Disaster plan in place for abbey as a whole, but not for library in specific.

No more than three users allowed at a time, users are observed by staff during use.

Large part of muniments collection is housed within original storage chests.

\section{Conclusions}

This collection is preserved in its integrity.

The collection manager observes space problems while at the same time there is no possibility of expansion due to historical setting.

Not many other problems are observed, as there is a fairly small number of library users and the collection is not catalogued. 


\section{References}

none 


\section{CASE STUDY PROFORMA: West Yorkshire Archive Service}

Case study identification

No. 70

Site

West Yorkshire Archive Service, Bradford

15 Canal Road, Bradford, BD1 4AT

Tel. $01274 / 731931$

Building or monument

Building was used as warehouse for textile industry (production and offices), now owned by commercial company (maintenance is within the responsibility of the archive as long as repairs are only minor).

In use as archive since the early 1980s.

Building shared with hair dressing supplier.

\section{Collection}

Predominantly paper-based, no film, some videos.

c.2,000 users a year, mainly genealogists or project work.

Collecting policy shared between different archives within Bradford district (there is no policy regarding digital media).

Some objects may go on loan, usually for local exhibitions.

\section{Specific issues}

No conservation expertise on site, objects in need for conservation will be treated in main office at Wakefield.

Natural light in reading room.

Heat build-up in summer.

Open chimneys: entry point for pests?

General problems in use of building/monument

Wedge shaped building causes problems with shelving.

Storage of chemicals from hair dressing supplier causes concern.

Difficult access to collection (no elevator).

$4^{\text {th }}$ floor had unsuitable storage conditions; collection was therefore moved to other parts of the building; only semi-basement and $1^{\text {st }}$ floor are now used for storage (less of a space problem than in other archives).

raised floors, sunken radiators.

limited head room.

direct access to storage area through garage is security concern.

staff complaints concerning heating.

Damp-related problems affecting building/monument and/collection

River Beck flows directly under the building (caused problems in the $19^{\text {th }}$ century). Incoming material is being checked for mould; in case of infestation it is treated before being stored within the facilities.

Dead comers due to wedge shaped building; little air flow. 


\section{Good/bad practice}

Recognition of environmental problems on top floor and consequently moving of collection.

$\mathrm{CO}_{2}$ and water extinguishers.

Smoke detectors, directly linked to fire brigade.

Flood detectors in basement.

$\mathrm{RH}$ is rather too low than too high $(\sim 45 \% \mathrm{RH})$; conditions higher in semi-basement.

Environmental monitoring using thermohygrographs.

Fairly stable conditions.

Use of blinds in strong rooms.

Every room is being walked through at least once a day.

\section{Conclusions}

No current damp problems, but potential for damp problem due to river under building.

\section{References}

Anon. (n.d.): Bradford Archives 1974-1995, An Illustrated Guide to Bradford District Archives, West Yorkshire Archive Service, ISBN 1870453190

http://www.archives.wyjs.org.uk/bradloc.htm 


\section{CASE STUDY PROFORMA: Wisbech \& Fenland Museum}

Case study identification

No. 188

Site

Wisbech \& Fenland Museum

Museum Square, Wisbech, PE13 1ES

Tel $01945 / 583817$

Building or monument

Built in former castle moat.

Completed in 1847.

Shared function (museum, library, and archive) since opened.

Literary society founded in 1851; library use to museum in 1880 s.

Collection

Library holding 12,000 volumes.

Early printed books from $16^{\text {th }} / 17^{\text {th }}$ centuries.

$17^{\text {th }} / 18^{\text {th }}$ century collection moved from church porch to museum in $1880 \mathrm{~s}(1,200$ volumes and manuscripts).

Town library collection dates from $17^{\text {th }}$ century.

Specific issues

Registered museum (not considered to be an archive by Resource).

Free museum as independent charitable trust.

Funds from district council.

Some funds from county council (short-term revenue funding: $£ 5,000$ for Education

Officer post).

No English Heritage funds as seen as the responsibility of others.

No conservation expertise on site.

General problems in use of building/monument

Potential conflict between different requirements.

Damp-related problems affecting building/monument and/collection

Problems with lead-covered roofs.

Outbreak of dry rot in gallery.

Dry rot outbreak treated 30 years ago and recently repeated (walls irrigated then and now).

Main roof needs replacing (leaks when wind in certain direction).

Flat roof rainwater disposal system taken through museum roof space.

Roof/sky lights present.

Rainfall down vertical chimney stack - not lined and affecting display case.

Erratic heating system.

\section{Good/bad practice}

Service level agreement for building maintenance (roofs and gutters).

Off-site storage less than adequate. 
Conclusions

Interesting split use of building with potential conflict between specific requirements.

Keen to see copy/conclusions of report.

\section{References}

None 


\section{APPENDIX E - NOTES FOR MEETINGS}

\section{Library and Information Commission Preservation of and Access to the Recorded Heritage Predicting damp-related problems in historic buildings and monuments used for library and archive purposes}

1. Tour of building and site including (where appropriate) basement, attic, storage areas, display areas, reading room

2. Discussion relating to principal problems affecting the building and its facilities

3. Discussion relating to the principal problems affecting the collection

4. Discussion regarding availability of environmental monitoring data and possibility of siting monitoring equipment for agreed period

5. Discussion relating to past and/or present problems of damp and fungal/mould growth

6. Discussion relating to current sources of advice and information

7. Discussion of any other matters relevant to the aims and objectives of the project:

\section{Aims}

(a) to improve existing knowledge of building performance

(b) to develop an improved awareness of the interface between buildings and preservation measures

(c) to ensure greater efficiency and reliability in the use of historic buildings and monuments for library and archive purposes

(d) to seek sustainable solutions for the re-use of historic buildings and monuments

\section{Objectives}

(a) to investigate and quantify the effects of dampness on building fabric, indoor environments and library/archive collections

(b) to compile a database of related cause and effects

(c) to critically assess current and innovative remedial techniques, and appropriate design solutions

(d) to develop a predictive computer model for simulating changing conditions within historic buildings and monuments used for library and archive purposes

(e) to develop and disseminate practical advice for dealing with damp-related problems in historic buildings and monuments 


\section{APPENDIX F - DETAILS OF DUMMY BOOKS}

\section{Book 1:}

Title of book: Good Words for 1866

Edited by Norman Macleod, D.D.

Publisher: Strahan \& Co, Magazine Publishers, London/New York

Year: 1866

Size of book: $235 \times 165 \times 44 \mathrm{~mm}$

Fibre composition: Mixed rag pulp, consisting mainly of esparto grass, with additions of hemp and flax fibres

\section{Additional Information:}

Esparto grass grows wild in North Africa and the Mediterranean areas of southern Spain. Spanish esparto is superior to African as it yields more fibre and responds better to bleaching processes. However, its fibres are short in comparison to traditional fibres, such as cotton or hemp fibres, which makes the addition of other fibres desirable. Pulping of esparto started in England in 1856 as a substitute for rags.

Esparto contains 2 - $4 \%$ ashes, $14-17 \%$ lignin, $42 \%$ cellulose and $33 \%$ pentosans (i.e. hemicellulose). Paper made from esparto grass, though superior to wood-pulp, therefore contains much more lignin than pure rag paper.

\section{Book 2:}

Title of book: Taciti Opera Quae Exstant

Author: lustus Lipsius

Antverpiae ex officina plantiniana

Apud Balthasarem Moretum, \& Viduam loannis Moreti, \& lo. Meursium

Antwerp

Year: MDCXXVII (1627)

Size of book: $384 \times 245 \times 50 \mathrm{~mm}$

Fibre composition: Pure rag pulp, consisting of hemp or flax fibres (distinction impossible)

\section{Additional Information:}

Rags were the predominantly source for paper fibres in Europe until the middle of the $19^{\text {th }}$ century. Depending on the source of the rags and the quality of selection, anything from used ropes to discarded clothing was utilised. Rag papers therefore typically consist of different types of fibres, with flax and hemp being the most common.

Flax and hemp contain 1 - 2\% ashes, 1 - $6 \%$ lignin, more than $60 \%$ cellulose and $2-6 \%$ pentosans.

\section{References:}

HotAL, J.A.G. (n.d.): Constituyentes fibrosos de pastas y papeles. Universitat Politécnica de Catalunya, Escuela Técnica Superior de Ingenieros Industriales de Terrassa, Especialidad Papalera y Grafica, p.15

MISRA, D.K. (1980): Pulping and Bleaching of Nonwood Fibres. In: Pulp and Paper Chemistry and Chemical Technology (J.P. Casey, ed.), John Wiley \& Sons, New York, Chichester, Brisbane, Toronto. Vol. 1, pp. 504-68 


\section{APPENDIX G - PREVEnTIVe Conservation OF Collections}

\section{Relative Humidity}

\begin{tabular}{|c|c|c|}
\hline Material & Comment / Recommendation & Reference \\
\hline \multirow{16}{*}{$\begin{array}{l}\text { Paper- } \\
\text { based and } \\
\text { archival } \\
\text { material }\end{array}$} & $45-60 \% \pm 5 \%$ : for all archival material & BS 5454:2000 \\
\hline & $<55 \%$ : paper-based material & Klotz-Berendes, 2000 \\
\hline & 25-50\%: temperature irrelevant & Michalski 1999 \\
\hline & 55-65\%: archival material & HMC, 1997 \\
\hline & $\begin{array}{l}<65 \% \text { : archival material; equilibrium moisture } \\
\text { content of parchment and leather }<15 \%\end{array}$ & Gallo et al, 1996 \\
\hline & 45-60\%: paper-based material & Sclocchi et al, 1996 \\
\hline & 30-35\%: paper-based material & van der Reyden, 1995 \\
\hline & $30-55 \%$ : sensitive materials $\pm 2 \%$ fluctuation & Wilson, 1995 \\
\hline & $\begin{array}{l}30-50 \% \text { : paper-based materials possibly } 25-80 \% \text {, } \\
\text { with caution } \\
25-40 \% \text { : protein-based material }\end{array}$ & $\begin{array}{l}\text { Erhardt and Mecklenburg, } \\
1994\end{array}$ \\
\hline & $>25 \%:$ parchment & Ginell, 1994 \\
\hline & $\begin{array}{l}\text { 35-65\%: press release (printed in Abbey } \\
\text { Newsletter) }\end{array}$ & $\begin{array}{l}\text { Smithsonian Institution, } \\
1994\end{array}$ \\
\hline & $45 \pm 2 \%$ : archival material & Ritzenthaler, 1993 \\
\hline & $30 \%:$ vellum & Hansen et al, 1992 \\
\hline & 45-50\%: paper-based material & Kelsey, 1991 \\
\hline & 35-70\%: archival material & Padfield, 1988 \\
\hline & $\begin{array}{l}\text { 40-50\%: paper-based material } \\
55-56 \% \text { : parchment }\end{array}$ & Briggs, 1987 \\
\hline \multirow{3}{*}{$\begin{array}{l}\text { Modern } \\
\text { media (incl. } \\
\text { photo- } \\
\text { graphs) }\end{array}$} & $30-50 \%$ & BS 5454: 2000 \\
\hline & $30-50 \%$ & Michalski, 1999 \\
\hline & $\begin{array}{l}50+2 \%: \text { film } \\
35-45 \%: \text { magnetic tape }\end{array}$ & HMC, 1997 \\
\hline \multirow[t]{3}{*}{ Paintings } & $\begin{array}{l}40-60 \% \text { : least risk of dimensional changes through } \\
\text { fluctuations }\end{array}$ & Ashley-Smith, 1999 \\
\hline & $50 \pm 5 \%$ : canvas & Michalski, 1998 \\
\hline & $50+2 \%:$ wood panel & Darragh and Snyder, 1993 \\
\hline Textiles & $50 \pm 5 \%$ & Michalski, 1998 \\
\hline \multirow[t]{2}{*}{ Furniture } & $50 \pm 5 \%$ & Michalski, 1998 \\
\hline & $50 \pm 5 \%$ & McGiffin, 1989 \\
\hline \multirow[t]{4}{*}{$\begin{array}{l}\text { Musical } \\
\text { instruments }\end{array}$} & $\begin{array}{l}\text { Warping and shrinkage caused by low RH levels } \\
\text { can affect sound of instrument }\end{array}$ & Thomson, 1986 \\
\hline & $\begin{array}{l}\text { Environmental strategy dependent upon various } \\
\text { factors relating to building, instrument, and funding }\end{array}$ & Cassar and Barclay, 1997 \\
\hline & $\begin{array}{l}\text { Woodwind instruments require conditioning before } \\
\text { use due to risk of cracking }\end{array}$ & Waitzman et al., 1997 \\
\hline & $\begin{array}{l}\text { Keyboard instruments particularly vulnerable to } \\
\text { fluctuations due to tension exerted by strings }\end{array}$ & Waitzman et al., 1997 \\
\hline
\end{tabular}


Relative Humidity, continued

\begin{tabular}{|c|c|c|}
\hline Material & Comment / Recommendation & Reference \\
\hline \multirow[t]{2}{*}{ Glass } & $0-45 \%$ : unstable glass & $\begin{array}{l}\text { Erhardt and Mecklenburg, } \\
1994\end{array}$ \\
\hline & $<40 \%$ & Thomson, 1986 \\
\hline Ceramics & $\begin{array}{l}40-65 \% \text { : fluctuations no more than } 5 \% \text { within one } \\
\text { hour }\end{array}$ & Buys, 1993 \\
\hline $\begin{array}{l}\text { Natural } \\
\text { history } \\
\text { specimens }\end{array}$ & $\begin{array}{l}30 \pm 5 \% \text { : fur and fur-trimmed garments, birdskin } \\
\text { garments }\end{array}$ & Darragh and Snyder, 1993 \\
\hline \multirow[t]{3}{*}{ Metals } & $15-20 \%$ : to avoid decay of archaeological iron & Child, 1998 \\
\hline & $0-45 \%$ & $\begin{array}{l}\text { Erhardt and Mecklenburg, } \\
1994\end{array}$ \\
\hline & $<45 \%$ & Thomson, 1986 \\
\hline
\end{tabular}

\section{References}

ASHLEY-SMITH, J. (1999): Risk Assessment for Object Conservation. ButterworthHeinemann, Oxford.

BRIGGS, J.R. (1987): Environmental Control of Modem Records. In: Petherbridge, G. (Ed.), Conservation of Library and Archive Materials and the Graphic Arts. Butterworth, London.

BSI (2000): Recommendations for the Storage and Exhibition of Archival Documents. BS 5454:2000. British Standards Institution, London.

BUYS, S. and OAKLEY, V. (1993): The Conservation and Restoration of Ceramics. Butterworth-Heinemann, Oxford.

CASSAR, M. and BARCLAY, R.. (1997): Instruments in their Environment. In: Barclay, R.L. (Ed.), The Care of Historical Musical Instruments. Museums \& Galleries Commission, London, and Canadian Conservation Institute, Ottawa, pp. 9-17.

CHILD, R.E. (1998): Relative Humidity and Museum Collections. In: $3^{\text {rd }}$ Intemational Symposium on Humidity and Moisture. National Physical Laboratory, London, Vol. 2, pp. 112-13.

DARRAGH, J. and SNYDER, J.S. (1993): Museum Design - Planning and Building for Art. Oxford University Press, Oxford.

ERHARDT, D. and MECKLENBURG, M. (1994): Relative Humidity Re-examined. In: Preventive Conservation - Practice, Theory and Research. (A. Roy, and P. Smith, eds.), IIC, Ottawa, 12-16 September 1994, pp. 32-38.

GINELL, W.S. (1994): The Nature of Changes Caused by Physical Factors. In: Durabiltiy and Change: The Science, Responsibility, and Cost of Sustaining Cultural Heritage. W.E. Krumbein, P. Brimblecombe, D.E. Cosgrove, and S. Staniforth, eds.), John Wiley \& Sons, London, pp. 81-94.

HANSEN, E.F., LEE, S.N. and SOBEL, H. (1992): The Effects of Relative Humidity on Some Physical Properties of Modern Vellum, Joumal of the American Institute of Conservation, Vol. 31, No. 3, pp. 325-42.

HMC (1997): HMC Publications: Standard for Record Repositories. $2^{\text {nd }}$ ed. Public Record Office, Royal Commission on Historic Manuscripts and the Scottish Record Office.

KELSEY, D.G. (1991): Environmental Control in Libraries: Managing Existing Spaces. In: Preservation of Library and Archival Materials (F. Pflieger, ed.), APPA, Alexandria, VA, pp. 17-27. 
KLOTZ-BERENDES, B. (2000): Schimmelpilzbefall in Bibliotheken: Vorkommen, Gefährdung, Bekämpfung. Bibliotheksdienst, Vol. 34, No. 1, pp. 47-59.

MCGIFFIN, R.F. (1989): Furniture Care and Conservation. American Association for State and Local History (AASLH), Nashville, Tennessee, pp. 12-23.

MICHALSKI, S. (1998): Climate Control Priorities and Solutions for Collections in Historic Buildings. Historic Preservation Forum, Vol. 12, No. 4, pp. 8-14.

MICHALSKI, S. (1999): Museums, Libraries and Archives. Heating, Ventilating, and Airconditioning Applications, ASHRAE, Atlanta, GA, pp. 20.21-20.13.

PADFIELD, T. (1988): Climate Control in Libraries and Archives,. AlCCM Bulletin, Vol. 14, No. $1 / 2$, pp. $49-68$.

RITZENTHALER, M.L. (1993): Preserving Archives and Manuscripts. Archival Fundamental Series. Society of American Archivists, Chicago, IL.

SCLOCCHI, M.C., RUSCHIONI, E., CAVALlINI, F. and PERSIA, F. (1996): Research on Biodeterioration of Archival Assets. In: Intermational Conference on Conservation and Restoration of Archive and Library Materials. Istituto centrale per la patologia del libro (Roma), Erice, Italy, 22-29 April 1996, Vol. 1, pp. 175-90.

SMITHSONIAN INSTITUTION (1994): Work of Smithsonian Scientists Revises Guidelines for Climate Control in Museums and Archives. Abbey Newsletter, Vol. 18, No. 4-5, pp. 1-3.

THOMSON, G. (1986): The Museum Environment. $2^{\text {nd }}$ ed. Butterworths, London.

VAN DER REYDEN, D. (1995): Paper Documents. In: Storage of Natural History Collections: A Preventive Conservation Approach. (C.L. Rose, C.A. Hawks, and H.H. Genoways, eds.), Society for the Preservation of Natural History Collections, lowa City, IA. Vol. 1, pp. 327-53.

WaItZMAN, M., BaRClay, R., Odell, J., KARP, C. and HELlWIG, F. (1997): Basic Maintenance of Playing Instruments. In: The Care of Historical Musical Instruments. (R.L. Barclay, ed.), Museums \& Galleries Commission, London, and Canadian Conservation Institute, Ottawa, pp. 83-108. 


\section{Temperature}

\begin{tabular}{|c|c|c|}
\hline Material & Comment / Recommendation & Reference \\
\hline \multirow{10}{*}{$\begin{array}{l}\text { Paper- } \\
\text { based and } \\
\text { archival } \\
\text { material }\end{array}$} & $\begin{array}{l}16-19^{\circ} \mathrm{C} \pm 1^{\circ} \mathrm{C}: \text { frequently-handled material } \\
13-16^{\circ} \mathrm{C} \pm 1^{\circ} \mathrm{C} \text { : infrequently-handled material }\end{array}$ & BS 5454: 2000 \\
\hline & $<25^{\circ} \mathrm{C}$ : paper-based material & Klotz-Berendes, 2000 \\
\hline & $13-18^{\circ} \mathrm{C}$ : archival material & HMC, 1997 \\
\hline & 16-20 $20^{\circ}$ : paper-based material & Sclocchi et al, 1996 \\
\hline & $60-72^{\circ} \mathrm{F}:$ paper-based material & van der Reyden, 1995 \\
\hline & $70 \pm 5^{\circ} \mathrm{F}$ : paper-based material & Wilson, 1995 \\
\hline & $\begin{array}{l}\text { 52-88 } 8 \text { : press release (printed in Abbey } \\
\text { Newsletter) }\end{array}$ & $\begin{array}{l}\text { Smithsonian Institution, } \\
1994\end{array}$ \\
\hline & $70 \pm 2^{\circ} \mathrm{F}$ : archival material & Ritzenthaler, 1993 \\
\hline & $68^{\circ} \mathrm{F}$ : paper-based material & Kelsey, 1991 \\
\hline & $21^{\circ} \mathrm{C}$ : archival material & Briggs, 1987 \\
\hline \multirow{3}{*}{$\begin{array}{l}\text { Modern } \\
\text { media (incl. } \\
\text { photo- } \\
\text { graphs) } \\
\end{array}$} & $-5-18^{\circ} \mathrm{C}$ : depending on type of media & BS 5454: 2000 \\
\hline & $10^{\circ} \mathrm{C}$ & Michalski, 1999 \\
\hline & $\begin{array}{l}55^{\circ} \mathrm{F}\left(13^{\circ} \mathrm{C}\right) \pm 5^{\circ} \mathrm{F}: \text { film } \\
18-22^{\circ} \mathrm{C}: \text { magnetic tape }\end{array}$ & HMC, 1997 \\
\hline Paintings & $21^{\circ} \mathrm{C} \pm 1^{\circ} \mathrm{C}$ & Michalski, 1998 \\
\hline Textiles & $21^{\circ} \mathrm{C} \pm 1^{\circ} \mathrm{C}$ & Michalski, 1998 \\
\hline \multirow[t]{2}{*}{ Furniture } & $21^{\circ} \mathrm{C} \pm 1^{\circ} \mathrm{C}$ & Michalski, 1998 \\
\hline & $68^{\circ} \mathrm{F} \pm 5^{\circ} \mathrm{F}$ & McGiffin, 1989 \\
\hline $\begin{array}{l}\text { Musical } \\
\text { instruments }\end{array}$ & $\begin{array}{l}\text { Environmental strategy dependent upon various } \\
\text { factors relating to building, instrument, and funding }\end{array}$ & Cassar and Barclay, 1997 \\
\hline \multirow[t]{2}{*}{ Glass } & $\begin{array}{l}\text { Below } 0^{\circ} \mathrm{C} \text { : in ethanol/water mixtures, for certain } \\
\text { archaeological glass }\end{array}$ & Earl, 1999 \\
\hline & $70-76^{\circ} \mathrm{F}$ : stable glass & Darragh and Snyder, 1993 \\
\hline Ceramics & $18-25^{\circ} \mathrm{C}$ : temperature shocks can be detrimental & Buys, 1993 \\
\hline $\begin{array}{l}\text { Natural } \\
\text { history } \\
\text { specimens }\end{array}$ & $\begin{array}{l}\text { Temperature will only affect fluid collections and } \\
\text { frozen specimens }\end{array}$ & Weintraub and Wolf, 1995 \\
\hline Metals & $70-76^{\circ} \mathrm{F}$ & Darragh and Snyder, 1993 \\
\hline
\end{tabular}

\section{References}

BRIGGS, J.R. (1987): Environmental Control of Modern Records. In: Conservation of Library and Archive Materials and the Graphic Arts. (G. Petherbridge, ed.), Butterworths, London, pp. 297-305.

BSI (2000): Recommendations for the Storage and Exhibition of Archival Documents. BS 5454:2000. British Standards Institution, London.

BUYS, S. and OAKLEY, V. (1993): The Consenvation and Restoration of Ceramics. Butterworth-Heinemann, Oxford.

CASSAR, M. and BARCLAY, R.. (1997): Instruments in their Environment. In: The Care of Historical Musical Instruments. (R.L. Barclay, ed.), Museums \& Galleries Commission, London, and Canadian Conservation Institute, Ottawa, pp. 9-17.

DARRAGH, J. and SNYDER, J.S. (1993). Museum Design - Planning and Building for Art. Oxford University Press, Oxford.

EARL, N. (1999): The Investigation of Glass Deterioration as a result of Storage Systems for Waterlogged Archaeological Glass. In: The Conservation of Glass and Ceramics. (N.H. Tennent, ed.), James \& James, London, pp. 96-113. 
HMC (1997): HMC Publications: Standard for Record Repositories. $2^{\text {nd }}$ ed. Public Record Office, Royal Commission on Historic Manuscripts and the Scottish Record Office.

KELSEY, D.G. (1991): Environmental Control in Libraries: Managing Existing Spaces. In: Preservation of Library and Archival Materials. (F. Pflieger, ed.), Association of Physical Plant Administrators, Alexandria, VA, Vol., pp. 17-27.

KLOTZ-BERENDES, B. (2000): Schimmelpilzbefall in Bibliotheken: Vorkommen, Gefährdung, Bekämpfung. Bibliotheksdienst, Vol. 34, No. 1, pp. 47-59.

MCGIFFIN, R.F. (1989): Fumiture Care and Conservation. American Association for State and Local History (AASLH), Nashville, Tennessee, pp. 12-23.

MICHALSKI, S. (1998): Climate Control Priorities and Solutions for Collections in Historic Buildings. Historic Preservation Forum, Vol. 12, No. 4, pp. 8-14.

RITZENTHALER, M.L. (1993): Preserving Archives and Manuscripts. Archival Fundamental Series. Society of American Archivists, Chicago, IL.

SCLOCCHI, M.C., RuSCHIONI, E., CAVALINI, F. and PERSIA, F. (1996): Research on Biodeterioration of Archival Assets. In: Intemational Conference on Conservation and Restoration of Archive and Library Materials. Istituto centrale per la patologia del libro (Roma), Erice, Italy, 22-29 April 1996, Vol. 1, pp. 175-90.

SMITHSONIAN INSTITUTION (1994): Work of Smithsonian Scientists Revises Guidelines for Climate Control in Museums and Archives. Abbey Newsletter, Vol. 18, No. 4-5, pp. 1-3.

VAN DER REYDEN, D. (1995): Paper Documents. In: Storage of Natural History Collections: A Preventive Conservation Approach. (C.L. Rose, C.A. Hawks, and H.H. Genoways, eds.), Society for the Preservation of Natural History Collections, lowa City, IA. Vol. 1, pp. 327-53.

WEINTRAUB, S. and WOLF, S.J. (1995): Macro- and Microenvironments. In: Storage of Natural History Collections: A Preventive Conservation Approach. (C.L. Rose, C.A. Hawks, and H.H. Genoways, eds.), Society for the Preservation of Natural History Collections, lowa City, IA. Vol. 1, pp. 123-34. 


\begin{tabular}{|c|c|c|}
\hline Material & Comment / Recommendation & Reference \\
\hline \multirow{3}{*}{$\begin{array}{l}\text { Paper- } \\
\text { based and } \\
\text { archival } \\
\text { material } \\
\end{array}$} & \multirow{3}{*}{$\begin{array}{l}\text { Avoid localised heating through (heating ducts, } \\
\text { radiators, light sources) }\end{array}$} & Bordass, 1996 \\
\hline & & Weintraub and Wolf, 1995 \\
\hline & & Thomson, 1986 \\
\hline \multirow{3}{*}{$\begin{array}{l}\text { Modern } \\
\text { media (incl. } \\
\text { photo- } \\
\text { graphs) }\end{array}$} & \multirow{3}{*}{$\begin{array}{l}\text { Avoid localised heating through (heating ducts, } \\
\text { radiators, light sources) }\end{array}$} & Bordass, 1996 \\
\hline & & Weintraub and Wolf, 1995 \\
\hline & & Thomson, 1986 \\
\hline \multirow[t]{3}{*}{ Paintings } & \multirow{3}{*}{$\begin{array}{l}\text { Avoid localised heating through (heating ducts, } \\
\text { radiators, light sources) }\end{array}$} & Bordass, 1996 \\
\hline & & Weintraub and Wolf, 1995 \\
\hline & & Thomson, 1986 \\
\hline \multirow[t]{3}{*}{ Textiles } & \multirow{3}{*}{$\begin{array}{l}\text { Avoid localised heating through (heating ducts, } \\
\text { radiators, light sources) }\end{array}$} & Bordass, 1996 \\
\hline & & Weintraub and Wolf, 1995 \\
\hline & & Thomson, 1986 \\
\hline \multirow[t]{2}{*}{ Furniture } & \multirow{2}{*}{$\begin{array}{l}\text { Avoid localised heating through (heating ducts, } \\
\text { radiators, light sources) }\end{array}$} & Bordass, 1996 \\
\hline & & $\begin{array}{l}\text { Weintraub and Wolf, } 1995 \\
\text { Thomson, } 1986\end{array}$ \\
\hline $\begin{array}{l}\text { Musical } \\
\text { instruments }\end{array}$ & $\begin{array}{l}\text { Environmental strategy dependent upon various } \\
\text { factors relating to building, instrument, and funding }\end{array}$ & Cassar and Barclay, 1997 \\
\hline \multirow[t]{3}{*}{ Glass } & \multirow{3}{*}{$\begin{array}{l}\text { Avoid localised heating through (heating ducts, } \\
\text { radiators, light sources) }\end{array}$} & Bordass, 1996 \\
\hline & & Weintraub and Wolf, 1995 \\
\hline & & Thomson, 1986 \\
\hline \multirow[t]{3}{*}{ Ceramics } & \multirow{3}{*}{$\begin{array}{l}\text { Avoid localised heating through (heating ducts, } \\
\text { radiators, light sources) }\end{array}$} & Bordass, 1996 \\
\hline & & Weintraub and Wolf, 1995 \\
\hline & & Thomson, 1986 \\
\hline \multirow{3}{*}{$\begin{array}{l}\text { Natural } \\
\text { history } \\
\text { specimens } \\
\end{array}$} & \multirow{3}{*}{$\begin{array}{l}\text { Avoid localised heating through (heating ducts, } \\
\text { radiators, light sources) }\end{array}$} & Bordass, 1996 \\
\hline & & Weintraub and Wolf, 1995 \\
\hline & & Thomson, 1986 \\
\hline \multirow[t]{3}{*}{ Metals } & \multirow{3}{*}{$\begin{array}{l}\text { Avoid localised heating through (heating ducts, } \\
\text { radiators, light sources) }\end{array}$} & Bordass, 1996 \\
\hline & & Weintraub and Wolf, 1995 \\
\hline & & Thomson, 1986 \\
\hline
\end{tabular}

\section{References}

BORDASS, B. (1996): Museum Collections in Industrial Buildings - A Selection and Adaptation Guide. Museums \& Galleries Commission, London.

CASSAR, M. and BARCLAY, R.. (1997): Instruments in their Environment. In: The Care of Historical Musical Instruments. (R.L. Barclay, ed.), Museums \& Galleries Commission, London, and Canadian Conservation Institute, Ottawa, pp. 9-17.

Thomson, G. (1986): The Museum Environment. $2^{\text {nd }}$ ed. Butterworth-Heinemann, London.

WEINTRAUB, S. and WOLF, S.J. (1995): Macro- and Microenvironments. In: Storage of Natural History Collections: A Preventive Conservation Approach. (C.L. Rose, C.A. Hawks, and H.H. Genoways, eds.), Society for the Preservation of Natural History Collections, lowa City, IA. Vol. 1, pp. 123-34. 


\section{Electromagnetic Radiation}

\begin{tabular}{|c|c|c|}
\hline Material & Comment / Recommendation & Reference \\
\hline \multirow{5}{*}{$\begin{array}{l}\text { Paper- } \\
\text { based and } \\
\text { archival } \\
\text { material }\end{array}$} & $\begin{array}{l}<254 \mathrm{~nm} \text { : induces photolysis (the lower the } \\
\text { wavelength, the greater the potential for scission) }\end{array}$ & Feller, 1994 \\
\hline & $\begin{array}{l}290-400 \mathrm{~nm} \text { : initiates chromofore-forming } \\
\text { reactions in lignin-containing papers }\end{array}$ & $\begin{array}{l}\text { Havermans and Dufour, } \\
1997\end{array}$ \\
\hline & $\begin{array}{l}380-400 \mathrm{~nm} \text { : may cause serious damage (UV } \\
\text { causes yellowing; blue light bleaches) }\end{array}$ & Michalski, 1997 \\
\hline & 50 lux; all UV radiation must be filtered out & Staniforth, 1987 \\
\hline & $\begin{array}{l}\text { All electromagnetic radiation is potentially } \\
\text { damaging; cumulative effect }\end{array}$ & Thomson, 1986 \\
\hline $\begin{array}{l}\text { Modern } \\
\text { media (incl. } \\
\text { photo- } \\
\text { graphs) } \\
\end{array}$ & $\begin{array}{l}380-400 \mathrm{~nm} \text { : may cause serious damage (UV } \\
\text { causes yellowing; blue light bleaches) }\end{array}$ & Michalski, 1997 \\
\hline \multirow[t]{2}{*}{ Paintings } & 200 lux; cumulative effect & Staniforth, 1987 \\
\hline & 150 lux; cumulative effect & Thomson, 1986 \\
\hline \multirow[t]{2}{*}{ Textiles } & 50 lux; cumulative effect & Staniforth, 1987 \\
\hline & 50 lux; cumulative effect & Thomson, 1986 \\
\hline \multirow[t]{2}{*}{ Furniture } & $\begin{array}{l}\text { Cumulative effect (dark wood may bleach, light } \\
\text { wood may darken) }\end{array}$ & $\mathrm{CCl}, 2002$ \\
\hline & 150 lux ( 50 lux for sensitive textiles, e.g. covers) & McGiffin, 1989 \\
\hline $\begin{array}{l}\text { Musical } \\
\text { instruments }\end{array}$ & $\begin{array}{l}\text { High levels of visible and UV light, and associated } \\
\text { excessive heat, can cause irreversible damage }\end{array}$ & Cassar and Barclay, 1997 \\
\hline Glass & Do not exceed 300 lux & Thomson, 1986 \\
\hline \multirow[t]{2}{*}{ Ceramics } & $50-250$ lux & Buys, 1993 \\
\hline & Do not exceed 300 lux & Thomson, 1986 \\
\hline \multirow{2}{*}{$\begin{array}{l}\text { Natural } \\
\text { history } \\
\text { specimens }\end{array}$} & 50 lux; cumulative effect & Thomson, 1986 \\
\hline & 50-300 lux depending on sensitivity & Weintraub and Wolf, 1995 \\
\hline Metals & Do not exceed 300 lux & Thomson, 1986 \\
\hline
\end{tabular}

\section{References}

BUYS, S. and OAKLEY, V. (1993): The Conservation and Restoration of Ceramics. Butterworth - Heinemann, Oxford.

CASSAR, M. and BARCLAY, R.. (1997): Instruments in their Environment. In: The Care of Historical Musical instruments. (R.L. Barclay, ed.), Museums \& Galleries Commission, London, and Canadian Conservation Institute, Ottawa, pp. 9-17.

CCI (2002): How to Care for....http://www.preservation.gc.ca/howto/grid_e.asp; 20 June 2002.

FELLER, R.L. (1994): Accelerated Aging. Photochemical and Themal Aspects. Research in Conservation 4. The Getty Conservation Institute.

HAVERMANS, J. and DUfOUR, J. (1997): Photo Oxidation of Paper Documents: A Literature Review. Restaurator, Vol. 18, No. 3, pp. 103-14.

MCGIFFIN, R.F. (1989): Fumiture Care and Conservation. American Association for State and Local History (AASLH), Nashville, Tennessee, pp. 12-23

MICHALSKI, S. (1997): The Lighting Decision. In: Fabric of an Exhibition: An Interdisciplinary Approach. Canadian Conservation Institute, Ottawa, 22-25 September 1997, pp. 97-104. 
STANIFORTH, S. (1987): Light and Environmental Measurement and Control in National Trust Houses. In: Jubilee Conservation Conference, (J. Black, ed.), University of London (Institute of Archaeology), Summer Schools Press, London, pp. 327-33.

THOMSON, G. (1986). The Museum Environment. $2^{\text {nd }}$ ed. Butterworth-Heinemann, London.

WEINTRAUB, S. and WOLF, S.J. (1995): Macro- and Microenvironments. In: Storage of Natural History Collections: A Preventive Conservation Approach, (C.L. Rose, C.A. Hawks, and H.H. Genoways, eds.), Society for the Preservation of Natural History Collections, lowa City, IA. Vol. 1, pp. 123-34. 


\begin{tabular}{|c|c|c|}
\hline Material & Comment / Recommendation & Reference \\
\hline \multirow{3}{*}{$\begin{array}{l}\text { Paper- } \\
\text { based and } \\
\text { archival } \\
\text { material }\end{array}$} & $\begin{array}{l}\text { Raise lowest shelves } \\
\text { Keep racks away from external walls }\end{array}$ & Bordass, 1996 \\
\hline & $\begin{array}{l}\text { Avoid stagnant air, especially in small spaces } \\
\text { (behind books) }\end{array}$ & Scott, 1994 \\
\hline & $\begin{array}{l}\text { Environmental control is easier if air exchange rate } \\
\text { does not exceed one change per hour }\end{array}$ & Staniforth, 1987 \\
\hline $\begin{array}{l}\text { Modern } \\
\text { media (incl. } \\
\text { Photo- } \\
\text { graphs) }\end{array}$ & $\begin{array}{l}\text { Avoid stagnant air, especially in small spaces } \\
\text { (behind books) }\end{array}$ & Scott, 1994 \\
\hline \multirow[t]{2}{*}{ Paintings } & $\begin{array}{l}\text { Raise lowest shelves } \\
\text { Keep racks away from external walls }\end{array}$ & Bordass, 1996 \\
\hline & $\begin{array}{l}\text { Environmental control is easier if air exchange rate } \\
\text { does not exceed one change per hour }\end{array}$ & Staniforth, 1987 \\
\hline \multirow[t]{2}{*}{ Textiles } & $\begin{array}{l}\text { Raise lowest shelves } \\
\text { Keep racks away from extemal walls }\end{array}$ & Bordass, 1996 \\
\hline & $\begin{array}{l}\text { Environmental control is easier if air exchange rate } \\
\text { does not exceed one change per hour }\end{array}$ & Staniforth, 1987 \\
\hline Furniture & $\begin{array}{l}\text { Environmental control is easier if air exchange rate } \\
\text { does not exceed one change per hour }\end{array}$ & Staniforth, 1987 \\
\hline $\begin{array}{l}\text { Musical } \\
\text { instruments }\end{array}$ & $\begin{array}{l}\text { Move instruments into areas of higher air flow and } \\
\text { establish programmes of regular inspection }\end{array}$ & Barclay, 1997 \\
\hline Glass & $\begin{array}{l}\text { Environmental control is easier if air exchange rate } \\
\text { does not exceed one change per hour }\end{array}$ & Staniforth, 1987 \\
\hline \multirow[t]{2}{*}{ Ceramics } & $\begin{array}{l}\text { Raise lowest shelves } \\
\text { Keep racks away from external walls }\end{array}$ & Bordass, 1996 \\
\hline & $\begin{array}{l}\text { Environmental control is easier if air exchange rate } \\
\text { does not exceed one change per hour }\end{array}$ & Staniforth, 1987 \\
\hline \multirow{2}{*}{$\begin{array}{l}\text { Natural } \\
\text { history } \\
\text { specimens }\end{array}$} & $\begin{array}{l}\text { Raise lowest shelves } \\
\text { Keep racks away from external walls }\end{array}$ & Bordass, 1996 \\
\hline & $\begin{array}{l}\text { Environmental control is easier if air exchange rate } \\
\text { does not exceed one change per hour }\end{array}$ & Staniforth, 1987 \\
\hline Metals & $\begin{array}{l}\text { Environmental control is easier if air exchange rate } \\
\text { does not exceed one change per hour }\end{array}$ & Staniforth, 1987 \\
\hline
\end{tabular}

\section{References}

BARCLAY, R. (1997): General Care of Musical Instrument Collections. In: The Care of Historical Musical Instruments. (Barclay, R.L. ed.), Museums \& Galleries Commission, London, and Canadian Conservation Institute, Ottawa, pp. 19-26.

BORDASS, B. (1996): Museum Collections in Industrial Buildings - A Selection and Adaptation Guide. Museums \& Galleries Commission, London.

ScoTT, G. (1994): Moisture, Ventilation and Mould Growth. In: Preventive Conservation Practice, Theory and Research. (A. Roy, and P. Smith, eds.), IIC, Ottawa, 12-16 September 1994, pp. 149-53.

STANIFORTH, S. (1987): Light and Environmental Measurement and Control in National Trust Houses. In: Jubilee Conservation Conference, (J. Black, ed.), University of London (Institute of Archaeology), Summer Schools Press, London, pp. 327-33. 


\section{Pollution}

\begin{tabular}{|c|c|c|}
\hline Material & Comment/ Recommendation & Reference \\
\hline \multirow{6}{*}{$\begin{array}{l}\text { Paper-based } \\
\text { and archival } \\
\text { material }\end{array}$} & \multirow{2}{*}{$\begin{array}{l}\text { Appropriate enclosures can give almost complete } \\
\text { protection if no other control method is possible }\end{array}$} & Guttman and Jewett, 1993 \\
\hline & & Passaglia, 1989 \\
\hline & $\begin{array}{l}\text { Pollutants in combination with other environmental } \\
\text { factors cause embrittlement and discolouration }\end{array}$ & Baer and Banks, 1985 \\
\hline & $\begin{array}{l}\text { Embrittlement and discolouration caused by sulphur } \\
\text { oxides }\end{array}$ & Baer and Banks, 1994 \\
\hline & $\begin{array}{l}\text { Remove at least } 95 \% \text { of all particulates using charcoal } \\
\text { or equivalent filtration }\end{array}$ & NBS, 1983 \\
\hline & $\begin{array}{l}\text { Levels of pollutants should not exceed } 10 \mathrm{ppb} \\
\text { Consider central air purification system in high ambient } \\
\text { areas }\end{array}$ & Lafontaine, 1979 \\
\hline \multirow{6}{*}{$\begin{array}{l}\text { Modern } \\
\text { media (incl. } \\
\text { photographs) }\end{array}$} & \multirow{2}{*}{$\begin{array}{l}\text { Appropriate enclosures can give almost complete } \\
\text { protection if no other control method is possible }\end{array}$} & Guttman and Jewett, 1993 \\
\hline & & Passaglia, 1989 \\
\hline & $\begin{array}{l}\text { Pollutants in combination with other environmental } \\
\text { factors cause micro-blemishes }\end{array}$ & Baer and Banks, 1985 \\
\hline & $\begin{array}{l}\text { Micro-blemishes caused by sulphur oxides and } \\
\text { hydrogen sulphide }\end{array}$ & Baer and Banks, 1994 \\
\hline & $\begin{array}{l}\text { Remove at least } 95 \% \text { of all particulates using charcoal } \\
\text { or equivalent filtration }\end{array}$ & NBS, 1983 \\
\hline & $\begin{array}{l}\text { Levels of pollutants should not exceed } 10 \mathrm{ppb} \\
\text { Consider central air purification system in high ambient } \\
\text { areas }\end{array}$ & Lafontaine, 1979 \\
\hline \multirow[t]{2}{*}{ Paintings } & $\begin{array}{l}\text { Pollutants in combination with other environmental } \\
\text { factors cause discolouration and soiling }\end{array}$ & Baer and Banks, 1985 \\
\hline & $\begin{array}{l}\text { Discolouration and soiling caused by sulphur oxides, } \\
\text { hydrogen sulphide, and alkaline aerosol }\end{array}$ & Baer and Banks, 1994 \\
\hline \multirow[t]{2}{*}{ Textiles } & $\begin{array}{l}\text { Pollutants in combination with other environmental } \\
\text { factors cause soiling and reduced strength (textile dyes } \\
\text { may fade or change colour) }\end{array}$ & Baer and Banks, 1985 \\
\hline & $\begin{array}{l}\text { Reduced tensile strength and soiling caused by sulphur } \\
\text { and nitrogen oxides } \\
\text { Fading and colour change caused by ozone and } \\
\text { nitrogen oxides } \\
\text { Weakening and powdered surface of leather caused by } \\
\text { sulphur oxides }\end{array}$ & \\
\hline Fumiture & $\begin{array}{l}\text { Pollutants in combination with other environmental } \\
\text { factors cause discolouration and soiling }\end{array}$ & Baer and Banks, 1985 \\
\hline \multirow{2}{*}{$\begin{array}{l}\text { Musical } \\
\text { instruments }\end{array}$} & Cracking of rubber caused by ozone & Baer and Banks, 1994 \\
\hline & $\begin{array}{l}\text { Pollutants react with non-ferrous metals, organic } \\
\text { materials, textile dyes, natural pigments, rubbers and } \\
\text { plastics } \\
\text { Particulates cause abrasion and soiling of all surfaces }\end{array}$ & Cassar and Barclay, 1997 \\
\hline Glass & $\begin{array}{l}\text { Pollution in combination with high RH can cause } \\
\text { damage }\end{array}$ & Tennent, 1999 \\
\hline Ceramics & $\begin{array}{l}\text { damage } \\
\text { All pollutants should be removed }\end{array}$ & $\begin{array}{l}\text { Thomson, } 1986 \\
\text { Buvs } 1993\end{array}$ \\
\hline $\begin{array}{l}\text { Natural } \\
\text { history } \\
\text { specimens }\end{array}$ & $\begin{array}{l}\text { Pollutants in combination with other environmental } \\
\text { factors cause discolouration and soiling }\end{array}$ & Baer and Banks, 1985 \\
\hline \multirow[t]{2}{*}{ Metals } & $\begin{array}{l}\text { Corrosion and tarnishing caused by sulphur oxides, } \\
\text { hydrogen sulphide and other acidic gases }\end{array}$ & Baer and Banks, 1994 \\
\hline & $\begin{array}{l}\text { Pollutants in combination with other environmental } \\
\text { factors cause corrosion and tarnishing }\end{array}$ & Baer and Banks, 1985 \\
\hline
\end{tabular}




\section{References}

BAER, N.S. and BANKS, P.N. (1985): Indoor Air Pollution: Effects on Cultural and Historic Materials. The International Journal of Museum Management and Curatorship, Vol. 4, No. 1, pp. 9-20.

BAER, N.S. and BANKS, P.N. (1994): Indoor Air Pollution: Effects on Cultural and Historic Materials. In: Care of Collections, (S. Knell, ed.), Routledge, London, pp. 135-46.

BUYS, S. and OAKLEY, V. (1993): The Conservation and Restoration of Ceramics. Butterworth - Heinemann, Oxford.

CASSAR, M. and BARCLAY, R. (1997): Instruments in their Environment. In: The Care of Historical Musical Instruments. (R.L. Barclay, ed.), Museums \& Galleries Commission, London, and Canadian Conservation Institute, Ottawa, pp. 9-17.

GUTTMAN, C.M. and JeWETT, K.L. (1993): Protection of Archival Materials from Pollutants: Diffusion of Sulfur Dioxide through Boxboard. Journal of the American Institute of Conservation, Vol. 32, No. 1, pp. 81-92.

LAFONTAINE, R.H. (1979): Environmental Norms for Canadian Museums, Art Galleries and Archives. Technical Bulletin 3. Canadian Conservation Institute, Ottawa.

NBS (1983): Air Quality Criteria for Storage of Paper-Based Archival Records. NBSIR 83-2795. National Bureau of Standards, Washington DC.

PASSAGLIA, E. (1989): The Characterization of Microenvironments and the Degradation of Archival Records. Restaurator, Vol. 10, No. 3/4, pp. 123-50.

TENNENT, N.H. (ed.)(1999): The Conservation of Glass and Ceramics. James \& James, London.

THOMSON, G. (1986): The Museum Environment. $2^{\text {nd }}$ ed. Butterworths, London. 


\begin{tabular}{|c|c|c|}
\hline Material & Comment / Recommendation & Reference \\
\hline \multirow{3}{*}{$\begin{array}{l}\text { Paper- } \\
\text { based and } \\
\text { archival } \\
\text { material }\end{array}$} & Good housekeeping helps avoid pest infestation & Child, 1996 \\
\hline & $\begin{array}{l}\text { Avoid attractors (garbage, plants, light, drainage) in } \\
\text { vicinity of buildings }\end{array}$ & Strang, 1996 \\
\hline & $\begin{array}{l}\text { All cellulose- or protein-based materials can attract } \\
\text { insect pests as nutritional source } \\
\text { Birds and mammals use paper as nesting material }\end{array}$ & Ritzenthaler, 1993 \\
\hline \multirow{2}{*}{$\begin{array}{l}\text { Modern } \\
\text { media (incl. } \\
\text { photo- } \\
\text { graphs) }\end{array}$} & Good housekeeping helps avoid pest infestation & Child, 1996 \\
\hline & $\begin{array}{l}\text { Avoid attractors (garbage, plants, light, drainage) in } \\
\text { vicinity of buildings }\end{array}$ & Strang, 1996 \\
\hline \multirow[t]{2}{*}{ Paintings } & Good housekeeping helps avoid pest infestation & Child, 1996 \\
\hline & $\begin{array}{l}\text { Avoid attractors (garbage, plants, light, drainage) in } \\
\text { vicinity of buildings }\end{array}$ & Strang, 1996 \\
\hline \multirow[t]{3}{*}{ Textiles } & Wool attracts insects as a source of nutrition & Blyth, 1996 \\
\hline & Good housekeeping helps avoid pest infestation & Child, 1996 \\
\hline & $\begin{array}{l}\text { Avoid attractors (garbage, plants, light, drainage) in } \\
\text { vicinity of buildings }\end{array}$ & Strang, 1996 \\
\hline \multirow[t]{3}{*}{ Furniture } & Good housekeeping helps avoid pest infestation & Child, 1996 \\
\hline & $\begin{array}{l}\text { Wood and upholstery attract insects as sources of } \\
\text { nutrition }\end{array}$ & Blyth, 1996 \\
\hline & $\begin{array}{l}\text { Install window screens throughout building } \\
\text { Avoid storing fire wood inside building } \\
\text { Maintain clean environment }\end{array}$ & McGiffin, 1989 \\
\hline $\begin{array}{l}\text { Musical } \\
\text { instruments }\end{array}$ & $\begin{array}{l}\text { Organic materials within instruments are } \\
\text { particularly susceptible to insect attack } \\
\text { Large instruments are ideal habitat for vertebrate } \\
\text { pests } \\
\text { Preventive cleaning and regular inspection are } \\
\text { essential, although access to parts of instruments } \\
\text { may be awkward }\end{array}$ & Barclay, 1997 \\
\hline Glass & Good housekeeping helps avoid pest infestation & Child, 1996 \\
\hline Ceramics & Good housekeeping helps avoid pest infestation & Child, 1996 \\
\hline \multirow{2}{*}{$\begin{array}{l}\text { Natural } \\
\text { history } \\
\text { specimens }\end{array}$} & Good housekeeping helps avoid pest infestation & Child, 1996 \\
\hline & $\begin{array}{l}\text { Metal storage cabinets with tightly-welded joins are } \\
\text { preferred } \\
\text { Provide easy access for checking and cleaning }\end{array}$ & Jessup, 1995 \\
\hline Metals & Good housekeeping helps avoid pest infestation & Child, 1996 \\
\hline
\end{tabular}

\section{References}

BARCLAY, R. (1997): General Care of Musical Instrument Collections. In: The Care of Historical Musical Instruments. (R.L. Barclay, ed.), Museums \& Galleries Commission, London, and Canadian Conservation Institute, Ottawa, pp. 19-26.

BLYTH, V.J. (1996): Pest Management at the Victoria and Albert Museum. In: Pest Attack \& Pest Control in Organic Materials. (A. Neher, and D. Rogers, eds.), UKIC, London, 18 November 1996, pp. 7-12. 
CHILD, R.E. (1996): Detection, Monitoring and Control of Instect Pests. In: Pest Attack \& Pest Control in Organic Materials. (A. Neher, and D. Rogers, eds.), UKIC, London, 18 November 1996, pp. 4-6.

JESSUP, W.C. (1995): Pest Management. In: Storage of Natural History Collections: $A$ Preventive Consenation Approach. (C.L. Rose, C.A. Hawks, and H.H. Genoways, eds.), Society for the Preservation of Natural History Collections, lowa City, IA. Vol. 1, pp. 211-20.

MCGIFFIN, R.F. (1989): Furniture Care and Conservation. American Association for State and Local History (AASLH), Nashville, Tennessee, pp. 149-155

RITZENTHALER, M.L. (1993): Preserving Archives and Manuscripts. Archival Fundamental Series. Society of American Archivists, Chicago, IL.

StRANG, T.J.K. (1996): Museum Pest Management. Seminar Notes, Canadian Conservation Institute, Ottawa. 


\section{Visitor Management}

\begin{tabular}{|c|c|c|}
\hline & Comment / Recommendation & Reference \\
\hline \multirow{2}{*}{$\begin{array}{l}\text { Paper- } \\
\text { based and } \\
\text { archival } \\
\text { material }\end{array}$} & $\begin{array}{l}\text { Staff and users should wash their hands and/or } \\
\text { use cotton gloves while handling documents }\end{array}$ & van der Reyden, 1995 \\
\hline & Provide coverings for wallpaper & Lloyd and Mullany, 1994 \\
\hline $\begin{array}{l}\text { Modern } \\
\text { media (incl. } \\
\text { photo- } \\
\text { graphs) }\end{array}$ & $\begin{array}{l}\text { Staff and users should wash their hands and/or } \\
\text { use cotton gloves while handling documents }\end{array}$ & van der Reyden, 1995 \\
\hline Paintings & $\begin{array}{l}\text { Regulate the number of visitors in the building to } \\
\text { an appropriate maximum } \\
\text { Rope off areas }\end{array}$ & Lloyd and Mullany, 1994 \\
\hline Textiles & $\begin{array}{l}\text { Regulate the number of visitors in the building to } \\
\text { an appropriate maximum } \\
\text { Rope off areas }\end{array}$ & Lloyd and Mullany, 1994 \\
\hline Furniture & $\begin{array}{l}\text { Regulate the number of visitors in the building to } \\
\text { an appropriate maximum } \\
\text { Rope off areas }\end{array}$ & Lloyd and Mullany, 1994 \\
\hline $\begin{array}{l}\text { Musical } \\
\text { instruments }\end{array}$ & $\begin{array}{l}\text { Playing and use of instruments by visiting } \\
\text { musicians must be balanced against historic value } \\
\text { and risk to collection }\end{array}$ & Waitzman et al., 1997 \\
\hline Glass & $\begin{array}{l}\text { Regulate the number of visitors in the building to } \\
\text { an appropriate maximum } \\
\text { Rope off areas }\end{array}$ & Lloyd and Mullany, 1994 \\
\hline Ceramics & $\begin{array}{l}\text { Regulate the number of visitors in the building to } \\
\text { an appropriate maximum } \\
\text { Rope off areas }\end{array}$ & Lloyd and Mullany, 1994 \\
\hline $\begin{array}{l}\text { Natural } \\
\text { history } \\
\text { specimens } \\
\end{array}$ & $\begin{array}{l}\text { Regulate the number of visitors in the building to } \\
\text { an appropriate maximum } \\
\text { Rope off areas }\end{array}$ & Lloyd and Mullany, 1994 \\
\hline Metals & $\begin{array}{l}\text { Regulate the number of visitors in the building to } \\
\text { an appropriate maximum } \\
\text { Rope off areas }\end{array}$ & Lloyd and Mullany, 1994 \\
\hline
\end{tabular}

\section{References}

LLOYD, H. and MULLANY, T. (1994): The Impact of Overvisiting: Methods of Assessing the Sustainable Capacity of Historic Houses. In: Preventive Conservation - Practice, Theory and Research. (A. Roy, and P. Smith, eds.), IIC, Ottawa, 12-16 September 1994, pp. 132-38.

VAN DER REYDEN, D. (1995): Paper Documents. In: Storage of Natural History Collections: A Preventive Conservation Approach, (C.L. Rose, C.A. Hawks, and H.H. Genoways, eds.), Society for the Preservation of Natural History Collections, lowa City, IA. Vol. 1, pp. 327-53.

Waitzman, M., Barclay, R., Odell, J., KarP, C. And Hellwig, F. (1997): Basic Maintenance of Playing Instruments. In: The Care of Historical Musical Instruments. (R.L. Barclay, ed.), Museums \& Galleries Commission, London, and Canadian Conservation Institute, Ottawa, pp. 83-108. 


\section{Handling and Transportation}

\begin{tabular}{|c|c|c|}
\hline Material & Comment / Recommendation & Reference \\
\hline \multirow{3}{*}{$\begin{array}{l}\text { Paper- } \\
\text { based and } \\
\text { archival } \\
\text { material }\end{array}$} & Store in acid-free cardboard boxes or envelopes & $\mathrm{CCl}, 2002$ \\
\hline & $\begin{array}{l}\text { Handling and transportation only by experienced } \\
\text { and well-equipped staff familiar with installation } \\
\text { and location }\end{array}$ & Ashley-Smith, 1999 \\
\hline & $\begin{array}{l}\text { Staff and users should wash their hands and/or } \\
\text { use cotton gloves while handling documents }\end{array}$ & van der Reyden, 1995 \\
\hline $\begin{array}{l}\text { Modern } \\
\text { media (incl. } \\
\text { photo- } \\
\text { graphs) }\end{array}$ & $\begin{array}{l}\text { Store in photo-quality cardboard boxes or } \\
\text { envelopes }\end{array}$ & $\mathrm{CCl}, 2002$ \\
\hline Paintings & $\begin{array}{l}\text { Handling and transportation only by experienced } \\
\text { and well-equipped staff familiar with installation } \\
\text { and location }\end{array}$ & Ashley-Smith, 1999 \\
\hline \multirow[t]{2}{*}{ Textiles } & $\begin{array}{l}\text { Store in acid-free cardboard boxes with acid-free } \\
\text { tissue paper or pre-washed unbleached cotton } \\
\text { muslin }\end{array}$ & $\mathrm{CCl}, 2002$ \\
\hline & $\begin{array}{l}\text { Handling and transportation only by experienced } \\
\text { and well-equipped staff familiar with installation } \\
\text { and location }\end{array}$ & Ashley-Smith, 1999 \\
\hline \multirow[t]{3}{*}{ Furniture } & $\begin{array}{l}\text { Cushion items from vehicle as well as from each } \\
\text { other } \\
\text { Secure loose parts with soft cotton straps }\end{array}$ & $\mathrm{CCl}, 2002$ \\
\hline & $\begin{array}{l}\text { Handling and transportation only by experienced } \\
\text { and well-equipped staff familiar with installation } \\
\text { and location }\end{array}$ & Ashley-Smith, 1999 \\
\hline & $\begin{array}{l}\text { Use mover's blankets to cushion and hold in place } \\
\text { Avoid thermal shock by using insulation packaging } \\
\text { material, e.g. fibreglass house insulation material }\end{array}$ & McGiffin, 1989 \\
\hline $\begin{array}{l}\text { Musical } \\
\text { instruments }\end{array}$ & $\begin{array}{l}\text { Historic instruments readily affected by incautious } \\
\text { handling and inappropriate transportation (handling } \\
\text { guidelines given) }\end{array}$ & Barclay, 1997 \\
\hline \multirow[t]{2}{*}{ Glass } & $\begin{array}{l}\text { Handling and transportation only by experienced } \\
\text { and well-equipped staff familiar with installation } \\
\text { and location }\end{array}$ & Ashley-Smith, 1999 \\
\hline & $\begin{array}{l}\text { Choose appropriate cushioning material to avoid } \\
\text { abrasion of surfaces and decrease vibration }\end{array}$ & Buys, 1993 \\
\hline \multirow[t]{2}{*}{ Ceramics } & $\begin{array}{l}\text { Handling and transportation only by experienced } \\
\text { and well-equipped staff familiar with installation } \\
\text { and location }\end{array}$ & Ashley-Smith, 1999 \\
\hline & $\begin{array}{l}\text { Chose appropriate cushioning material to avoid } \\
\text { abrasion of surfaces and decrease vibration }\end{array}$ & Buys, 1993 \\
\hline
\end{tabular}


Handling and Transportation, continued

\begin{tabular}{|c|c|c|}
\hline Material & Comment / Recommendation & Reference \\
\hline $\begin{array}{l}\text { Natural } \\
\text { history } \\
\text { specimens }\end{array}$ & $\begin{array}{l}\text { Handling and transportation only by experienced } \\
\text { and well-equipped staff familiar with installation } \\
\text { and location }\end{array}$ & Ashley-Smith, 1999 \\
\hline \multirow[t]{2}{*}{ Metals } & $\begin{array}{l}\text { Avoid humid conditions (wear cotton gloves for } \\
\text { handling) }\end{array}$ & $\mathrm{CCl}, 2002$ \\
\hline & $\begin{array}{l}\text { Handling and transportation only by experienced } \\
\text { and well equipped staff familiar with installation and } \\
\text { location }\end{array}$ & Ashley-Smith, 1999 \\
\hline
\end{tabular}

\section{References}

ASHLEY-SMITH, J. (1999): Risk Assessment for Object Conservation. Butterworth Heinemann, Oxford.

BARCLAY, R. (1997): General Care of Musical Instrument Collections. In: The Care of Historical Musical Instruments. (R.L. Barclay, ed.), Museums \& Galleries Commission, London, and Canadian Conservation Institute, Ottawa, pp. 19-26.

BUYS, S. and OAKLEY, V. (1993): The Conservation and Restoration of Ceramics. Butterworth -Heinemann, Oxford.

CCI (2002): How to Care for....http://www.preservation.gc.ca/howto/grid_e.asp; 20 June 2002.

MCGIFFIN, R.F. (1989): Fumiture Care and Conservation. American Association for State and Local History (AASLH), Nashville, Tennessee, pp. 134-148

VAN DER REYDEN, D. (1995): Paper Documents. In: Storage of Natural History Collections: A Preventive Conservation Approach. (C.L. Rose, C.A. Hawks, and H.H. Genoways, eds.), Society for the Preservation of Natural History Collections, lowa City, IA. Vol. 1, pp. 327-53. 


\section{Publications}

WATT D.S., COLSTON B.J. and BÖLOW A.E. (2002): Libraries and Archives in Historic Buildings: Predicting the Effects of Dampness. Library and Information Commission Research Report No. 138. Council for Museums, Libraries and Archives (Resource), De Montfort University, Leicester.

BÜLOW, A.E., Colston, B.J. AND WATT, D.S. (2002): Preventive Conservation of Paperbased Collections within Historic Buildings. In: Works of Art on Paper: Techniques and Consenvation (V. Daniels, A. Donnithome and P. Smith, eds.), IIC Baltimore, MD, USA, 1-6 September 2002, pp. 27-31. (Presentation).

WATT, D., Colston, B. AND BÖLOW, A. (2001): Predicting Damp-related Problems in Historic Buildings and Monuments Used for Library and Archive Purposes. Proceedings of the RICS Foundation, Construction and Building Research Conference, Glasgow Caledonian University, Glasgow, Scotland, 3-5 September 2001, Vol. 2, pp. 690-700. (Presentation).

Bülow, A., BEgin, P., Carter, H. ANd BuRns, T. (2000): Migration of Volatile Compounds through Stacked Sheets of Paper during Accelerated Ageing. Part II: Variable Temperature Studies. Restaurator, Vol. 21, No. 4, pp. 187-203.

\section{ATTENDED CONFERENCES}

9 September 2002: Where Conservation Meets Conservation, De Montfort University, Leicester, UK

1 - 6 September 2002: Works of Art on Paper. Techniques and Conservation, IIC Baltimore, MD, USA

3 - 5 September 2001: Construction and Building Research Conference, Glasgow Caledonian University, Glasgow, Scotland, UK

17 - 20 May 2000: Symposium 2000: The Conservation of Heritage Interiors, Ottawa, Ontario, Canada

\section{ADDITIONAL TRAINING}

Terms 99/00 MA Architectural Conservation: Understanding Historic Buildings, Professor Peter Swallow

MSc Conservation Science: different modules on buildings, building materials, construction, defects, decay, repair, reuse, and conservation, Dr David Watt

12 November 1999 The Creative Use of Historic Buildings, Guest Lecture, Derek Latham

Terms 00/01

MA Architectural Conservation: Maintenance and Repair of Historic Buildings, Dr David Watt 


\section{FIELD TRIPS}

6 October 2000 Geology/stone Tour through Stamford (Lincolnshire), Alan Dawn

17 November 2000 Norman \& Underwood (manufacturer of cast lead and other roofing materials; stained glass), Leicester

2 February $2001 \quad$ National Monuments Record Centre, Swindon 